University of Redlands

\title{
Information and Communications Technology Utilization and the Digital Divide: An Analysis of United States Counties
}

A Major Individual Project submitted in partial satisfaction of the requirements

for the degree of Master of Science in Geographic Information Systems

by

Lisa Nicole Florkowski

Fang Ren, Ph.D., Committee Chair

Avijit Sarkar, Ph.D.

August 2014 
Information and Communications Technology Utilization and the Digital Divide: An Analysis of United States Counties

Copyright (C) 2014

by

Lisa Nicole Florkowski 
The report of Lisa Nicole Florkowski is approved.

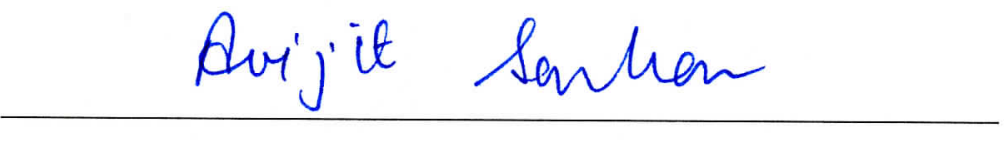

Avijit Sarkar, Ph.D.

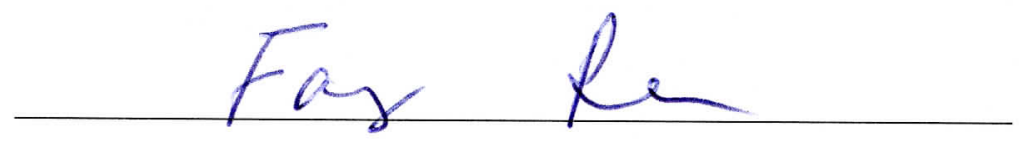

Fang Ren, Ph.D., Committee Chair

August 2014 



\section{Acknowledgements}

First and foremost, I would like to thank my husband for supporting me through this program. His smile, shoulder to cry on, and steadfast presence cannot be thanked enough. I would like to thank my clients, Avijit and Jim, for all their knowledge and encouragement throughout the process.

Thank you Fang for helping me to get through the process and helping me to understand spatial statistics. 



\begin{abstract}
Information and Communications Technology Utilization and the Digital Divide: An Analysis of United States Counties

by

Lisa Nicole Florkowski

Information and communications technologies (ICT), such as the Internet, have become increasingly important in society; however, access to these technologies has been unequal across socio-economic and demographic groups. Statistical methods, including k-means clustering analysis, spatial autocorrelation analysis, ordinary least squares regression analysis, geographically weighted regression analysis, and spatial dependence analysis were used to analyze spatial patterns of Internet usage in US counties. The results of these analyses showed strong urban and rural divides in the dependent variables. The regression analyses showed that urban, educational attainment, and employment explained the most variation in ICT use and adoption. When incorporating spatial regression models, strong spatial dependence was found in all models.
\end{abstract}





\section{Table of Contents}

Chapter 1 - Introduction .................................................................................................... 1

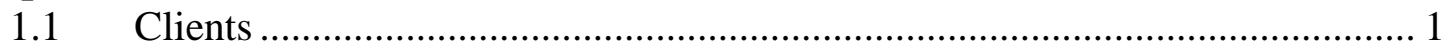

$1.2 \quad$ Problem Statement ................................................................................. 1

$1.3 \quad$ Proposed Solution ................................................................................. 1

1.3.1 Goals and Objectives .............................................................................. 2

1.3 .2 Scope

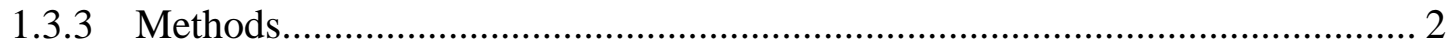

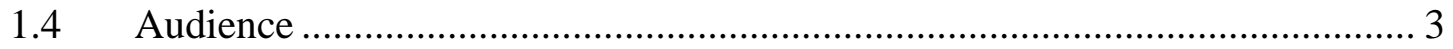

$1.5 \quad$ Overview of the Rest of this Report .............................................................. 3

Chapter 2 - Background and Literature Review ........................................................... 5

$2.1 \quad$ Digital Divide and Its Associated Factors ……………...................................... 5

2.1.1 Factors Associated with Digital Divide …………………………………….... 5

2.1.2 The Digital Divide in the United States ............................................................ 6

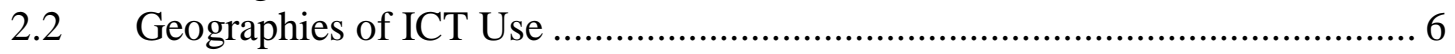

2.3 Summary ......................................................................................... 7

Chapter 3 - Systems Analysis and Design......................................................................... 9

3.1 Problem Statement ...................................................................................... 9

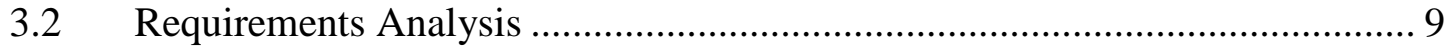

3.3 System Design .......................................................................................... 11

3.4 Project Plan ......................................................................................... 12

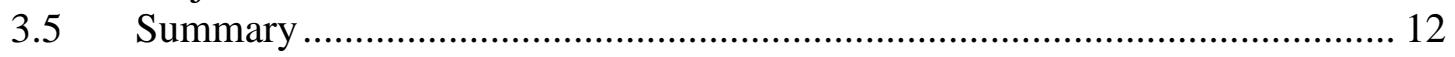

Chapter 4 - Database Design.............................................................................................. 15

$4.1 \quad$ Conceptual Data Model ............................................................................. 15

4.2 Logical Data Model .......................................................................... 16

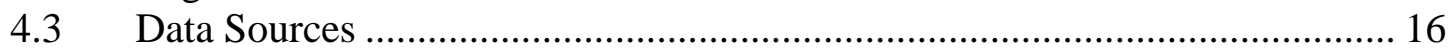

4.4 Data Collection Methods ........................................................................... 17

4.5 Data Scrubbing and Loading …………………........................................ 17

4.5.1 Steps for All Data Sources .......................................................................... 17

4.5.2 American Community Survey ……………………...................................... 18

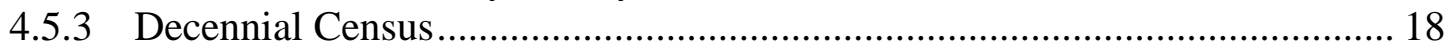

4.5.4 Economic Census........................................................................................ 19

4.5.5 Local Area Personal Income Estimates ……………....................................... 19

4.5.6 Local Education Agency (School District) Finance Survey ............................ 20

4.5.7 Local Telephone Competition and Broadband Reporting ………………......... 20

4.5.8 State Broadband Initiative......................................................................... 20

4.5.9 Esri/GfK MRI DoubleBase Survey …………………………………….... 20

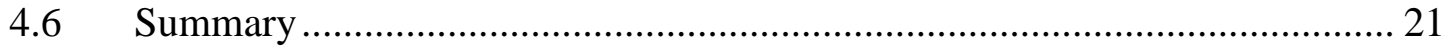

Chapter 5 - Data Exploration and Visualization .......................................................... 23

5.1 Descriptive Statistics...................................................................................... 23

5.1.1 Summaries of Independent Variables ............................................................... 23

5.1.2 Summaries of Dependent Variables............................................................... 26

$5.2 \quad$ Pearson Correlation Coefficients …………………………………………... 31 


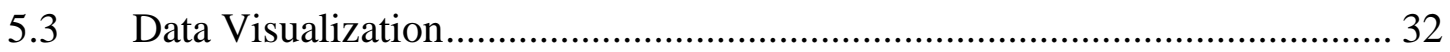

Chapter 6 - Cluster Analysis and Results.......................................................................... 37

6.1 Attribute Space Clustering Analysis ............................................................ 37

6.1.1 Selecting the Appropriate Number of Clusters ............................................. 37

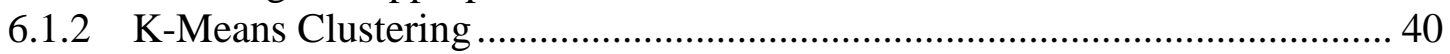

6.2 Spatial Autocorrelation Cluster Analysis........................................................ 43

6.2.1 Defining Spatial Contiguity ……………………….................................... 43

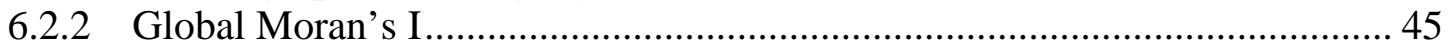

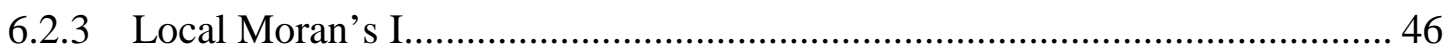

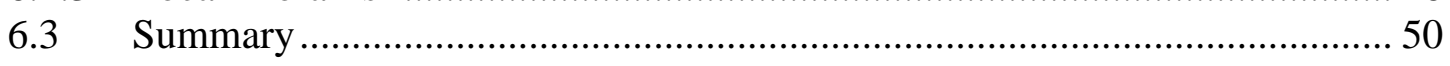

Chapter 7 - Regression Analysis and Results........................................................... 51

7.1 Ordinary Least Squares Regression Analysis ................................................ 51

7.1.1 Ordinary Least Squares Models................................................................... 51

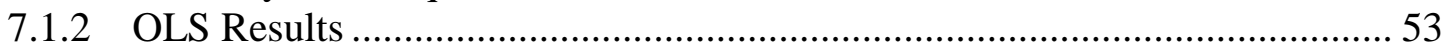

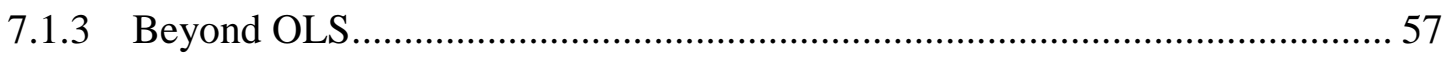

7.2 Geographically Weighted Regression Analysis.............................................. 57

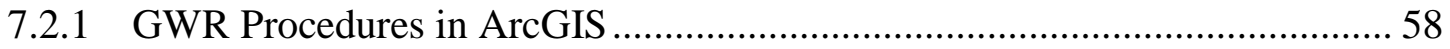

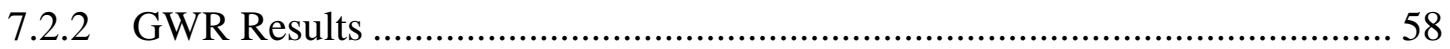

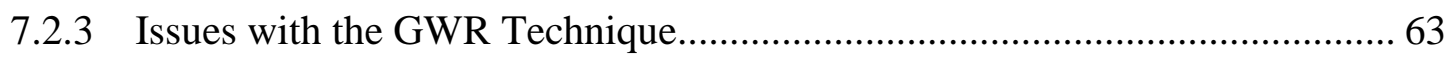

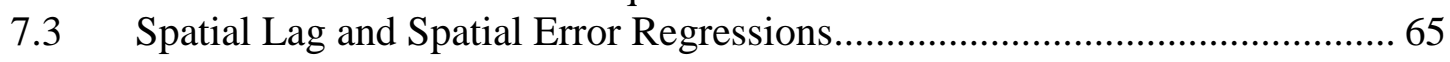

7.3.1 Spatial Dependence Regression Analysis Methods ...........................................6 66

7.3.2 Spatial Dependence Model Results ................................................................. 66

7.4 Summary ............................................................................................... 72

Chapter 8 - Conclusions and Future Work ……..................................................... 73

$8.1 \quad$ Project Summary ..................................................................................... 73

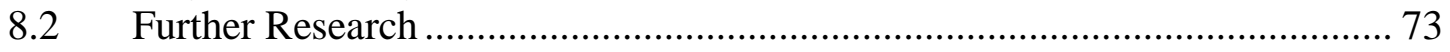

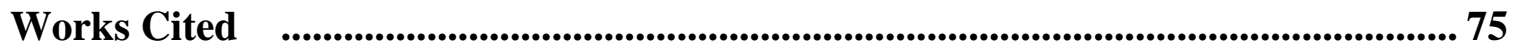

Appendix A. Data Codebook ......................................................................................... 81

Appendix B. Pearson Correlation Coefficient Matrices ............................................... 89

Appendix C. Data Visualization Maps............................................................................ 109

Appendix D. Results of K-Means Cluster Analysis .................................................... 151

Appendix E. Spatial Autocorrelation Results ........................................................... 185

Appendix F. Geographically-Weighted Regression Analysis Results .................... 187 


\section{Table of Figures}

Figure 3-1: System design showing the basic components of this project.

Figure 4-1 Conceptual model of information and communications technologies and socio-economic and demographic factors.

Figure 5-1: Map of the variable percentage of households with cellular telephones.32

Figure 5-2: Percent of households with dial-up Internet connections. ......................33

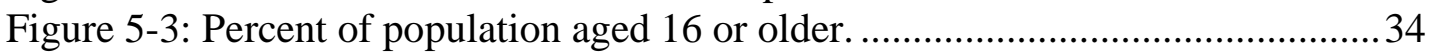

Figure 5-4: Number of residential Internet service providers with speeds greater than

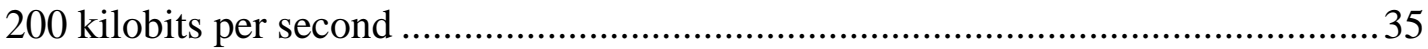

Figure 6-1: Scree plot of the coefficients from Table 6-1. .....................................38

Figure 6-2: Dendrogram of percent of adults with cable modem Internet connections

at home variable.

39

Figure 6-3: Map of k-means cluster membership for the percent of adults with cable

modem Internet connections at home variable.

Figure 6-4: Map of k-means cluster membership for the set of 13 Internet use

variables.

Figure 6-5: Moran's I values for all neighborhoods compared to the rook

neighborhood.

Figure 6-6: Map of local Moran's I high-high clusters. Darker red indicates that the county is in a greater percentage of a possible 54 high-high clusters.

Figure 6-7: Map of local Moran's I low-low clusters. Darker blue indicates that the

county is in a greater percentage of a possible 54 low-low clusters.

Figure 6-8: Map of local Moran's I outliers. Darker color indicates that the county is

in a greater percentage of a possible 54 outliers.

Figure 7-1: Map of OLS regression residuals for the any high speed internet variable.

Figure 7-2: Regression residuals for the percent of population that accessed facebook.com in the past 30 days. Top: OLS regression residuals; Bottom: GWR residuals.

Figure 7-3: GWR coefficients for percent of population that visited facebook.com in

the past 30 days. All coefficients share the same symbology.

Figure 7-4: Graph of AICc value for varying number of neighbors for the

FACEBOOKR GWR model. The orange line is derived from individual runs of the algorithm at each bandwidth size. The blue dot is the AICc value at 761 neighbors calculated using the AICc optimization algorithm in ArcGIS Desktop. 64 Figure 7-5: Images of the the percent total employment at different bandwidth sizes.

a) 14 neighbors; b) 24 neighbors; c) 80 neighbors; d) 761 neighbors. 65 



\section{List of Tables}

Table 3-1. Functional requirements

Table 4-1: Results of quality control steps conducted when combining independent

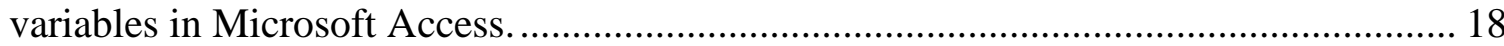

Table 5-1: Independent variable descriptive statistics.................................................. 24

Table 5-2: Descriptive statistics for dependent variables related to Internet speed and availability.....

Table 5-3: Descriptive statistics for dependent variables related to Internet access and technology availability .................................................................................................. 29

Table 5-4: Descriptive statistics for dependent variables related to Internet activities .... 30

Table 5-5: Descriptive statistics for dependent variables related to e-commerce ............. 31

Table 6-1: Agglomeration schedule for the percent of adults with cable modem Internet connections at home 38

Table 6-2: Cluster centers and number of counties in each cluster for the percent of adults with cable modem Internet connections at home variable. 40 Table 6-3: Determining number of neighbors using different spatial contiguity methods.

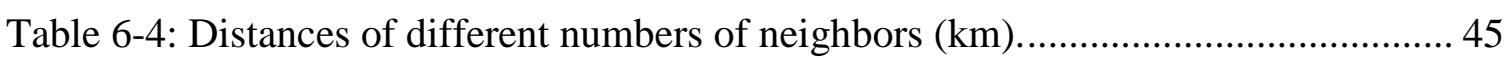

Table 6-5: Excerpt from Local Moran's I reclassification scheme. ................................... 47

Table 7-1: Independent and dependent variables used in exploratory regression analysis.

Table 7-2: Standardized OLS regression results for ICT infrastructure dependent variables. 52 Table 7-3: Standardized OLS regression results for telephone and social media dependent variables. 55

Table 7-4: Change in Aikake's Information Criterion (AICc) between OLS and GWR models. Regression models are listed in ascending order of AICc change. ...................... 59 Table 7-5: Lagrange multiplier statistics for the exploratory regression models. ............. 66 Table 7-6: Comparison of diagnostic statistics for four regression models. Best-fit model is highlighted. 68 Table 7-7: Standardized spatial error (top) and spatial lag (bottom) regression results for ICT infrastructure dependent variables. 70 Table 7-8: Standardized spatial error (top) and spatial lag (bottom) regression results for telephone and social media dependent variables. 71

Table D-1: K-means cluster centers and number of cluster members.............................. 151 Table D-2: Cluster centers for traditional ICT research variables. Clusters are ordered from highest to lowest values. 154 Table D-3: Cluster centers for Internet use variables. Clusters are ordered from highest to lowest values. 154 Table E-4: Results of global Moran's I spatial autocorrelation analysis using ArcGIS Desktop. Note that all values are significant at $\mathrm{p}<0.000001$ level. 185 



\section{List of Acronyms and Definitions}

$\begin{array}{ll}\text { AICc } & \text { Akaike’s Information Criterion } \\ \text { BEA } & \text { Bureau of Economic Analysis } \\ \text { FCC } & \text { Federal Communications Commission } \\ \text { GIS } & \text { Geographic Information Systems } \\ \text { GWR } & \text { Geographically Weighted Regression } \\ \text { ICT } & \text { Information and Communications Technology } \\ \text { IT } & \text { Information Technology } \\ \text { LM } & \text { Lagrange Multiplier } \\ \text { MIP } & \text { Major Individual Project } \\ \text { NAICS } & \text { North American Industry Classification System } \\ \text { NTIA } & \text { National Telecommunications and Information Administration } \\ \text { OECD } & \text { Organisation for Economic Co-operation and Development } \\ \text { OLS } & \text { Ordinary Least Squares Regression }\end{array}$





\section{Chapter 1 - Introduction}

This document is an in-depth discussion of the project "Information and Communications Technology and the Digital Divide: An Analysis of United States Counties”. The digital divide is defined as the difference in information and communications technologies (ICT) use and availability between geographical areas. Using various cluster and regression analytical techniques, this project examined how selected socio-economic and demographic variables influence the use of ICTs at the county scale.

The project determined that there was significant spatial clustering of ICT variables at the county level. The results of both the k-means cluster technique and the spatial autocorrelation analysis showed similar spatial patterns. Clusters of high technology were found near metropolitan areas throughout the country, while clusters of low technology were found in the central, southern, and Appalachia regions of the United States.

The results of the regression analyses showed that the percent of urban area, the percent of college graduates or higher, and the percent of employed civilians all positively contributed to the use and adoption of ICTs within a county. When spatial regression techniques were incorporated, the model fit improved significantly and the spatial variables were usually the most important variable in the model. All of these results suggest that there is an important spatial process governing the spread of ICT use and adoption at the county level in the United States.

\subsection{Clients}

Professors James Pick and Avijit Sarkar, University of Redlands School of Business, were the clients for this project. They are academic researchers interested in using spatial pattern analysis methods to determine how socio-economic and demographic factors affect ICT adoption and use in the United States. Their previous work in this topic was conducted at three different scales: nations, states or their equivalent units, and smaller regions including counties and metropolitan areas. In this project, the clients provided the domain knowledge regarding variable selections and analytical methods.

\subsection{Problem Statement}

The clients had examined ICT adoption for the United States at a state level; however, they had not investigated the spatial variations of ICT usage over the entire country at a finer scale. Therefore, the project sought to answer 1) how the spatial patterns of ICT adoption and its usage varied in United States counties between 2007 and 2012 and 2) how those patterns were related to the spatial patterns of socio-economic and demographic variables. Revealing the interrelation of both sets of spatial patterns could allow the clients to draw new conclusions about the digital divide in the United States at a scale finer than previously observed.

\subsection{Proposed Solution}

The solution to the project was to apply statistical and spatial methods to determine the presence of pattern and process. To perform those methods, the first step was to select 
data that were similar to the previous study, but available at the county scale. A total of 82 variables were selected. The data was then gathered, collated, and organized into geodatabase and tabular form. Then each variable was visualized to determine its spatial distribution. Finally, statistical and spatial patterns were analyzed using two clustering techniques, k-means and Moran's I, and four regression techniques - ordinary least squares regression, geographically weighted regression, spatial lag regression, and spatial error regression. The results of these two sets of analyses would provide answers to the research questions.

\subsubsection{Goals and Objectives}

The goals of this project were to enhance the understanding of ICT use and availability in the United States and to convey the project findings to the broader academic and research community. To achieve this goal, there were three objectives 1) to determine if there were spatial patterns in ICT use and availability, 2) to ascertain whether there were statistically significant relationships between ICT use and socio-economic or demographic variables, and 3) to present the findings of the research in academic forums such as conferences and peer-reviewed journals.

\subsubsection{Scope}

The scope of the project was to analyze ICT adoption and usage for the entire United States at the county level. The deliverables for this project consisted of six general items. First, a geodatabase was created, which included the county geometry and all relevant variables in tabular form. This geodatabase could be used in any further spatial analyses the clients may perform in ArcGIS. Second, a Microsoft Excel spreadsheet containing all of the variables was made for further analyses performed in statistical software packages. Third, a data codebook was generated, which included the metadata and descriptions of the variables. This was used by the clients to understand the data provenance and variable names during further research and analysis. Fourth, thematic maps of all 82 variables were created so that the clients could discern visual patterns in the data. Fifth, all statistical analysis outputs were collected for the clients to use to interpret the results of the clustering and regression analyses. And sixth, a final report was written which included all pertinent information related to the project.

\subsubsection{Methods}

Each project phase consisted of its own set of methods. The project concept and scope phase consisted of initial research and scoping meetings with the clients and a written project proposal.

The second phase, data ingest, consisted of gathering data for 82 variables, 56 dependent and 26 independent variables. The data were available online from United States government sources, including the Bureau of Economic Analysis (Bureau of Economic Analysis, 2012), the Census Bureau (U.S. Census Bureau, 2012; U.S. Census Bureau, 2010b; U.S. Census Bureau, 2007), the Federal Communications Commission (FCC) (Federal Communications Commission, 2011), and the National Telecommunications \& Information Administration (NTIA) (National 
Telecommunications and Information Administration, 2012). Additional data were found in the Esri Business Analyst package (Esri, 2013).

The third phase, data visualization, consisted of creating choropleth maps of each variable. A standard map template was created using ArcGIS for Desktop (Esri, 2014) and a Python (Python Software Foundation, 2014) program was written to output the 82 requested maps. The program was transformed into an ArcGIS toolbox to provide the clients with the capability to produce these maps for later projects.

The fourth phase, spatial statistical analysis, consisted of conducting various analyses including descriptive statistics and correlation analysis, k-means clustering analysis, spatial autocorrelation analysis, ordinary least squares linear regression, geographically weighted regression, spatial lag regression, and spatial error regression. These analyses were performed using ArcGIS for Desktop, SPSS (IBM, 2014), and GeoDa (Anselin, Syabri, \& Kho, 2006).

The fifth phase, reporting results, included providing the clients with results and visualizations from the statistical analyses as required for publication. The graphics and tabular results were produced to meet publication standards and to provide the specified support for the clients' research conclusions.

\subsection{Audience}

The audience for this project was academics and researchers in both the digital divide and GIS fields. Drs. Pick and Sarkar intend to publish this research, which is a portion of their overall research, in a peer-reviewed journal. They provided the opportunity to co-author this publication based upon the extent and quality of the contributions provided via the MIP.

Another group of users of this MIP was professionals in the spatial statistics field. The clients work closely with the Esri geostatistical group. They may be interested in any advances in techniques or changes in variables that were implemented in this project that have not typically been used in the past.

\subsection{Overview of the Rest of this Report}

This report consists of seven chapters. The first chapter is the introduction, of which this is the final section. The background and literature review can be found in the second chapter. Chapter three consists of the systems analysis and design, which includes the project plan. Chapter four contains detailed information about phase II of this project and a discussion of the database design. Chapters five, six, and seven include information about phase III of this project, including detailed statistical analysis methods, results, and discussion. Chapter eight contains discussions about overall conclusions and suggestions for further research on this topic. 



\section{Chapter 2 - Background and Literature Review}

This chapter focuses on a discussion of the previous work conducted on the subject of the digital divide. Section 2.1 discusses the digital divide in general, with a focus on the United States in Section 2.1.2. Section 2.2 addresses any work that includes spatial analysis. Section 2.3 concludes with a discussion of how this project was different from a previous study conducted by the clients, after which this study was modeled.

\subsection{Digital Divide and Its Associated Factors}

Information and communications technologies (ICT), including broadband and dial-up Internet, mobile phones, and other wireless technologies, has grown exponentially worldwide (Pick \& Azari, 2011). This technological growth has been driven by the diverse applications and resources that ICT offers including changing organizations, introducing new businesses, increasing productivity, and upgrading living standards (Azari \& Pick, 2005; Pick \& Azari, 2008). However, adoption and use of ICT has been unequal throughout the world (Azari \& Pick, 2005; Pick \& Azari, 2008; Pick \& Azari, 2011; National Telecommunications and Information Administration, 2000; Pick \& Nishida, 2014). Eighty-eight percent of Internet users come from countries that contain only 15 percent of the world population (Pick \& Azari, 2008; Pick, Sarkar, \& Johnson, 2014; World Economic Forum, 2002). “[This] gap between individuals, households, businesses, and geographic areas at different socio-economic levels with regard both to their opportunities to access [ICT] and to their use of the Internet for a wide variety of activities” (Organisation for Economic Co-operation and Development, 2001, p. 5) has been termed digital divide.

In the past two decades, a large body of research has been conducted on the causes of digital divide throughout the world (Dasgupta, Lall, \& Wheeler, 2005; Korupp \& Szydlik, 2005; Liu \& San, 2006; Onyeiwu, 2002; Hoffman \& Novak, 1998; Comer \& Wikle, 2008; Grubesic, 2006; Kvasny \& Keil, 2006; Yates, Gulati, \& Weiss, 2011). This research on ICT use and availability has been performed at three scales: nations, states or their equivalent, and smaller regions including counties and metropolitan areas. Comparing ICT use at the various scales has the potential to greatly enhance our understanding of the legal and social frameworks between the different administrative units. However, when making these types of comparisons the researcher must control for the ability for governmental units to regulate or change ICT use and availability, socioeconomic variables through for example taxes, or demographic variables through policies aimed at favoring ethnic and cultural diversity.

\subsubsection{Factors Associated with Digital Divide}

To better understand the inequality of ICT use across different social groups, it is necessary to look into what factors or variables are associated with the digital divide. Studies comparing digital divide among nations have suggested that: income, education, occupation, infrastructure, and democratic values are the significant factors determining ICT use and availability (Ahn \& Lee, 1999; Comer \& Wikle, 2008; Pick \& Azari, 2008; Pick, Nishida, \& Zhang, 2013; Yates, Gulati, \& Weiss, 2011). In order to close the gap in 
ICT use and availability between countries, some researchers have suggested that countries should increase the availability of higher education, incentivize research and innovation, and promote an independent judiciary, as these variables have been shown to correlate with high ICT use (Pick \& Azari, 2011; Pick \& Nishida, 2014). However, in some countries this level of financial support for technology will continue to fall behind the very basic needs of its populace: food, shelter, clean water, and a rudimentary education (Pick \& Azari, 2011; Pick \& Nishida, 2014).

The Organisation for Economic Co-operation and Development (OECD) postulated that the Digital Divide between communities may be as stark as the divide found at the international scale (Organisation for Economic Co-operation and Development, 2000). This assumption was supported by studies addressing the variability of ICT use and availability between states/provinces within a single country have been conducted, including in China (Pick, Nishida, \& Zhang, 2013), India (Pick, Nishida, \& Sarkar, 2013), and Japan (Nishida, Pick, \& Sarkar, 2012). Traditional statistical methods, such as correlation analysis, regression analysis, and attribute cluster analysis, have been applied to analyze how ICT usage and availability in the selected administrative units vary by socio-economic factors. The typical dependent variables include "personal computers, Internet users, broadband users, mobile phone users or subscribers, and fixed phone users or subscribers” (Pick, Nishida, \& Zhang, 2013, p. 30). These studies have found that the drivers for disparity in ICT use and availability included characteristics of individuals such as education level, age, and wealth - and characteristics of national policy - such as economic drivers, democracy, and research and innovation (Pick, Sarkar, \& Johnson, 2014).

\subsubsection{The Digital Divide in the United States}

The digital divide in the United States has also been studied at a variety of administrative scales, including states, counties, and cities. The findings suggest that while the United States is a leader in ICT use and availability, digital divide continues to exist and may be increasing already existing social divides (Organisation for Economic Co-operation and Development, 2000). For example, Azari and Pick (2005) found that "professional/scientific/technical services workforce, other service workforce, household income, federal grant funds, college education, and ethnicity” (p. 21) significantly affect technology sector payroll in a study of selected United States counties. The results show that ICT use requires a level of competency and understanding that is fostered by research and development industries, professional and technical jobs, and college education. A study by Crandall (2001) found that "income, occupation, rural residence, large household size, and female head of household” (Azari \& Pick, 2005, p. 23) significantly accounts for computer ownership and Internet use among racial groups in the United States. This suggests that the shift to digital computing may be increasing the gap between racial groups in the United States (Organisation for Economic Co-operation and Development, 2000).

\subsection{Geographies of ICT Use}

An emerging research method for studying the digital divide is to use spatial statistics to examine the variability in the digital divide. This is because geography has been found to 
be one of the main indicators to explain both ICT spread and the digital divide worldwide (DeVol, Klowden, Bedroussian, \& Yeo, 2009; Chen, 2013; Grubesic, 2006; Kvasny \& Keil, 2006; Pick, Nishida, \& Zhang, 2013). For example, Greenstein and Prince (2006) found a disparity in the use of the Internet in the United States between rural, urban, and inner city users. They posit that this is related to technology infrastructure quality and Internet Service Provider competition, or lack thereof, as well as the socio-economic, educational attainment, and income levels of the users.

The consistent findings that location is an explanatory variable in ICT studies also justify the use of geospatial analytical methods (Pick, Sarkar, \& Johnson, 2014). Pick and his colleagues have used spatial methods in their work and have found geographic variation in ICT adoption (Nishida, Pick, \& Sarkar, 2012; Pick \& Nishida, 2014; Pick, Nishida, \& Sarkar, 2013; Pick, Nishida, \& Zhang, 2013; Pick, Sarkar, \& Johnson, 2014). Using k-means cluster analysis, Pick et al. (2014) found four clusters of ICT use and availability in the United States. Low technology clusters were found in the central United States and higher technology clusters were found in the coastal and Rocky Mountain areas.

While the digital divide has been revealed across different states in the United States, an analysis at a more granular level is necessary to show how inequality of ICT use varies locally. To address this issue, location should be treated beyond just an independent variable, because statistical independence is often violated for spatial datasets because of spatial autocorrelation (O'Sullivan \& Unwin, 2010). Autocorrelation, epitomized by Tobler's First Law of Geography "Everything is related to everything else, but near things are more related than distant things" (Tobler, 1970, p. 236), is a key feature of geographic data (O'Sullivan \& Unwin, 2010). If spatial autocorrelation is ignored in statistical analysis, the Type I error, or the probability of rejecting a correct null hypothesis, is increased (Griffith, 1987).

\subsection{Summary}

This project was modeled after the study conducted by Pick and colleagues (2014), two of whom were the clients for this project. In addition to asking similar spatial questions and using similar methods to those used by Pick et al., this study made use of similar variables. Independent variables included population variables, economic variables, and societal openness variables were sourced from the United States Census Bureau and the Bureau of Economic Analysis. The dependent variables included ICT use and availability information sourced from the United States Census Bureau, the Federal Communications Commission, the National Telecommunications and Information Administration, and the Esri Business Analyst package (see Appendix A for a full list of variables and sources).

The major difference between this study and the Pick et al. (2014) study was that this study used United States counties as the geographic unit of study instead of states. A systematic study at this geographic scale and examination of numerous types of ICT variables has not been conducted (Sarkar, A. \& Pick, J. B., personal communication). The detail available for this analysis was possible because of a focus on the digital divide by the United States government and the newly released data available as a result of that focus (Sarkar, A. \& Pick, J. B., personal communication). This project determined the spatial patterns at the new analysis scale and if and how they varied from the state level study. 



\section{Chapter 3 - Systems Analysis and Design}

This chapter focuses on the requirements analysis for the project and the system design. Section 3.1 contains the project problem. Functional requirements are discussed in Section 3.2. In Section 3.3, the system design is discussed. The project plan can be found in Section 3.4 and a summary in Section 3.5.

\subsection{Problem Statement}

The clients, Dr. James Pick and Dr. Avijit Sarkar, were interested in investigating the spatial variations of information and communications technology (ICT) usage at the county level in the United States. This project sought to answer 1) how the spatial patterns of ICT adoption and its usage varied in United States counties between 2007 and 2012,2 ) how those patterns were related to the spatial patterns of socio-economic and demographic variables.

\subsection{Requirements Analysis}

In general, there were two types of requirements for a project, functional and nonfunctional requirements. A functional requirement is a specific task, action, or item that must be completed during the project. A non-functional requirement is one that judges the operation of the system that is being developed. Because this project focused on statistical analyses of the ICT usage and not a software program, all of the requirements for the project were functional requirements (Table 3-1). 


\section{Table 3-1. Functional requirements}

\begin{tabular}{|l|l|}
\hline Requirement & Description \\
\hline Data codebook & $\begin{array}{l}\text { This data codebook was used to track } \\
\text { the metadata of the variables. }\end{array}$ \\
\hline Data sourcing document & $\begin{array}{l}\text { A text document describing the data } \\
\text { collection methods and was used by the } \\
\text { clients to understand the data sourcing } \\
\text { and collection methodologies. }\end{array}$ \\
\hline $\begin{array}{l}\text { Geodatabase and Excel } \\
\text { spreadsheets }\end{array}$ & $\begin{array}{l}\text { The clients require the raw data in } \\
\text { geodatabase format for further analysis } \\
\text { in ArcGIS and in tabular format for } \\
\text { further statistical analysis. }\end{array}$ \\
\hline Maps of variables & $\begin{array}{l}\text { Maps of each variable were used to } \\
\text { visualize the variables. These maps } \\
\text { were used solely for visual analysis of } \\
\text { patterns and were not publication } \\
\text { quality. }\end{array}$ \\
\hline $\begin{array}{l}\text { Outputs of statistical } \\
\text { analyses }\end{array}$ & $\begin{array}{l}\text { Analyses included: } \\
\text { a. Descriptive statistics } \\
\text { b. Correlation matrix } \\
\text { c. K-means cluster analysis } \\
\text { d. Spatial autocorrelation (Moran's I) } \\
\text { e. Ordinary least squares regression } \\
\text { f. Maps of regression residuals } \\
\text { g. Geographically weighted regression }\end{array}$ \\
\hline
\end{tabular}

The requirements included the specific documents and analyses the clients requested. The first set of documents the clients requested were related to metadata. The clients requested a data codebook modeled after the codebook they used in their previous study. It contained the following items: variable name and abbreviation, data source, North American Industry Classification System (NAICS) code (if applicable), data collection date, and variable definition. For tracking capabilities, raw data filename and field name in the raw dataset were added. The codebook is included in this document as Appendix A. The other metadata document the clients requested was the data sourcing document. It included information describing each data source. Where possible, data collection methods were obtained from the source. 
The second set of documents requested by the clients were the data tables. These tables were provided to the clients in two formats: geodatabase format in the event that further spatial analysis might be required, and Microsoft Excel format for further statistical analysis.

The clients requested choropleth maps of each of the variables used in the study. These maps were initially scoped as publication quality maps; however, after further discussion with the clients, it was determined that draft quality maps were all that were necessary. The clients intended to use these maps to visualize patterns in the data and did not require them for publication. Any maps required for publication could be created at a later date.

The final requirement was the statistical analysis. The clients provided a list of analyses used in their previous projects. These requirements were generally described at the outset of the project, including descriptive statistics, k-means cluster analysis, spatial autocorrelation analysis, ordinary least squares regression analysis, and geographicallyweighted regression analysis. The specific details of variable combinations and analysis steps were finalized as the project progressed.

\subsection{System Design}

The major components of the system were the input database, the software, and the analytical outputs as shown in Figure 3-1. The system was analytical in nature. It began with the external data sources, such as the US Census Bureau, Federal Communications Commission, and the National Telecommunications and Information Administration, which provide the data in tabular format. These raw data files were imported into the project geodatabase and feature classes of these files were generated to be processed and analyzed in ArcGIS Desktop and GeoDa. The processed attribute tables of the feature classes were then exported from the geodatabase for use in SPSS. These three software programs were used to conduct various spatial and statistical analyses. The output of these analyses were tables and maps that were used to present the spatial patterns of ICT usage across counties in the United States and relationships between ICT usage and various socio-economic variables by considering spatial dependency and heterogeneity.

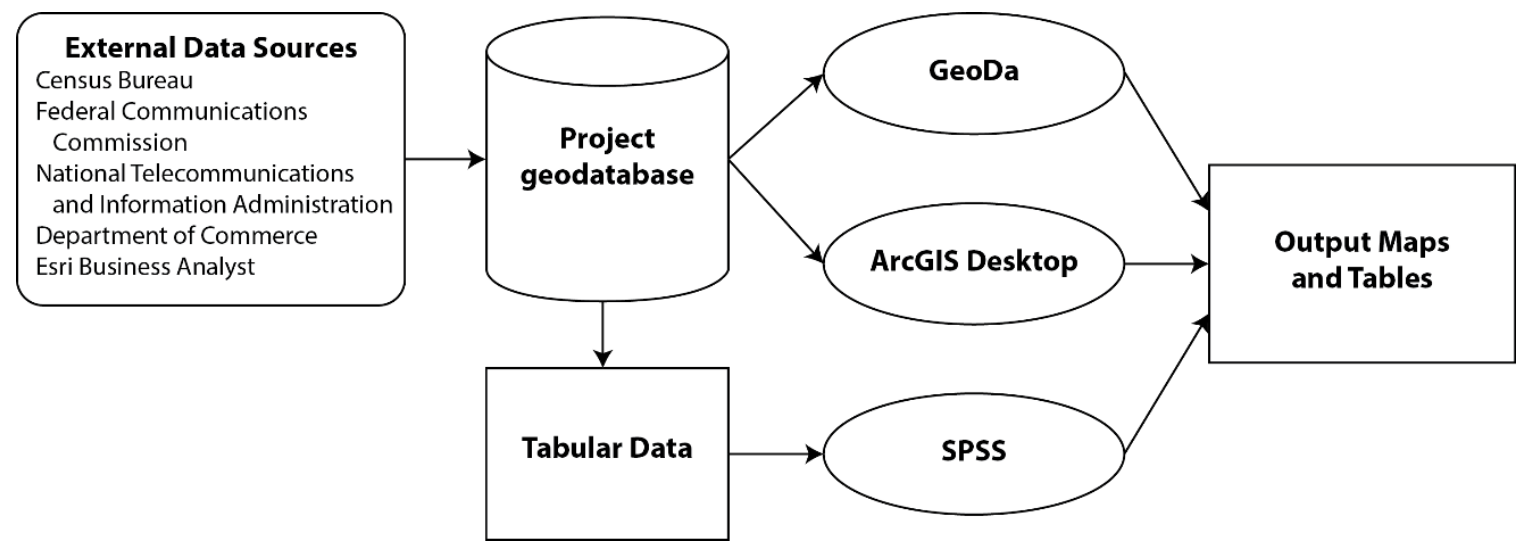

Figure 3-1: System design showing the basic components of this project. 


\subsection{Project Plan}

The project was initially planned in five phases: 1) project concept and scope, 2) data ingest, 3) data visualization, 4) spatial statistical analysis, and 5) project completion. The project concept and scope phase consisted of initial scoping meetings with the clients and research in the field of information and communications technologies. This initial phase required 80 hours of analyst time.

The data ingest phase consisted of obtaining access to the data sources, downloading the proper datasets, formatting the datasets for ingest into ArcGIS, and exporting the data in tabular format for use in SPSS. This phase was planned for 120 hours of analyst time. It also required additional information technology (IT) resources, specifically, obtaining access to the Esri Business Analyst extension and databases. Actual analyst time was approximately half of that budgeted; however, accessing IT resources was more time consuming than expected. This resulted in a major schedule change for the project. The problem became a project management learning opportunity because it showed that the availability of limited outside resources has a significant schedule impact and therefore more calendar days may need to be budgeted when relying on these resources.

The data visualization phase consisted of making maps for each variable in the study. This phase was budgeted up to 240 hours of analyst time in the event that publication quality maps were required and that map creation could not be automated. The scope of this phase was discussed during a requirements meeting with the clients and resulted in a major scope reduction. The clients clarified their needs and removed the initial requirements for publication quality maps and innovative data visualizations. This resulted in a decrease in the time budgeted for this phase to 40 hours from the initial 240 hours. The map automation process reduced this phase by another 75 percent, which returned the project to the original schedule after the delay in the data ingest phase.

The spatial statistical analysis phase consisted of all of the analysis the clients required. Each of the four major analysis types were budgeted 80 hours and the descriptive statistics were budgeted 10 hours, resulting in a total of 330 hours budgeted for analysis. Because there were no major issues with the analysis, analytical time was approximately half of what was budgeted.

The project completion phase consisted of compiling final tabular and graphical results for the clients and writing the MIP report. The tabular and graphical results were budgeted 80 hours of analyst time and the report was budgeted 160 hours. Because of the nature of these tasks, it was not possible to separate the creation of finalized results from the report draft. These tasks included the MIP report, the conference presentation, and conference poster. The combined length of time required to complete these tasks was approximately 200 hours of time. This was approximately the length of time budgeted for the phase.

\subsection{Summary}

The clients for this project desired a series of spatial statistical analyses to determine if there were any patterns in information and communications technology (ICT) use and availability and how those patterns were related to socio-economic and demographic variables. The clients laid out clear functional requirements that did not vary significantly throughout the project. This resulted in a clear project plan of five phases - project 
concept and scope, data ingest, data visualization, spatial statistical analysis, and project completion. The original resource budget was significantly overestimated and the project was completed on schedule. 



\section{Chapter 4 - Database Design}

This chapter discusses the specific information related to the database design and data ingest. Section 4.1 discusses the Information and Communications Technology conceptual model. The logical data model used in this project is discussed in Section 4.2. The specific data sources used in this project are discussed in Section 4.3. Data collection methods can be found in Section 4.4. Section 4.5 contains a detailed discussion of the data scrubbing methods and loading the data into the geodatabase. The chapter concludes with a brief summary in Section 4.6.

\subsection{Conceptual Data Model}

The conceptual data model for this project addresses the Information and Communications Technologies (ICT) usage in the United States. It consists of eight interconnected object classes (Figure 4-1). The clients were interested in determining how the attributes of the person: household, business, and county (right side of the figure) affected the use and availability of the ICT devices: online activities, and Internet service providers (left side of the figure). Specific attributes for each class were chosen by the clients as they are experts in the ICT research field and provided the domain knowledge for this project. The rationale behind including many of these variables was discussed in Chapter 2.

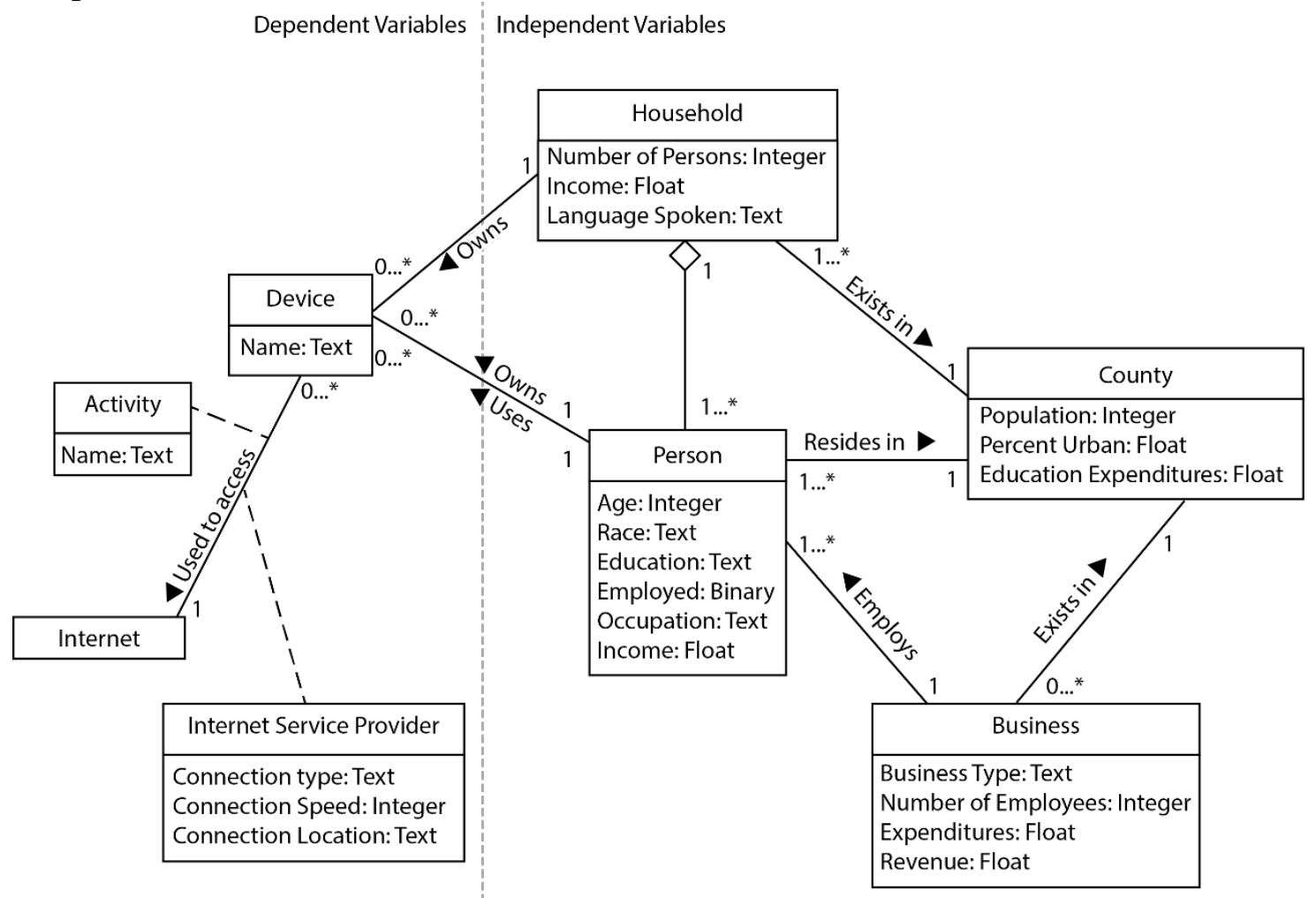

Figure 4-1 Conceptual model of information and communications technologies and socio-economic and demographic factors. 
In general, one would expect that individuals and households with a higher income and higher educational attainment would tend to make use of ICT more than those with lower income or less education. The literature has shown that urban areas are more likely to have better access to ICT than rural areas as a result of both access to technological infrastructure as well as socio-economic, educational attainment, and income factors (Greenstein \& Prince, 2006). Additionally, ethnicity has been shown to relate to the disparity in Internet use between households with white and Asian households having increased broadband access compared to black or Hispanic households (Agarwal, Animesh, \& Prasad, 2009).

\subsection{Logical Data Model}

Based on the conceptual model, the logical database model was designed at the county level as data were only available at this scale. A total of 82 variables were chosen from the data providers. Seven of the object classes described in Figure 4-1 became attributes of the eighth object, county.

As a result of the collapsed logical model, the database design included two tables and three vector feature classes. One table was created for the independent variables and a second table was created for the dependent variables. The three vector feature classes were county boundary polygons. One contained the boundaries and the attributes describing the counties. The second and third feature classes were materialized views of the study data. One included the independent variables and the other included the dependent variables.

As the analysis was conducted, additional feature classes were created as derivatives of the original data. The analysis methods that created new feature classes were the kmeans cluster analysis, the spatial autocorrelation analysis, the ordinary least squares regression analysis, and the geographically weighted regression analysis. Feature datasets were created for each process to house the new items. All output files were named such that the input or dependent variables were apparent.

\subsection{Data Sources}

The data were obtained from United States government sources - Census Bureau, Department of Commerce, and Federal Communications Commission - and the Esri Business Analyst. Data were collected by these entities between 2007 and 2012. The specific census, surveys or estimates, were the American Community Survey 5-year estimates (2008-2012), Decennial Census (2010), Economic Census (2007), Local Area Personal Income Estimates (2012), Local Education Agency (School District) Finance Survey, F-33 (2009), Local Telephone Competition and Broadband Reporting Form 477 (2012), State Broadband Initiative (2012), and Esri/GfK MRI DoubleBase Survey (2010) (U.S. Census Bureau, 2012; U.S. Census Bureau, 2010b; U.S. Census Bureau, 2007; Bureau of Economic Analysis, 2012; National Center for Education Statistics, 2009; Federal Communications Commission, 2011; National Telecommunications and Information Administration, 2012; Esri, 2013). The specific tables and columns used from these data sources are listed in the data codebook in Appendix A. 


\subsection{Data Collection Methods}

For this project, no data was collected via methods such as surveys, fieldwork, lab methods, or remote sensing. All data were available from government agencies and commercial data providers. Each of the data sets were downloaded in one of four formats: comma separated values (.csv), Microsoft Excel (.xls or .xlsx), text (.txt), or Business Analyst data source (.bds). A shapefile of the county boundaries was downloaded from the Census Bureau (U.S. Census Bureau, 2010c).

\subsection{Data Scrubbing and Loading}

All raw datasets required some manipulation prior to loading into the geodatabase developed for this project. In some cases, manipulation was as minimal as selecting the appropriate attributes and exporting a file containing only those attributes of interest. In other cases, a custom Python script was developed to create the dataset needed for the project. The following sections discuss the steps required for each data source.

\subsubsection{Steps for All Data Sources}

Two Microsoft Access databases were created for this project, one for the dependent variables and one for the independent variables. These databases were used to join the attributes from the raw data tables that were downloaded from the data sources into one table. The final table was exported in the Microsoft Excel format. The Excel table was imported into ArcGIS and joined to the vector county polygons using the unique county identifier. This joined feature class was then exported into the final geodatabase to be used in the analysis. The attribute table of that feature class was exported into a database file (.dbf) and converted to an Excel table for use in SPSS.

Quality control was conducted at various points during the data migration to ensure that no data was lost or changed. The quality control steps used when combining the numerous independent variable tables in Microsoft Access are shown in Table 4-1.These steps included comparing the number of records found in the input table to the combined tables, confirming that all fields were included in the combined table, and spot checking various records to confirm that no records were skipped. As a result of quality control, errors in the independent variable datasets were discovered. Any subsequent errors and their solutions are discussed in the following sections relating to each data source. The dependent variables did not contain any errors or missing values. No errors were found in any other conversion steps for either dataset. 
Table 4-1: Results of quality control steps conducted when combining independent variables in Microsoft Access.

\begin{tabular}{|c|l|c|c|c|c|c|c|}
\hline \multirow{2}{*}{} & Table added & \multicolumn{2}{|c|}{ Number of Records in: } & \multicolumn{2}{c|}{ Number of Fields in: } \\
\cline { 3 - 7 } & & Table & Join & $\begin{array}{c}\text { Join, } \\
\text { total }\end{array}$ & $\begin{array}{c}\text { Begin } \\
\text { Table }\end{array}$ & $\begin{array}{c}\text { Table } \\
\text { added }\end{array}$ & $\begin{array}{c}\text { Final } \\
\text { Table }\end{array}$ \\
\hline-- & GEO_id & 3143 & 3143 & 3143 & 1 & 0 & 1 \\
\hline 01 & ACS_12_5YR_DP02 & 3143 & 3143 & 3143 & 1 & 8 & 9 \\
\hline 02 & ACS_12_5YR_DP03 & 3143 & 3143 & 3143 & 9 & 7 & 16 \\
\hline 03 & DEC_10_SF1_SF1DP1 & 3143 & 3143 & 3143 & 16 & 42 & 58 \\
\hline 04 & ECN_2007_US_00A1_5111 & 186 & 186 & 3143 & 58 & 1 & 59 \\
\hline 05 & ECN_2007_US_00A1_51111 & 64 & 64 & 3143 & 59 & 1 & 60 \\
\hline 06 & ECN_2007_US_00A1_51112 & 63 & 63 & 3143 & 60 & 1 & 61 \\
\hline 07 & ECN_2007_US_00A1_51113 & 17 & 17 & 3143 & 61 & 1 & 62 \\
\hline 08 & ECN_2007_US_00A1_54A1 & 1949 & 1948 & 3143 & 62 & 8 & 70 \\
\hline 08 & ECN_2007_US_00A1_54A1 & 3110 & 3108 & 3143 & 62 & 8 & 70 \\
\hline 09 & Pct urban by county & 3143 & 3143 & 3143 & 70 & 4 & 74 \\
\hline 10 & PerCapita_Personal_Income & 3138 & 3088 & 3143 & 74 & 1 & 75 \\
\hline 11 & Personal_Income & 3138 & 3088 & 3143 & 75 & 1 & 76 \\
\hline 12 & SDF091a & 3121 & 3120 & 3143 & 76 & 1 & 77 \\
\hline
\end{tabular}

\subsubsection{American Community Survey}

Data from the 2012 American Community Survey were downloaded from the American FactFinder in .csv format (U.S. Census Bureau, 2012). Specific attributes from tables DP02 and DP-03 were selected from the raw input files and imported into the Access database. These two tables provided 16 attributes, which were combined into six independent variables (see Appendix A for specifics). Data were available for each of the 3143 counties in the study. The quality control steps found no errors or missing values in this dataset (see Table 4-1).

\subsubsection{Decennial Census}

The 2010 Decennial Census data were downloaded from the American FactFinder in .csv format (U.S. Census Bureau, 2010b). Specific attributes from the Summary File 1 table were selected from the raw input file and imported into the Access database. This table provided 42 attributes, which were combined into 13 independent variables (see Appendix A for specifics). Data were available for all 3143 counties in the study. No errors or missing values were found in this dataset during quality control (see Table 4-1).

An additional independent variable, percent urban by county, also was derived from the Decennial Census; however, it is not included as part of the Decennial Census Summary Files. This data was downloaded from the Census Bureau website (U.S. Census Bureau, 2010a). The percent urban attribute was selected from the raw file and imported into the Access database. Data were available for all 3143 counties in the study and no errors or missing values were found during quality control. 


\subsubsection{Economic Census}

The 2007 Economic Census data were downloaded from the American FactFinder in .csv format (U.S. Census Bureau, 2007). The data for the 2012 Economic Census had been collected by the Census Bureau; however, they were not publicly available at the time of this project. Two tables were downloaded from the Census Bureau: one for newspaper, periodical, book, and directory publishers (NAICS 5111) and the other one for professional, scientific, and technical services (NAICS 54). The newspaper, periodical, book, and directory publishers included information on all categories combined: newspaper publishers (NAICS 51111), periodical publishers (NAICS 51112), and book publishers (NAICS 51113). These data were used for three independent variables: annual sales revenues of all publishers revenue, book publishers revenues, and newspaper and periodical publisher revenues. The professional, scientific, and technical services table provided two independent variables, revenues and number of employees.

The Economic Census only provided data for a county if there were a certain number of businesses of specific types within the county. This protects the anonymity of businesses within that county. This resulted in 186 or fewer records for publishers. For professional, scientific, and technical services there were 3110 records with the number of establishments and only 1949 records with full attribute data. No errors or missing data were found for the publisher data (see Table 4-1); however, during quality control, it was noted that there were two missing records in the professional, scientific, and technical services overall data set (3108) and one missing record in the set with full data (1948). Upon further research, there were two counties in Alaska that were split and merged into other counties between the 2007 Economic Census and the 2010 Decennial Census. There were no reasonable methods to split this data into the new counties, so the extra data were removed from the dataset.

\subsubsection{Local Area Personal Income Estimates}

The 2012 Local Area Personal Income Estimates were downloaded from the Bureau of Economic Analysis website (Bureau of Economic Analysis, 2012). The personal income, per capita income, and population (CA1-3) tables were provided as .csv files for each state. A Python script was written to loop through all of the .csv files and parse the data for each county into a single file for use in the analysis. The output attributes, one for personal income and one for per capita income, were imported into the Access database as independent variables.

When imported into the database, a discrepancy in the number of records was noted (see Table 4-1). This discrepancy was due to the small number of residents of independent cities in Virginia and one county in Hawaii. These areas were combined with other nearby counties to protect the anonymity of the residents. To address this, the per capita income value provided by the BEA was given to both of the combined counties. For the personal income variables, the population for both counties was summed and the total income was divided by the summed population. The resulting income value was assigned to both counties. After this change, there were no missing values for these two independent variables. 


\subsubsection{Local Education Agency (School District) Finance Survey}

The 2009 Local Education Agency (School District) Finance Survey (F-33) data was downloaded from the United States Department of Education's National Center for Education Statistics (National Center for Education Statistics, 2009). Data were available from the website in text format (.txt). The education expenditures were listed for each school district. Therefore, a Python program was written to combine the expenditures of multiple school districts within a single county. The resulting .csv file was imported into the Access database.

During quality control, it was noted that there was one missing record between the input file and the Access table (see Table 4-1). Additionally, there were 23 missing records from the input file and four records with zero expenditures. The four zero value records were manually corrected using the values in the original dataset. Upon further investigation, one missing record was due to a missing character in the county identifier. This typographical error was fixed and that record was imported into the database. For the 23 missing records, further research noted that some school districts covered multiple counties and some county identifiers were mis-labeled in the raw dataset. In the case that a school district covered multiple counties, the population of the counties was pooled and the resulting expenditure ratio was given to both counties. When a school district was mis-labeled, the county identifier was changed to match the identifiers used in this study. These manual changes resulted in no missing values in the independent variable file.

\subsubsection{Local Telephone Competition and Broadband Reporting}

The 2011 Local Telephone Competition and Broadband Deployment data were downloaded from the Federal Communications Commission website in .csv format (Federal Communications Commission, 2011). These data provided six dependent variables related to the number of Internet service providers in each county. There were records for all 3143 counties as well as the minor islands. Unneeded data were removed from the dataset when joining tables in Microsoft Access. No errors or missing values were found during quality control.

\subsubsection{State Broadband Initiative}

The 2011 State Broadband Initiative data were downloaded from the National Broadband Map website in .xlsx format (National Telecommunications and Information Administration, 2012). These data provided eight dependent variables related to the number of households in each county with specific types of Internet connections. There were records for all 3143 counties as well as the minor islands. Unneeded data were removed from the data set when joining tables in Microsoft Access. No errors or missing values were found during quality control.

\subsubsection{Esri/GfK MRI DoubleBase Survey}

The 2010-2012 Esri/Gfk MRI DoubleBase data were available through the Esri Business Analyst data and extension (Esri, 2013). These data were proprietary and required a software license to access. The clients chose 41 information and communications 
technology use and availability attributes as dependent variables. These attributes were available in .bds format, a proprietary Business Analyst data format. The .bds data were imported into a geodatabase as a feature class, which allowed for access outside Business Analyst. The data was then exported as a .dbf file, imported into Microsoft Excel, and then imported into Microsoft Access. Data were available for all 3143 counties. No errors or missing values were found during quality control.

\subsection{Summary}

For this project, data for 84 variables were downloaded from United States government sources and a commercial data provider. The complex Information and Communications Technologies conceptual model was simplified into a geodatabase of three vector feature classes and two tables. These raw data were mostly complete with relatively few errors that had to be corrected during data scrubbing. This extensive dataset provided the clients the capability to draw numerous conclusions without sacrificing statistical rigor. 



\section{Chapter 5 - Data Exploration and Visualization}

Before examining the spatial distributions of ICT usage variables and how they relate to various socio-economic variables, it was important to explore data distribution, map the variables in space, and compare relationships among these variables. Section 5.1 describes the descriptive statistics calculated for the independent and dependent variables. The Pearson correlation coefficients analysis is discussed in Section 5.2. Finally, the visible spatial patterns in the data are discussed in Section 5.3.

\subsection{Descriptive Statistics}

The first step in the statistical analysis was to calculate descriptive statistics for each independent and dependent variable. The descriptive statistics - minimum, maximum, mean, median, and standard deviation - were calculated in SPSS. In most cases, the values for the variables range from 0 to 1 because they represent the percent of population or households in the county with that trait. When the variable does not follow that range, it is the value per capita or per unit land area. All of the raw variables have been normalized using one of these methods in order to adjust for population variations across different counties.

\subsubsection{Summaries of Independent Variables}

The independent variable descriptive statistics are shown in Table 5-1. The first seven variables relate to the age distribution in each county. The first variable , "TOTPOP10R", is total population per square kilometer. This is a variable with a large range, greater than 26,000 people per square kilometer difference, and is highly variable with a standard deviation greater than six times the mean. The next five variables - " POP0_19R", “POP20_64R”, “POP65_UPR”, “POP16_UPR”, and “POP25_44R” - are the percent of population in a specific age range. These variables show a range less than 50 percent and are not highly varied with standard deviations around three percent. The young dependency ratio, "YOUNGDEPR", is the ratio of children to adult population. This variable has a large range from 0 to almost 1 , or an equal number of children and adults but has a standard deviation of only seven percent. 
Table 5-1: Independent variable descriptive statistics.

\begin{tabular}{|c|c|c|c|c|c|c|}
\hline Variable & $\mathrm{N}$ & Minimum & Maximum & Mean & Median & $\begin{array}{l}\text { Standard } \\
\text { Deviation }\end{array}$ \\
\hline TOTPOP10R & 3143 & 0.01 & 26821.91 & 100.13 & 17.45 & 665.706 \\
\hline POP0_19R & 3143 & 0.00 & 0.46 & 0.26 & 0.26 & 0.035 \\
\hline POP20_64R & 3143 & 0.46 & 0.82 & 0.58 & 0.58 & 0.034 \\
\hline POP65_UPR & 3143 & 0.03 & 0.43 & 0.16 & 0.16 & 0.042 \\
\hline POP16_UPR & 3143 & 0.65 & 1.00 & 0.81 & 0.81 & 0.029 \\
\hline POP25_44R & 3143 & 0.14 & 0.43 & 0.24 & 0.24 & 0.032 \\
\hline YOUNGDEPR & 3143 & 0.00 & 0.94 & 0.45 & 0.45 & 0.072 \\
\hline URBAN & 3143 & 0.00 & 100.00 & 41.35 & 40.47 & 31.513 \\
\hline COLLEGER & 3143 & 0.03 & 0.54 & 0.13 & 0.12 & 0.059 \\
\hline LGOVEDEXPR & 3143 & 69.57 & 36664.34 & 2015.56 & 1812.89 & 1220.183 \\
\hline TOTEMPLR & 3143 & 0.25 & 0.95 & 0.59 & 0.60 & 0.076 \\
\hline WKAGEPOP & 3143 & 0.46 & 0.82 & 0.58 & 0.58 & 0.034 \\
\hline SERVICER & 3143 & 0.03 & 0.21 & 0.10 & 0.10 & 0.019 \\
\hline CONSTRUCTR & 3143 & 0.00 & 0.16 & 0.04 & 0.04 & 0.014 \\
\hline PINC12R & 3143 & 0.00 & 472.96 & 3.95 & 1.24 & 14.433 \\
\hline PINCPC12 & 3143 & 17264.00 & 116843.00 & 36615.19 & 34628.00 & 9240.988 \\
\hline INCOMER & 3143 & 0.37 & 2.32 & 0.86 & 0.83 & 0.224 \\
\hline FORLANGR & 3143 & 0.00 & 0.86 & 0.09 & 0.05 & 0.106 \\
\hline ASIANR & 3143 & 0.00 & 0.62 & 0.02 & 0.01 & 0.031 \\
\hline BLACKR & 3143 & 0.00 & 0.86 & 0.09 & 0.03 & 0.146 \\
\hline HISPANICR & 3143 & 0.00 & 0.96 & 0.08 & 0.03 & 0.132 \\
\hline PUBLISHR & 186 & 0.04 & 15.96 & 0.65 & 0.38 & 1.311 \\
\hline PUBNEWSPRR & 91 & 0.04 & 11.58 & 0.47 & 0.24 & 1.243 \\
\hline PUBBOOKR & 17 & 0.02 & 0.89 & 0.32 & 0.25 & 0.253 \\
\hline PSTSVCEXPR & 1948 & 0.03 & 46.80 & 1.25 & 0.55 & 2.753 \\
\hline PSTSVCEMPR & 1948 & 0.00 & 0.18 & 0.01 & 0.01 & 0.01 \\
\hline
\end{tabular}

Note: Full variable names can be found in the data codebook in Appendix A

The eighth variable in Table 5-1, "URBAN", is the percent of the county considered urban. This variable ranges from 0 to 100 percent and is moderately variable with a standard deviation 75 percent of the mean value. 
The ninth and tenth variables, "COLLEGER" and "LGOVEDEXPR", are related to a county's education. The first is the percent of population with a Bachelor's degree or greater, which ranges from 3 to 54 percent and has a standard deviation of six percent. The second variable is the school district's expenditures divided by the total population. This variable has a 36,000 dollar range and a standard deviation of 1,200 dollars, or almost half of the mean value.

The next four variables - "TOTEMPLR", "WKAGEPOP”, "SERVICER”, and "CONSTRUCTR" - relate to the employment status of the county population. The first variable, “TOTEMPLR”, is the percent of employed civilians. This ranges from 25 to 95 percent and has a relatively small standard deviation of seven percent. The next variable, "WKAGEPOP", is the percent of working age population, or the ratio of individuals aged 20 to 64 compared to the total population. This ranges from 46 to 86 percent with a small standard deviation of 3 percent. The next two variables are the percent of population that works in either the construction or the service industries. These individuals are less than 20 percent of the population with a standard deviation less than 2 percent.

The next three variables - "PINC12R", "PINCPC12", and "INCOMER" - relate to income levels. The first is personal income that has been standardized by total county population. It has a range of 0 to 472 dollars per person and a standard deviation of 14 dollars per person. The next variable is per capita personal income as calculated by the Bureau of Economic Analysis. This variable has a 100,000 dollar range and a standard deviation of almost 10,000 . This is comparable to the other variables in the data set as the standard deviation is approximately one-third of the mean value. The final variable in this group is the ratio of median household income for the county divided by median household income for the United States $(\$ 53,046)$. This variable shows how wealthy a county is compared to the national average. It ranges from 37 to 232 percent, with a mean value of 86 percent and a standard deviation of 22 percent.

The next four variables - "FORLANGR”, “ASIANR”, "BLACKR” , and "HISPANICR" - relate to household racial and ethnic information. The first variable is the percent of households that speak a language other than English. This variable has a range of 86 percent and a standard deviation (10 percent) that is greater than the mean value (9 percent). The remaining variables are the percent of household of specific racial or ethnic groups - Asian, Black, or Hispanic - in the county. Asian households range from 0 to 62 percent of the population, with a mean value of two percent and a standard deviation of three percent. The percent of Black households ranges from 0 to 86 percent, with a mean of nine percent and a relatively large standard deviation of 15 percent. The percent of Hispanic households ranges from 0 to 96 percent with a mean of eight percent and a relatively large standard deviation of 13 percent.

The final five independent variables - "PUBLISHR”, "PUBNEWSPRR”, “PUBBOOKR", "PSTSVCEXPR", and "PSTSVCEMPR” - are related to businesses within the county. The first three variables indicate the publisher revenues standardized by the total population of the county, which have up to a 15 dollar range and a standard deviation of two to three times the mean value. The fourth variable is the percent expenditures for professional, scientific, and technical services businesses standardized by the total population. This variable has a 46 dollar per person range and a standard deviation of twice the mean value. The final variable is the number of employees for professional, scientific, and technical services businesses standardized by the total 
population. This variable has a small range of 17 percent and a standard deviation equal to the mean of one percent.

\subsubsection{Summaries of Dependent Variables}

The descriptive statistics for the dependent variables are summarized in Table 5-2 through Error! Reference source not found., each describing a general topic. Table 5-2 describes variables related to Internet speed and availability. The first variable, "TOTHHOLDSR", is the number of households per square kilometer in the county. The range of this variable is very large, from 0 to 13,000 households. The standard deviation is large compared to the mean. The next eight variables in the table - "BRDBNDHH", "WIRELNEHH”, "DSLHH”, “CABLEHH”, "FIBERHH”, "WIRELESSHH”, "SATELLITHH", and "MOBILEWLHH" - are the percentage of households with specific Internet connection types. Except for percentage of households with satellite internet, these variables range from 0 to 100 percent. The standard deviations for these variables range from five percent to 32 percent. The percentage of households with satellite internet variable has a value of zero for every county. Because of this lack of information, the variable was dropped from further analysis. 
Table 5-2: Descriptive statistics for dependent variables related to Internet speed and availability

\begin{tabular}{|c|c|c|c|c|c|}
\hline Variable & Minimum & Maximum & Mean & Median & $\begin{array}{c}\text { Standard } \\
\text { Deviation }\end{array}$ \\
\hline TOTHHOLDSR & 0.01 & 12918.95 & 39.34 & 6.70 & 288.88 \\
\hline BRDBNDHH & 0.000 & 1.000 & 0.985 & 0.999 & 0.053 \\
\hline WIRELNEHH & 0.000 & 1.000 & 0.869 & 0.919 & 0.147 \\
\hline DSLHH & 0.000 & 1.000 & 0.784 & 0.833 & 0.191 \\
\hline CABLEHH & 0.000 & 1.000 & 0.590 & 0.656 & 0.321 \\
\hline FIBERHH & 0.000 & 1.000 & 0.134 & 0.005 & 0.239 \\
\hline WIRELESSHH & 0.000 & 1.000 & 0.960 & 0.995 & 0.098 \\
\hline SATELLITHH & 0.000 & 0.000 & 0.000 & 0.000 & 0.000 \\
\hline MOBILEWLHH & 0.000 & 1.000 & 0.954 & 0.994 & 0.115 \\
\hline DIALUPINTR & 0.012 & 0.080 & 0.043 & 0.044 & 0.013 \\
\hline CABLEINTR & 0.076 & 0.435 & 0.229 & 0.225 & 0.079 \\
\hline DSLINTR & 0.075 & 0.289 & 0.224 & 0.224 & 0.028 \\
\hline FIBERINTR & 0.010 & 0.185 & 0.036 & 0.028 & 0.024 \\
\hline WIRLSSINTR & 0.109 & 0.383 & 0.215 & 0.214 & 0.038 \\
\hline HSPEEDINTR & 0.314 & 0.910 & 0.619 & 0.608 & 0.097 \\
\hline RESFIX200 & 1.000 & 5.000 & 3.343 & 3.000 & 0.799 \\
\hline RSFX200BTP & 0.000 & 5.000 & 3.091 & 3.000 & 0.875 \\
\hline NUMFIXPROV & 1.000 & 62.000 & 12.307 & 11.000 & 6.597 \\
\hline NMRESPR200 & 1.000 & 21.000 & 7.517 & 7.000 & 2.915 \\
\hline NMRESPRO3M & 0.000 & 17.000 & 4.651 & 5.000 & 2.705 \\
\hline NUMPROVMOB & 0.000 & 8.000 & 3.284 & 4.000 & 1.913 \\
\hline
\end{tabular}

In addition to the Internet connection variables from the National

Telecommunications and Information Administration (NTIA), similar variables are available from the Esri Business Analyst Market Potential dataset. They are listed as "DIALUPINTR", “CABLEINTR", "DSLINTR", "FIBERINTR", "WIRLSSINTR”, and "HSPEEDINTR", representing percentage of adults with dial-up, cable, DSL, fiber, wireless, and any high speed Internet connections, respectively, at home. The descriptive statistics for these variables are very different from the statistics from the NTIA. This may be due to different data collection methods. While the NTIA measured availability of a specific Internet connection type, Esri measured the adoption of connection types. In short, while the shortening of variable names provides the appearance of equality, the 
variables in question measured different aspects of the type of Internet connection in a county.

The final six variables - "RESFIX200”, "RSFX200BTP”, “NUMFIXPROV”, “NMRESPR200”, “NMRESPRO3M”, and "NUMPROVMOB” - in Table 5-2 were provided by the Federal Communications Commission and describe the number of Internet service providers within a county. The providers are separated by speeds; however, all speeds are considered to be broadband. These variables range from 0 to 62 providers with a median value less than 11 .

The second group of dependent variables are the variables related to Internet access and technology availability (Table 5-3). The first variable in the table, "INTUSE30R", is any Internet use in the past 30 days. This variable ranges from 37 to 94 percent, with a small standard deviation of 8 percent. The next three variables - "INTATHOMER", "INTATWORKR" and "INTATSCHLR" - describe where individuals access the internet - home, work, or school/library. Internet access at home is most common, with 30 to 91 percent of the county population having access. The variation is relatively small with a standard deviation of less than 10 percent. The following three variables “COMPINHHR”, "EREADERR”, and “SMRTPHNER" - describe the types of devices available in the home - a computer, an e-reader, or a smartphone. Between 40 and 91 percent of households have a computer, a similar range of the number of households with Internet access. The last four variables - "LANDLNEHHR”, "CLLONLYHHR”, "LNDONLYHHR", and "CELLINHHR" - in the table describe the type of telephone connection in the household and differentiates between households with only landlines or only cellphones. A large majority of the county households have cell phones, at least 80 percent. This matches the maximum value of 20 percent of households that only have a landline connection. These variables all have small standard deviations, less than 4.5 percent. 
Table 5-3: Descriptive statistics for dependent variables related to Internet access and technology availability

\begin{tabular}{|c|c|c|c|c|c|}
\hline Variable & Minimum & Maximum & Mean & Median & $\begin{array}{c}\text { Standard } \\
\text { Deviation }\end{array}$ \\
\hline INTUSE30R & 0.374 & 0.935 & 0.713 & 0.714 & 0.084 \\
\hline INTATHOMER & 0.306 & 0.908 & 0.622 & 0.616 & 0.099 \\
\hline INTATWORKR & 0.105 & 0.542 & 0.284 & 0.271 & 0.072 \\
\hline INTATSCHLR & 0.036 & 0.276 & 0.087 & 0.083 & 0.024 \\
\hline COMPINHHR & 0.399 & 0.908 & 0.697 & 0.693 & 0.072 \\
\hline EREADERR & 0.021 & 0.194 & 0.068 & 0.064 & 0.025 \\
\hline SMRTPHNER & 0.145 & 0.521 & 0.281 & 0.268 & 0.067 \\
\hline LANDLNEHHR & 0.466 & 0.824 & 0.673 & 0.682 & 0.040 \\
\hline CLLONLYHHR & 0.174 & 0.573 & 0.318 & 0.309 & 0.044 \\
\hline LNDONLYHHR & 0.021 & 0.194 & 0.099 & 0.101 & 0.027 \\
\hline CELLINHHR & 0.802 & 0.978 & 0.892 & 0.890 & 0.031 \\
\hline
\end{tabular}

Table 5-4 contains the dependent variables relating to individuals Internet activities. The first nine variables - "EMAIL30R”, "GOOGLE30R”, "NEWS30R”, “WEATHER30R”, “MAP30R”, “MEDICAL30R”, “EMPLOY30R”, “TVOL30R”, and "MOVIE30R" - are ordered by the largest mean values, describing the most common Internet activities first. According to this dataset, 60 percent of people in US counties have used the Internet to access email or Google.com in the past 30 days. Accessing news related websites is less common at 35 percent, and the remaining types of information are accessed by less than 20 percent of people in the counties. Specifically, less than 10 percent of individuals within counties access the Internet to watch television or movies. 
Table 5-4: Descriptive statistics for dependent variables related to Internet activities

\begin{tabular}{|c|c|c|c|c|c|}
\hline Variable & Minimum & Maximum & Mean & Median & $\begin{array}{c}\text { Standard } \\
\text { Deviation }\end{array}$ \\
\hline EMAIL30R & 0.258 & 0.886 & 0.600 & 0.591 & 0.097 \\
\hline GOOGLE30R & 0.285 & 0.866 & 0.596 & 0.591 & 0.091 \\
\hline NEWS30R & 0.130 & 0.657 & 0.350 & 0.340 & 0.076 \\
\hline WEATHER30R & 0.087 & 0.350 & 0.172 & 0.164 & 0.041 \\
\hline MAP30R & 0.065 & 0.329 & 0.147 & 0.137 & 0.046 \\
\hline MEDICAL30R & 0.064 & 0.288 & 0.157 & 0.152 & 0.038 \\
\hline EMPLOY30R & 0.068 & 0.334 & 0.128 & 0.119 & 0.032 \\
\hline TVOL30R & 0.040 & 0.292 & 0.095 & 0.085 & 0.030 \\
\hline MOVIE30R & 0.031 & 0.261 & 0.080 & 0.072 & 0.029 \\
\hline FACEBOOKR & 0.200 & 0.690 & 0.400 & 0.391 & 0.065 \\
\hline IM30R & 0.176 & 0.614 & 0.372 & 0.367 & 0.063 \\
\hline YOUTUBE30R & 0.138 & 0.510 & 0.285 & 0.271 & 0.063 \\
\hline BLOG30R & 0.034 & 0.250 & 0.086 & 0.078 & 0.033 \\
\hline TWITTERR & 0.019 & 0.135 & 0.042 & 0.036 & 0.016 \\
\hline VIDAUTH30R & 0.023 & 0.100 & 0.040 & 0.037 & 0.010 \\
\hline LINKEDINR & 0.011 & 0.195 & 0.035 & 0.028 & 0.021 \\
\hline
\end{tabular}

The last seven variables in Table 5-4 - "FACEBOOKR", "IM30R", "YOUTUBE30R", "BLOG30R”, “TWITTERR”, "VIDAUTH30R”, and "LINKEDINR" - describe access of social media. Similarly, these variables are ordered with the largest mean value, percent of individuals within the county who have accessed Facebook.com in the past 30 days, at the top of the list. Instant messaging and YouTube.com are the next most popular activities with 37 and 28 percent of people in a county, respectively, conducting these activities. The other social media activities are conducted by less than 10 percent of the population in a particular county.

The final group of dependent variables relates to e-commerce activities "BILLS30R”, "PURCH30R", "BANK12R", "FINANCE30R", "AMZ12R", "EBAY12R", "WALMART12R", and "ITUNE12R" (Table 5-5). Approximately 30 percent of the population of a specific county accessed the Internet to pay bills in the last 30 days, made an online purchase in the last 30 days, or to accessed online banking in the past 12 months. These variables also have similar standard deviations, around seven to eight percent. Accessing financial information being the next most common activity with 20 percent of the county population conducting the activity. Among the four e-commerce vendors included, Amazon.com is the most popular one with an average of 17 percent of the county population conducting transactions. 
Table 5-5: Descriptive statistics for dependent variables related to e-commerce

\begin{tabular}{|c|c|c|c|c|c|}
\hline Variable & Minimum & Maximum & Mean & Median & $\begin{array}{c}\text { Standard } \\
\text { Deviation }\end{array}$ \\
\hline BILLS30R & 0.125 & 0.611 & 0.316 & 0.300 & 0.083 \\
\hline PURCH30R & 0.122 & 0.581 & 0.297 & 0.290 & 0.070 \\
\hline BANK12R & 0.108 & 0.514 & 0.291 & 0.287 & 0.067 \\
\hline FINANCE30R & 0.069 & 0.440 & 0.213 & 0.205 & 0.066 \\
\hline AMZ12R & 0.056 & 0.397 & 0.168 & 0.160 & 0.053 \\
\hline EBAY12R & 0.052 & 0.145 & 0.091 & 0.090 & 0.012 \\
\hline WALMART12R & 0.039 & 0.093 & 0.074 & 0.075 & 0.007 \\
\hline ITUNE12R & 0.018 & 0.166 & 0.065 & 0.057 & 0.022 \\
\hline
\end{tabular}

The descriptive statistics provide insight into the data structure prior to any spatial analysis. This information can guide the choice of variables for use in further analyses and help determine if any variables do not meet analytical requirements.

\subsection{Pearson Correlation Coefficients}

After obtaining the descriptive statistics, correlations between independent variable and dependent variables were analyzed in two separate correlation matrices. These matrices include the Pearson correlation coefficients for pairs of variables. The Pearson correlation coefficient measures a linear relationship between two variables (Burt, Barber, \& Rigby, 2009). A positive coefficient means that one variables increases while the second also increases. On the other hand, a negative coefficient means that one variable decreases while the other increases. The coefficient varies from one to negative one. The extreme values indicate a perfect linear relationship between the two variables while values closer to zero indicate weak to no linear relationship.

Correlations were calculated for all independent variables. The full 26 variable matrix can be found in Appendix B. Between the 26 independent variables, there were 325 correlations calculated. Of those 325, 225 pairs were significant at the $p<0.001$ level. Ten pairs were significant at the $\mathrm{p}<0.01$ level and 16 pairs were significant at the $\mathrm{p}<0.05$ level. The remaining 74 pairs were not significant.

The dependent variables also were often correlated with one another. In the 56 variable matrix, only 12 of the 1540 variable pairs were not significantly correlated. Two of the pairs were significant at the $\mathrm{p}<0.05$ level, four variable pairs were significant at the $\mathrm{p}<0.01$ and the remaining pairs were significant at the $\mathrm{p}<0.001$ level. The entire matrix can be found in Appendix B.

It is worth pointing out that given the large sample size $(\mathrm{N}=3143)$, correlation coefficients of small magnitude became highly significant. Because of this, the correlation coefficient was not the only criterion used to decide which variables to use in further analysis. Prior experience and subject matter knowledge by the clients were applied to select variables for the regression analysis (see Chapter 7 -). 


\subsection{Data Visualization}

The final step in data exploration was to map all of the independent and dependent variables to determine if there were any recognizable spatial patterns. A map template was designed for this set of maps. The template included: the title, basemap, and default symbology. A Python script was developed to incorporate the descriptive statistics information previously calculated. The script generated the symbology break values, symbolized the map according to the correct variable, and exported the resulting maps in three formats - pdf, png, and tiff. The program was transformed into an ArcGIS toolbox to provide the clients with the capability to produce these maps for later projects. The set of 82 maps can be found in Appendix C.

The most common pattern, which can be found in 38 of the 82 variables, is shown in Figure 5-1. The pattern has high values in the major urban centers in the country: Seattle, Portland, Los Angeles, San Francisco, Salt Lake City, Denver, Dallas, Minneapolis, Chicago/Milwaukee, Atlanta, and Boston/New York/Philadelphia/Washington DC. All of the areas that have values greater than the mean contain a metro- or micropolitan area. The central spine of the country - Montana, North and South Dakota, Nebraska, Kansas, Oklahoma, and western Texas - show values that are significantly lower than the mean. The southern Unites States - Louisiana, Mississippi, Alabama, and Georgia -- and West Virginia are also significantly lower than the mean value.

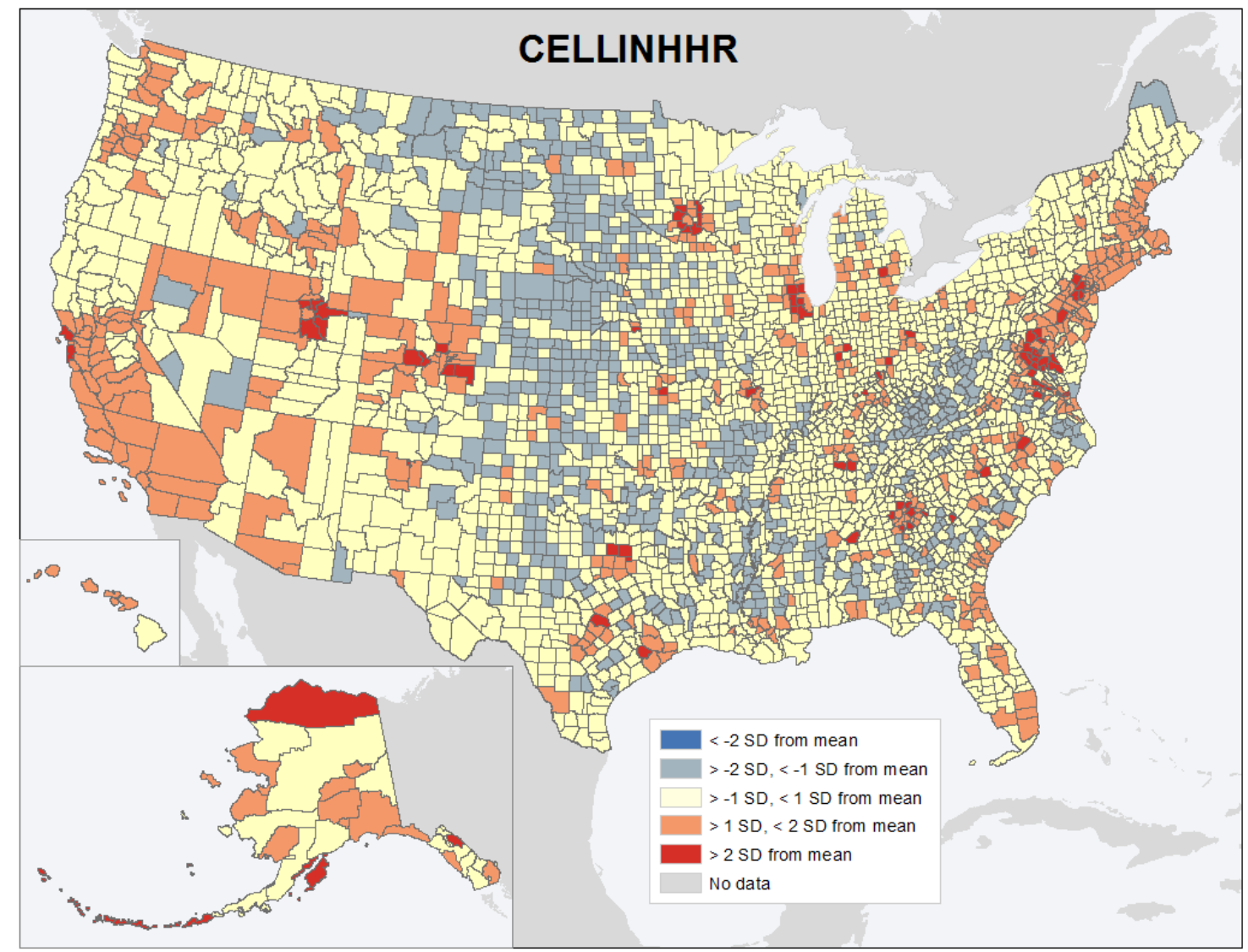

Figure 5-1: Map of the variable percentage of households with cellular telephones. 
In four of the variables - percent of landline only households, percent of households with dial-up Internet connections, percent of households with DSL Internet connections, and households that ordered from Walmart.com in the past 12 months - the pattern is reversed, as shown in Figure 5-2. This pattern shows low values in the metropolitan areas and high values in central, southern, and Appalachia regions of the United States. These four variables appear to be inversely related to technology centers.

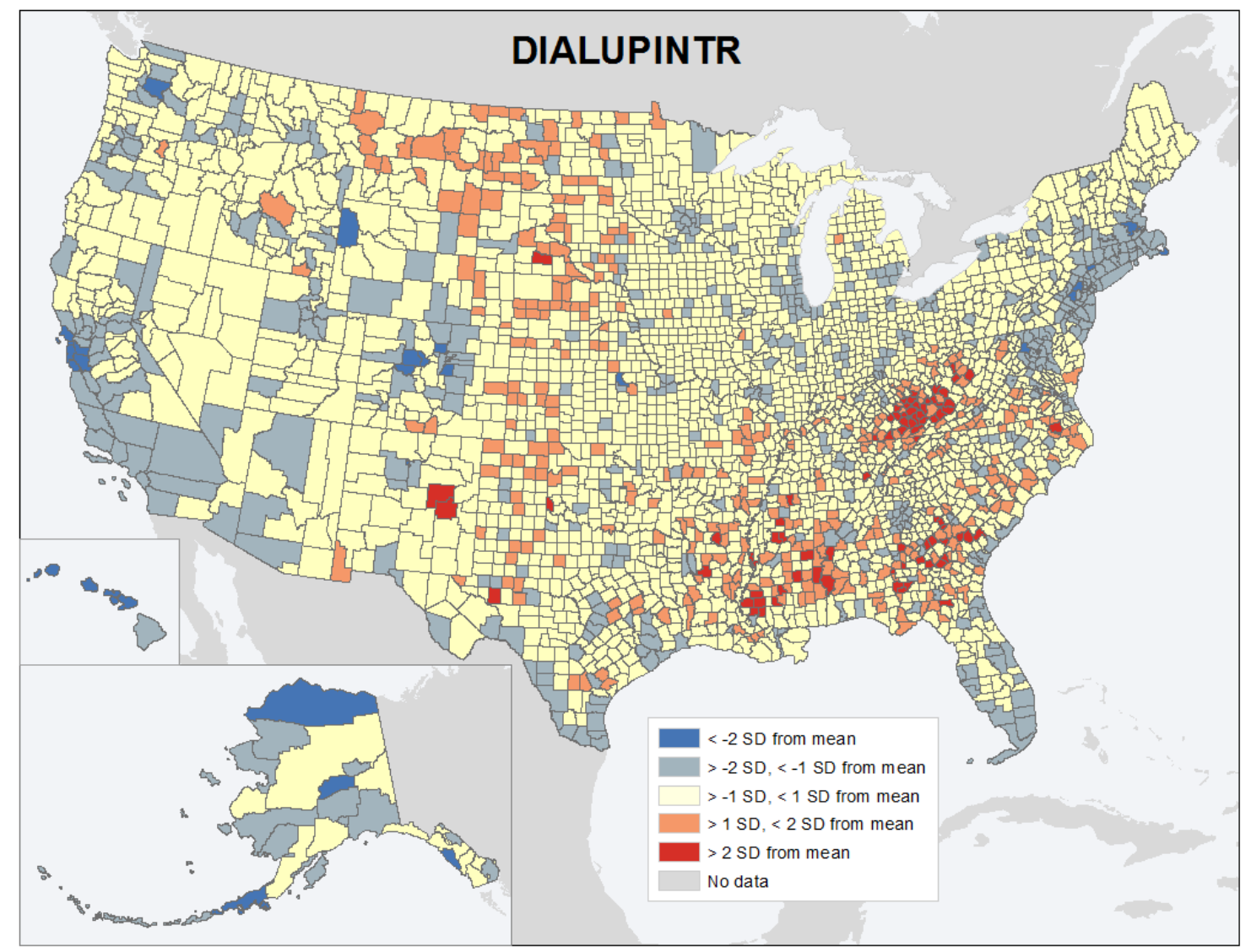

Figure 5-2: Percent of households with dial-up Internet connections.

The remaining variables do not show the same types of patterns. The nine variables related to population age and number of households show patterns that may not be related to ICT use. For example, the map of percentage of population aged 16 or older (Figure 5-3) shows a pattern that is much different than the ICT use variables. This pattern may be related to social or cultural norms rather than technology use. 


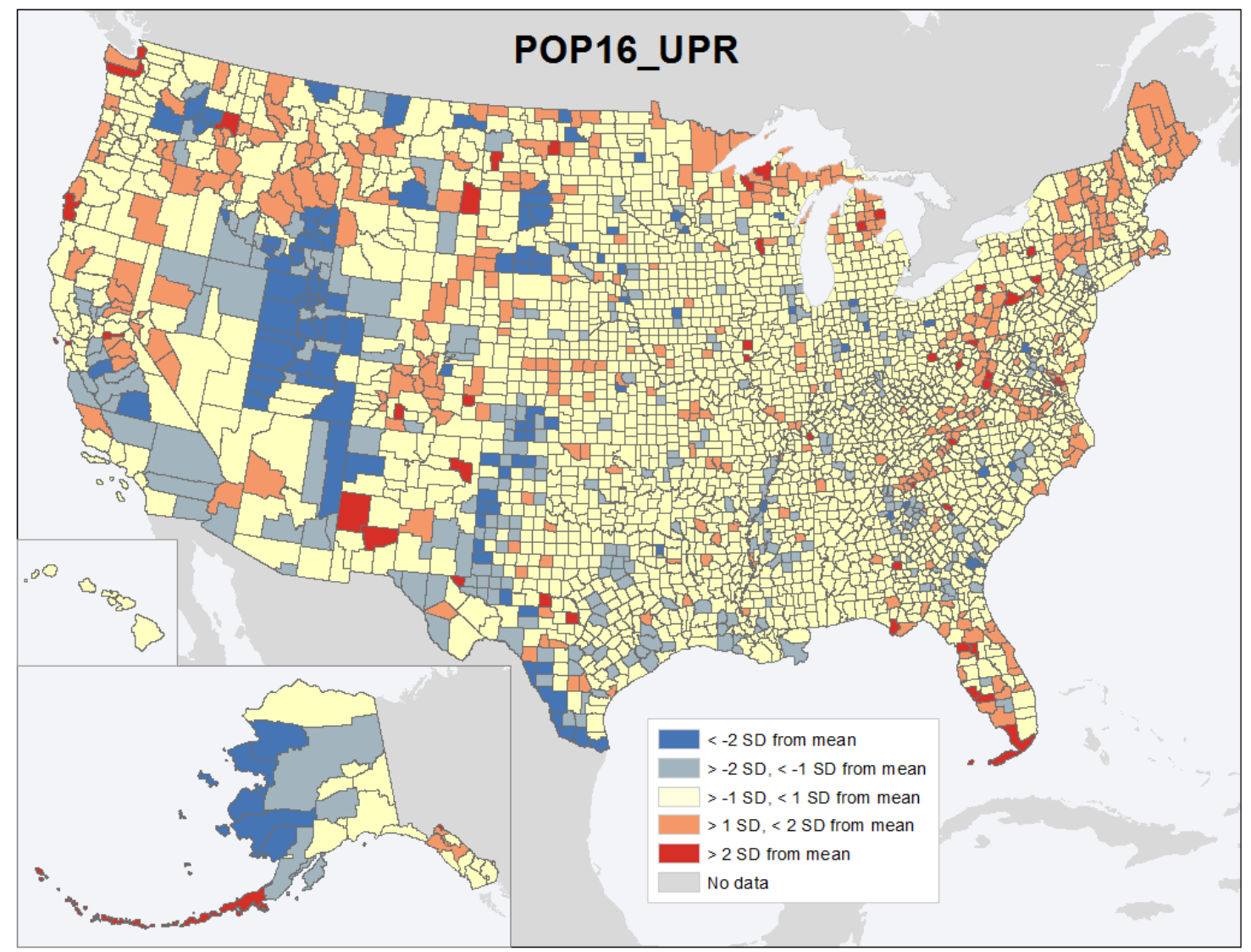

Figure 5-3: Percent of population aged 16 or older.

Finally, the pattern of infrastructure variables is much different than the previously observed patterns. For example, the number of residential Internet service providers (ISP) with speeds greater than 200 kilobits per second (the lowest speed for broadband Internet (Federal Communications Commission, 2011)), shows a different pattern than most other variables. It is likely that this pattern is related to ISP business practices rather than the use patterns previously observed. This pattern shows larger numbers of ISPs in most metropolitan areas; however, there is a comparatively low number of ISPs in the Washington DC and New York regions. Looking in the upper Midwest, there is a comparatively dense region of high values that previously was not apparent. 


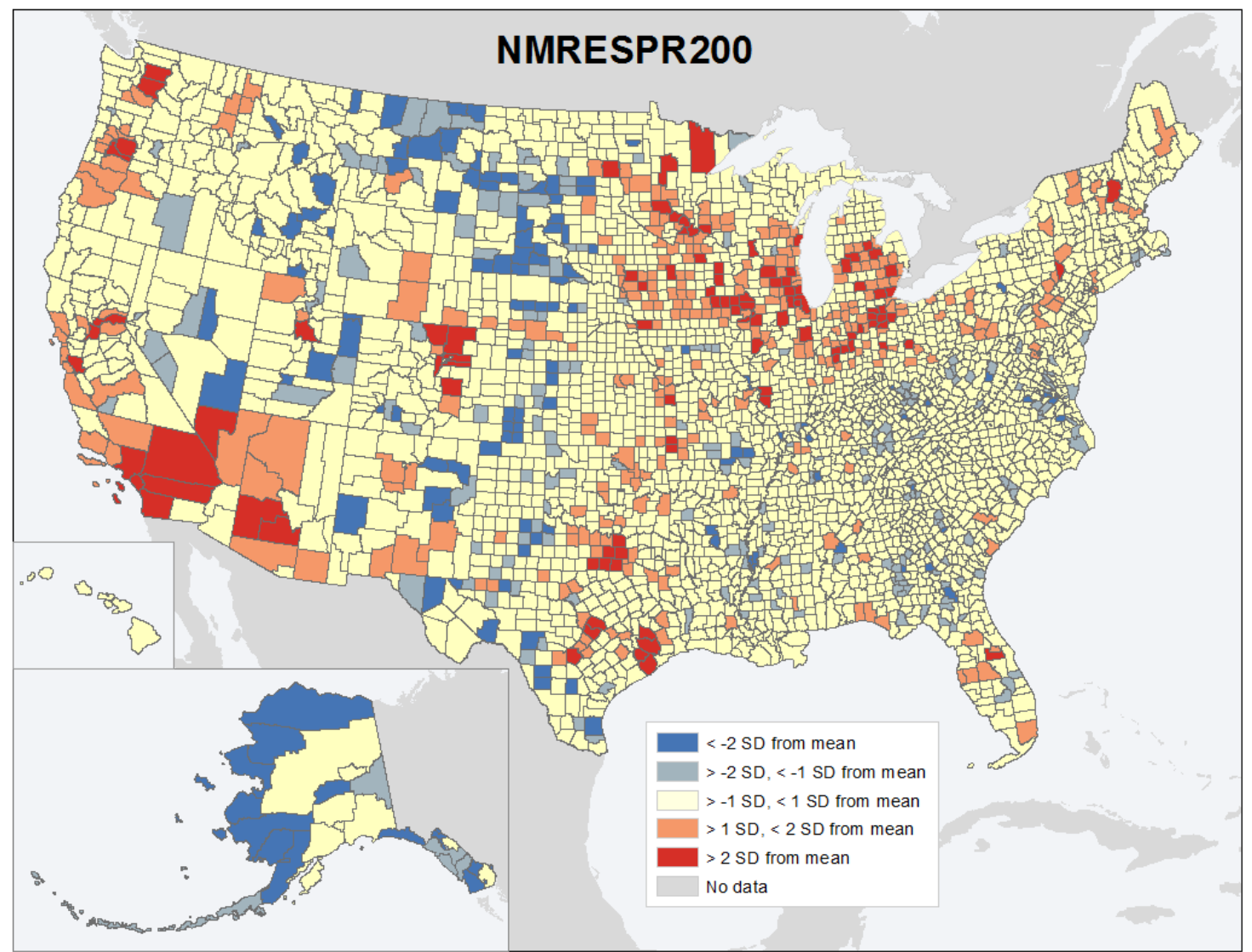

Figure 5-4: Number of residential Internet service providers with speeds greater than 200 kilobits per second

It is important to note that in almost all of the maps, it appears as though similar values tend to be near one another. There appear to be clusters of high values and clusters of low values. In rare cases, low values are surrounded by high values or high values are surrounded by low. These patterns suggest that there is high spatial autocorrelation in the dataset. The Moran's I analysis in Section 6.2 confirms the significance of this visual pattern. 



\section{Chapter 6 - Cluster Analysis and Results}

This chapter includes analysis of how the variables cluster in attribute space and geographic space. Section 6.1 describes the methods and results of the attribute space clustering using the k-means algorithm. Section 6.2 discusses the methods and results of the geographic space clustering using the global and local Moran's I analyses. The chapter closes with a brief summary of the clustering analysis in Section 6.3.

\subsection{Attribute Space Clustering Analysis}

Exploratory data analysis techniques to summarize large volumes of data have been used in a variety of disciplines (Jain, 2010). In particular, the k-means clustering algorithm was developed to determine how data groups naturally, particularly in multivariate analysis. It provides insight into data clustering and diffusion (Longley, Goodchild, Maguire, \& Rhind, 2011). This algorithm was used in this study for both univariate and multivariate clustering.

The k-means algorithm clusters all the data into $\mathrm{k}$ number of clusters. The value for $\mathrm{k}$ must be known before running the analysis. Determining the appropriate value of $\mathrm{k}$ is a limitation of the algorithm (Jain, 2010). In this study, hierarchical clustering was used to determine the optimum number of clusters to use for the k-means algorithm. In hierarchical clustering, each data point begins as its own cluster. In the attribute space, the observations with the smallest Euclidean distance separation are combined into a single cluster. This continues until all observations are grouped into a single cluster. The outputs of the algorithm in SPSS, the agglomeration schedule and the dendrogram, can be used to determine an appropriate number of clusters for the dataset.

\subsubsection{Selecting the Appropriate Number of Clusters}

The hierarchical clustering algorithm was applied individually to each dependent variable and to three sets of the dependent variables as defined by the clients. An example of the results of the hierarchical clustering algorithm is described in this section.

The output of the hierarchical clustering algorithm includes an agglomeration schedule and a dendrogram. The agglomeration schedule for the percent of adults with cable modem Internet connections at home is shown in Table 6-1. The column "Cluster Combines" tells which two clusters were combined, the column "Coefficient" shows the sum of squared Euclidean distance between the two clusters, the "Stage Cluster First Appears" indicates the step at which each of the two clusters first appeared, and the "Next Stage" points out the next stage at which the resulting cluster was joined with another cluster. The optimum cluster count occurs when the coefficient value increases sharply. Table 6-1 only shows the last 10 stages of the hierarchical clustering. Prior to that stage, the value in the coefficients column was less than 0.001 , which indicated that those cluster combinations were not of interest in determining the final cluster count. The first sharp increase in coefficients occurs between stage 3139 and 3140, indicating that the remaining four clusters are dissimilar, and therefore four is the optimum choice for the number of clusters. 
Table 6-1: Agglomeration schedule for the percent of adults with cable modem Internet connections at home.

\begin{tabular}{|c|c|c|c|c|c|c|}
\hline \multirow{3}{*}{ Stage } & \multicolumn{2}{|c|}{$\begin{array}{c}\text { Cluster } \\
\text { Combined }\end{array}$} & & \multicolumn{2}{|c|}{$\begin{array}{c}\text { Stage Cluster First } \\
\text { Appears }\end{array}$} & \\
\cline { 2 - 3 } & Cluster 1 & Cluster 2 & Coefficients & Cluster 1 & Cluster 2 & Stage \\
\hline 3133 & 37 & 45 & .001 & 3124 & 3128 & 3138 \\
3134 & 69 & 70 & .001 & 3125 & 3126 & 3138 \\
3135 & 6 & 254 & .001 & 3127 & 3116 & 3137 \\
3136 & 4 & 8 & .002 & 3132 & 3129 & 3139 \\
3137 & 3 & 6 & .002 & 3131 & 3135 & 3141 \\
3138 & 37 & 69 & .002 & 3133 & 3134 & 3140 \\
3139 & 1 & 4 & .004 & 3130 & 3136 & 3141 \\
3140 & 37 & 73 & .009 & 3138 & 0 & 3142 \\
3141 & 1 & 3 & .010 & 3139 & 3137 & 3142 \\
3142 & 1 & 37 & .020 & 3141 & 3140 & 0 \\
\hline
\end{tabular}

A visual method for determining the optimum number of clusters is to graph the coefficients in the agglomeration schedule in a scree plot (Figure 6-1). The scree plot allows the user to visualize the sharp increases in value of the coefficients. The optimum value for the coefficients is at the "elbow" of the line. In this case, the scree plot suggests either four clusters or two clusters as the optimum number.

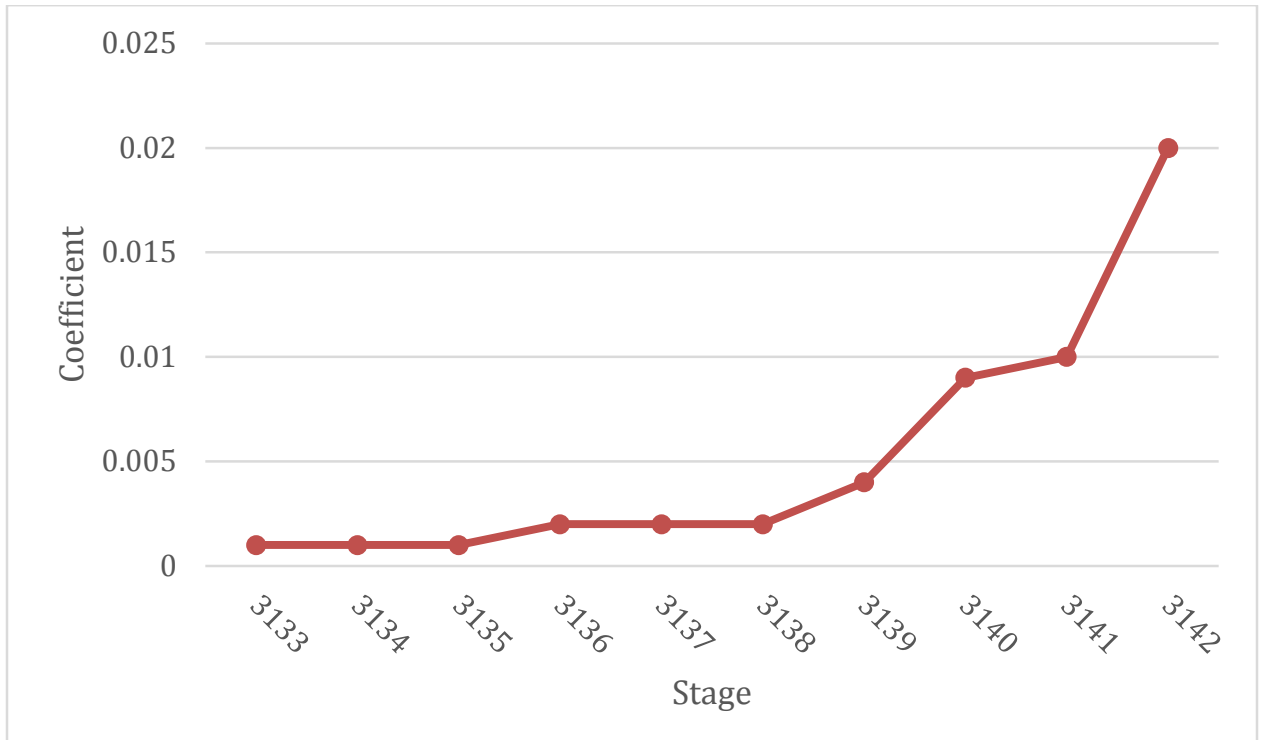

Figure 6-1: Scree plot of the coefficients from Table 6-1.

The second output of the hierarchical clustering algorithm is the dendrogram. This plot shows the clusters on the y-axis, and the x-axis is the distance between clusters, rescaled between 0 and 25. The longer the length of the horizontal line in the 
dendrogram, the larger the distance between clusters. The number of horizontal lines at the chosen rescaled distance tells the user the number of clusters at that point. The dendrogram suggests either two or four clusters for this variable (percent of adults with cable modem Internet connections at home).

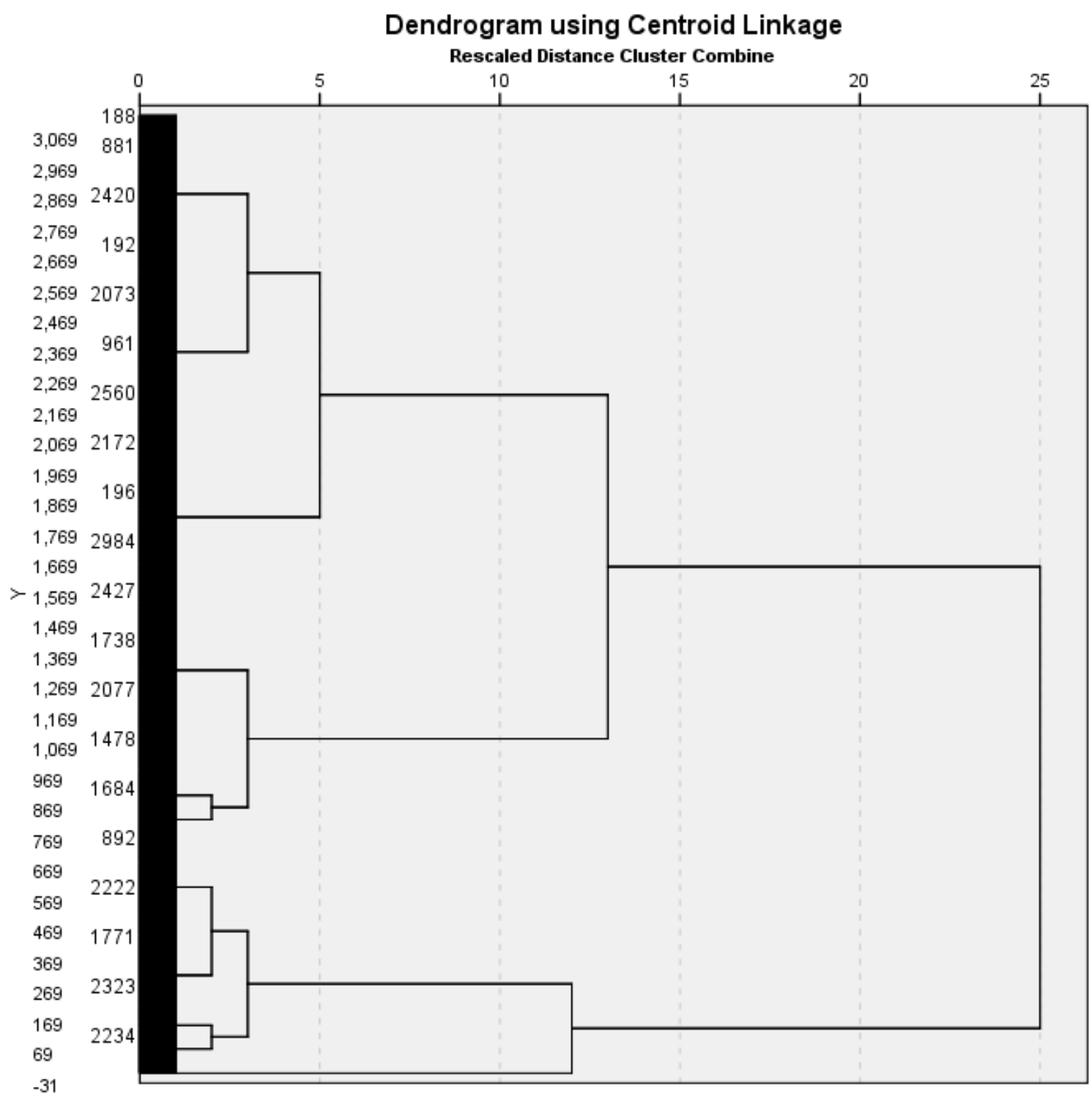

Figure 6-2: Dendrogram of percent of adults with cable modem Internet connections at home variable.

For this dataset, the combination of the agglomeration schedule, scree plot, and dendrogram suggested the optimum cluster number for all variables ranging between two and seven clusters for each variable. Eighty-five percent of variables have three, four, or five clusters. 


\subsubsection{K-Means Clustering}

The k-means clustering algorithm was run on each variable or set of variables using the number of clusters suggested by the hierarchical algorithm. The outputs of the k-means algorithm include the cluster center value (the mean value of the cluster), the number of counties in each cluster, and the cluster membership for each county. The example kmeans output discussed here continues the example discussed in Section 6.1.1. The remaining 53 tabular and graphical outputs can be found in Appendix D.

For the percent of adults with cable modem Internet connections at home variable, there are four clusters calculated. The cluster center value and the number of counties that are part of that cluster are listed in Table 6-2. The cluster centers are evenly spaced at a difference of seven percent. Additionally, the clusters contain similar numbers of variables, which indicates that there are no clusters of extreme values in the data. This suggests that this variable has a relatively uniform distribution with few outlying or extreme values.

Table 6-2: Cluster centers and number of counties in each cluster for the percent of adults with cable modem Internet connections at home variable.

\begin{tabular}{|c|c|c|c|c|}
\hline Cluster & 1 & 2 & 3 & 4 \\
\hline Center & 0.344 & 0.269 & 0.202 & 0.130 \\
\hline $\begin{array}{c}\text { Number of } \\
\text { members }\end{array}$ & 623 & 804 & 909 & 807 \\
\hline
\end{tabular}

While the k-means clustering algorithm is not inherently spatial, the unit of analysis, the United States county, does have a spatial component. This creates an opportunity to map how the clusters vary in geographic space even though clusters are constructed in attribute space. 


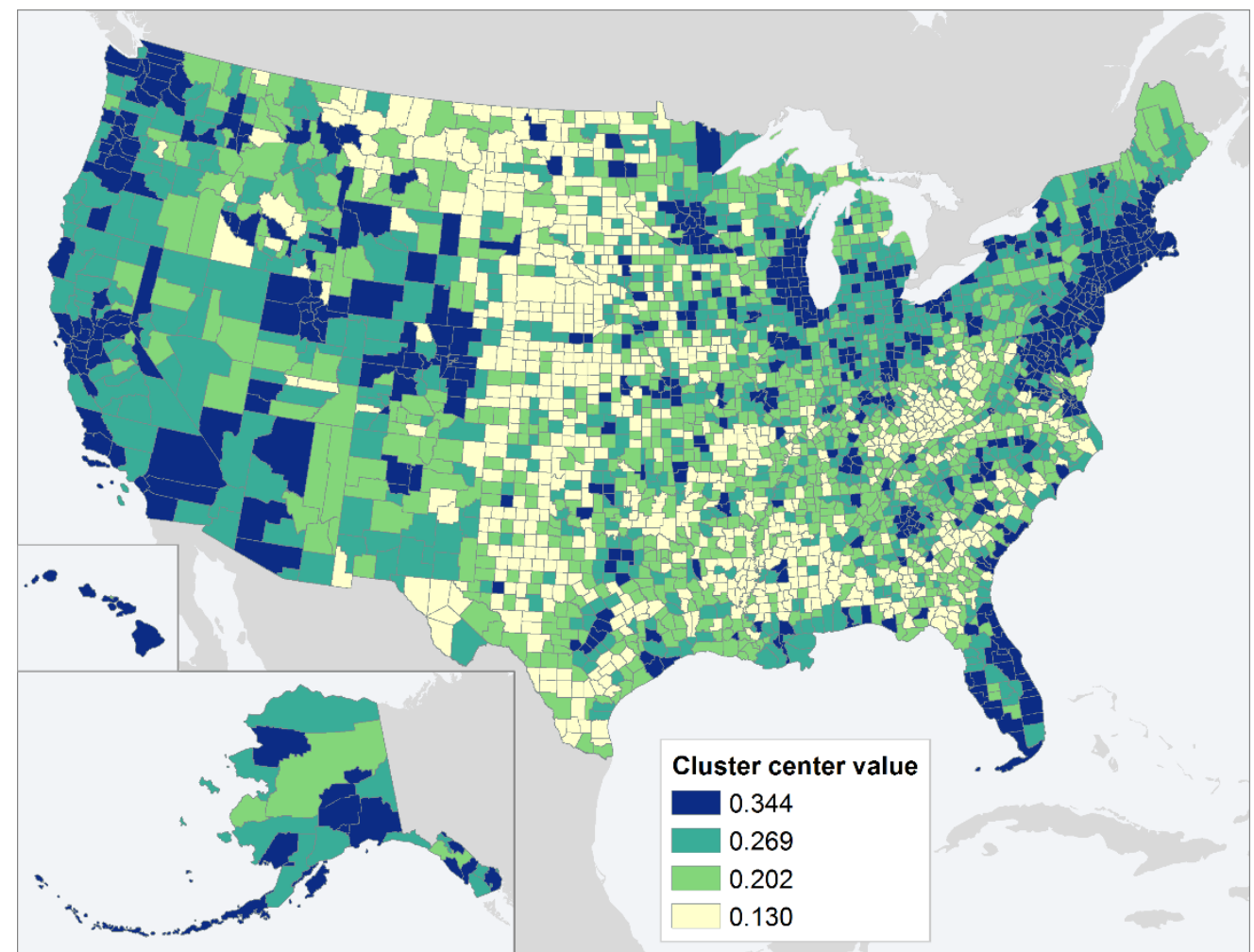

Figure 6-3: Map of k-means cluster membership for the percent of adults with cable modem Internet connections at home variable.

Figure 6-3 shows that the cluster with the largest percentage of cable modem Internet users consists of the major population centers in the country. As a county becomes further away from a metropolitan center, the percentage of cable modem Internet users decreases. The fourth cluster, containing the smallest percentage of cable modem Internet users, is located in the most rural areas in the United States - the central Great Plains, Appalachia (West Virginia and eastern Kentucky), and Louisiana and Mississippi.

While k-means cluster analysis can be used for one-dimensional data, as above, it has more utility in multi-dimensional clustering where it is difficult to visualize the patterns (Jain, 2010). Three additional k-means clustering analyses were conducted to determine clusters in the following variable sets: traditional ICT variable - such as type of phone access, computer access in the home, high speed Internet access, and social media variables - Internet use variables - including the websites visited and activities conducted while using the Internet, and e-commerce (electronic commerce) variables like online banking and purchasing. The results for ICT infrastructure variables and ecommerce variables can be found in Appendix D. The results for Internet use variables are discussed here.

Figure 6-4 shows the spatial pattern of the clusters of Internet use variables. The similar pattern is also found in the other two multi-dimensional clustering maps, traditional ICT variables and e-commerce variables. The high technology cluster in Figure 6-4 includes the largest values for every Internet use variable, which is spatially located in metropolitan areas. The medium-high cluster contains the second highest values for every variable in the set, and counties that make up this cluster are located 
outside metropolitan areas, but are not in rural areas of the country. The low-medium cluster contains the next smaller variable values, except for video authors and map users, which were the lowest values in all of the clusters. The counties that make up this cluster are located in the center of the country and the outskirts of the highest technology areas. Finally, the low cluster contains the lowest values of Internet use variables. These are the low technology areas of the country and can be found in the southern United States and Appalachia.

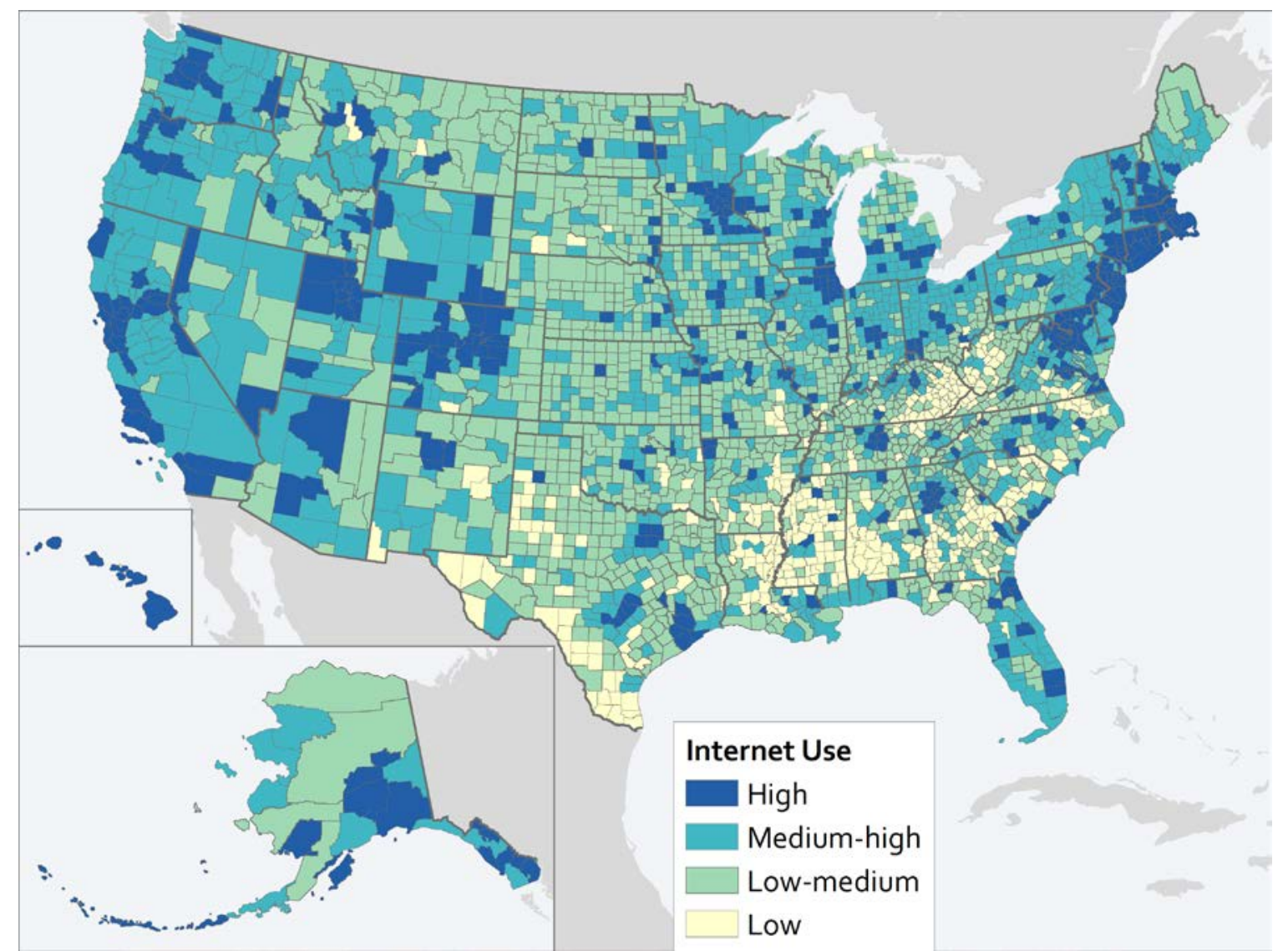

Figure 6-4: Map of k-means cluster membership for the set of 13 Internet use variables.

Compared to the study that was conducted at the state level (Pick, Sarkar, \& Johnson, 2014), this study provides a granular analysis of clustering of ICT adoption and use in the United States. By looking into a finer scale of variations in ICT adoption and use, more insight can be obtained. For example, in the Pick study, Georgia was included in the highest technology cluster; however, in this study, only the metropolitan area of Atlanta was included in the high technology cluster while most of the rest of the counties within the state are found in the second lowest cluster. The larger unit of analysis removes the within state variation, and Atlanta's high technology use overwhelms the areas of low technology use.

It is interesting to note that the clusters generated in attribute space using the kmeans algorithm also cluster in geographic space. The spatial patterns were consistent in 
the multi-dimensional clustering as well as the one-dimensional clustering. This suggests that the data are spatially autocorrelated and should be analyzed using spatial methods.

\subsection{Spatial Autocorrelation Cluster Analysis}

Spatial autocorrelation is described by Tobler's first law of geography: "Everything is related to everything else, but near things are more related than distant things (Tobler, 1970, p. 236).” Positive spatial autocorrelation occurs when features exhibit similar attributes in neighboring locations. Negative spatial autocorrelation occurs when neighboring features exhibit different attributes. Independent observations show zero spatial autocorrelation (Longley, Goodchild, Maguire, \& Rhind, 2011).

Spatial autocorrelation can be measured using the Moran's I statistic. This statistic provides an objective method to determine whether the observed spatial pattern is significantly different from a pattern created by random processes (O'Sullivan \& Unwin, 2010). The statistic ranges from negative one to one. The closer a value is to the extremes, the more intense spatial autocorrelation. The statistic is close to zero when the attribute pattern is random (Longley, Goodchild, Maguire, \& Rhind, 2011).

\subsubsection{Defining Spatial Contiguity}

Prior to conducting the Moran's I analysis, a spatial neighborhood must be defined. There is no set method to determine which neighborhood will produce the correct analysis for a particular study area (Feng \& Humphries, 2008). In this project, numerous neighborhoods were defined and the neighborhood with the strongest spatial autocorrelation, as measured by the magnitude of Moran's I, was used for further analysis.

Spatial neighborhood can be defined by spatial contiguity or by distance. Rather than arbitrarily setting distance thresholds, eight model neighborhoods were defined using a grid approach. The total number of neighbors was calculated for each neighborhood. The number of neighbors depended upon the spatial contiguity method. Rook spatial contiguity was defined as any polygon that shares an edge of the polygon of interest. Queen spatial contiguity was defined as any polygon that shares an edge or a corner with the polygon of interest. The order of the neighborhood determined how many sets of neighbors were included in the count. For example, first order neighbors are those that are adjacent to the polygon of interest. In this study, second order neighbors included first order neighbors and the polygons adjacent to the first order neighbors. These neighborhoods are visually depicted in Table 6-3. 
Table 6-3: Determining number of neighbors using different spatial contiguity methods.

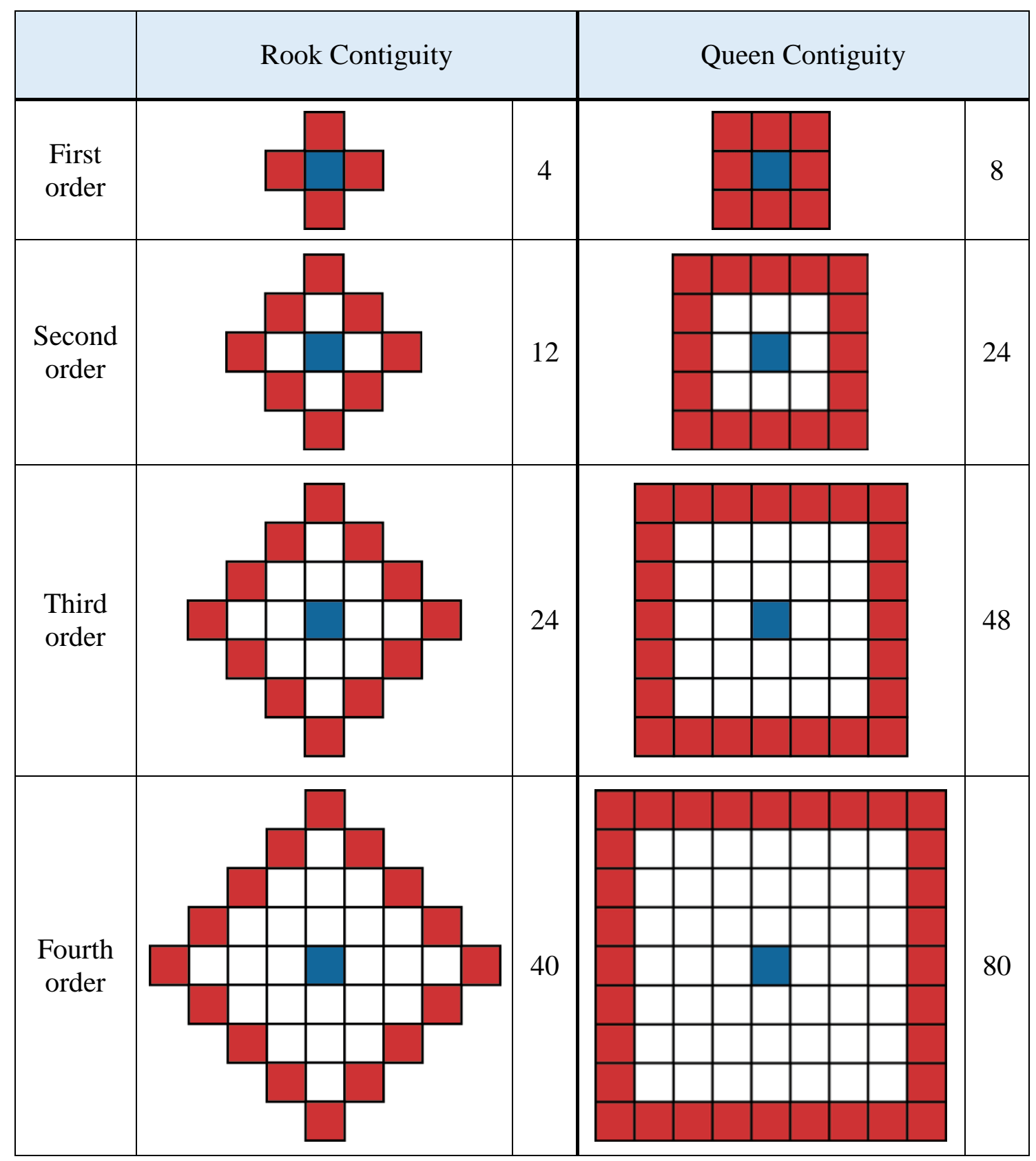

Once the number of neighbors had been defined, the ArcGIS Desktop tool 'Calculate Distance Band from Neighbor Count' was used. The tool output includes the minimum, average, and maximum distances required to reach the specified number of neighbors. 
Table 6-4: Distances of different numbers of neighbors (km).

\begin{tabular}{|c|c|c|c|}
\hline $\begin{array}{c}\text { Number of } \\
\text { Neighbors }\end{array}$ & $\begin{array}{c}\text { Minimum } \\
\text { Distance }\end{array}$ & $\begin{array}{c}\text { Average } \\
\text { Distance }\end{array}$ & $\begin{array}{c}\text { Maximum } \\
\text { Distance }\end{array}$ \\
\hline 12 & 41 & 95 & 394 \\
\hline 24 & 66 & 135 & 545 \\
\hline 40 & 88 & 176 & 646 \\
\hline 48 & 100 & 194 & 682 \\
\hline 80 & 138 & 256 & 803 \\
\hline
\end{tabular}

The values listed in Table 6-4 are customized for the county data used in this study. Note that first order rook and queen distance bands were not calculated because these neighborhood options are pre-defined in the spatial autocorrelation tool in ArcGIS Desktop. Four of the distances were selected for initial use in the spatial autocorrelation analysis: $135 \mathrm{~km}, 200 \mathrm{~km}, 250 \mathrm{~km}$, and $550 \mathrm{~km}$. In general, average distances were chosen because the counties in the United States are not of uniform size; however, the average distance for 80 neighbors was smaller than all of the maximum distances calculated. Therefore, the maximum distance for 24 neighbors, a neighborhood size in both the queen and the rook contiguity methods, was included in the analysis. In addition, both first-order rook and queen neighborhoods were used to analyze spatial autocorrelation.

\subsubsection{Global Moran's I}

To determine if the dependent variables exhibited spatial autocorrelation, a global Moran's I value was calculated for each of the six neighborhoods. All 54 of the variables exhibit significant positive spatial autocorrelation at all six neighborhoods $(\mathrm{p}<$ 0.000001). The magnitude of the Moran's I statistic ranged from 0.043 to 0.616. For full results, see Appendix E.

The global Moran's I algorithm also is available in the GeoDa software. This version of the algorithm allows for numerous random permutations of the attribute values to determine the probability of the observed pattern resulting from a random process (Anselin, Syabri, \& Kho, 2006; O'Sullivan \& Unwin, 2010). This is in contrast to the ArcGIS implementation, which uses a standard normal distribution to test whether the pattern is random. The lowest five values from the rook Moran's I tests - cellphone only households, household has a landline telephone, used Internet at school or library in the past 30 days, watched TV program online in the past 30 days, and looked for employment online in the past 30 days - also were tested in GeoDa using 99,999 permutations, the maximum number allowed. Additionally, the smallest magnitude Moran's I value, $550 \mathrm{~km}$ neighborhood for mobile wireless household, was tested. The results for all tests returned a pseudo $\mathrm{p}$ value of 0.00001 , meaning that there was a 1 in 100,000 chance that the observed pattern was created due to a random process. 


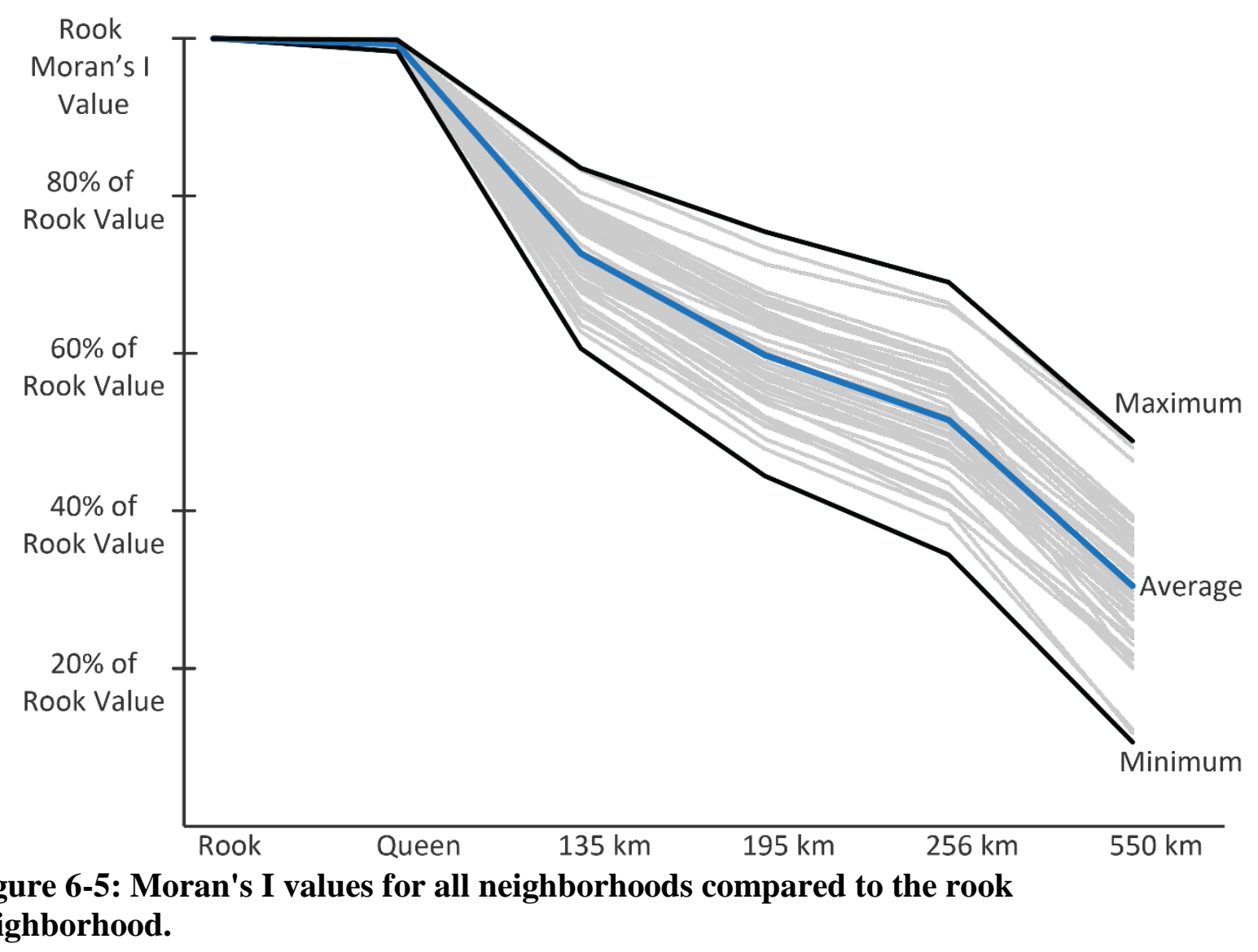

To determine at which neighborhood the spatial autocorrelation was most pronounced in the dataset, Figure 6-5 was created. This graph compares the value of the Moran's I statistic at each neighborhood to the value of the statistic at the rook neighborhood. This comparison was conducted for each of the 54 variables (gray lines). The minimum, maximum, and average patterns were also calculated. In all cases, the Moran's I statistic was maximized at the rook neighborhood. The queen neighborhood was at least 98 percent of the value of the rook neighborhood. The value of the statistics decreased as the neighborhood size increased. This pattern indicates that the spatial autocorrelation was strongest at the first order neighborhoods. Other spatial autocorrelation studies have suggested that in general, the smaller the neighborhood, the stronger the spatial autocorrelation (Stakhovych \& Bijmolt, 2008; Anselin, Syabri, \& Kho, 2006). Further spatial autocorrelation analyses only were conducted at the rook neighborhood, which maximized the spatial autocorrelation of the dataset.

\subsubsection{Local Moran's I}

The global Moran's I statistic indicates whether spatial autocorrelation occurs in the dataset; however, it provides neither an indication of where those clusters are located nor whether low or high values are clustered. The local Moran's I statistic provides both the location and type of clusters and outliers (Anselin, 1995). A cluster is defined as a location, in this case a county, that is surrounded by neighbors with similar values. Clusters can be defined as high-high, where the county of interest and the neighboring 
counties are all high values, or low-low, where both the county and its neighbors are all low values. The other entity identified by the local Moran's I analysis are outliers, namely counties that are surrounded by a neighborhood of opposite values. Outliers can be either high-low, where the county is a high value and the neighborhood is low values, or low-high, where the county is a low value and the neighborhood is high. The local Moran's I statistic was calculated for each of the 54 dependent variables in ArcGIS.

In order to summarize the information provided by the local Moran's I analysis, three maps were created using a new summary feature class. The summary feature class was a copy of the original county feature class. A field was added to the summary feature class for each dependent variable. The feature classes that were output from the ArcGIS process were joined to the summary feature class and the field value for that dependent variable was calculated. A custom Python script was written to change the text description of the cluster or outlier type to a numeric value: 1 for high-high clusters, -1 for low-low clusters, 100 for high-low outliers, and -100 for low-high outliers. Four variables - dial-up modem Internet connection at home, DSL Internet connection at home, household has landline telephone only, and ordered from Walmart.com website in the past 12 months - showed the inverse pattern from the other of the variables. Highhigh clusters of these variables indicated areas of low technology use. In these four cases, the values that were input into the summary feature class were inversed. The feature class table was exported to a dbf file and then imported into Microsoft Excel. The total number of each type of cluster and each type of outliers were calculated for each county using the SUMIF function in Excel. A small excerpt from the Excel entire table is shown in Table 6-5. This table shows seven counties, the cluster results for four of the 54 dependent variables, and the four summary attributes - number of high-high clusters, number of low-low clusters, number of high-low clusters, and number of low-high clusters. These four summary attributes were imported into ArcGIS and joined to the county feature class. This data was used to create three local Moran's I maps included in this section.

Table 6-5: Excerpt from Local Moran's I reclassification scheme.

\begin{tabular}{|c|c|c|c|c|c|c|c|}
\hline DSLINTR & HSPEEDINTR & INTUSE30R & INTATHOMER & $\begin{array}{c}\text { High- } \\
\text { High }\end{array}$ & $\begin{array}{c}\text { Low- } \\
\text { Low }\end{array}$ & $\begin{array}{c}\text { High- } \\
\text { Low }\end{array}$ & $\begin{array}{c}\text { Low- } \\
\text { High }\end{array}$ \\
\hline 100 & 0 & 0 & 0 & 0 & 0 & 100 & 0 \\
\hline-100 & 0 & 0 & 0 & 0 & 0 & 0 & -100 \\
\hline 1 & -1 & -1 & -1 & 1 & -3 & 0 & 0 \\
\hline 0 & 1 & 1 & 1 & 3 & 0 & 0 & 0 \\
\hline 0 & -1 & -1 & 0 & - & -2 & 0 & 0 \\
\hline 0 & 100 & 0 & 100 & 0 & 0 & 200 & 0 \\
\hline 100 & -1 & -1 & -1 & 0 & -3 & 100 & 0 \\
\hline
\end{tabular}

The high-high cluster map shows the location of counties that fall within high-high clusters in more than ten percent of the 54 dependent variables (Figure 6-6). There are two counties, Bucks County and Montgomery County in Pennsylvania, that fall within 48 high-high clusters, the largest number of times a county is found in a high-high cluster. There are 537 (of 3109) counties symbolized in the high-high cluster map. Each of the high-high cluster areas contain or are adjacent to a major metropolitan area. Major cities are labeled on the map. The large metropolitan areas are highlighted by the high-high 
clusters; however, the data has been normalized to remove population effects. This suggests that urban areas and infrastructure are important to the dispersion of ICT use and adoption.

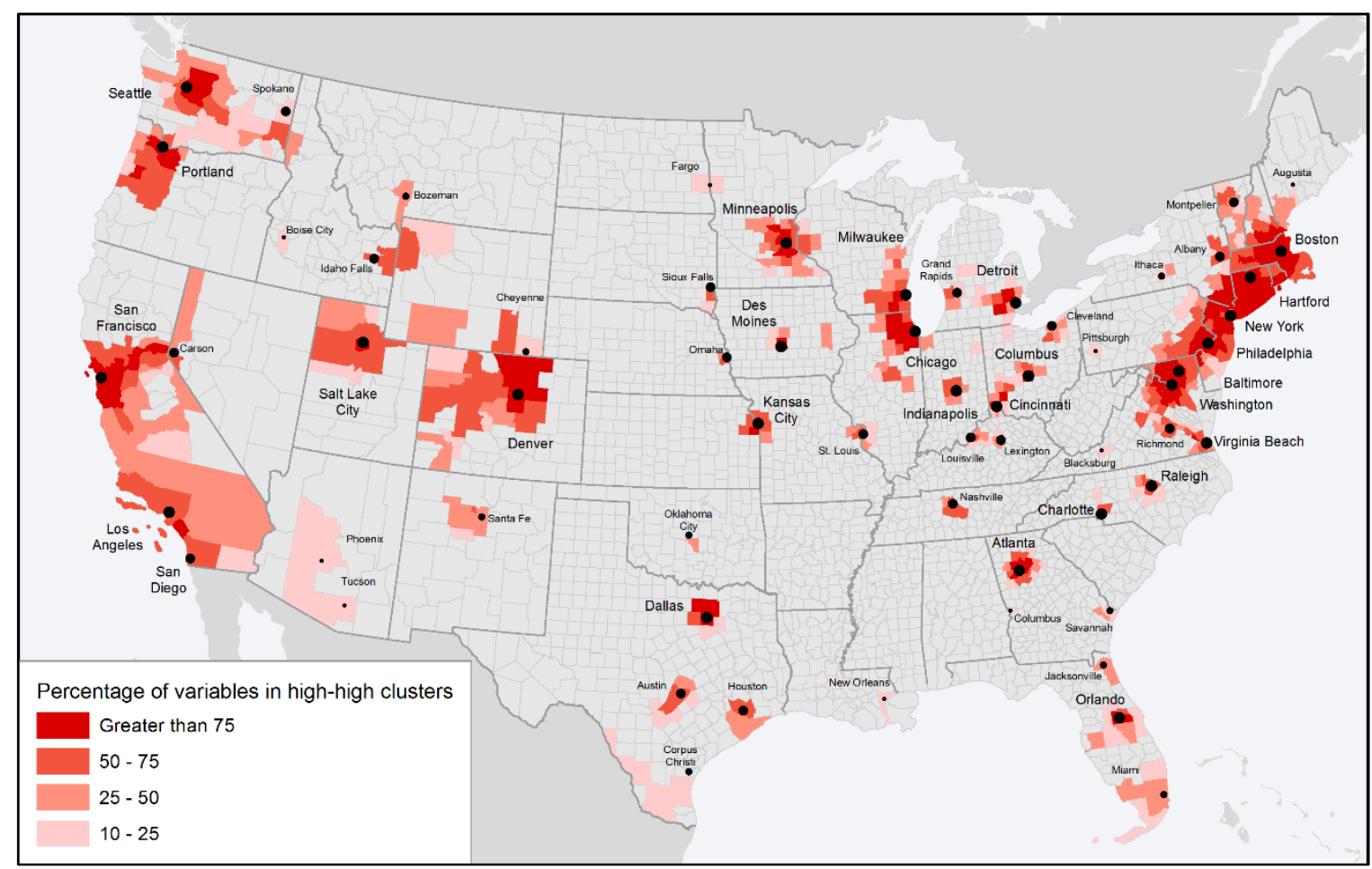

Figure 6-6: Map of local Moran's I high-high clusters. Darker red indicates that the county is in a greater percentage of a possible 54 high-high clusters.

In contrast to the high-high cluster map, the low-low cluster map shows that the more rural areas of the country are in the low-low clusters (Figure 6-7). Calhoun County, West Virginia falls within 43 low-low clusters, the largest number of times a county is found in a low-low cluster. There are 698 (of 3109) counties within the low-low clusters. The cities labeled on the map are to provide reference to the reader. No large cities are located within any of the low-low cluster counties. The area with the most low-low clusters is eastern Kentucky and most of West Virginia. Other areas of low-low clusters are the southern United States and the central Great Plains. These patterns suggest that the more rural a county is, the less likely its population is to adopt or use ICT. 


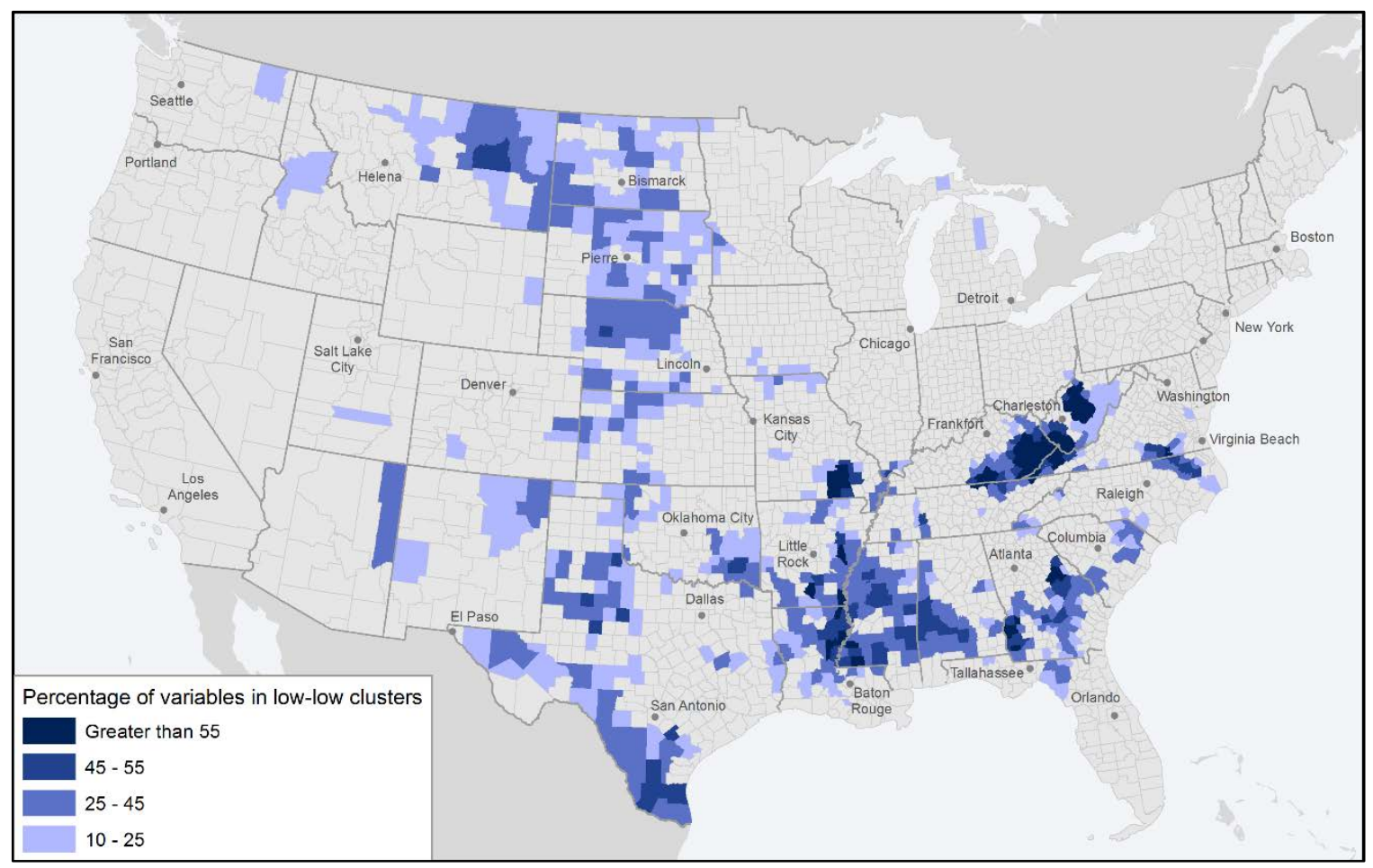

Figure 6-7: Map of local Moran's I low-low clusters. Darker blue indicates that the county is in a greater percentage of a possible 54 low-low clusters.

The final map in this series contains both the high-low and low-high outliers (Figure 6-8). There are 10 low-high outliers symbolized on the map. The most variables in which a single county is a low-high outlier is 25 (of 54). The low-high outliers generally contain small population centers surrounded by counties with medium to large cities. For example, Jackson County in Colorado is the county with the most low-high outliers. Referring back to Figure 6-6, Jackson is surrounded by the Denver, Colorado and Cheyenne, Wyoming metropolitan areas. According to the raw data, Jackson is the fourth least populous county in Colorado and a reference map shows that there is only one small population center in the county (Google, 2014). These types of factors are found in all 10 of the low-high outlier counties. 


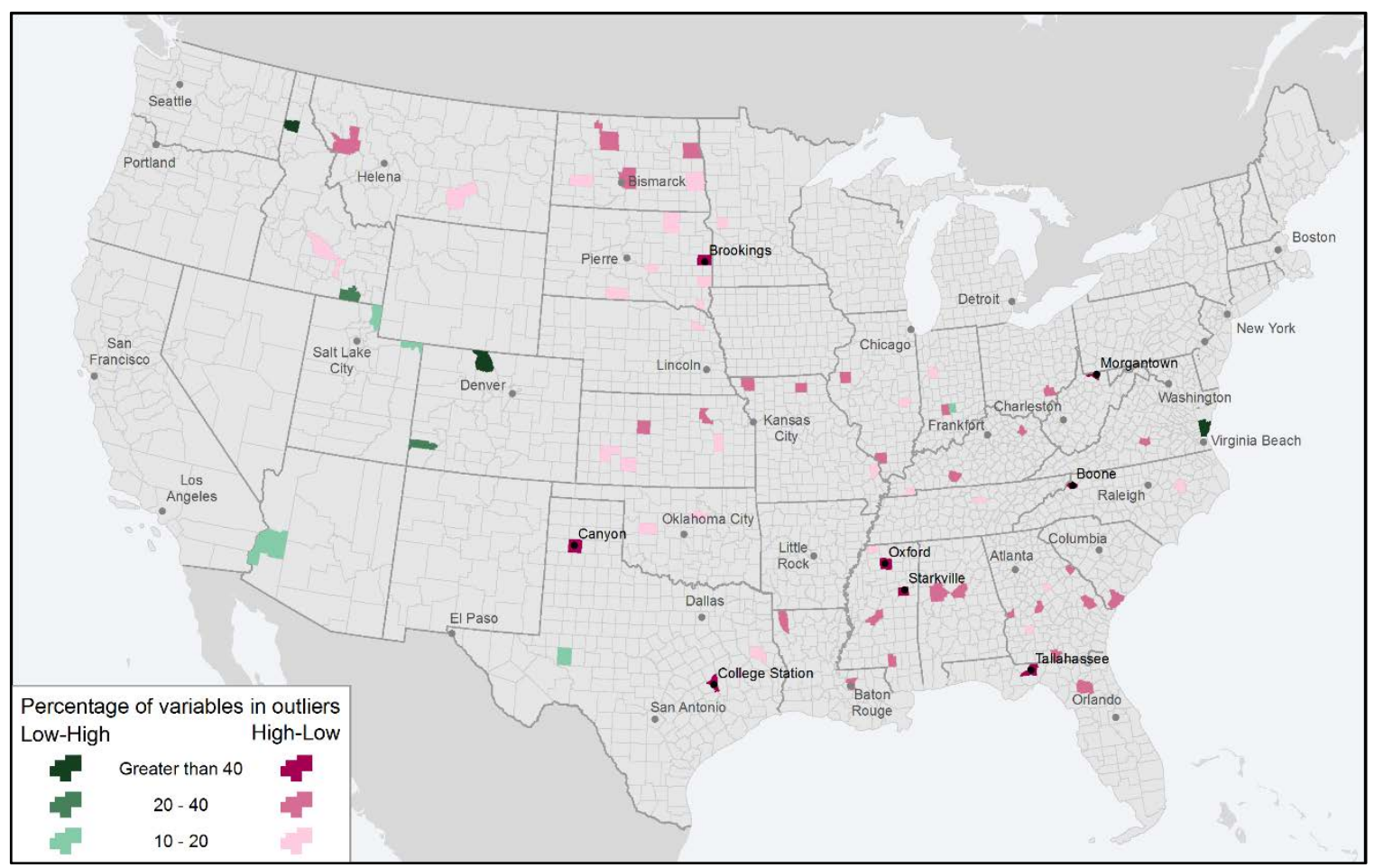

Figure 6-8: Map of local Moran's I outliers. Darker color indicates that the county is in a greater percentage of a possible 54 outliers.

There are 63 high-low outliers symbolized on the map (Figure 6-8). Oktibbeha County in Mississippi is found as a high-low outlier in 30 of the 54 dependent variables. Most of the high-low outlier counties contain both an airport and a hospital (Google, 2014). Of the 63 counties, 54 contain at least one college or university, three of the remaining nine contain a military reservation or government laboratory, and three others contain only a portion of an urban area, the extent of which contains a college or a university. This suggests that these institutions increase the ICT use and adoption in a county and presence of a university could be a variable of interest for future studies.

\subsection{Summary}

The clustering analyses presented in Chapter 6 found similar patterns even though one analysis was conducted in attribute space and the other was conducted in geographic space. These analyses answered the first of the clients' research questions: How the spatial patterns of ICT adoption and its usage varied in United States counties between 2007 and 2012. The analyses provided new insights into the scale and diffusion of ICT use and adoption. The diffusion of ICT use in the United States is localized to a county's immediate neighbors. This suggested that states, as used in the Pick et al. (2014) study, are too large of a unit of analysis for ICT studies in the United States. If the data were available, further analyses could be conducted at a smaller scale, such as census tracts, which would help to define the scale of ICT diffusion from urban centers. 


\section{Chapter 7 - Regression Analysis and Results}

This chapter includes analysis of how the socio-economic and demographic variables relate to the ICT use and adoption variables. Section 7.1 describes the methods and results of the ordinary least squares regression analysis. Section 7.2 discusses the methods and results of the geographically weighted regression analysis, a local regression model that accounts for spatial variation. Two other types of spatial regression analyses are discussed in Section 7.3, spatial lag regression and spatial error regression. The chapter closes with a brief summary of the regression analyses in Section 7.4.

\subsection{Ordinary Least Squares Regression Analysis}

Regression analysis was used in this project to examine the effect of socio-economic and demographic variables on ICT use and adoption. Ordinary least squares (OLS) regression was used to determine if there was a linear relationship between the selected variables (O'Sullivan \& Unwin, 2010). As discussed in Chapter 5 -, the variables used in the regression analysis were chosen by the clients based on their prior knowledge of the subject.

\subsubsection{Ordinary Least Squares Models}

The clients requested separate regression analyses for each of ten dependent variables. The same nine independent variables were used for each regression. The list of variables used in the regression models can be found in Table 7-1.The first step in the analysis was to determine which set of variables would provide significant explanatory power for the dependent variables. The 'Exploratory regression' tool was used in ArcGIS Desktop because it evaluates all possible combinations of independent variables and outputs a summary of the best-fit models. Two of the test statistics included in the output summary were the adjusted R-squared and the Akaike's Information Criterion (AICc). The adjusted $\mathrm{R}$-squared value is used to determine the amount of variation in the dependent variable that is explained by the OLS model. The larger the R-squared value the better the model. The AICc value is used to compare different models to determine which is the best fit. Smaller AICc values mean a better goodness of fit. Both test statistics account for model complexity, which is important when testing this many independent variables. In general, goodness of fit of a model always improves with more independent variables. Because both statistics are penalized as terms are added, they are useful in determining the best model in a multivariate environment. 
Table 7-1: Independent and dependent variables used in exploratory regression analysis.

\begin{tabular}{|c|c|}
\hline Independent Variables & Dependent Variables \\
\hline Percent urban population & Household owns a computer \\
\hline Percent race - Asian & Used Internet in past 30 days at home \\
\hline $\begin{array}{l}\text { Percent race - black or African } \\
\text { American }\end{array}$ & Any high speed Internet access at home \\
\hline Percent ethnicity - Hispanic or Latino & Broadband access at home \\
\hline Percent employed in labor force & Mobile wireless access in household \\
\hline Percent $16+$ in service occupations & Any cellphone in household \\
\hline $\begin{array}{l}\text { Percent } 16+\text { in construction } \\
\text { occupations }\end{array}$ & Cellphone only household \\
\hline Percent college graduates $18+$ & Landline only household \\
\hline \multirow{2}{*}{$\begin{array}{l}\text { Local government education } \\
\text { expenditures }\end{array}$} & Visited facebook.com in past 30 days \\
\hline & Visited twitter.com in past 30 days \\
\hline
\end{tabular}

Each dependent variable was run through the exploratory regression tool. The exploratory regression tool recommends models with the largest adjusted R-squared and smallest AICc values that also pass the regression diagnostic tests: Jarque-Bera statistic, Koenker's (BP), Moran's I statistic (Esri, 2013). None of the OLS models in this study passed all of the criteria required by the tool; therefore, the best fit model, with highest adjusted R-squared and smallest AICc value, was chosen for further analysis. The initial OLS regressions were exploratory in nature so significant diagnostic indicators would not prevent additional analysis.

The best-fit models from the exploratory regression analysis were analyzed in the 'Ordinary least squares' tool in ArcGIS desktop. The tool output provides a number of diagnostic statistical tests to determine model fitness and if the data follow the assumptions for the OLS model. The first diagnostic indicator to examine was the Koenker (BP) Statistic, which measures whether the variables have equivalent variances in both data and geographic space, known as homoscedasticity and stationarity respectively (Esri, 2014; Lyon \& Tsai, 1996). If this assumption is not met, meaning the test is significant, then the Joint-Wald test should be used to determine model significance and the robust t-tests used to assess coefficient significance.

With significant model results, the next step is to look at the independent variable coefficient diagnostics and tests. The variance inflation factor tells whether multiple coefficients exhibit multicollinearity, which would result in redundant variables in the model (Craney \& Surles, 2002). Where required by a significant Koenker (BP) statistic, the robust t-test probabilities were used to assess coefficient significance. If an independent variable was found not to be significant using the robust t-test, it was removed from the model and the OLS analysis was conducted again. When all model coefficients were significant using the robust t-tests, the final two diagnostic tests were conducted.

The last two diagnostic tests for the OLS analysis were conducted on the residuals, or the unexplained variation. The Jarque-Bera statistic is included in the OLS output. It is 
used to test whether the residuals were normally distributed, as assumed by the OLS method (Jarque \& Bera, 1980). The second diagnostic test was a spatial autocorrelation test on the residuals as residuals are assumed to be random for OLS. The global Moran's I test was conducted using the same procedure from Section 6.2. For OLS, a nonsignificant result is desired, as that would indicate that the randomness assumption is valid.

\subsubsection{OLS Results}

No model passed all of the diagnostic tests in the exploratory regression tool. Therefore, the model with the combination of the largest adjusted R-squared value and smallest AICc value were used to conduct initial analyses. Three of the ten best-fit models included all nine independent variables. Six of the ten included eight independent variables. The tenth model included seven independent variables.

The results of the OLS models for all ten variables are shown in Table 7-2 and Table 7-3. All ten models showed significant Koenker (BP) statistics, resulting in the use of the Joint Wald statistic and robust t-tests for the coefficients. In all models, the Joint Wald statistic was significant at the $\mathrm{p}<0.001$ level, indicating a significant model. Using the robust t-test rather than the regular t-test resulted in non-significant coefficients in all but one of the models. Those coefficients were removed from the models and the models were recalculated. All coefficients shown in Table 7-2 and Table 7-3 were significant at least at $\mathrm{p}<0.05$ and no other parameters were included in the models. 
Table 7-2: Standardized OLS regression results for ICT infrastructure dependent variables.

\begin{tabular}{|c|c|c|c|c|c|c|c|c|c|c|}
\hline & \multicolumn{2}{|c|}{ COMPINHHR } & \multicolumn{2}{|c|}{ INTUSE30R } & \multicolumn{2}{|c|}{ HSPEEDINTR } & \multicolumn{2}{|c|}{ BRDBNDHH } & \multicolumn{2}{|c|}{ MOBILEWLHH } \\
\hline & Beta & $\begin{array}{c}\text { Std } \\
\text { Error }\end{array}$ & Beta & $\begin{array}{c}\text { Std } \\
\text { Error }\end{array}$ & Beta & $\begin{array}{c}\text { Std } \\
\text { Error }\end{array}$ & Beta & $\begin{array}{c}\text { Std } \\
\text { Error }\end{array}$ & Beta & $\begin{array}{c}\text { Std } \\
\text { Error }\end{array}$ \\
\hline URBANR & $0.326 * * *$ & 0.000 & $0.374 * * *$ & 0.000 & $0.386 * * *$ & 0.000 & $0.242 * * *$ & 0.000 & $0.237 * * *$ & 0.000 \\
\hline ASIANR & $0.075 * * *$ & 0.045 & -- & -- & $0.077 * * *$ & 0.058 & $-0.210 *$ & 0.178 & $-0.161 * *$ & 0.201 \\
\hline BLACKR & $-0.276 * * *$ & 0.005 & $-0.272 * * *$ & 0.006 & $-0.204 * * *$ & 0.006 & $0.087 * * *$ & 0.009 & $0.138 * * *$ & 0.011 \\
\hline HISPANICR & $-0.110 * * *$ & 0.007 & $-0.210 * * *$ & 0.010 & $-0.168 * * *$ & 0.010 & $0.061 *$ & 0.006 & $0.086 * * *$ & 0.022 \\
\hline TOTEMPLR & $0.201 * * *$ & 0.015 & $0.283 * * *$ & 0.018 & $0.243 * * *$ & 0.017 & $0.137 * * *$ & 0.026 & $0.250 * * *$ & 0.045 \\
\hline SERVICER & $-0.048 * * *$ & 0.052 & -- & -- & -- & -- & -- & -- & -- & -- \\
\hline CONSTRUCTR & $0.132 * * *$ & 0.071 & $0.074 * * *$ & 0.072 & $0.066 * * *$ & 0.077 & -- & -- & $-0.070 *$ & 0.270 \\
\hline COLLEGER & $0.402 * * *$ & 0.021 & $0.356 * * *$ & 0.021 & $0.401^{* * *}$ & 0.025 & -- & -- & -- & -- \\
\hline LGOVEDEXPR & $-0.041^{* * *}$ & 0.000 & -- & -- & $-0.018^{*}$ & 0.000 & $-0.171^{* *}$ & 0.000 & $-0.244 * * *$ & 0.000 \\
\hline \multicolumn{11}{|c|}{ Diagnostics } \\
\hline Adj. R-squared & \multicolumn{2}{|c|}{0.719} & \multicolumn{2}{|c|}{0.758} & \multicolumn{2}{|c|}{0.798} & \multicolumn{2}{|c|}{0.128} & \multicolumn{2}{|c|}{0.209} \\
\hline Joint Wald & \multicolumn{2}{|c|}{ 7014.3*** } & \multicolumn{2}{|c|}{$7747.0 * * *$} & \multicolumn{2}{|c|}{$10452.8 * * *$} & \multicolumn{2}{|c|}{$222.4 * * *$} & \multicolumn{2}{|c|}{$394.1 * * *$} \\
\hline Koenker (BP) & \multicolumn{2}{|c|}{$112.5^{* * *}$} & \multicolumn{2}{|c|}{$258.2^{* * *}$} & \multicolumn{2}{|c|}{$173.2^{* * *}$} & \multicolumn{2}{|c|}{$294.4 * * *$} & \multicolumn{2}{|c|}{$393.3 * * *$} \\
\hline Jarque-Bera & \multicolumn{2}{|c|}{$3535.4 * * *$} & \multicolumn{2}{|c|}{$599.3 * * *$} & \multicolumn{2}{|c|}{$820.7 * * *$} & \multicolumn{2}{|c|}{$2551625.1 * * *$} & \multicolumn{2}{|c|}{$110138.7 * * *$} \\
\hline AICc & \multicolumn{2}{|c|}{-11562.8} & \multicolumn{2}{|c|}{-11105.8} & \multicolumn{2}{|c|}{-10738.5} & \multicolumn{2}{|c|}{-9987.7} & \multicolumn{2}{|c|}{-5383.6} \\
\hline Moran's I & \multicolumn{2}{|c|}{$0.442 * * *$} & \multicolumn{2}{|c|}{$0.368 * * *$} & \multicolumn{2}{|c|}{$0.371 * * *$} & 0.453 & & $0.412^{*}$ & \\
\hline
\end{tabular}

Note that the standard error is related to the robust test. Statistical significance is indicated as: $*=p<0.05, * *=p<0.01, * * *=p$ $<0.001$. 
Table 7-3: Standardized OLS regression results for telephone and social media dependent variables.

\begin{tabular}{|c|c|c|c|c|c|c|c|c|c|c|}
\hline & \multicolumn{2}{|c|}{ CELLINHHR } & \multicolumn{2}{|c|}{ CLLONL YHHR } & \multicolumn{2}{|c|}{ LNDONL YHHR } & \multicolumn{2}{|c|}{ FACEBOOKR } & \multicolumn{2}{|c|}{ TWITTERR } \\
\hline & Beta & $\begin{array}{c}\text { Std } \\
\text { Error }\end{array}$ & Beta & $\begin{array}{c}\text { Std } \\
\text { Error }\end{array}$ & Beta & $\begin{array}{c}\text { Std } \\
\text { Error }\end{array}$ & Beta & $\begin{array}{c}\text { Std } \\
\text { Error }\end{array}$ & Beta & $\begin{array}{c}\text { Std } \\
\text { Error }\end{array}$ \\
\hline URBANR & $0.492 * * *$ & 0.000 & $0.425 * * *$ & 0.000 & $-0.463 * * *$ & 0.000 & $0.430 * * *$ & 0.000 & $0.346 * * *$ & 0.000 \\
\hline ASIANR & $0.084^{* * *}$ & 0.018 & -- & -- & $-0.077 * * *$ & 0.016 & $0.055 *$ & 0.050 & $0.144 * * *$ & 0.014 \\
\hline BLACKR & -- & -- & $0.139 * * *$ & 0.004 & -- & -- & $-0.143^{* * *} *$ & 0.004 & $0.248 * * *$ & 0.001 \\
\hline HISPANICR & $0.036 * * *$ & 0.003 & $0.150 * * *$ & 0.005 & $-0.054 * * *$ & 0.002 & $-0.172 * * *$ & 0.007 & $0.090 * * *$ & 0.001 \\
\hline TOTEMPLR & $0.249 * * *$ & 0.007 & $0.161^{* * *}$ & 0.012 & $-0.320 * * *$ & 0.006 & $0.306 * * *$ & 0.014 & $0.133^{* * *}$ & 0.004 \\
\hline SERVICER & $-0.096 * * *$ & 0.024 & $0.138 * * *$ & 0.043 & $0.109 * * *$ & 0.021 & -- & -- & $0.058 * *$ & 0.016 \\
\hline CONSTRUCTR & $0.120 * * *$ & 0.034 & $-0.059 * *$ & 0.058 & $-0.108 * * *$ & 0.029 & -- & -- & $-0.087 * * *$ & 0.022 \\
\hline COLLEGER & $0.205^{* * *}$ & 0.009 & $-0.224^{* * *}$ & 0.020 & $-0.199 * * *$ & 0.008 & $0.295 * * *$ & 0.018 & 0.307 & 0.006 \\
\hline LGOVEDEXPR & -- & -- & -- & -- & -- & -- & -- & -- & -- & -- \\
\hline \multicolumn{11}{|c|}{ Diagnostics } \\
\hline Adj. R-squared & \multicolumn{2}{|c|}{0.617} & \multicolumn{2}{|c|}{0.335} & \multicolumn{2}{|c|}{0.647} & \multicolumn{2}{|c|}{0.721} & \multicolumn{2}{|c|}{0.629} \\
\hline Joint Wald & \multicolumn{2}{|c|}{$6046.8 * * *$} & \multicolumn{2}{|c|}{$1945.8 * * *$} & \multicolumn{2}{|c|}{$6340.7 * * *$} & \multicolumn{2}{|c|}{$7702.8 * * *$} & \multicolumn{2}{|c|}{$4275.0 * * *$} \\
\hline Koenker (BP) & \multicolumn{2}{|c|}{$252.6 * * *$} & \multicolumn{2}{|c|}{$226.5 * * *$} & \multicolumn{2}{|c|}{$135.9 * * *$} & \multicolumn{2}{|c|}{$123.3 * * *$} & \multicolumn{2}{|c|}{$92.6 * * *$} \\
\hline Jarque-Bera & \multicolumn{2}{|c|}{$79.1 * * *$} & \multicolumn{2}{|c|}{$6028.2^{* * *}$} & \multicolumn{2}{|c|}{$261.1^{* * *}$} & \multicolumn{2}{|c|}{$2575.5 * * *$} & \multicolumn{2}{|c|}{$48747.8 * * *$} \\
\hline AICc & \multicolumn{2}{|c|}{-15962.2} & \multicolumn{2}{|c|}{-11984.7} & \multicolumn{2}{|c|}{-17029.1} & \multicolumn{2}{|c|}{-12242.9} & \multicolumn{2}{|c|}{-20012.7} \\
\hline Moran's I & \multicolumn{2}{|c|}{$0.415 * * *$} & \multicolumn{2}{|c|}{$0.204^{* * *}$} & \multicolumn{2}{|c|}{$0.372 * * *$} & \multicolumn{2}{|c|}{$0.210 * * *$} & 0.169 & \\
\hline
\end{tabular}

Note that the standard error is related to the robust test. Statistical significance is indicated as: $*=\mathrm{p}<0.05, * *=\mathrm{p}<0.01, * * *=\mathrm{p}$ $<0.001$. 
The percent of variation in the dependent variable that is explained by the OLS model is extremely high for most of the models tested, ranging between 60 and 80 percent. For example, the model developed for Any High Speed Internet in Household variable had the largest adjusted R-squared value of 0.798 . Three models had adjusted Rsquared values less than 0.350, with Broadband in Household having the lowest at 0.128. Comparing the adjusted R-squared values from this study with Pick et al (2014), in which the largest adjusted R-squared value is 0.456 , this study suggests that models constructed at a finer geographic scale yield stronger explanatory power for ICT adoption.

According to the standardized coefficients, two of the three following variables always provide the largest effect: percent urban, percent college graduates, and total employment. Because the variables were modified to remove population effects, the increase in urban population may be a surrogate for the infrastructure associated with urban environments (Grubesic, 2002). Individuals within a county that has increasing urban environment are more likely to use or adopt ICT. Educational attainment has often been associated with ICT adoption in previous studies (National Telecommunications and Information Administration, 2011). Percent employed population is a strong predictor for ICT use in this study as well. It may be that employment is acting as a surrogate for income in these models as previous studies have reported that increased income is related to increased ICT adoption (Baliamoune-Lutz, 2003; Dasgupta, Lall, \& Wheeler, 2005).

The results of the OLS regression models generally meet the expectations of the conceptual model developed in Section 4.1. The counties with a greater percentage of higher educated citizens make use of ICT more than those with less educated citizens. The counties with a greater percentage of urban population have better access to ICT than rural areas. Employment, a likely surrogate for income, follows the expected trend of counties with a greater percentage of employed citizens show greater use of ICT. The ethnic and racial variables do not relate to ICT as strongly as has been shown in other studies. This will be shown later in this chapter to be due to confounding factors associated with spatial dependence (see Section 7.3).

The residual tests suggest that there are major issues with the OLS models that were developed. The Jarque-Bera test is significant in all models, which indicates that the residuals are not normally distributed; however, there are a number of factors that could result in a significant Jarque-Bera test, including a non-linear relationship, outliers, or heteroscedasticity (Esri, 2014). In general, histograms of the residuals for all ten models were skewed, positive or negative being equally likely. Additionally, heteroscedasticity is a known issue in these models, as discussed previously.

For all ten regression analyses, the global Moran's I test on the residuals show significant spatial autocorrelation. An example map of the residuals is provided in Figure 7-1. For this particular example of the adoption of high speed Internet, the Moran's I statistic of residuals was 0.371 ( $\mathrm{p}<0.000001)$. The observed pattern in the residuals was similar to the patterns found in the clustering analysis (Chapter 6). This OLS model over predicts the percent of households with high speed Internet access in urban areas, particularly in the east and west coast regions of the United States, shown in red on the map. The OLS model under predicts in rural areas, particularly in the central United States and West Virginia and eastern Kentucky, shown in blue on the map. The strong spatial autocorrelation of the OLS residuals indicates that the residuals are not independent, suggesting that the model is misspecified (O'Sullivan \& Unwin, 2010). 


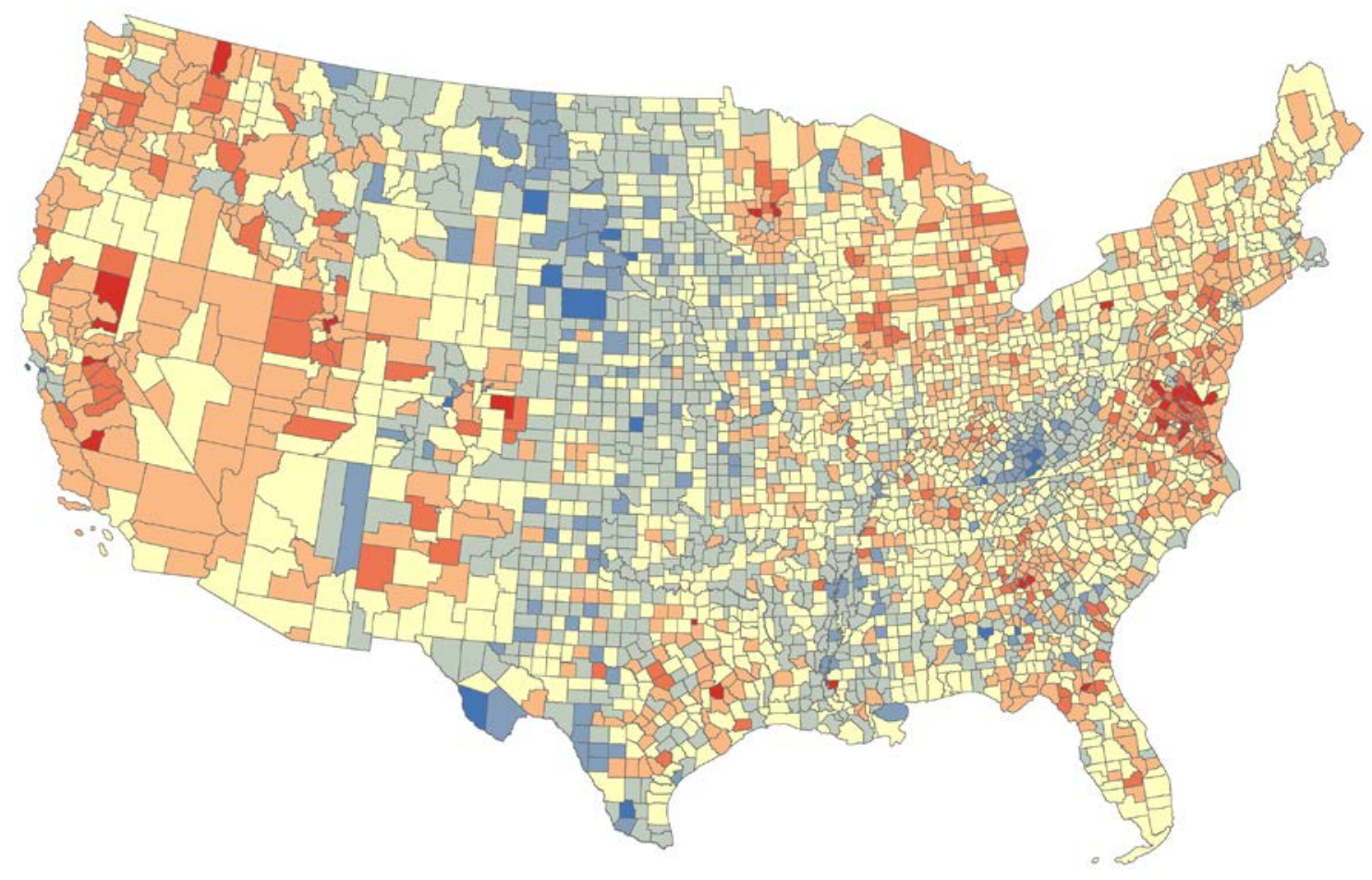

Figure 7-1: Map of OLS regression residuals for the any high speed internet variable.

\subsubsection{Beyond OLS}

When modeling spatial data, it is normal to observe variation in the phenomena of interest across space (Tobler, 1970). This non-stationarity in geographic data can be problematic for traditional diagnostic tests (Rosenshein, Scott, \& Pratt, 2011; Esri, 2014). The strategies to address this issue include, incorporating relevant spatial variables or using an alternative regression model that can account for the regional variation of the variables. In this study, geographically weighted regression was applied to examine how the relationships between the independent variables and dependent variables vary across the geographic space.

\subsection{Geographically Weighted Regression Analysis}

Geographically weighted regression (GWR) can be taken as a local version of OLS. In OLS regression, the model assumes that the relationship between the independent and dependent variables is constant (O'Sullivan \& Unwin, 2010). When dealing with spatial phenomena, this is rarely the case. The GWR technique allows regression coefficients to vary over space and provides a local regression model rather than the global method provided by the OLS method (Longley, Goodchild, Maguire, \& Rhind, 2011; O'Sullivan \& Unwin, 2010). 
The GWR technique does not allow for significance testing nor does it have the rich diagnostic tests available for OLS. Therefore, a properly specified OLS model must be calculated prior to conducting GWR. Since the OLS models generally show a reasonable fit for the data, they were used in the GWR model to determine if introducing local variability could help to reduce the known issues.

\subsubsection{GWR Procedures in ArcGIS}

Because the OLS models were already specified, there was minimal preparation necessary prior to conducting the GWR analysis. The GWR tool does not automatically standardize the regression coefficients as the OLS tool does. To compensate, the input variables were standardized using the tools in SPSS and re-imported into ArcGIS Desktop. Similar to the OLS analysis, standardization allowed for the comparison of the magnitude of the local regression coefficients.

The next step in the GWR preparation was to determine the local neighborhood used in the analysis. The bandwidth, or size of the neighborhood, used in the calculation of GWR heavily influences the calculation of the coefficients (O'Sullivan \& Unwin, 2010). For this project, an adaptive kernel was used for the calculations because of the varying size of the analysis units (Charlton \& Fotheringham, 2009). The area of United States counties varies significantly from Falls Church City, Virginia at five square kilometers to San Bernardino County, California at almost 52,000 square kilometers. As a result, a fixed distance band would have to be large enough to provide neighbors for San Bernardino, which would overwhelm a small county like Falls Church.

The specific number of neighbors used is highly dependent upon the GWR tool itself. The spatial autocorrelation analysis conducted as part of this project suggests that the strongest spatial processes in this data operated at the scale of a first order neighborhood. The smallest neighborhood at which the GWR tool would successfully complete was 12 neighbors, the second-order rook neighborhood; however, at that bandwidth, there were counties for which the tool could not calculate parameters. The smallest number of neighbors for which the tool could consistently calculate all parameters was 18 neighbors. This was greater than the hypothetical second-order rook neighborhood, but less than the hypothetical second-order queen neighborhood; however, when using non-gridded data, such as counties, there is little observed difference between the two contiguity schemes; therefore, the larger second-order neighborhood of 24 neighbors was used as the adaptive bandwidth size for the GWR regression analyses (GeoDa Center for Geospatial Analysis and Computation, 2014).

\subsubsection{GWR Results}

To interpret the model performance, the Aikake's Information Criterion (AICc) value for the GWR model was compared to the value for the equivalent OLS regression (Table 7-4) (Charlton \& Fotheringham, 2009). The magnitude of the AICc value in isolation cannot be interpreted; however, when comparing two models, a smaller AICc value indicates a better fitting model. For Table 7-4, the OLS AICc value was subtracted from the GWR AICc value. A negative number, therefore, indicates that the GWR model was better fitting. For five of the ten models, the GWR model yields a better fit than the OLS algorithm. The two best performing GWR models, percent of households with access to 
broadband and percent of houesholds with access to mobile wireless Internet connections, are those that performed the poorest using the OLS model, as measured by the adjusted $\mathrm{R}$-squared value (see Table 7-2). This likely indicates that there is strong local variation in those dependent variables that cannot be explained appropriately by the global model.

Table 7-4: Change in Aikake's Information Criterion (AICc) between OLS and GWR models. Regression models are listed in ascending order of AICc change.

\begin{tabular}{|c|c|c|c|c|}
\hline $\begin{array}{c}\text { Dependent } \\
\text { Variable }\end{array}$ & $\begin{array}{c}\text { GWR } \\
\text { AICc }\end{array}$ & $\begin{array}{c}\text { OLS } \\
\text { AICc }\end{array}$ & $\begin{array}{c}\text { AICc Change } \\
\text { (GWR - OLS) }\end{array}$ & $\begin{array}{c}\text { Best-Fit } \\
\text { Model }\end{array}$ \\
\hline BRDBNDHH & 5905.07 & 8494.94 & -2589.87 & GWR \\
\hline MOBILEWLHH & 5681.78 & 8191.93 & -2510.15 & GWR \\
\hline FACEBOOKR & 4364.80 & 4912.26 & -547.46 & GWR \\
\hline TWITTERR & 5769.85 & 5813.44 & -43.59 & GWR \\
\hline INTUSE30R & 4438.71 & 4460.91 & -22.20 & GWR \\
\hline CLLONLYHHR & 7915.86 & 7645.18 & 270.68 & OLS \\
\hline COMPINHHR & 5966.27 & 4945.14 & 1021.13 & OLS \\
\hline HSPEEDINTR & 4920.00 & 3894.16 & 1025.84 & OLS \\
\hline CELLINHHR & 7274.87 & 5903.86 & 1371.01 & OLS \\
\hline LNDONLYHHR & 7315.89 & 5658.30 & 1657.59 & OLS \\
\hline
\end{tabular}

For the remainder of this section, the results of the geographically weighted regression of the percent of population that visited facebook.com in the past 30 days will be discussed. Graphics and tables of the results for the other nine GWR analyses are located in Appendix F.

Since GWR is designed to fit local models, the residuals from a proper GWR model are expected to show less spatial autocorrelation than the equivalent OLS model. A graphic showing the comparison between the OLS residuals and the GWR residuals is displayed in Figure 7-3. The top portion of the figure shows the OLS residuals, in which clusters of red counties (over predicted values) are observed in the central region. This positive autocorrelation is confirmed with a Moran's I of $0.210(\mathrm{p}<0.001)$. In contrast, the residual pattern looks much closer to random for the GWR model as no obvious clustering is evident in the bottom map. The Moran's I decreases to -0.10 ( $p<0.001)$ from 0.210 . While the Moran's I remains significant, the decrease in magnitude indicates that the strength of the pattern has decreased dramatically. Additionally, the change in sign shows that the pattern is no longer clustered, it has become much closer to random with a slight tendency towards dispersion. 

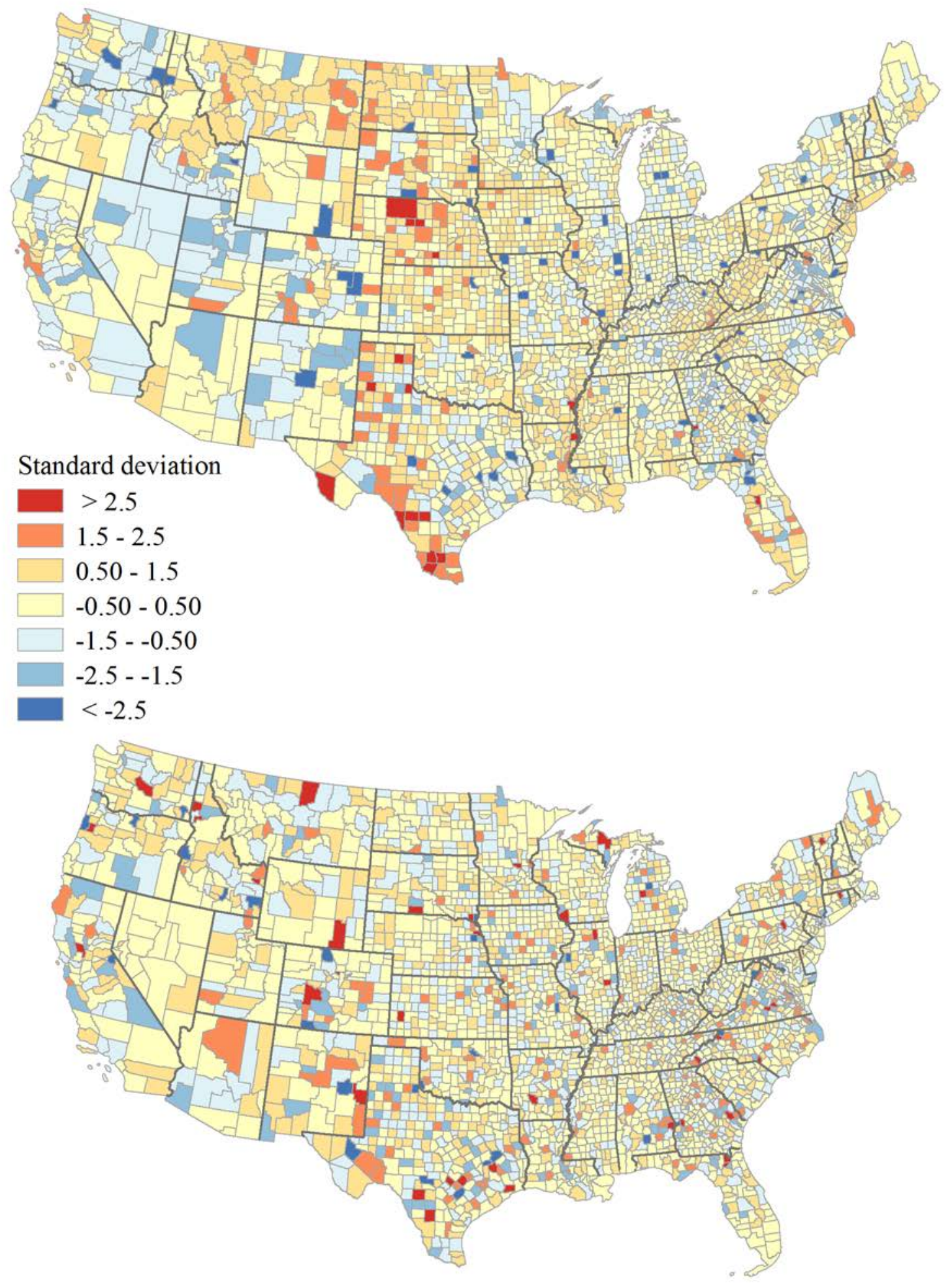

Figure 7-2: Regression residuals for the percent of population that accessed facebook.com in the past 30 days. Top: OLS regression residuals; Bottom: GWR residuals. 
The GWR regression coefficients vary spatially, indicating that an independent variable can have a larger or smaller effect on the dependent variable based upon a county's spatial location (Charlton \& Fotheringham, 2009). The coefficients maps from the GWR tool provide a visualization of the effect of each variable. Figure 7-3 shows the effects of percent urban (URBANR), percent total employment (TOTEMPLR), percent college graduates (COLLEGER), percent Asian (ASIANR), percent Black (BLACKR), and percent Hispanic (HISPANICR) on the percent of population that visited facebook.com in the past 30 days. In the global OLS model, the variables URBANR, TOTEMPLR, COLLEGER, and ASIANR show positive relationships with the dependent variable while HISPANICR and BLACKR are negatively related to the dependent variable. The change in sign of the GWR coefficients indicates that the relationships are spatially heterogeneous (Charlton \& Fotheringham, 2009). The observed spatial heterogeneity could explain the significant Koenker (BP) statistics from the OLS regression results. 

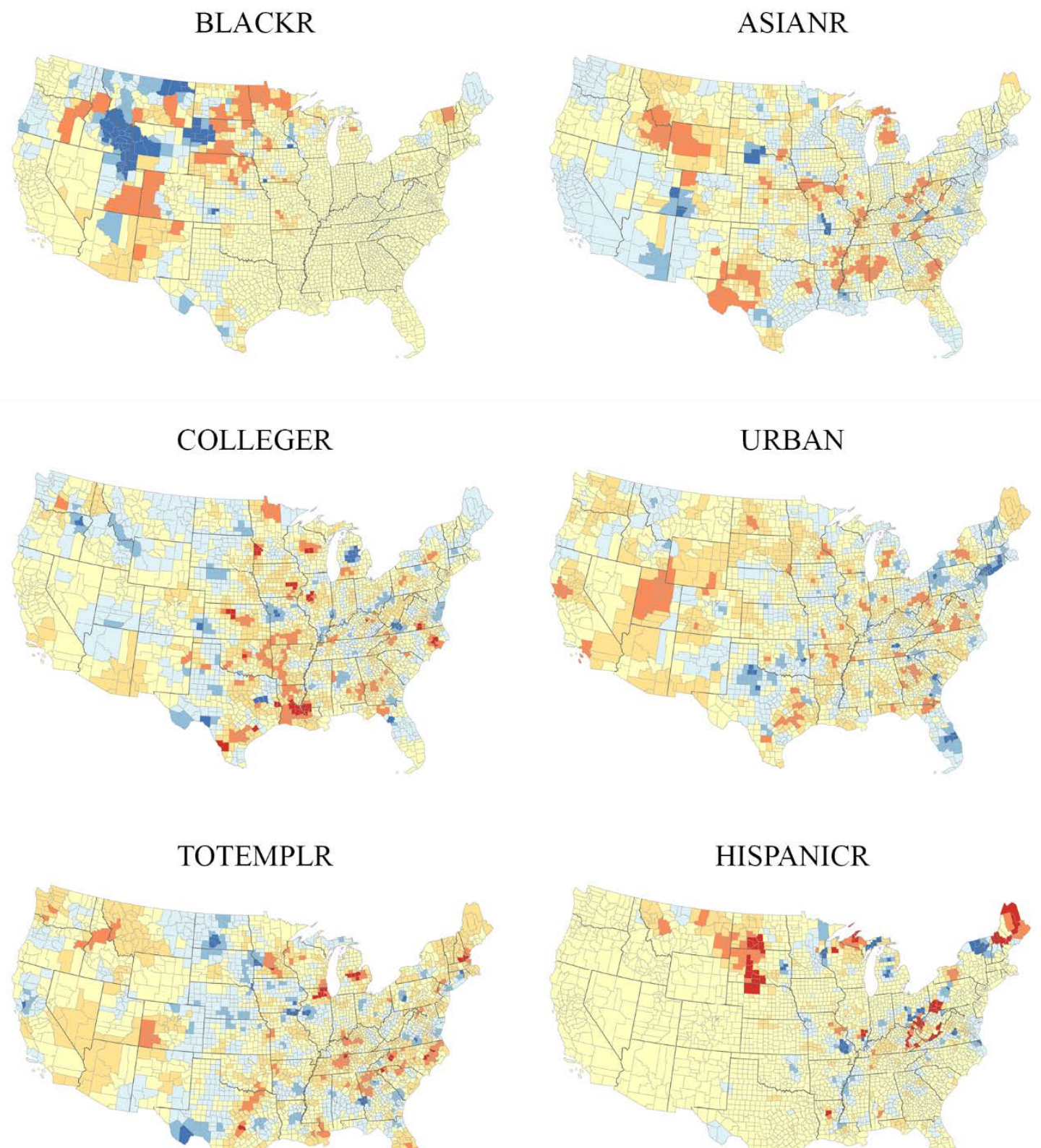

Standard deviation

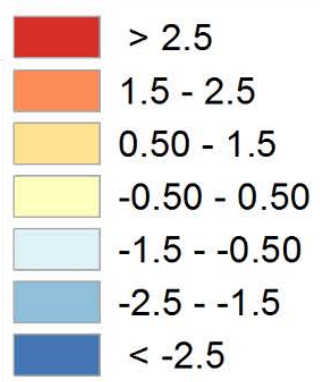

Figure 7-3: GWR coefficients for percent of population that visited facebook.com in the past 30 days. All coefficients share the same symbology. 
The regional coefficient patterns are different for each coefficient. For the percent urban variable (URBANR), the largest coefficients generally were found in small clusters throughout the country. There was one large cluster, which contained most of the counties in Utah. For these counties, an increase in the percent urban population results in a large increase in the percentage of facebook.com visitors. This could indicate that in rural areas, small increases in urban population are more important for the use of facebook than elsewhere in the country. On the other hand, any county with a value less than one standard deviation below the mean has a negative coefficient. This corresponds to the dark blue and some of the medium blue counties in Figure 7-3, particularly in the east coast megalopolis and Florida. In these areas, increased urban population results in a decrease in the number of facebook.com visitors. This is a somewhat counterintuitive results, but it may indicate that there is a ceiling to the amount of variation in facebook users that the urban population can explain.

The total employment coefficient (TOTEMPLR) is positively correlated with facebook use. The coefficient has high values on the outskirts of large cities and low and negative values inside many cities. An example is in the Atlanta area where the center of the city is a negative coefficient which may be due to high employment in the city and that there is minimal variation in facebook use among employed persons. However, the employment status has a much greater impact on the facebook use in the outskirts of the city.

The percent of population with a college degree (COLLEGER) and the percent of Asian population (ASIANR) show patterns of regional variation with high and low coefficient values throughout the country. The specific locations of high and low coefficient values vary between the variables, but the regional variation is seen throughout the country.

The two coefficients that were negative in the OLS model, percent Hispanic population and percent black population show regional variation in only part of the country. For the Hispanic population variable, there is no variability in the coefficient in the western and southwestern United States. The counties in these areas have coefficients close to the mean value. However, in the northern and eastern United States, the regional variability is apparent, similar to the other previously discussed variables. For the percent of black population, the general pattern of regional variability is found in the western United States while there is minimal variability in the eastern part of the country. The coefficients of the percent black population show much sharper divisions between the high and low coefficients rather than a smooth change seen in many of the other variables.

\subsubsection{Issues with the GWR Technique}

The GWR method has the potential to provide very interesting results, in theory; however, in practice, the method is impractical and prone to mistakes. When preparing to run the model, the bandwidth decision is arbitrary and there is no good method to choose the size of the kernel. There is a method in the ArcGIS Desktop implementation to use the bandwidth size of the smallest AICc value. In practice, this method does not necessarily provide the best bandwidth result. For example, the FACEBOOKR GWR was conducted at bandwidths of 12 to 80 neighbors, incremented by one, in an attempt to determine the optimal neighborhood size. The pattern of AICc results is shown in Figure 
7-4. The orange line in the figure was derived from the 68 separate runs of the GWR algorithm. According to the GWR tool documentation, "when AICc or CV are selected [as the bandwidth method], the tool will find the optimal distance/neighbor parameter for you" (Esri, 2014). The blue dot shows the AICc value of the "optimal” regression model found using 761 neighbors. This AICc value is not the smallest value, suggesting that the optimization method is not accurate. The tool documentation recommends use of this optimization method when there is no known bandwidth size.

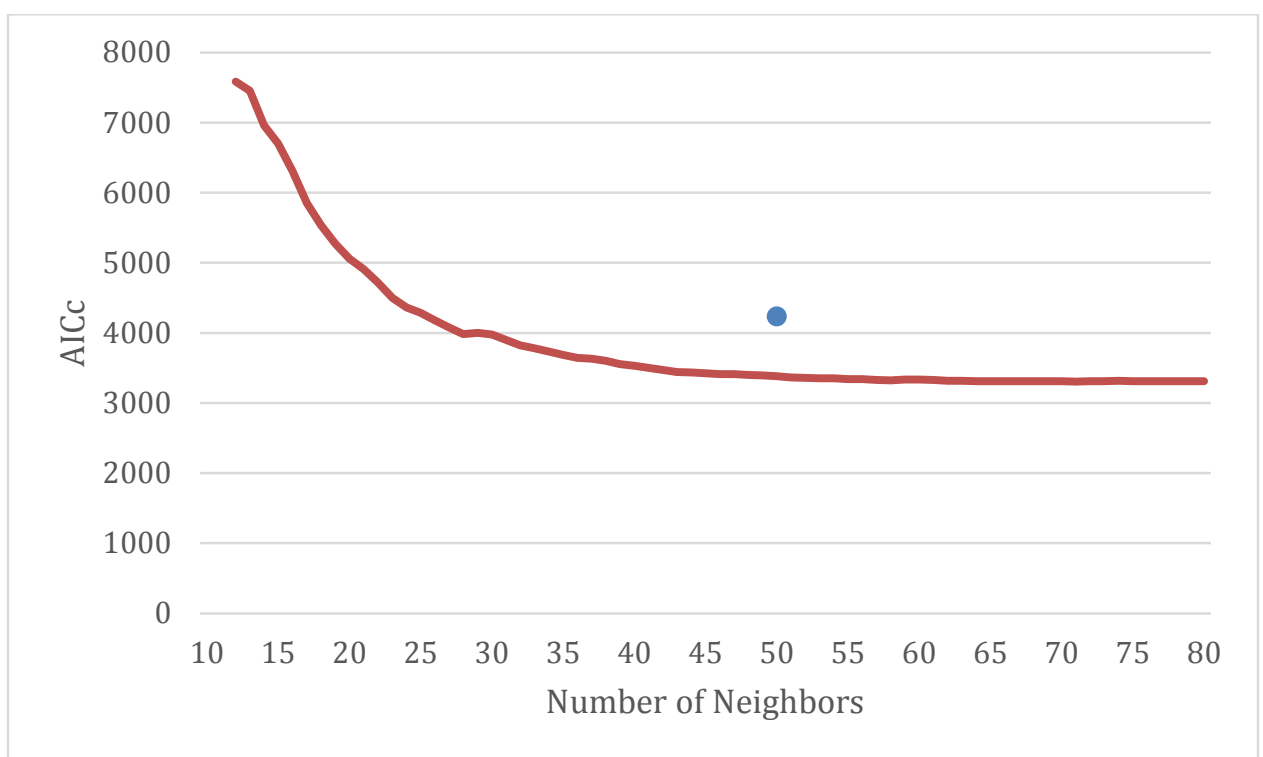

Figure 7-4: Graph of AICc value for varying number of neighbors for the FACEBOOKR GWR model. The orange line is derived from individual runs of the algorithm at each bandwidth size. The blue dot is the AICc value at 761 neighbors calculated using the AICc optimization algorithm in ArcGIS Desktop.

In addition to the inaccurate optimization, the bandwidth size has a significant effect on the coefficients returned from the model. Images of the same coefficient, TOTEMPLR, for the FACEBOOKR GWR model at different bandwidth sizes are shown in Figure 7-5. The size of the neighborhood has a major impact on the coefficient calculated for a specific county For example, the Montana area has a coefficient greater than the mean in models a, b, and c; however in model $\mathrm{d}$ the coefficient is now less than the mean. The underlying data values did not change, but the coefficients are remarkably different. In California, the San Francisco and Los Angeles areas show below mean coefficients in models a and b, but in models $\mathrm{c}$ and $\mathrm{d}$ those coefficients become close to the mean. These dramatic changes in the coefficient values, which can include changes in sign, show that the bandwidth value, arbitrarily defined even when using the "optimization" strategy, is extremely important to the model results. 
a)

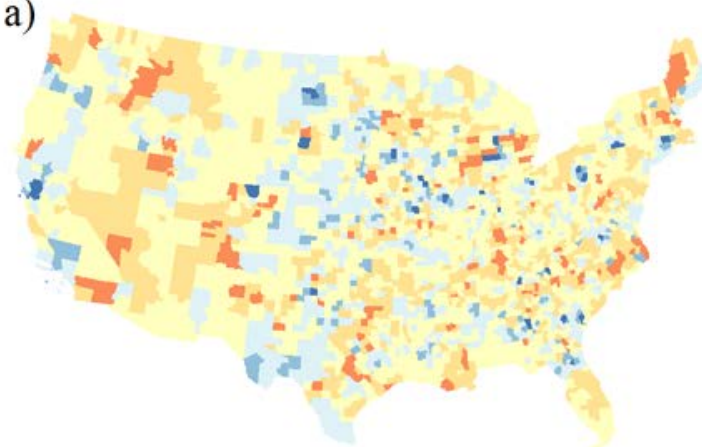

c)

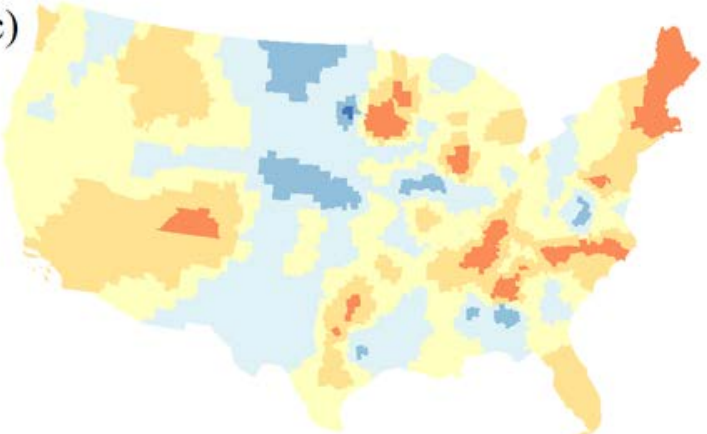

b)

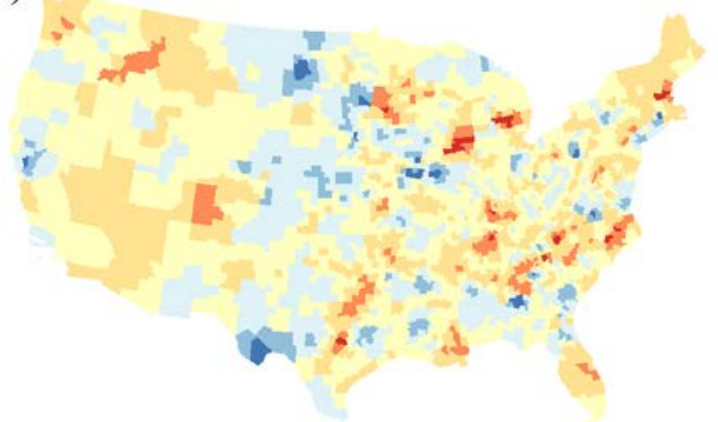

d)

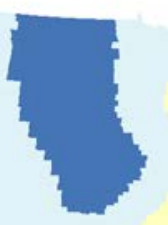

Figure 7-5: Images of the the percent total employment at different bandwidth sizes. a) 14 neighbors; b) 24 neighbors; c) 80 neighbors; d) 761 neighbors.

The other issues discovered with the GWR algorithm are that the model lacks diagnostic tests and that the coefficients are sometimes difficult to explain. There are a number of literature reviews of the algorithm that discuss the lack of diagnostic tests and the issue has been acknowledged by the techniques' authors (Charlton \& Fotheringham, 2009). The difficulty in explaining the coefficients is not a defined issue. There is literature discussing the best methods to visualize the model coefficients (Cho, Lambert, Kim, \& Jung, 2009; Mennis, 2006; Matthews \& Yang, 2012; Wheeler, 2008); however, there is very little to explain how to interpret the coefficients. In fact, in their 17-page white paper discussing GWR, Charlton and Fotheringham (2009) provide a oneparagraph discussion on interpreting the parameter estimates.

\subsection{Spatial Lag and Spatial Error Regressions}

There are two other spatial regression models which are implemented in the Geoda software program. They are spatial lag regression and spatial error regression. These two models are global models that investigate spatial dependence (Anselin \& Rey, 1991). In the spatial lag model, the value of the dependent variable is correlated with its value at other nearby locations. This model treats the spatial dependence as a part of the variables in the model. The spatial error model, on the other hand, treats the spatial dependence in the error, or residuals, as a nuisance that must be eliminated from the model. According to Anselin and Rey (1991), the presence of spatial error in the model will affect the validity of the OLS tests, particularly tests for heteroscedasticity. The following models 
were developed using the rook neighborhood because this was the neighborhood at which spatial autocorrelation was highest.

\subsubsection{Spatial Dependence Regression Analysis Methods}

To determine which spatial dependence model to use on a particular dataset, Anselin (2008) recommends using the Lagrange multiplier (LM) statistic. The LM lag and LM error statistics are calculated as part of the OLS algorithm implemented in the Geoda software package. The LM statistics are compared and the most significant statistic suggests which spatial dependence model is best for the data (Anselin, 2005). If both statistics are significant, robust statistics should be compared. If all four of the LM statistics are significant, normal and robust for both spatial lag and spatial error, the model with the largest test statistic should be used for the analysis.

To determine the spatial regression model to use, all previous OLS models were rerun in the Geoda algorithm in order to calculate the LM statistics. In all cases, the robust statistics were used to determine the spatial regression model because the normal statistics were both highly significant (Table 7-5). In eight of the ten models, the robust LM error statistic had the largest value, suggesting the use of the spatial error model. In two cases the robust LM lag statistic had the largest value. These two models were the broadband in household and mobile wireless household models. These models had the lowest adjusted R-squared value in the OLS regression models (Table 7-2). This suggests that these models may be misspecified and that the missing variable has a strong spatial characteristic.

Table 7-5: Lagrange multiplier statistics for the exploratory regression models.

\begin{tabular}{|c|c|c|c|c|}
\hline $\begin{array}{c}\text { Dependent } \\
\text { Variable }\end{array}$ & LM Lag & $\begin{array}{c}\text { Robust } \\
\text { LM Lag }\end{array}$ & LM Error & $\begin{array}{c}\text { Robust } \\
\text { LM error }\end{array}$ \\
\hline BRDBNDHH & $1996.0^{* * *}$ & $238.2^{* * *}$ & $1758.9^{* * *}$ & 1.13 \\
\hline CELLINHHR & $1228.1^{* * *}$ & $137.8^{* * *}$ & $1474.3^{* * *}$ & $384.0^{* * *}$ \\
\hline CLLONLYHHR & $156.9^{* * *}$ & $52.6^{* * *}$ & $356.3^{* * *}$ & $252.1^{* * *}$ \\
\hline COMPINHHR & $909.4^{* * *}$ & $100.8^{* * *}$ & $1673.4^{* * *}$ & $864.7^{* * *}$ \\
\hline FACEBOOKR & $276.5^{* * *}$ & $39.6^{* * *}$ & $376.4^{* * *}$ & $139.4^{* * *}$ \\
\hline HSPEEDINTR & $866.7^{* * *}$ & $186.6^{* * *}$ & $1176.8^{* * *}$ & $496.6^{* * *}$ \\
\hline INTUSE30R & $859.2^{* * *}$ & $150.8^{* * *}$ & $1157.9^{* * *}$ & $449.5^{* * *}$ \\
\hline LNDONLYHHR & $986.3^{* * *}$ & $126.1^{* * *}$ & $1183.4^{* * *}$ & $323.2^{* * *}$ \\
\hline MOBILEWLHHR & $1706.1^{* * *}$ & $255.0^{* * *}$ & $1452.4^{* * *}$ & 1.4 \\
\hline TWITTERR & $118.1^{* * *}$ & 0.01 & $244.8^{* * *}$ & $126.7^{* * *}$ \\
\hline
\end{tabular}

Note: $* * *=\mathrm{p}<0.001$.

\subsubsection{Spatial Dependence Model Results}

For exploratory purposes, both the spatial lag and spatial error regression models were run for all ten models. In the case where a coefficient was not significant for either the spatial error or the spatial lag model, it was removed from the model and the algorithm 
was re-run. The diagnostic statistics for the models with significant coefficients were compared to the diagnostic statistics for the OLS and GWR models (Table 7-6). For the log likelihood and Schwarz criterion, the statistic closest to zero indicates the best-fit model. For the Aikake Information Criterion, a smaller number indicates the best-fit model. For these ten dependent variables, a spatial model is always the best model. The spatial error model was the best fit for seven of the ten variables and the GWR model was the best fit for the remaining three. This indicates that the processes relating the independent and dependent variables have a strong spatial component. 
Table 7-6: Comparison of diagnostic statistics for four regression models. Best-fit model is highlighted.

\begin{tabular}{|c|c|c|c|c|}
\hline $\begin{array}{c}\text { Dependent } \\
\text { Variable }\end{array}$ & $\begin{array}{l}\text { Regression } \\
\text { Model }\end{array}$ & $\begin{array}{c}\text { Log } \\
\text { Likelihood }\end{array}$ & $\begin{array}{c}\text { Akaike Info } \\
\text { Criterion }\end{array}$ & $\begin{array}{l}\text { Schwarz } \\
\text { Criterion } \\
\end{array}$ \\
\hline \multirow{4}{*}{ BRDBNDHH } & OLS & -4240.5 & 8494.9 & 8537.3 \\
\hline & GWR & & 5905.1 & \\
\hline & Spatial Lag & -3555.3 & 7122.6 & 7158.9 \\
\hline & Spatial Error & -3579.0 & 7168.0 & 7198.2 \\
\hline \multirow{4}{*}{ CELLINHHR } & OLS & -2943.9 & 5903.9 & 5952.3 \\
\hline & GWR & & 7274.9 & \\
\hline & Spatial Lag & -2460.4 & 4936.8 & 4985.2 \\
\hline & Spatial Error & -2366.7 & 4749.4 & 4797.9 \\
\hline \multirow{4}{*}{ CLLONLYHHR } & OLS & -3814.6 & 7645.2 & 7693.6 \\
\hline & GWR & & 7915.9 & \\
\hline & Spatial Lag & -3744.0 & 7506.0 & 7560.5 \\
\hline & Spatial Error & -3659.0 & 7334.0 & 7382.4 \\
\hline \multirow{4}{*}{ COMPINHHR } & OLS & -2462.6 & 4945.1 & 5005.7 \\
\hline & GWR & & 5966.3 & \\
\hline & Spatial Lag & -2014.8 & 4051.6 & 4118.2 \\
\hline & Spatial Error & -1837.7 & 3695.5 & 3756.0 \\
\hline \multirow{4}{*}{ FACEBOOKR } & OLS & -2449.1 & 4912.3 & 4954.6 \\
\hline & GWR & & 4364.8 & \\
\hline & Spatial Lag & -2326.3 & 4668.6 & 4717.0 \\
\hline & Spatial Error & -2298.9 & 4611.8 & 4654.2 \\
\hline \multirow{4}{*}{ HSPEEDINTR } & OLS & -1938.1 & 3894.2 & 3948.6 \\
\hline & GWR & & 4920.0 & \\
\hline & Spatial Lag & -1565.2 & 3150.4 & 3210.9 \\
\hline & Spatial Error & -1482.4 & 2982.7 & 3037.2 \\
\hline \multirow{4}{*}{ INTUSE30R } & OLS & -2223.5 & 4460.9 & 4503.3 \\
\hline & GWR & & 4438.7 & \\
\hline & Spatial Lag & -1853.9 & 3723.7 & 3772.1 \\
\hline & Spatial Error & -1783.3 & 3580.7 & 3623.1 \\
\hline \multirow{4}{*}{ LNDONLYHHR } & OLS & -2821.2 & 5658.3 & 5706.7 \\
\hline & GWR & & 7315.9 & \\
\hline & Spatial Lag & -2426.1 & 4870.2 & 4924.7 \\
\hline & Spatial Error & -2360.0 & 4736.0 & 4784.4 \\
\hline \multirow{4}{*}{ MOBILEWLHH } & OLS & -4088.0 & 8191.9 & 8240.4 \\
\hline & GWR & & 5681.8 & \\
\hline & Spatial Lag & -3457.2 & 6932.4 & 6986.8 \\
\hline & Spatial Error & -3484.4 & 6980.7 & 7017.0 \\
\hline \multirow{4}{*}{ TWITTERR } & OLS & -2897.7 & 5813.4 & 5867.9 \\
\hline & GWR & & 5769.9 & \\
\hline & Spatial Lag & -2842.3 & 5704.5 & 5765.0 \\
\hline & Spatial Error & -2793.3 & 5604.7 & 5659.1 \\
\hline
\end{tabular}


For the spatial error regressions, the spatial autoregressive coefficient (lambda) is always the largest coefficient in the model (Table 7-7 and Table 7-8). For the spatial lag model, the spatial autoregressive coefficient, or lagged coefficient (w), is the largest in seven of the ten models, and the second largest coefficient in one of the remaining models. In the social media models, the spatial lag coefficient is large, but not the most important factor in the model. These results suggest that spatial dependence is highly important in these models and should be further investigated. It is likely that there are other variables that should be added to the model, which could help to explain the spatial variability. 
Table 7-7: Standardized spatial error (top) and spatial lag (bottom) regression results for ICT infrastructure dependent variables.

\begin{tabular}{|c|c|c|c|c|c|}
\hline & BRDBNDHH & COMPINHHR & HSPEEDINTR & INTUSE30R & MOBILEWLHH \\
\hline URBAN & $0.162 * * *$ & $0.231 * * *$ & $0.326 * * *$ & $0.322 * * *$ & $0.192 * * *$ \\
\hline ASIAN & $-0.054 * *$ & $0.093 * * *$ & $0.067 * * *$ & -- & -- \\
\hline BLACK & -- & $-0.379 * * *$ & $-0.248 * * *$ & $-0.292 * * *$ & -- \\
\hline HISPANIC & -- & $-0.097 * * *$ & $-0.144 * * *$ & $-0.191 * * *$ & $0.050 *$ \\
\hline TOTEMPLR & $0.078 * * *$ & $0.195 * * *$ & $0.220 * * *$ & $0.251 * * *$ & $0.121^{* * *}$ \\
\hline LGOVEDEXP & $-0.074 * * *$ & $-0.044 * * *$ & $-0.027 * * *$ & -- & $-0.137 * * *$ \\
\hline SERVICE & -- & $-0.023 * *$ & -- & -- & -- \\
\hline CONSTRUCT & -- & $0.070 * * *$ & $0.035 * * *$ & $0.041 * * *$ & $-0.050 * *$ \\
\hline COLLEGE & -- & $0.348 * * *$ & $0.370 * * *$ & $0.324 * * *$ & -- \\
\hline Lambda & $0.702 * * *$ & $0.694 * * *$ & $0.637 * * *$ & $0.628 * * *$ & $0.710 * * *$ \\
\hline URBAN & $0.176^{* * *}$ & $0.258 * * *$ & $0.335 * * *$ & $0.318 * * *$ & $0.175^{* * *}$ \\
\hline ASIAN & $-0.092 * * *$ & $0.053 * * *$ & $0.050 * * *$ & -- & $-0.063 * * *$ \\
\hline BLACK & -- & $-0.198 * * *$ & $-0.153 * * *$ & $-0.193 * * *$ & $0.043^{* *}$ \\
\hline HISPANIC & -- & $-0.089 * * *$ & $-0.138 * * *$ & $-0.167 * * *$ & $0.044^{* *}$ \\
\hline TOTEMPLR & $0.058 * * *$ & $0.152 * * *$ & $0.184 * * *$ & $0.207 * * *$ & $0.133 * * *$ \\
\hline LGOVEDEXP & $-0.076 * * *$ & $-0.035 * * *$ & $-0.018 *$ & -- & $-0.156 * * *$ \\
\hline SERVICE & -- & $-0.051 * * *$ & -- & -- & -- \\
\hline CONSTRUCT & -- & $0.093 * * *$ & $0.045^{* * *}$ & $0.054 * * *$ & $-0.060 * * *$ \\
\hline COLLEGE & -- & $0.305^{* * *}$ & $0.325^{* * *}$ & $0.279 * * *$ & -- \\
\hline W & $0.676^{* * *}$ & $0.414 * * *$ & $0.342^{* * *}$ & $0.371 * * *$ & $0.654 * * *$ \\
\hline
\end{tabular}

Note: Statistical significance is indicated as: $*=\mathrm{p}<0.05$, ** $=\mathrm{p}<0.01$, *** $=\mathrm{p}<0.001$. 
Table 7-8: Standardized spatial error (top) and spatial lag (bottom) regression results for telephone and social media dependent variables.

\begin{tabular}{|c|c|c|c|c|c|}
\hline & CELLINHHR & CLLONLYHHR & LNDONLYHHR & FACEBOOKR & TWITTERR \\
\hline URBAN & $0.327 * * *$ & $0.438 * * *$ & $-0.322 * * *$ & $0.411 * * *$ & $0.328 * * *$ \\
\hline ASIAN & $0.067 * * *$ & -- & $-0.073^{* * *}$ & $0.051 * * *$ & $0.135 * * *$ \\
\hline BLACK & -- & $0.143^{* * *}$ & -- & $-0.152 * * *$ & $0.255^{* * *}$ \\
\hline HISPANIC & $0.127 * * *$ & $0.186 * * *$ & $-0.129 * * *$ & $-0.149 * * *$ & $0.109 * * *$ \\
\hline TOTEMPLR & $0.291 * * *$ & $0.165 * * *$ & $-0.332 * * *$ & $0.283 * * *$ & $0.140 * * *$ \\
\hline LGOVEDEXP & -- & -- & -- & -- & -- \\
\hline SERVICE & $-0.039 * * *$ & $0.160 * * *$ & $0.052 * * *$ & -- & $0.068 * * *$ \\
\hline CONSTRUCT & $0.068 * * *$ & $-0.087 * * *$ & $-0.067 * * *$ & -- & $-0.099 * * *$ \\
\hline COLLEGE & $0.215 * * *$ & $-0.148 * * *$ & $-0.211 * * *$ & $0.300 * * *$ & $0.318 * * *$ \\
\hline Lambda & $0.679 * * *$ & $0.445^{* * *}$ & $0.635 * * *$ & $0.424 * * *$ & $0.371^{* * *}$ \\
\hline URBAN & $0.384 * * *$ & $0.412 * * *$ & $-0.372 * * *$ & $0.402 * * *$ & $0.330 * * *$ \\
\hline ASIAN & $0.047 * * *$ & -- & $-0.047 * * *$ & $0.039 * * *$ & $0.121 * * *$ \\
\hline BLACK & -- & $0.112 * * *$ & -- & $-0.115 * * *$ & $0.210 * * *$ \\
\hline HISPANIC & -- & $0.103 * * *$ & $-0.025^{*}$ & $-0.150 * * *$ & $0.066^{* * *}$ \\
\hline TOTEMPLR & $0.199 * * *$ & $0.139 * * *$ & $-0.253 * * *$ & $0.252 * * *$ & $0.115^{* * *}$ \\
\hline LGOVEDEXP & -- & -- & -- & -- & -- \\
\hline SERVICE & $-0.060 * * *$ & $0.151^{* * *}$ & $0.076 * * *$ & -- & $0.067 * * *$ \\
\hline CONSTRUCT & $0.071 * * *$ & $-0.068 * * *$ & $-0.067 * * *$ & -- & $-0.097 * * *$ \\
\hline COLLEGE & $0.127 * * *$ & $-0.202 * * *$ & $-0.132 * * *$ & $0.256^{* * *}$ & $0.272 * * *$ \\
\hline W & $0.480 * * *$ & $0.276^{* * *}$ & $0.435 * * *$ & $0.249 * * *$ & $0.203^{* * *}$ \\
\hline
\end{tabular}

Note: Statistical significance is indicated as: $*=\mathrm{p}<0.05$, ** $=\mathrm{p}<0.01$, *** $=\mathrm{p}<0.001$. 
When investigating the non-spatial coefficients in the spatial error and spatial lag models, percent urban population, percent college graduates, and percent employed remain important variables in the models; however, they were no longer the top three variables in all of the models. In the spatial dependence models, the racial and ethnic variables, percent black and percent Hispanic, become important predictors of ICT variables. In the state-level study, the percent black population was a strong correlate with social capital variables (Pick, Sarkar, \& Johnson, 2014). As in that case, the racial variables could be indicative of other un-modeled variables. Because the coefficients increase in magnitude in the spatial dependence models, it could be indicative of the spatial pattern masking or confounding the importance of those variables in the OLS models.

\subsection{Summary}

The regression analysis resulted in the discovery of strong spatial patterns among the relationships between the independent and dependent variables. The most important independent variables for explaining the variation in the ICT indicators were percent urban, percent college graduates, and percent employment. These variables remained important in both the traditional OLS regression as well as the spatial dependence models. The results of the four regression algorithms suggest that questions about model specification remain and that there may be variables missing from the analysis that could better explain the variability of the dependent variables. The missing variables could include spatial variables such as the county's distance from a city of a certain size, or a city's network connectivity to major urban centers. These and other variables could be investigated in future work on this subject. 


\section{Chapter 8 - Conclusions and Future Work}

This chapter provides an overview of the work conducted in this project. Section 8.1 provides a summary of the problem, solution, and results. Section 8.2 provides four potential spatially-oriented extensions of this work.

\subsection{Project Summary}

This Major Individual Project (MIP) was conducted to determine 1) if there were spatial patterns in information and communications technology (ICT) use and adoption in the United States, and 2) if there were relationships between ICT use and socio-economic and demographic indicators. The work was conducted with the clients, James Pick and Avijit Sarkar, faculty at the University of Redlands School of Business. The project was modeled after their previous work at the state level.

The clients requested five items: a data codebook, a data sourcing document, the data, maps of the data, and the results of the statistical analyses. The data codebook and data sourcing document were the metadata information that allowed the clients to understand where the data came from, how the data was collected, and how to interpret the attribute names. The data itself was provided to the clients in a geodatabase and Microsoft Excel format for use in further statistical analyses after the project was completed. Statistical analyses conducted included: descriptive statistics, correlation analysis, k-means clustering, spatial autocorrelation, ordinary least squares regression, geographically weighted regression, and spatial dependence regression. The results of the seven analysis techniques were provided to the clients and fulfilled the functional requirements they described at the outset of the project.

The results of the clustering analyses found significant spatial patterns of ICT use and adoption at the county scale. The highest technology clusters were found in metropolitan areas and the low technology clusters were found in rural areas of the United States. Because population effects were removed from the data prior to analysis, it is likely that the increased use of ICT is related to improved technology infrastructure in urban areas.

The regression analysis found significant relationships between ICT use and urban, educational attainment, and employment variables. These relationships were likely related to infrastructure, knowledge, and financial capabilities. When spatial processes were introduced into the regression analysis, the spatial variables became the most important variable in the model. This suggested that there were missing variables in the models and that further work should be conducted in model specification to determine if there are other variables which could explain ICT diffusion.

\subsection{Further Research}

There are numerous avenues for further research in this topic as the dataset is rich with information and very few regression models were explored. First, inclusion of spatial variables, such as distance from population centers or network connectivity to major cities, could be incorporated into the regression models. These variables could explain the 
diffusion of ICT use without relying on spatial dependence models. Second, work could be conducted further analyzing the model specification issues found during this project. The exploratory regression analyses conducted as part of this project acknowledged numerous issues with the diagnostic tests. If the significant diagnostics could be investigated and solved, then the modeled relationships could better explain the diffusion of ICT use.

Further work could be conducted on the spatial scale of ICT use and adoption. The spatial neighborhoods used in these analyses could be further explored to determine the scale at which diffusion is occurring. Data for smaller areal units, such as Census tracts could be collected and the clustering analysis re-conducted to determine if a smaller aggregation provided a better indicator of diffusion. If point data were available, that would provide another scale at which to test the relationships. Additional analyses could be conducted at the regional scale to determine if the observed variation at the country scale is still found when fewer units are included.

The opportunities to conduct further statistical analysis on this rich dataset are immense. Incorporating spatial analysis into the research has been shown to improve the statistical results. Spatial variables have been shown to explain a large amount of the variation in ICT use and adoption. Further work could provide interesting research projects and papers. 


\section{Works Cited}

Agarwal, R., Animesh, A., \& Prasad, K. (2009). Social interactions and the digital divide: Explaining variations in Internet use. Information Systems Research, 20(2), 277294. doi:10.1287/isre.1080.0194

Ahn, H., \& Lee, M.-H. (1999). An econometric analysis of the demand for access to mobile telephone networks. Information Economics and Policy, 11(3), 297-305. doi:10.1016/S0167-6245(99)00016-5

Anselin, L. (1995). Local indicators of spatial association - LISA. Geographical Analysis, 27(2), 93-115. doi:10.1111/j.1538-4632.1995.tb00338.x

Anselin, L. (2005). Exploring spatial data with GeoDa: A workbook. Center for Spatially Integrated Social Science. Retrieved July 5, 2014, from https://geodacenter.asu.edu/system/files/geodaworkbook.pdf

Anselin, L. (2008, March 18). Spatial lag and error model. Arizona. Retrieved July 5, 2014, from http://geodacenter.asu.edu/spatial-lag-and

Anselin, L., \& Rey, S. (1991). Properties of tests for spatial dependence in linear regression models. Geographical Analysis, 23(2), 112-131. doi:10.1111/j.15384632.1991.tb00228.x

Anselin, L., Syabri, I., \& Kho, Y. (2006). GeoDa: An introduction to spatial data analysis. Geographical Analysis, 38(1), 5-22.

Azari, R., \& Pick, J. B. (2005). Technology and society: socioeconomic influences on technological sectors for United States counties. International Journal of Information Management, 25, 21-37. doi:10.1016/j.ijinfomgt.2004.10.001

Baliamoune-Lutz, M. (2003). An analysis of the determinants and effects of ICT diffusion in developing countries. Information Technology for Development, 10, 151-169.

Bureau of Economic Analysis. (2012). BEA regional economic accounts. Retrieved December 28, 2013, from http://www.bea.gov/regional/index.htm

Burt, J. E., Barber, G. M., \& Rigby, D. L. (2009). Elementary statistics for geographers (Third ed.). New York, New York: The Guilford Press.

Charlton, M., \& Fotheringham, A. S. (2009). Geographically weighted regression white paper. Retrieved July 3, 2014, from http://www.geos.ed.ac.uk/ gisteac/fspat/gwr/gwr_arcgis/GWR_WhitePaper.pdf

Chen, W. (2013). The implications of social capital for the digital divides in America. The Information Society: An International Journal, 29(1), 13-25. doi:10.1080/01972243.2012.739265

Cho, S.-H., Lambert, D. M., Kim, S. G., \& Jung, S. H. (2009). Extreme coefficients in geographically weighted regression and their effects on mapping. Milwaukee, Wisconsin. Retrieved from http://ageconsearch.umn.edu/bitstream/49117/2/Selected_paper_613303_Cho_et_ al.pdf

Comer, J. C., \& Wikle, T. A. (2008). Worldwide diffusion of the cellular telephone, 1995-2005. The Professional Geographer, 60(2), 252-269. doi:10.1080/00330120701836303

Crandall, R. W. (2001). Bridging the divide: Naturally. The Brookings Review, 19(1), 3841. Retrieved from http://www.jstor.org/stable/20080960 
Craney, T. A., \& Surles, J. G. (2002). Model-dependent variance inflation factor cutoff values. Quality Engineering, 14(3), 391-403.

Dasgupta, S., Lall, S., \& Wheeler, D. (2005). Policy reform, economic growth and the digital divide. Oxford Development Studies, 33(2), 229-243. doi:10.1080/13600810500137889

DeVol, R. C., Klowden, K., Bedroussian, A., \& Yeo, B. (2009). North America's hightech economy: The geography of knowledge-based industries. Santa Monica, CA: Milken Institute. Retrieved from http://www.milkeninstitute.com/pdf/NAHTweb.pdf

Esri. (2013). ArcGIS Business Analyst. Redlands, California. Retrieved February 13, 2014, from http://www.esri.com/software/arcgis/extensions/businessanalyst

Esri. (2013, 18 April). How exploratory regression works. Retrieved July 20, 2014, from ArcGIS Help 10.1:

http://resources.arcgis.com/en/help/main/10.1/index.html\#//005p00000054000000

Esri. (2014). ArcGIS for Desktop - Advanced desktop mapping | GIS editing software.

Retrieved from http://www.esri.com/software/arcgis/arcgis-for-desktop

Esri. (2014, April 18). Geographically Weighted Regression (GWR) (Spatial Statistics).

Retrieved July 4, 2014, from ArcGIS Help 10.1:

http://resources.arcgis.com/en/help/main/10.1/index.html\#/Geographically_Weigh ted_Regression_GWR/005p00000021000000/

Esri. (2014, March 4). Interpreting OLS results. Retrieved July 1, 2014, from ArcGIS Help 10.2, 10.1, and 10.2.2:

http://resources.arcgis.com/en/help/main/10.2/index.html\#//005p00000030000000

Federal Communications Commission. (2011). Local telephone competition and broadband deployment. Retrieved December 19, 2013, from http://transition.fcc.gov/wcb/iatd/comp.html

Feng, X., \& Humphries, B. R. (2008). Assessing the economic impact of sports facilities on residential property values: A spatial hedonic approach. International Association of Sports Economists Working Papers, 08-12, 1-19.

GeoDa Center for Geospatial Analysis and Computation. (2014). Tips. Retrieved 2 July, 2014, from ASU GeoDa Center for Geospatial Analysis and Computation: https://geodacenter.asu.edu/node/402\#choice

Google. (2014). Google maps. Mountain View, California. Retrieved June 23, 2014, from www.maps.google.com

Greenstein, S., \& Prince, J. (2006). The diffusion of the Internet and the geography of the digital divide in the United States. Cambridge, MA: National Bureau of Economic Research Working Paper 12182. Retrieved from http://cendoc.esan.edu.pe/fulltext/e-documents/NBER/w12182.pdf

Griffith, D. A. (1987). Spatial autocorrelation a primer. Washington, DC: Association of American Geographers. Retrieved from http://zxtm01-ti1.utdallas.edu/ dag054000/Taiwan_lectures/background\%20readings/ESM2005.pdf

Grubesic, T. H. (2002). Spatial dimensions of Internet activity. Telecommunications Policy, 26(7-8), 363-387. doi:10.1016/S0308-5961(02)00021-6 
Grubesic, T. H. (2006). A spatial taxonomy of broadband regions in the United States. Information Economics and Policy, 18(4), 423-448. doi:10.1016/j.infoecopol.2006.05.001

Hoffman, D. L., \& Novak, T. P. (1998). Bridging the racial divide on the Internet. Science, 280(5362), 390-391.

IBM. (2014). IBM SPSS software. Retrieved from http://www01.ibm.com/software/analytics/spss/

Jain, A. K. (2010). Data clustering: 50 years beyond k-means. Pattern Recognition Letters, 31, 651-666. doi:10.1016/j.patrec.2009.09.011

Jarque, C. M., \& Bera, A. K. (1980). Efficient tests for normality, homoscedasticity and serial independence of regression residuals. Economics Letters, 6(3), 255-259. doi:10.1016/0165-1765(80)90024-5

Korupp, S. E., \& Szydlik, M. (2005). Causes and trends of the digital divide. European Sociological Review, 21(4), 409-422. doi:10.1093/esr/jci030

Kvasny, L., \& Keil, M. (2006). The challenges of redressing the digital divide: a tale of two US cities. Information Systems Journal, 16(1), 22-53. doi:10.1111/j.13652575.2006.00207.x

Liu, M., \& San, G. (2006). Social learning and digital divides: A case study of Internet technology diffusion. Kyklos, 59(2), 307-321. doi:10.1111/j.14676435.2006.00329.x

Longley, P. A., Goodchild, M. F., Maguire, D. J., \& Rhind, D. W. (2011). Geographic information systems \& science (Third ed.). Hoboken, New Jersey: John Wiley \& Sons, Inc.

Lyon, J. D., \& Tsai, C.-L. (1996). A comparison of tests for heteroscedasticity. Journal of the Royal Statistical Society. Series D (The Statistician), 45(3), 337-349.

Retrieved from http://www.jstor.org/stable/2988471

Matthews, S. A., \& Yang, T.-C. (2012). Mapping the results of local statistics: Using geographically weighted regression. DEMOGRAPHIC RESEARCH, 26(6), 151166. doi:10.4054/DemRes.2012.26.6

Mennis, J. (2006). Mapping the results of geographically weighted regression. The Cartographic Journal, 43(2), 171-179. Retrieved from http://astro.temple.edu/ jmennis/pubs/mennis_cj06.pdf

National Center for Education Statistics. (2009). Common core of data (CCD) - Local education agency (school district) finance survey (F-33) data. Retrieved February 4, 2014, from http://nces.ed.gov/ccd/f33agency.asp

National Telecommunications and Information Administration. (2000). Falling through the net: Toward digital inclusion. Washington, DC: US Department of Commerce. Retrieved from http://www.ntia.doc.gov/files/ntia/publications/fttn00.pdf

National Telecommunications and Information Administration. (2011). Exploring the digital nation computer and Internet use at home. Washington, DC: National Telecommunications and Information Administration. Retrieved from http://www.ntia.doc.gov/files/ntia/publications/exploring_the_digital_nation_com puter_and_internet_use_at_home_11092011.pdf 
National Telecommunications and Information Administration. (2012). Download data National broadband map. Retrieved January 15, 2014, from http://www.broadbandmap.gov/data-download

Nishida, T., Pick, J. B., \& Sarkar, A. (2012). Spatial and multivariate analysis of Japan's prefectural digital divide. AMCIS 2012 Proceedings. Retrieved from http://aisel.aisnet.org/amcis2012/proceedings/DecisionSupport/38

Onyeiwu, S. (2002). Inter-country variations in digital technology in Africa: Evidence, determinants, and policy implications. WIDER Discussion Papers // World Institute for Development Economics (UNU-WIDER), No. 2002/72, ISBN 9291902691.

Organisation for Economic Co-operation and Development. (2000). Learning to bridge the digital divide. Schooling for Tomorrow, OECD Publishing. doi:10.1787/19900716

Organisation for Economic Co-operation and Development. (2001). Understanding the digital divide. Organisation for Economic Co-operation and Development.

O'Sullivan, D., \& Unwin, D. J. (2010). Geographic information analysis (Second ed.). Hoboken, New Jersey: John Wiley \& Sons, Inc.

Pick, J. B., \& Azari, R. (2008). Global digital divide: Influence of socioeconomic, governmental, and accessibility factors on information technology. Information Technology for Development, 14(2), 91-115. doi:10.1002/itdj.20095

Pick, J. B., \& Azari, R. (2011). A global model of technological utilization based on governmental, business-investment, social, and economic factors. Journal of Management Information Systems, 28(1), 49-83. doi:0.2753/MIS07421222280103

Pick, J. B., \& Nishida, T. (2014). Digital divides in the world and its regions: A spatial and multivariate analysis of technological utilization. Technological Forecasting and Social Change. doi:10.1016/j.techfore.2013.12.026

Pick, J. B., Nishida, T., \& Sarkar, A. (2013). Broadband utilization in the Indian states: Socioeconomic correlates and geographic aspects. In J. Choudrie, \& C. Middleton, Management of Broadband Technology Innovation (pp. 269-296). Oxford, England: Routledge.

Pick, J. B., Nishida, T., \& Zhang, X. (2013). Determinants of China's technology availability and utilization 2006-2009: A spatial analysis. The Information Society: An International Journal, 29(1), 26-48. doi:10.1080/01972243.2012.739266

Pick, J., Sarkar, A., \& Johnson, J. (2014). Information technology availability and use in the United States: A multivariate and geospatial analysis by state. Proceedings of 47th Hawaiian International Conference on Information System Sciences (pp. 3317 - 3326). Waikoloa, HI: IEEE. doi:10.1109/HICSS.2014.411

Python Software Foundation. (2014). Welcome to python.org. Retrieved from https://www.python.org/

Rosenshein, L., Scott, L., \& Pratt, M. (2011, Winter). Finding a meaningful model. ArcUser Online, pp. 40-45. Retrieved July 2, 2014, from http://www.esri.com/news/arcuser/0111/files/findmodel.pdf 
Stakhovych, S., \& Bijmolt, T. H. (2008). Specification of spatial models: A simulation study on weights matrices. Papers in Regional Science, 88(2). doi:10.1111/j.1435-5957.2008.00213.x

Tobler, W. R. (1970). A computer movie simulating urban growth in the Detroit region. Economic Geography, 46, 234-240. Retrieved from http://www.jstor.org/stable/143141

U.S. Census Bureau. (2007). Economic Survey. Retrieved February 10, 2014, from American FactFinder <http://factfinder2.census.gov>

U.S. Census Bureau. (2010a). Census urban lists record layouts; Percent urban and rural by county. Retrieved March 12, 2014, from http://www.census.gov/geo/reference/ua/ualists_layout.html

U.S. Census Bureau. (2010b). Decennial Census. Retrieved February 10, 2014, from American FactFinder $<$ http://factfinder2.census.gov $>$

U.S. Census Bureau. (2010c). TIGER/Line ${ }^{\circledR}$ shapefiles and TIGER/Line ${ }^{\circledR}$ files. Retrieved December 16, 2013, from http://www.census.gov/geo/mapsdata/data/tiger-line.html

U.S. Census Bureau. (2012). American Community Survey 5-year estimates. Retrieved February 10, 2014, from American FactFinder <http://factfinder2.census.gov>

Wheeler, D. (2008). Visualizing and diagnosing output from geographically weighted regression models. Retrieved July 3, 2014, from http://ww.thehealthproject.com/departments_centers/bios/techdocs/documents/20 08/Tech_Report_08-02.pdf

World Economic Forum. (2002). Annual report of the global digital divide initiative. Geneva: World Economic Forum. Retrieved from http://www.weforum.org/pdf/Initiatives/Digital_Divide_Report_2001_2002.pdf

Yates, D. J., Gulati, G. J., \& Weiss, J. W. (2011). Different paths to broadband access: The impact of governance and policy on broadband diffusion in the developed and developing worlds. 44th Hawaii International Conference on System Sciences (pp. 1 - 10). Kauai, HI: IEEE. doi:10.1109/HICSS.2011.165 



\section{Appendix A. Data Codebook}

Table A-1. Independent variable data codebook.

\begin{tabular}{|c|c|c|c|c|}
\hline Abbreviation & $\begin{array}{c}\text { Name of Independent } \\
\text { Variable }\end{array}$ & Source & $\begin{array}{l}\text { Year of } \\
\text { Data }\end{array}$ & Definition \\
\hline TOTPOP10R & Total County Population & CENDEC10_DP01 & 2010 & Total County Population \\
\hline POP0-19R & Population Age 0-19 & CENDEC10_DP01 & 2010 & Population Age 0-19 \\
\hline POP20-64R & Population Age 20-64 & CENDEC10_DP01 & 2010 & Population Age 20-64 \\
\hline POP65_UPR & Population Age 65+ & CENDEC10_DP01 & 2010 & Population Age 65+ \\
\hline POP16_UPR & Population Age 16+ & CENDEC10_DP01 & 2010 & Population Age 16+ \\
\hline YOUNGDEPR & Young Dependency Ratio & CENDEC10_DP01 & 2010 & POP0-19/POP20-64 \\
\hline TOTEMPLR & $\begin{array}{l}\text { Total Employment in All } \\
\text { Occupations }\end{array}$ & CENACS10_DP03 & $\begin{array}{l}2008- \\
2012\end{array}$ & $\begin{array}{l}\text { Estimate; EMPLOYMENT STATUS - In } \\
\text { labor force }\end{array}$ \\
\hline PSTSVCEXPR & $\begin{array}{l}\text { Professional, Scientific, \& } \\
\text { Tech Services Expenditures }\end{array}$ & CENECON07 & 2007 & $\begin{array}{l}\text { Professional, Scientific, and Technical } \\
\text { Services }\end{array}$ \\
\hline COLLEGER & $\begin{array}{l}\text { College Graduates or Higher, } \\
\text { Age } 18+\end{array}$ & CENACS10_DP02 & $\begin{array}{l}2008- \\
2012\end{array}$ & $\begin{array}{l}\text { Population Estimate of College Graduates } \\
\text { or Higher, Age } 18+\end{array}$ \\
\hline POP25_44R & Population Age 25 to 44 & CENDEC10_DP01 & 2010 & Population Age 25 to 44 \\
\hline PINC12R & Personal Income & BEA_CA1-3 & 2012 & Personal Income \\
\hline PINCPC12 & Personal Income Per Capita & BEA_CA1-3 & 2012 & Personal Income Per Capita \\
\hline WKAGEPOP & $\begin{array}{l}\text { Working Age Pop (Pop. 20- } \\
\text { 64)/Total Population }\end{array}$ & CENDEC10_DP01 & NA & РОР20-64/ТОТРОР \\
\hline SERVICER & Service Occupations & CENACS10_DP03 & $\begin{array}{l}2008- \\
2012\end{array}$ & Persons 16+ in Service Occupations \\
\hline CONSTRUCTR & $\begin{array}{l}\text { Construction Industry, } \\
\text { Employed Persons } 16+\end{array}$ & CENACS10_DP03 & $\begin{array}{l}2008- \\
2012\end{array}$ & $\begin{array}{l}\text { Construction Industry, Employed Persons } \\
16+\end{array}$ \\
\hline
\end{tabular}




\begin{tabular}{|c|c|c|c|c|}
\hline Abbreviation & $\begin{array}{l}\text { Name of Independent } \\
\text { Variable }\end{array}$ & Source & $\begin{array}{c}\text { Year of } \\
\text { Data }\end{array}$ & Definition \\
\hline INCOMER & Median Household Income & CENACS10_DP03 & $\begin{array}{l}2008- \\
2012\end{array}$ & $\begin{array}{l}\text { Estimate; INCOME AND BENEFITS (IN } \\
2010 \text { INFLATION-ADJUSTED } \\
\text { DOLLARS) - Median household income } \\
\text { (dollars) }\end{array}$ \\
\hline FORLANGR & $\begin{array}{l}\text { Language other than English } \\
\text { Spoken at Home, Persons 5+ }\end{array}$ & CENACS10_DP02 & $\begin{array}{l}2008- \\
2012\end{array}$ & $\begin{array}{l}\text { Language other than English Spoken at } \\
\text { Home, Persons } 5+\end{array}$ \\
\hline ASIANR & Asian Population & CENDEC10_DP01 & 2010 & $\begin{array}{l}\text { Number; RACE - Race alone or in } \\
\text { combination with one or more other races: } \\
\text { [4] - Asian }\end{array}$ \\
\hline BLACKR & Black Population & CENDEC10_DP01 & 2010 & $\begin{array}{l}\text { Number; RACE - Race alone or in } \\
\text { combination with one or more other races: } \\
\text { [4] - Black or African American }\end{array}$ \\
\hline HISPANICR & Hispanic/Latino Population & CENDEC10_DP01 & 2010 & $\begin{array}{l}\text { Number; HISPANIC OR LATINO - Total } \\
\text { population }\end{array}$ \\
\hline PUBLISHR & $\begin{array}{l}\text { Newspaper, Periodical, } \\
\text { Book, and Directory } \\
\text { Publishers }\end{array}$ & CENECON07 & 2007 & Value of Annual Sales Revenue (\$1,000s) \\
\hline PUBNEWSPERR & $\begin{array}{l}\text { Newspaper and Periodical } \\
\text { Publishers }\end{array}$ & CENECON07 & 2007 & Value of Annual Sales Revenue (\$1,000s) \\
\hline PUBBOOKR & Book Publishers & CENECON07 & 2007 & Value of Annual Sales Revenue ( $\$ 1,000 \mathrm{~s})$ \\
\hline URBAN & Urban Population & CENDEC10_DP01 & 2010 & Urban Population \\
\hline LGOVEDEXPR & $\begin{array}{l}\text { Local Govt Education } \\
\text { Expenditures }\end{array}$ & NCES_F33 & 2009 & $\begin{array}{l}\text { Total Expenditures (see variable } \\
\text { definition document for more } \\
\text { information) }\end{array}$ \\
\hline PSTSVCEMPR & $\begin{array}{l}\text { Professional, Scientific, and } \\
\text { Tech Services Employees }\end{array}$ & CENECON07 & 2007 & $\begin{array}{l}\text { Number of Professional, Scientific, and } \\
\text { Technical Services Employees }\end{array}$ \\
\hline
\end{tabular}


Table A-2. Dependent Variable Codebook

\begin{tabular}{|c|c|c|c|c|}
\hline Abbreviation & Name of Dependent Variable & Source & $\begin{array}{l}\text { Year of } \\
\text { Data }\end{array}$ & Definition \\
\hline TOTHHOLDSR & Total Households & CENDEC10_DP01 & 2010 & $\begin{array}{l}\text { Number; HOUSEHOLDS BY TYPE - } \\
\text { Total households }\end{array}$ \\
\hline BRDBNDHH & $\begin{array}{l}\text { Households with access to } \\
\text { broadband }\end{array}$ & NTIA_SBI_Analyze & 2012 & $\begin{array}{l}\text { \% of HHU/POP with access to any } \\
\text { broadband technology (excluding } \\
\text { satellite) }\end{array}$ \\
\hline WIRELNEHH & $\begin{array}{l}\text { Households with access to } \\
\text { wireline technology }\end{array}$ & NTIA_SBI_Analyze & 2012 & $\begin{array}{l}\% \text { of HHU/POP with access to any } \\
\text { wireline technology }\end{array}$ \\
\hline DSLHH & $\begin{array}{l}\text { Households with access to DSL, } \\
\text { any }\end{array}$ & NTIA_SBI_Analyze & 2012 & $\begin{array}{l}\text { \% of HHU/POP with access to any DSL } \\
\text { technology }\end{array}$ \\
\hline CABLEHH & $\begin{array}{l}\text { Households with access to cable, } \\
\text { any }\end{array}$ & NTIA_SBI_Analyze & 2012 & $\begin{array}{l}\% \text { of } \mathrm{HHU} / \mathrm{POP} \text { with access to any Cable } \\
\text { technology }\end{array}$ \\
\hline FIBERHH & Households with access to Fiber & NTIA_SBI_Analyze & 2012 & $\begin{array}{l}\% \text { of HHU/POP with access to Fiber } \\
\text { technology }\end{array}$ \\
\hline WIRELESSHH & $\begin{array}{l}\text { Households with access to } \\
\text { wireless, any }\end{array}$ & NTIA_SBI_Analyze & 2012 & $\begin{array}{l}\% \text { of HHU/POP with access to any } \\
\text { wireless technology (excluding satellite) }\end{array}$ \\
\hline SATELLITEHH & $\begin{array}{l}\text { Households with access to } \\
\text { satellite }\end{array}$ & NTIA_SBI_Analyze & 2012 & $\begin{array}{l}\% \text { of HHU/POP with access to Satellite } \\
\text { technology (of the States that submitted } \\
\text { Satellite data) }\end{array}$ \\
\hline MOBILEWLHH & $\begin{array}{l}\text { Households with access to mobile } \\
\text { wireless }\end{array}$ & NTIA_SBI_Analyze & 2012 & $\begin{array}{l}\% \text { of HHU/POP with access to Mobile } \\
\text { Wireless (Licensed) technology }\end{array}$ \\
\hline RESFIX200 & $\begin{array}{l}\text { Residential fixed connections } \\
\text { over } 200 \mathrm{kbps}\end{array}$ & FCC_477 & 2012 & $\begin{array}{l}\text { Residential fixed connection over } 200 \\
\text { kbps in at least one direction per } 1000 \\
\text { households }\end{array}$ \\
\hline RSFX200BTP & $\begin{array}{l}\text { Residential fixed connections } \\
\text { over } 200 \text { kbps, BTOP }\end{array}$ & FCC_477 & 2012 & $\begin{array}{l}\text { Residential fixed connection over } 200 \\
\text { kbps in at least one direction per } 1000 \\
\text { households, BTOP/BIP Definition }\end{array}$ \\
\hline
\end{tabular}




\begin{tabular}{|c|c|c|c|c|}
\hline Abbreviation & Name of Dependent Variable & Source & $\begin{array}{l}\text { Year of } \\
\text { Data }\end{array}$ & Definition \\
\hline NUMFIXPROV & $\begin{array}{l}\text { Number of providers of fixed } \\
\text { connections over } 200 \mathrm{kbps}\end{array}$ & FCC_477 & 2012 & $\begin{array}{l}\text { Providers of fixed connection over } 200 \\
\text { kbps in at least one direction }\end{array}$ \\
\hline NMRESPR200 & $\begin{array}{l}\text { Number of providers of } \\
\text { residential fixed connections over } \\
200 \mathrm{kbps}\end{array}$ & FCC_477 & 2012 & $\begin{array}{l}\text { Providers of residential fixed connections } \\
\text { over } 200 \mathrm{kbps} \text { in at least one direction }\end{array}$ \\
\hline NMRESPRO3M & $\begin{array}{l}\text { Number of providers of } \\
\text { residential fixed connections over } \\
3 \text { mbps }\end{array}$ & FCC_477 & 2012 & $\begin{array}{l}\text { Providers of residential fixed connections } \\
\text { at least } 3 \text { mbps downstream and at least } \\
768 \text { kbps upstream }\end{array}$ \\
\hline NUMPROVMOB & $\begin{array}{l}\text { Number of providers for mobile } \\
\text { connections }\end{array}$ & FCC_477 & 2012 & Providers of Mobile Connections \\
\hline EREADERR & $\begin{array}{l}\text { Own any e-reader/tablet (such as } \\
\text { Kindle or iPad) }\end{array}$ & BA & $\begin{array}{l}2010- \\
2012\end{array}$ & \\
\hline COMPINHHR & HH owns a computer & BA & $\begin{array}{c}2010- \\
2012\end{array}$ & \\
\hline DIALUPINTR & $\begin{array}{l}\text { Connection to Internet at home: } \\
\text { dial-up modem }\end{array}$ & BA & $\begin{array}{l}2010- \\
2012\end{array}$ & \\
\hline CABLEINTR & $\begin{array}{l}\text { Connection to Internet at home: } \\
\text { cable modem }\end{array}$ & BA & $\begin{array}{l}2010- \\
2012\end{array}$ & \\
\hline DSLINTR & $\begin{array}{l}\text { Connection to Internet at home: } \\
\text { DSL }\end{array}$ & BA & $\begin{array}{l}2010- \\
2012\end{array}$ & \\
\hline FIBERINTR & $\begin{array}{l}\text { Connection to Internet at home: } \\
\text { fiber optic }\end{array}$ & BA & $\begin{array}{c}2010- \\
2012\end{array}$ & \\
\hline WIRELESSINTR & $\begin{array}{l}\text { Connection to Internet at home: } \\
\text { wireless }\end{array}$ & BA & $\begin{array}{l}2010- \\
2012\end{array}$ & \\
\hline HSPEEDINTR & $\begin{array}{l}\text { Connection to Internet at home: } \\
\text { any high speed }\end{array}$ & BA & $\begin{array}{l}2010- \\
2012\end{array}$ & \\
\hline
\end{tabular}




\begin{tabular}{|c|c|c|c|c|}
\hline Abbreviation & Name of Dependent Variable & Source & $\begin{array}{l}\text { Year of } \\
\text { Data }\end{array}$ & Definition \\
\hline INTUSE30R & Any Internet usage in last 30 days & BA & $\begin{array}{l}2010- \\
2012\end{array}$ & \\
\hline INTATHOMER & Used Internet/30 days: at home & BA & $\begin{array}{l}2010- \\
2012\end{array}$ & \\
\hline INTATWORKR & Used Internet/30 days: at work & BA & $\begin{array}{l}2010- \\
2012\end{array}$ & \\
\hline INTATSCHLR & $\begin{array}{l}\text { Used Internet/30 days: at } \\
\text { school/library }\end{array}$ & BA & $\begin{array}{l}2010- \\
2012\end{array}$ & \\
\hline EMAIL30R & Internet last 30 days: used email & BA & $\begin{array}{l}2010- \\
2012\end{array}$ & \\
\hline IM30R & Internet last 30 days: used IM & BA & $\begin{array}{l}2010- \\
2012\end{array}$ & \\
\hline PURCH30R & $\begin{array}{l}\text { Internet last } 30 \text { days: made } \\
\text { personal purchase }\end{array}$ & BA & $\begin{array}{l}2010- \\
2012\end{array}$ & \\
\hline BILLS30R & $\begin{array}{l}\text { Internet last } 30 \text { days: paid bills } \\
\text { online }\end{array}$ & BA & $\begin{array}{l}2010- \\
2012\end{array}$ & \\
\hline EMPLOY30R & $\begin{array}{l}\text { Internet last } 30 \text { days: looked for } \\
\text { employment }\end{array}$ & BA & $\begin{array}{l}2010- \\
2012\end{array}$ & \\
\hline FINANCE30R & $\begin{array}{l}\text { Internet last } 30 \text { days: obtained } \\
\text { financial info }\end{array}$ & BA & $\begin{array}{l}2010- \\
2012\end{array}$ & \\
\hline MEDICAL30R & $\begin{array}{l}\text { Internet last } 30 \text { days: obtained } \\
\text { medical nfo }\end{array}$ & BA & $\begin{array}{l}2010- \\
2012\end{array}$ & \\
\hline NEWS30R & $\begin{array}{l}\text { Internet last } 30 \text { days: obtained } \\
\text { latest news }\end{array}$ & BA & $\begin{array}{l}2010- \\
2012\end{array}$ & \\
\hline BLOG30R & $\begin{array}{l}\text { Internet last } 30 \text { days: visited } \\
\text { online blog }\end{array}$ & BA & $\begin{array}{l}2010- \\
2012\end{array}$ & \\
\hline VIDAUTH30R & $\begin{array}{l}\text { Internet last } 30 \text { days: added video } \\
\text { to website }\end{array}$ & BA & $\begin{array}{l}2010- \\
2012\end{array}$ & \\
\hline
\end{tabular}




\begin{tabular}{|c|c|c|c|c|}
\hline Abbreviation & Name of Dependent Variable & Source & $\begin{array}{l}\text { Year of } \\
\text { Data }\end{array}$ & Definition \\
\hline MOVIE30R & $\begin{array}{l}\text { Internet last } 30 \text { days: watched } \\
\text { movie online }\end{array}$ & BA & $\begin{array}{l}2010- \\
2012\end{array}$ & \\
\hline TVOL30R & $\begin{array}{l}\text { Internet last } 30 \text { days: watched TV } \\
\text { program online }\end{array}$ & BA & $\begin{array}{l}2010- \\
2012\end{array}$ & \\
\hline FACEBOOKR & $\begin{array}{l}\text { Visited website in last } 30 \text { days: } \\
\text { facebook.com }\end{array}$ & BA & $\begin{array}{l}2010- \\
2012\end{array}$ & \\
\hline LINKEDINR & $\begin{array}{l}\text { Visited website in last } 30 \text { days: } \\
\text { LinkedIn.com }\end{array}$ & BA & $\begin{array}{l}2010- \\
2012\end{array}$ & \\
\hline TWITTERR & $\begin{array}{l}\text { Visited website in last } 30 \text { days: } \\
\text { twitter.com }\end{array}$ & BA & $\begin{array}{l}2010- \\
2012\end{array}$ & \\
\hline YOUTUBE30R & $\begin{array}{l}\text { Visited website in last } 30 \text { days: } \\
\text { YouTube.com }\end{array}$ & BA & $\begin{array}{l}2010- \\
2012\end{array}$ & \\
\hline GOOGLE30R & $\begin{array}{l}\text { Used website/search engine/30 } \\
\text { days: google.com }\end{array}$ & BA & $\begin{array}{l}2010- \\
2012\end{array}$ & \\
\hline BANK12R & $\begin{array}{l}\text { Did banking online in last } 12 \\
\text { months }\end{array}$ & BA & $\begin{array}{c}2010- \\
2012\end{array}$ & \\
\hline SMRTPHNER & Have a smartphone & BA & $\begin{array}{l}2010- \\
2012\end{array}$ & \\
\hline WEATHER30R & $\begin{array}{l}\text { Used cell phone last mo: for } \\
\text { weather }\end{array}$ & BA & $\begin{array}{l}2010- \\
2012\end{array}$ & \\
\hline MAP30R & $\begin{array}{l}\text { Used cell phone last mo: for } \\
\text { map/directions }\end{array}$ & BA & $\begin{array}{l}2010- \\
2012\end{array}$ & \\
\hline LANDLNEHHR & HH has a landline telephone & BA & $\begin{array}{c}2010- \\
2012\end{array}$ & \\
\hline CLLONLYHHR & $\begin{array}{l}\text { HH has cell phone only (no } \\
\text { landline telephone) }\end{array}$ & BA & $\begin{array}{l}2010- \\
2012\end{array}$ & \\
\hline LNDONLYHHR & $\begin{array}{l}\text { HH has landline telephone only } \\
\text { (no cell phone) }\end{array}$ & BA & $\begin{array}{l}2010- \\
2012\end{array}$ & \\
\hline
\end{tabular}




\begin{tabular}{|c|c|c|c|c|}
\hline Abbreviation & Name of Dependent Variable & Source & $\begin{array}{l}\text { Year of } \\
\text { Data }\end{array}$ & Definition \\
\hline CELLINHHR & Any cell phone in household & BA & $\begin{array}{l}2010- \\
2012\end{array}$ & \\
\hline AMZ12R & $\begin{array}{l}\text { Ordered from website last } 12 \text { mo: } \\
\text { amazon.com }\end{array}$ & BA & $\begin{array}{l}2010- \\
2012\end{array}$ & \\
\hline EBAY12R & $\begin{array}{l}\text { Ordered from website last } 12 \text { mo: } \\
\text { ebay.com }\end{array}$ & BA & $\begin{array}{l}2010- \\
2012\end{array}$ & \\
\hline ITUNE12R & $\begin{array}{l}\text { Ordered from website last } 12 \text { mo: } \\
\text { iTunes.com }\end{array}$ & BA & $\begin{array}{l}2010- \\
2012\end{array}$ & \\
\hline WALMART12R & $\begin{array}{l}\text { Ordered from website last } 12 \text { mo: } \\
\text { walmart.com }\end{array}$ & BA & $\begin{array}{l}2010- \\
2012\end{array}$ & \\
\hline
\end{tabular}


Table A-3. List of source abbreviations

\begin{tabular}{|c|c|c|}
\hline Source & Abbreviation & Detailed Reference \\
\hline $\begin{array}{l}\text { US Census Bureau, DEC } \\
\text { 2010, Table DP-01 }\end{array}$ & CENDEC10_DP01 & $\begin{array}{l}\text { US Census Bureau, Decennial Census 2010, } \\
\text { Summary File } 1\end{array}$ \\
\hline $\begin{array}{l}\text { US Census Bureau, ACS } \\
\text { 2012, Table DP-02 }\end{array}$ & CENACS12_DP02 & $\begin{array}{l}\text { US Census Bureau, American Community } \\
\text { Survey 2012, 5-year estimates, Table DP-02 }\end{array}$ \\
\hline $\begin{array}{l}\text { US Census Bureau, ACS } \\
\text { 2012, Table DP-03 }\end{array}$ & CENACS12_DP03 & $\begin{array}{l}\text { US Census Bureau, American Community } \\
\text { Survey 2012, 5-year estimates, Table DP-03 }\end{array}$ \\
\hline $\begin{array}{l}\text { US Census Bureau, ACS } \\
\text { 2012, Table DP-04 }\end{array}$ & CENACS12_DP04 & $\begin{array}{l}\text { US Census Bureau, American Community } \\
\text { Survey 2012, 5-year estimates, Table DP-04 }\end{array}$ \\
\hline $\begin{array}{l}\text { US Census Bureau, ACS } \\
\text { 2012, Table DP-05 }\end{array}$ & CENACS12_DP05 & $\begin{array}{l}\text { US Census Bureau, American Community } \\
\text { Survey 2012, 5-year estimates, Table DP-05 }\end{array}$ \\
\hline $\begin{array}{l}\text { Federal Communications } \\
\text { Commission, Form } 477\end{array}$ & FCC_477 & $\begin{array}{l}\text { Federal Communications Commission, } \\
\text { Form 477, Local Telephone Competition } \\
\text { and Broadband Deployment }\end{array}$ \\
\hline $\begin{array}{l}\text { Bureau of Economic } \\
\text { Analysis, CA1-3 }\end{array}$ & BEA_CA1-3 & $\begin{array}{l}\text { US Dept of Commerce, Bureau of Economic } \\
\text { Analysis, CA1-3, Personal Income, Per } \\
\text { Capita Income }\end{array}$ \\
\hline $\begin{array}{l}\text { Bureau of Economic } \\
\text { Analysis, CA04 }\end{array}$ & BEA_CA04 & $\begin{array}{l}\text { US Dept of Commerce, Bureau of Economic } \\
\text { Analysis, CA04, Personal Income Summary }\end{array}$ \\
\hline $\begin{array}{l}\text { US Census Bureau, } \\
\text { Economic Census } 2007\end{array}$ & CENECON07 & US Census Bureau, Economic Census 2007 \\
\hline $\begin{array}{l}\text { US Department of } \\
\text { Commerce, NTIA, State } \\
\text { Broadband Initiative, } \\
\text { Analyze Table }\end{array}$ & NTIA_SBI_Analyze & $\begin{array}{l}\text { US Dept of Commerce, National } \\
\text { Telecommunications and Information } \\
\text { Administration, State Broadband Initiative } \\
\text { (CSV format December 31, 2012). }\end{array}$ \\
\hline $\begin{array}{l}\text { National Center for } \\
\text { Education Statistics, F-33 }\end{array}$ & NCES_F33 & $\begin{array}{l}\text { US Census Bureau, Governments Division, } \\
\text { Local Education Agency (School District) } \\
\text { Finance Survey (F-33), National Center for } \\
\text { Education Statistics, Common Core of Data }\end{array}$ \\
\hline $\begin{array}{l}\text { Esri Business Analyst } \\
\text { Data }\end{array}$ & BA & $\begin{array}{l}\text { Esri Business Analyst Data, GfK MRI } \\
\text { DoubleBase Survey } 2012\end{array}$ \\
\hline
\end{tabular}




\section{Appendix B. Pearson Correlation Coefficient Matrices}

Independent Variables

\begin{tabular}{|c|c|c|c|c|c|c|c|}
\hline & TOTPOP10R & POP0_19R & POP20_65UPR & POP65UPR & POP16_UPR & POP25_44R & YOUNGDEPR \\
\hline TOTPOP10R & 1 & & & & & & \\
\hline POP0-19R & $-0.040 *$ & 1 & & & & & \\
\hline POP20-64R & $0.181 * * *$ & $-0.255^{* * *}$ & 1 & & & & \\
\hline POP65_UPR & $-0.112 * * *$ & $-0.632 * * *$ & $-0.588 * * *$ & 1 & & & \\
\hline POP16_UPR & $0.043^{*}$ & $-0.950 * * *$ & $0.298 * * *$ & $0.555^{* * *}$ & 1 & & \\
\hline POP25_44R & $0.226 * * *$ & $0.283 * * *$ & $0.694 * * *$ & $-0.792 * * *$ & $-0.312 * * *$ & 1 & \\
\hline YOUNGDEPR & $-0.087 * * *$ & $0.941 * * *$ & $-0.554 * * *$ & $-0.343 * * *$ & $-0.915 * * *$ & 0.013 & 1 \\
\hline TOTEMPLR & $0.096 * * *$ & $0.291 * * *$ & $0.122 * * *$ & $-0.341 * * *$ & $-0.303 * * *$ & $0.187 * * *$ & $0.205 * * *$ \\
\hline PSTSVCEXPR & $0.558 * * *$ & $-0.074 * *$ & $0.378^{* * *}$ & $-0.242 * * *$ & $0.073^{* *}$ & $0.405^{* * *}$ & $-0.183^{* * *}$ \\
\hline COLLEGER & $0.241^{* * *}$ & $-0.167 * * *$ & $0.348^{* * *}$ & $-0.139 * * *$ & $0.185^{* * *}$ & $0.154 * * *$ & $-0.262 * * *$ \\
\hline PINC12R & $-0.036^{*}$ & $-0.197 * * *$ & $-0.041^{*}$ & $0.198 * * *$ & $0.163 * * *$ & $-0.211^{* * *}$ & $-0.124 * * *$ \\
\hline PINCPC12 & $0.229 * * *$ & $-0.087 * * *$ & 0.033 & $0.046 * *$ & $0.050 * *$ & $-0.036 *$ & $-0.085 * * *$ \\
\hline WKAGEPOP & $0.181 * * *$ & $-0.255 * * *$ & $1 * * *$ & $-0.588 * * *$ & $0.298 * * *$ & $0.694 * * *$ & $-0.554 * * *$ \\
\hline SERVICER & $0.070 * * *$ & 0.028 & $0.083 * * *$ & $-0.090 * * *$ & 0.006 & $0.035^{*}$ & 0.000 \\
\hline CONSTRUCTR & $-0.083^{* * *}$ & -0.004 & -0.009 & 0.011 & $-0.061 * * *$ & -0.034 & -0.001 \\
\hline INCOMER & $0.140^{* * *}$ & $0.111^{* * *}$ & $0.292^{* * *}$ & $-0.327 * * *$ & $-0.141 * * *$ & $0.295 * * *$ & -0.011 \\
\hline FORLANGR & $0.198 * * *$ & $0.341^{* * *}$ & 0.012 & $-0.295 * * *$ & $-0.331 * * *$ & $0.261^{* * *}$ & $0.308^{* * *}$ \\
\hline ASIANR & $0.276^{* * *}$ & 0.023 & $0.334 * * *$ & $-0.287 * * *$ & -0.004 & $0.331^{* * *}$ & $-0.086 * * *$ \\
\hline BLACKR & $0.103^{* * *}$ & $0.074 * * *$ & $0.221^{* * *}$ & $-0.239 * * *$ & $-0.039 *$ & $0.258 * * *$ & -0.020 \\
\hline HISPANICR & $0.084^{* * *}$ & $0.313^{* * *}$ & $-0.065 * * *$ & $-0.210 * * *$ & $-0.313^{* * *}$ & $0.184^{* * *}$ & $0.301^{* * *}$ \\
\hline PUBLISHR & $0.870 * * *$ & $-0.260 * * *$ & $0.293 * * *$ & -0.024 & $0.227 * *$ & $0.283^{* * *}$ & $-0.296 * * *$ \\
\hline PUBNEWSPRR & $0.908^{* * *}$ & $-0.371^{* * *}$ & $0.331^{* * *}$ & 0.072 & $0.363^{* * *}$ & $0.279 * *$ & $-0.365 * * *$ \\
\hline PUBBOOKR & 0.223 & -0.138 & 0.118 & 0.081 & 0.096 & 0.150 & -0.103 \\
\hline URBAN & $0.221^{* * *}$ & $0.254 * * *$ & $0.320^{* * *}$ & $-0.468 * * *$ & $-0.195 * * *$ & $0.473 * * *$ & $0.089 * * *$ \\
\hline LGOVEDEXPR & 0.022 & $0.162 * * *$ & $-0.078 * * *$ & $-0.073^{* * *}$ & $-0.163^{* * *}$ & $-0.037 *$ & $0.172 * * *$ \\
\hline PSTSVCEMPR & $0.444^{* * *}$ & $-0.068 * *$ & $0.376^{* * *}$ & $-0.244 * * *$ & $0.077 * * *$ & $0.380 * * *$ & $-0.183^{* * *}$ \\
\hline
\end{tabular}




\begin{tabular}{|c|c|c|c|c|c|c|c|c|}
\hline & TOTEMPLR & PSTSVCEXPR & COLLEGER & PINC12R & PINCPC12 & WKAGEPOP & SERVICER & CONSTRUCTR \\
\hline \multicolumn{9}{|l|}{ TOTPOP10R } \\
\hline \multicolumn{9}{|l|}{ POP0-19R } \\
\hline \multicolumn{9}{|l|}{ POP20-64R } \\
\hline \multicolumn{9}{|l|}{ POP65_UPR } \\
\hline \multicolumn{9}{|l|}{ POP16_UPR } \\
\hline \multicolumn{9}{|l|}{ POP25_44R } \\
\hline \multicolumn{9}{|l|}{ YOUNGDEPR } \\
\hline TOTEMPLR & 1 & & & & & & & \\
\hline PSTSVCEXPR & $0.303 * * *$ & 1 & & & & & & \\
\hline COLLEGER & $0.5222 * * *$ & $0.622 * * *$ & 1 & & & & & \\
\hline PINC12R & $0.100 * * *$ & $-0.136 * * *$ & 0.024 & 1 & & & & \\
\hline PINCPC12 & $0.563^{* * *}$ & $0.473^{* * *}$ & $0.627 * * *$ & $0.194^{* * *}$ & 1 & & & \\
\hline WKAGEPOP & $0.122^{* * *}$ & $0.378 * * *$ & $0.348 * * *$ & $-0.041^{*}$ & 0.033 & 1 & & \\
\hline SERVICER & $0.390 * * *$ & $0.090 * * *$ & $0.255^{* * *}$ & -0.014 & $0.210 * * *$ & $0.083 * * *$ & 1 & \\
\hline CONSTRUCTR & $0.307 * * *$ & $-0.085 * * *$ & $0.122 * * *$ & $0.114 * * *$ & $0.136 * * *$ & -0.009 & $0.094 * * *$ & 1 \\
\hline INCOMER & $0.666^{* * *}$ & $0.444 * * *$ & $0.698 * * *$ & -0.002 & $0.654 * * *$ & $0.292^{* * *}$ & $0.158 * * *$ & $0.246 * * *$ \\
\hline FORLANGR & $0.123^{* * *}$ & $0.232 * * *$ & $0.119 * * *$ & -0.008 & $0.130 * * *$ & 0.012 & $0.198 * * *$ & -0.004 \\
\hline ASIANR & $0.281^{* * *}$ & $0.430 * * *$ & $0.436 * * *$ & -0.017 & $0.269 * * *$ & $0.334^{* * *}$ & $0.132 * * *$ & $-0.073 * * *$ \\
\hline BLACKR & $-0.241 * * *$ & $0.111^{* * *}$ & $-0.108 * * *$ & $-0.104 * * *$ & $-0.203 * * *$ & $0.221 * * *$ & $-0.110 * * *$ & $-0.228 * * *$ \\
\hline HISPANICR & 0.025 & $0.073 * *$ & -0.019 & 0.019 & 0.032 & $-0.065 * * *$ & $0.172 * * *$ & 0.027 \\
\hline PUBLISHR & $0.149 *$ & $0.614^{* * *}$ & $0.340 * * *$ & -0.031 & $0.558 * * *$ & $0.293 * * *$ & -0.124 & $-0.268 * * *$ \\
\hline PUBNEWSPRR & 0.063 & $0.604^{* * *}$ & $0.332 * *$ & 0.051 & $0.547 * * *$ & $0.331^{* *}$ & -0.144 & $-0.357 * * *$ \\
\hline PUBBOOKR & 0.149 & 0.196 & 0.090 & 0.452 & 0.304 & 0.118 & 0.318 & 0.151 \\
\hline URBAN & $0.347 * * *$ & $0.419 * * *$ & $0.434 * * *$ & $-0.251 * * *$ & $0.203 * * *$ & $0.320 * * *$ & $0.265 * * *$ & $-0.169 * * *$ \\
\hline LGOVEDEXPR & $0.132 * * *$ & $0.046^{*}$ & 0.023 & $0.362 * * *$ & $0.226 * * *$ & $-0.078 * * *$ & $0.087 * * *$ & $0.072 * * *$ \\
\hline PSTSVCEMPR & $0.346^{* * *}$ & $0.915 * * *$ & $0.652 * * *$ & $-0.148 * * *$ & $0.464 * * *$ & $0.376^{* * *}$ & $0.138 * * *$ & $-0.067 * *$ \\
\hline
\end{tabular}




\begin{tabular}{|c|c|c|c|c|c|c|c|c|}
\hline & INCOMER & FORLANGR & ASIANR & BLACKR & HISPANICR & PUBLISHR & PUBNEWSPRR & PUBBOOKR \\
\hline \multicolumn{9}{|l|}{ TOTPOP10R } \\
\hline \multicolumn{9}{|l|}{ POP0-19R } \\
\hline \multicolumn{9}{|l|}{ POP20-64R } \\
\hline \multicolumn{9}{|l|}{ POP65_UPR } \\
\hline \multicolumn{9}{|l|}{ POP16_UPR } \\
\hline \multicolumn{9}{|l|}{ POP25_44R } \\
\hline \multicolumn{9}{|l|}{ YOUNGDEPR } \\
\hline \multicolumn{9}{|l|}{ TOTEMPLR } \\
\hline \multicolumn{9}{|l|}{ PSTSVCEXPR } \\
\hline \multicolumn{9}{|l|}{ COLLEGER } \\
\hline \multicolumn{9}{|l|}{ PINC12R } \\
\hline \multicolumn{9}{|l|}{ PINCPC12 } \\
\hline \multicolumn{9}{|l|}{ WKAGEPOP } \\
\hline \multicolumn{9}{|l|}{ SERVICER } \\
\hline \multicolumn{9}{|l|}{ CONSTRUCTR } \\
\hline INCOMER & 1 & & & & & & & \\
\hline FORLANGR & $0.171^{* * *}$ & 1 & & & & & & \\
\hline ASIANR & $0.431 * * *$ & $0.349 * * *$ & 1 & & & & & \\
\hline BLACKR & $-0.225 * * *$ & $-0.083^{* * *}$ & 0.020 & 1 & & & & \\
\hline HISPANICR & $0.036 *$ & $0.899 * * *$ & $0.143 * * *$ & $-0.096 * * *$ & 1 & & & \\
\hline PUBLISHR & $0.146^{*}$ & 0.142 & $0.164^{*}$ & 0.120 & 0.023 & 1 & & \\
\hline PUBNEWSPRR & 0.056 & 0.067 & 0.102 & 0.100 & -0.025 & $0.985 * * *$ & 1 & \\
\hline PUBBOOKR & -0.053 & -0.033 & -0.158 & 0.060 & 0.026 & $0.783 * * *$ & 0.176 & 1 \\
\hline URBAN & $0.389 * * *$ & $0.351 * * *$ & $0.401 * * *$ & $0.129 * * *$ & $0.278 * * *$ & 0.110 & 0.037 & 0.038 \\
\hline LGOVEDEXPR & $0.153 * * *$ & $0.241 * * *$ & 0.014 & $-0.092 * * *$ & $0.213 * * *$ & $0.150^{*}$ & 0.144 & -0.256 \\
\hline PSTSVCEMPR & $0.458 * * *$ & $0.203^{* * *}$ & $0.420 * * *$ & $0.089 * * *$ & $0.048 *$ & $0.511^{* * *}$ & $0.489 * * *$ & -0.023 \\
\hline
\end{tabular}




\begin{tabular}{|c|c|c|c|}
\hline & URBAN & LGOVEDEXPR & PSTSVCEMPR \\
\hline \multicolumn{4}{|l|}{ TOTPOP10R } \\
\hline \multicolumn{4}{|l|}{ POP0-19R } \\
\hline \multicolumn{4}{|l|}{ POP20-64R } \\
\hline \multicolumn{4}{|l|}{ POP65_UPR } \\
\hline \multicolumn{4}{|l|}{ POP16_UPR } \\
\hline \multicolumn{4}{|l|}{ POP25_44R } \\
\hline \multicolumn{4}{|l|}{ YOUNGDEPR } \\
\hline \multicolumn{4}{|l|}{ TOTEMPLR } \\
\hline \multicolumn{4}{|l|}{ PSTSVCEXPR } \\
\hline \multicolumn{4}{|l|}{ COLLEGER } \\
\hline \multicolumn{4}{|l|}{ PINC12R } \\
\hline \multicolumn{4}{|l|}{ PINCPC12 } \\
\hline \multicolumn{4}{|l|}{ WKAGEPOP } \\
\hline \multicolumn{4}{|l|}{ SERVICER } \\
\hline \multicolumn{4}{|l|}{ CONSTRUCTR } \\
\hline \multicolumn{4}{|l|}{ INCOMER } \\
\hline \multicolumn{4}{|l|}{ FORLANGR } \\
\hline \multicolumn{4}{|l|}{ ASIANR } \\
\hline \multicolumn{4}{|l|}{ BLACKR } \\
\hline \multicolumn{4}{|l|}{ HISPANICR } \\
\hline \multicolumn{4}{|l|}{ PUBLISHR } \\
\hline \multicolumn{4}{|l|}{ PUBNEWSPRR } \\
\hline \multicolumn{4}{|l|}{ PUBBOOKR } \\
\hline URBAN & 1 & & \\
\hline LGOVEDEXPR & $-0.066^{* * *}$ & 1 & \\
\hline PSTSVCEMPR & $0.477 * * *$ & 0.040 & 1 \\
\hline
\end{tabular}


Dependent Variables

\begin{tabular}{|c|c|c|c|c|c|c|c|}
\hline & TOTHHOLDSR & BRDBNDHH & WIRELNEHH & DSLHH & CABLEHH & FIBERHH & WIRELSSHH \\
\hline TOTHHOLDSR & 1 & & & & & & \\
\hline BRDBNDHH & $0.036^{*}$ & 1 & & & & & \\
\hline WIRELNEHH & $0.103 * * *$ & $0.523 * * *$ & 1 & & & & \\
\hline DSLHH & $0.110 * * *$ & $0.383 * * *$ & $0.717 * * *$ & 1 & & & \\
\hline CABLEHH & $0.145 * * *$ & $0.278 * * *$ & $0.568 * * *$ & $0.434^{* * *}$ & 1 & & \\
\hline FIBERHH & $0.115 * * *$ & $0.110 * * *$ & $0.272 * * *$ & -0.030 & $0.057 * *$ & 1 & \\
\hline WIRELESSHH & $0.048 * *$ & $0.793 * * *$ & $0.360 * * *$ & $0.308 * * *$ & $0.300 * * *$ & $0.091 * * *$ & 1 \\
\hline MOBILEWLHH & $0.047 * * *$ & $0.744 * * *$ & $0.369 * * *$ & $0.305 * * *$ & $0.311 * * *$ & $0.093 * * *$ & $0.923 * * *$ \\
\hline RESFIX200 & $0.128 * * *$ & $0.160 * * *$ & $0.527 * * *$ & $0.382 * * *$ & $0.479 * * *$ & $0.259 * * *$ & $0.130 * * *$ \\
\hline RESFX200BTP & $0.144^{* * *}$ & $0.219 * * *$ & $0.567 * * *$ & $0.409 * * *$ & $0.512^{* * *}$ & $0.282 * * *$ & $0.192 * * *$ \\
\hline NUMFIXPROV & $0.283 * * *$ & $0.217 * * *$ & $0.378 * * *$ & $0.361 * * *$ & $0.600 * * *$ & $0.149 * * *$ & $0.288 * * *$ \\
\hline NMRESPR200 & $0.104^{* * *}$ & $0.214 * * *$ & $0.259 * * *$ & $0.260 * * *$ & $0.426 * * *$ & 0.030 & $0.290 * * *$ \\
\hline NMRESPRO3M & $0.087 * * *$ & $0.202 * * *$ & $0.308 * * *$ & $0.296 * * *$ & $0.464 * * *$ & $0.064 * * *$ & $0.257 * * *$ \\
\hline NUMPROVMOB & $0.111^{* * *}$ & $0.215 * * *$ & $0.293 * * *$ & $0.277 * * *$ & $0.440 * * *$ & 0.018 & $0.278 * * *$ \\
\hline EREADERR & $0.218 * * *$ & $0.100 * * *$ & $0.359 * * *$ & $0.340 * * *$ & $0.562^{* * *}$ & 0.133 & $0.128 * * *$ \\
\hline COMPINHHR & $0.104^{* * *}$ & $0.102 * * *$ & $0.360 * * *$ & $0.323 * * *$ & $0.489 * * *$ & $0.157 * * *$ & $0.156 * * *$ \\
\hline DIALUPINTR & $-0.203 * * *$ & $-0.144 * * *$ & $-0.414 * * *$ & $-0.361 * * *$ & $-0.620 * * *$ & $-0.166 * * *$ & $-0.232 * * *$ \\
\hline CABLEINTR & $0.180 * * *$ & $0.125 * * *$ & $0.426 * * *$ & $0.411^{* * *}$ & $0.673 * * *$ & $0.135 * * *$ & $0.195 * * *$ \\
\hline DSLINTR & $-0.198 * * *$ & $-0.068 * * *$ & $-0.218 * * *$ & $-0.242 * * *$ & $-0.490 * * *$ & -0.007 & $-0.116 * * *$ \\
\hline FIBERINTR & $0.199 * * *$ & $0.090 * * *$ & $0.358 * * *$ & $0.318^{* * *}$ & $0.549 * * *$ & $0.218^{* * *}$ & $0.149 * * *$ \\
\hline WRLSSINTR & $0.169 * * *$ & $0.129 * * *$ & $0.323 * * *$ & $0.221 * * *$ & $0.301 * * *$ & $0.252 * * *$ & $0.150 * * *$ \\
\hline HSPEEDINTR & $0.154 * * *$ & $0.128 * * *$ & $0.414^{* * *}$ & $0.362 * * *$ & $0.548 * * *$ & $0.204^{* * *}$ & $0.190 * * *$ \\
\hline INTUSE30R & $0.121 * * *$ & $0.123 * * *$ & $0.383 * * *$ & $0.334 * * *$ & $0.495 * * *$ & $0.192 * * *$ & $0.191 * * *$ \\
\hline INTATHOMER & $0.132 * * *$ & $0.119 * * *$ & $0.387 * * *$ & $0.339 * * *$ & $0.510 * * *$ & $0.194 * * *$ & $0.179 * * *$ \\
\hline INTATWORKR & $0.142^{* * *}$ & $0.149 * * *$ & $0.414^{* * *}$ & $0.354 * * *$ & $0.533^{* * *}$ & $0.206^{* * *}$ & $0.219 * * *$ \\
\hline INTATSCHLR & $0.110^{* * *}$ & $0.134 * * *$ & $0.338 * * *$ & $0.283 * * *$ & $0.447 * * *$ & $0.161^{* * *}$ & $0.198 * * *$ \\
\hline EMAIL30R & $0.137 * * *$ & $0.108 * * *$ & $0.381 * * *$ & $0.338 * * *$ & $0.508 * * *$ & $0.194^{* * *}$ & $0.162 * * *$ \\
\hline IM30R & $0.120 * * *$ & $0.166 * * *$ & $0.434 * * *$ & $0.373 * * *$ & $0.584 * * *$ & $0.188 * * *$ & $0.255^{* * *}$ \\
\hline PURCH30R & $0.165^{* * *}$ & $0.098 * * *$ & $0.363 * * *$ & $0.325 * * *$ & $0.498 * * *$ & $0.194 * * *$ & $0.148 * * *$ \\
\hline BILLS30R & $0.171^{* * *}$ & $0.126^{* * *}$ & $0.413^{* * *}$ & $0.369 * * *$ & $0.582 * * *$ & $0.184^{* * *}$ & $0.197 * * *$ \\
\hline
\end{tabular}




\begin{tabular}{|c|c|c|c|c|c|c|c|}
\hline & TOTHHOLDSR & BRDBNDHH & WIRELNEHH & DSLHH & CABLEHH & FIBERHH & WIRELSSHH \\
\hline EMPLOY30R & $0.178 * * *$ & $0.109 * * *$ & $0.368 * * *$ & $0.350^{* * *}$ & $0.586^{* * *}$ & $0.128^{* * * *}$ & $0.175^{* * *}$ \\
\hline FINANCE30R & $0.141 * * *$ & $0.103 * * *$ & $0.388 * * *$ & $0.353 * * *$ & $0.556 * * *$ & $0.170 * * *$ & $0.158 * * *$ \\
\hline MEDICAL30R & $0.159 * * *$ & $0.101^{* * *}$ & $0.367 * * *$ & $0.331 * * *$ & $0.523 * * *$ & $0.176^{* * *}$ & $0.147 * * *$ \\
\hline NEWS30R & $0.164^{* * *}$ & $0.105^{* * *}$ & $0.388 * * *$ & $0.360 * * *$ & $0.559 * * *$ & $0.174 * * *$ & $0.163^{* * *}$ \\
\hline BLOG30R & $0.213 * * *$ & $0.094 * * *$ & $0.358 * * *$ & $0.335 * * *$ & $0.557 * * *$ & $0.130 * * *$ & $0.141^{* * *}$ \\
\hline VIDAUTH30R & $0.227 * * *$ & $0.081 * * *$ & $0.326 * * *$ & $0.297 * * *$ & $0.500 * * *$ & $0.132 * * *$ & $0.126 * * *$ \\
\hline MOVIE30R & $0.251^{* * *}$ & $0.100 * * *$ & $0.361^{* * *}$ & $0.331^{* * *}$ & $0.540 * * *$ & $0.157 * * *$ & $0.157 * * *$ \\
\hline TVOL30R & $0.203 * * *$ & $0.085 * * *$ & $0.329 * * *$ & $0.283^{* * *}$ & $0.459 * * *$ & $0.179 * * *$ & $0.132 * * *$ \\
\hline FACEBOOKR & $0.173^{* * *}$ & $0.135^{* * *}$ & $0.407 * * *$ & $0.361^{* * *}$ & $0.552^{* * *}$ & $0.187 * * *$ & $0.209 * * *$ \\
\hline LINKEDINR & $0.283^{* * *}$ & $0.084^{* * *}$ & $0.335 * * *$ & $0.304 * * *$ & $0.494 * * *$ & $0.179 * * *$ & $0.123 * * *$ \\
\hline TWITTERR & $0.291^{* * *}$ & $0.088 * * *$ & $0.322 * * *$ & $0.297 * * *$ & $0.500 * * *$ & $0.137 * * *$ & $0.144^{* * *}$ \\
\hline YOUTUBE30R & $0.228 * * *$ & $0.124 * * *$ & $0.418 * * *$ & $0.380 * * *$ & $0.602^{* * *}$ & $0.186 * * *$ & $0.191^{* * *}$ \\
\hline GOOGLE30R & $0.148^{* * *}$ & $0.133^{* * *}$ & $0.398 * * *$ & $0.343^{* * *}$ & $0.520^{* * *}$ & $0.203^{* * *}$ & $0.202^{* * *}$ \\
\hline BANK12R & $0.107^{* * *}$ & $0.116^{* * *}$ & $0.383 * * *$ & $0.328 * * *$ & $0.496 * * *$ & $0.187 * * *$ & $0.174 * * *$ \\
\hline SMRTPHNER & $0.230 * * *$ & $0.146 * * *$ & $0.429 * * *$ & $0.394 * * *$ & $0.642 * * *$ & $0.157 * * *$ & $0.223 * * *$ \\
\hline WEATHER30R & $0.224 * * *$ & $0.117 * * *$ & $0.403 * * *$ & $0.382 * * *$ & $0.615^{* * *}$ & $0.167 * * *$ & $0.176^{* * *}$ \\
\hline MAP30R & $0.217 * * *$ & $0.104^{* * *}$ & $0.395 * * *$ & $0.386 * * *$ & $0.633 * * *$ & $0.135 * * *$ & $0.156 * * *$ \\
\hline LANDLNEHHR & $-0.086 * * *$ & $-0.082 * * *$ & $-0.185 * * *$ & $-0.176 * * *$ & $-0.314 * * *$ & 0.014 & $-0.153 * * *$ \\
\hline CLLONLYHHR & $0.094 * * *$ & $0.086 * * *$ & $0.208 * * *$ & $0.206 * * *$ & $0.363 * * *$ & -0.015 & $0.155^{* * *}$ \\
\hline LNDONLYHHR & $-0.136 * * *$ & $-0.148 * * *$ & $-0.414 * * *$ & $-0.377 * * *$ & $-0.601 * * *$ & $-0.127 * * *$ & $-0.222 * * *$ \\
\hline CELLINHHR & $0.139 * * *$ & $0.138 * * *$ & $0.403^{* * *}$ & $0.380^{* * *}$ & $0.614^{* * *}$ & $0.107 * * *$ & $0.205^{* * *}$ \\
\hline AMZ12R & $0.176 * * *$ & $0.119 * * *$ & $0.398 * * *$ & $0.364 * * *$ & $0.568 * * *$ & $0.175^{* * *}$ & $0.176^{* * *}$ \\
\hline EBAY12R & $0.137 * * *$ & $0.200 * * *$ & $0.421^{* * *}$ & $0.333 * * *$ & $0.519 * * *$ & $0.169 * * *$ & $0.253^{* * *}$ \\
\hline ITUNE12R & $0.206^{* * *}$ & $0.122 * * *$ & $0.392^{* * *}$ & $0.347 * * *$ & $0.572^{* * *}$ & $0.164^{* * *}$ & $0.170^{* * *}$ \\
\hline WALMART12R & $-0.092 * * *$ & $0.067 * * *$ & -0.011 & $-0.073 * * *$ & $-0.125 * * *$ & $0.050 * * *$ & $0.095 * * *$ \\
\hline
\end{tabular}




\begin{tabular}{|c|c|c|c|c|c|c|}
\hline & MOBILEWLHH & RESFIX200 & RESFX200BTP & NUMFIXPROV & NMRESPR200 & NMRESPRO3M \\
\hline \multicolumn{7}{|l|}{ TOTHHOLDSR } \\
\hline \multicolumn{7}{|l|}{ BRDBNDHH } \\
\hline \multicolumn{7}{|l|}{ WIRELNEHH } \\
\hline \multicolumn{7}{|l|}{ DSLHH } \\
\hline \multicolumn{7}{|l|}{ CABLEHH } \\
\hline \multicolumn{7}{|l|}{ FIBERHH } \\
\hline \multicolumn{7}{|l|}{ WIRELESSHH } \\
\hline MOBILEWLHH & 1 & & & & & \\
\hline RESFIX200 & $0.135 * * *$ & 1 & & & & \\
\hline RESFX200BTP & $0.197 * * *$ & $0.858 * * *$ & 1 & & & \\
\hline NUMFIXPROV & $0.289 * * *$ & $0.432 * * *$ & $0.460 * * *$ & 1 & & \\
\hline NMRESPR200 & $0.290 * * *$ & $0.287 * * *$ & $0.289 * * *$ & $0.771 * * *$ & 1 & \\
\hline NMRESPRO3M & $0.257 * * *$ & $0.342^{* * *}$ & $0.355^{* * * *}$ & $0.703 * * *$ & $0.832 * * *$ & 1 \\
\hline NUMPROVMOB & $0.282 * * *$ & $0.252 * * *$ & $0.296 * * *$ & $0.483 * * *$ & $0.375^{* * *}$ & $0.364 * * *$ \\
\hline EREADERR & $0.131^{* * *}$ & $0.531^{* * *}$ & $0.536 * * *$ & $0.611^{* * *}$ & $0.320 * * *$ & $0.359 * * *$ \\
\hline COMPINHHR & $0.149 * * *$ & $0.646 * * *$ & $0.624^{* * *}$ & $0.527 * * *$ & $0.376^{* * *}$ & $0.435 * * *$ \\
\hline DIALUPINTR & $-0.214^{* * *}$ & $-0.549 * * *$ & $-0.559 * * *$ & $-0.633^{* * *}$ & $-0.398 * * *$ & $-0.430 * * *$ \\
\hline CABLEINTR & $0.193 * * *$ & $0.567 * * *$ & $0.571^{* * *}$ & $0.661^{* * *}$ & $0.433 * * *$ & $0.482 * * *$ \\
\hline DSLINTR & $-0.124 * * *$ & $-0.069 * * *$ & $-0.106 * * *$ & $-0.453 * * *$ & $-0.205^{* * *}$ & $-0.212 * * *$ \\
\hline FIBERINTR & $0.142 * * *$ & $0.524^{* * *}$ & $0.541^{* * *}$ & $0.654 * * *$ & $0.312 * * *$ & $0.345^{* * * *}$ \\
\hline WRLSSINTR & $0.140 * * *$ & $0.600 * * *$ & $0.592 * * *$ & $0.385 * * *$ & $0.256 * * *$ & $0.310 * * *$ \\
\hline HSPEEDINTR & $0.183^{* * *}$ & $0.664 * * *$ & $0.657 * * *$ & $0.587 * * *$ & $0.407 * * *$ & $0.463 * * *$ \\
\hline INTUSE30R & $0.178 * * *$ & $0.632 * * *$ & $0.619 * * *$ & $0.522 * * *$ & $0.390 * * *$ & $0.449 * * *$ \\
\hline INTATHOMER & $0.170 * * *$ & $0.653 * * *$ & $0.640 * * *$ & $0.546 * * *$ & $0.395 * * *$ & $0.453 * * *$ \\
\hline INTATWORKR & $0.215^{* * *}$ & $0.641^{* * *}$ & $0.637 * * *$ & $0.580 * * *$ & $0.402^{* * *}$ & $0.460 * * *$ \\
\hline INTATSCHLR & $0.186^{* * *}$ & $0.428 * * *$ & $0.445^{* * *}$ & $0.451^{* * *}$ & $0.315^{* * *}$ & $0.301^{* * *}$ \\
\hline EMAIL30R & $0.152 * * *$ & $0.649 * * *$ & $0.637 * * *$ & $0.551 * * *$ & $0.381 * * *$ & $0.439 * * *$ \\
\hline IM30R & $0.241 * * *$ & $0.581 * * *$ & $0.588 * * *$ & $0.568 * * *$ & $0.427 * * *$ & $0.481 * * *$ \\
\hline PURCH30R & $0.140 * * *$ & $0.648 * * *$ & $0.635^{* * *}$ & $0.559 * * *$ & $0.369 * * *$ & $0.424^{* * *}$ \\
\hline BILLS30R & $0.189 * * *$ & $0.625 * * *$ & $0.623 * * *$ & $0.617 * * *$ & $0.402 * * *$ & $0.459 * * *$ \\
\hline EMPLOY30R & $0.173^{* * *}$ & $0.410^{* * *}$ & $0.437 * * *$ & $0.586 * * *$ & $0.353^{* * *}$ & $0.399 * * *$ \\
\hline
\end{tabular}




\begin{tabular}{|c|c|c|c|c|c|c|}
\hline & MOBILEWLHH & RESFIX200 & RESFX200BTP & NUMFIXPROV & NMRESPR200 & NMRESPRO3M \\
\hline FINANCE30R & $0.151^{* * *}$ & $0.643^{* * *}$ & $0.632 * * *$ & $0.588^{* * *}$ & $0.388 * * *$ & $0.447 * * *$ \\
\hline MEDICAL30R & $0.134^{* * *}$ & $0.619 * * *$ & $0.609 * * *$ & $0.562 * * *$ & $0.360 * * *$ & $0.408 * * *$ \\
\hline NEWS30R & $0.156^{* * *}$ & $0.632 * * *$ & $0.623^{* * *}$ & $0.601^{* * *}$ & $0.400 * * *$ & $0.454^{* * *}$ \\
\hline BLOG30R & $0.137 * * *$ & $0.503^{* * *}$ & $0.512 * * *$ & $0.579 * * *$ & $0.323 * * *$ & $0.365 * * *$ \\
\hline VIDAUTH30R & $0.124^{* * *}$ & $0.438 * * *$ & $0.456 * * *$ & $0.541 * * *$ & $0.274 * * *$ & $0.310 * * *$ \\
\hline MOVIE30R & $0.151^{* * *}$ & $0.495 * * *$ & $0.505^{* * *}$ & $0.576^{* * *}$ & $0.336 * * *$ & $0.381 * * *$ \\
\hline TVOL30R & $0.127 * * *$ & $0.500 * * *$ & $0.512 * * *$ & $0.502^{* * *}$ & $0.282^{* * *}$ & $0.319 * * *$ \\
\hline FACEBOOKR & $0.202^{* * *}$ & $0.588 * * *$ & $0.588 * * *$ & $0.570 * * *$ & $0.401 * * *$ & $0.459 * * *$ \\
\hline LINKEDINR & $0.120 * * *$ & $0.529 * * *$ & $0.536 * * *$ & $0.599 * * *$ & $0.302 * * *$ & $0.338 * * *$ \\
\hline TWITTERR & $0.132 * * *$ & $0.383 * * *$ & $0.409 * * *$ & $0.550 * * *$ & $0.254 * * *$ & $0.288 * * *$ \\
\hline YOUTUBE30R & $0.182^{* * *}$ & $0.587 * * *$ & $0.594^{* * *}$ & $0.639 * * *$ & $0.394 * * *$ & $0.449 * * *$ \\
\hline GOOGLE30R & $0.190 * * *$ & $0.643 * * *$ & $0.634^{* * *}$ & $0.559 * * *$ & $0.399 * * *$ & $0.456 * * *$ \\
\hline BANK12R & $0.166^{* * *}$ & $0.655^{* * *}$ & $0.640^{* * *}$ & $0.527 * * *$ & $0.385 * * *$ & $0.444^{* * *}$ \\
\hline SMRTPHNER & $0.220 * * *$ & $0.530 * * *$ & $0.547 * * *$ & $0.675^{* * *}$ & $0.406 * * *$ & $0.456 * * *$ \\
\hline WEATHER30R & $0.184^{* * *}$ & $0.548 * * *$ & $0.562 * * *$ & $0.670 * * *$ & $0.389 * * *$ & $0.442 * * *$ \\
\hline MAP30R & $0.157 * * *$ & $0.548 * * *$ & $0.558 * * *$ & $0.674 * * *$ & $0.396 * * *$ & $0.448 * * *$ \\
\hline LANDLNEHHR & $-0.141^{* * *}$ & $-0.035^{*}$ & $-0.059 * * *$ & $-0.214^{* * *}$ & $-0.150 * * *$ & $-0.168 * * *$ \\
\hline CLLONLYHHR & $0.144^{* * *}$ & $0.077 * * *$ & $0.101^{* * *}$ & $0.256^{* * *}$ & $0.183^{* * *}$ & $0.205^{* * *}$ \\
\hline LNDONLYHHR & $-0.211^{* * *}$ & $-0.553^{* * *}$ & $-0.558 * * *$ & $-0.607 * * *$ & $-0.381 * * *$ & $-0.435 * * *$ \\
\hline CELLINHHR & $0.197 * * *$ & $0.535^{* * *}$ & $0.539 * * *$ & $0.613^{* * *}$ & $0.385^{* * *}$ & $0.438 * * *$ \\
\hline AMZ12R & $0.173^{* * *}$ & $0.626 * * *$ & $0.620 * * *$ & $0.606 * * *$ & $0.399 * * *$ & $0.456 * * *$ \\
\hline EBAY12R & $0.252 * * *$ & $0.542 * * *$ & $0.556 * * *$ & $0.524^{* * *}$ & $0.387 * * *$ & $0.438 * * *$ \\
\hline ITUNE12R & $0.165 * * *$ & $0.562 * * *$ & $0.575 * * *$ & $0.632 * * *$ & $0.356 * * *$ & $0.401 * * *$ \\
\hline WALMART12R & $0.111^{* * *}$ & $-0.125 * * *$ & $-0.099 * * *$ & $-0.132 * * *$ & -0.021 & -0.030 \\
\hline
\end{tabular}




\begin{tabular}{|c|c|c|c|c|c|c|c|}
\hline & NUMPROVMOB & EREADERR & COMPINHHR & DIALUPINTR & CABLEINTR & DSLINTR & FIBERINTR \\
\hline \multicolumn{8}{|l|}{ TOTHHOLDSR } \\
\hline \multicolumn{8}{|l|}{ BRDBNDHH } \\
\hline \multicolumn{8}{|l|}{ WIRELNEHH } \\
\hline \multicolumn{8}{|l|}{ DSLHH } \\
\hline \multicolumn{8}{|l|}{ CABLEHH } \\
\hline \multicolumn{8}{|l|}{ FIBERHH } \\
\hline \multicolumn{8}{|l|}{ WIRELESSHH } \\
\hline \multicolumn{8}{|l|}{ MOBILEWLHH } \\
\hline \multicolumn{8}{|l|}{ RESFIX200 } \\
\hline \multicolumn{8}{|l|}{ RESFX200BTP } \\
\hline \multicolumn{8}{|l|}{ NUMFIXPROV } \\
\hline \multicolumn{8}{|l|}{ NMRESPR200 } \\
\hline \multicolumn{8}{|l|}{ NMRESPRO3M } \\
\hline NUMPROVMOB & 1 & & & & & & \\
\hline EREADERR & $0.414^{* * *}$ & 1 & & & & & \\
\hline COMPINHHR & $0.376^{* * *}$ & $0.746 * * *$ & 1 & & & & \\
\hline DIALUPINTR & $-0.426 * * *$ & $-0.755 * * *$ & $-0.757 * * *$ & 1 & & & \\
\hline CABLEINTR & $0.486 * * *$ & $0.854 * * *$ & $0.848 * * *$ & $-0.874 * * *$ & 1 & & \\
\hline DSLINTR & $-0.368 * * *$ & $-0.454 * * *$ & $-0.101 * * *$ & $0.550 * * *$ & $-0.522 * * *$ & 1 & \\
\hline FIBERINTR & $0.406 * * *$ & $0.869 * * *$ & $0.680 * * *$ & $-0.810 * * *$ & $0.795 * * *$ & -0.522 & 1 \\
\hline WRLSSINTR & $0.202^{* * *}$ & $0.539 * * *$ & $0.766 * * *$ & $-0.574 * * *$ & $0.552 * * *$ & $0.090 * * *$ & $0.578 * * *$ \\
\hline HSPEEDINTR & $0.393 * * *$ & $0.787 * * *$ & $0.957 * * *$ & $-0.806 * * *$ & $0.894 * * *$ & $-0.168 * * *$ & $0.749 * * *$ \\
\hline INTUSE30R & $0.357 * * *$ & $0.676^{* * *}$ & $0.942 * * *$ & $-0.760 * * *$ & $0.840 * * *$ & $-0.078 * * *$ & $0.644 * * *$ \\
\hline INTATHOMER & $0.364^{* * *}$ & $0.734 * * *$ & $0.964 * * *$ & $-0.773 * * *$ & $0.859 * * *$ & $-0.105 * * *$ & $0.690 * * *$ \\
\hline INTATWORKR & $0.402^{* * *}$ & $0.761 * * *$ & $0.935 * * *$ & $-0.783^{* * *}$ & $0.853 * * *$ & $-0.187 * * *$ & $0.756 * * *$ \\
\hline INTATSCHLR & $0.301^{* * *}$ & $0.492^{* * *}$ & $0.606^{* * *}$ & $-0.719 * * *$ & $0.646^{* * *}$ & $-0.357 * * *$ & $0.577^{* * *} *$ \\
\hline EMAIL30R & $0.358 * * *$ & $0.761^{* * *}$ & $0.954 * * *$ & $-0.785 * * *$ & $0.869 * * *$ & $-0.129 * * *$ & $0.714^{* * *}$ \\
\hline IM30R & $0.421^{* * *}$ & $0.693 * * *$ & $0.854 * * *$ & $-0.857 * * *$ & $0.869 * * *$ & $-0.326 * * *$ & $0.717 * * *$ \\
\hline PURCH30R & $0.353^{* * *}$ & $0.812 * * *$ & $0.954 * * *$ & $-0.779 * * *$ & $0.861 * * *$ & $-0.148 * * *$ & $0.759 * * *$ \\
\hline BILLS30R & $0.428 * * *$ & $0.822 * * *$ & $0.920 * * *$ & $-0.869 * * *$ & $0.917 * * *$ & $-0.347 * * *$ & $0.815^{* * *}$ \\
\hline EMPLOY30R & $0.429 * * *$ & $0.658 * * *$ & $0.590 * * *$ & $-0.782 * * *$ & $0.798 * * *$ & $-0.641 * * *$ & $0.715^{* * *}$ \\
\hline
\end{tabular}




\begin{tabular}{|c|c|c|c|c|c|c|c|}
\hline & NUMPROVMOB & EREADERR & COMPINHHR & DIALUPINTR & CABLEINTR & DSLINTR & FIBERINTR \\
\hline FINANCE30R & $0.399 * * *$ & $0.831^{* * *}$ & $0.954 * * *$ & $-0.833^{* * *}$ & $0.915^{* * *}$ & $-0.271^{* * *}$ & $0.785 * * *$ \\
\hline MEDICAL30R & $0.354 * * *$ & $0.824^{* * *}$ & $0.915 * * *$ & $-0.849 * * *$ & $0.888 * * *$ & $-0.242 * * *$ & $0.774 * * *$ \\
\hline NEWS30R & $0.394^{* * *}$ & $0.846^{* * *}$ & $0.938 * * *$ & $-0.833 * * *$ & $0.913^{* * *}$ & $-0.272 * * *$ & $0.788 * * *$ \\
\hline BLOG30R & $0.388 * * *$ & $0.860 * * *$ & $0.719 * * *$ & $-0.824 * * *$ & $0.837 * * *$ & $-0.547 * * *$ & $0.825 * * *$ \\
\hline VIDAUTH30R & $0.347 * * *$ & $0.730 * * *$ & $0.592 * * *$ & $-0.751 * * *$ & $0.705^{* * *}$ & $-0.561 * * *$ & $0.791 * * *$ \\
\hline MOVIE30R & $0.379 * * *$ & $0.753^{* * *}$ & $0.715 * * *$ & $-0.846 * * *$ & $0.814^{* * *}$ & $-0.511 * * *$ & $0.760 * * *$ \\
\hline TVOL30R & $0.297 * * *$ & $0.729 * * *$ & $0.654 * * *$ & $-0.741 * * *$ & $0.714^{* * *}$ & $-0.391 * * *$ & $0.733 * * *$ \\
\hline FACEBOOKR & $0.402 * * *$ & $0.721 * * *$ & $0.869 * * *$ & $-0.816 * * *$ & $0.868 * * *$ & $-0.288 * * *$ & $0.702 * * *$ \\
\hline LINKEDINR & $0.355 * * *$ & $0.886 * * *$ & $0.715 * * *$ & $-0.804 * * *$ & $0.766 * * *$ & $-0.439 * * *$ & $0.887 * * *$ \\
\hline TWITTERR & $0.365 * * *$ & $0.718 * * *$ & $0.490 * * *$ & $-0.750 * * *$ & $0.686 * * *$ & $-0.652 * * *$ & $0.806 * * *$ \\
\hline YOUTUBE30R & $0.432 * * *$ & $0.815^{* * *}$ & $0.837 * * *$ & $-0.883^{* * *}$ & $0.908 * * *$ & $-0.452 * * *$ & $0.827 * * *$ \\
\hline GOOGLE30R & $0.376^{* * *}$ & $0.716 * * *$ & $0.946 * * *$ & $-0.803 * * *$ & $0.854 * * *$ & $-0.144 * * *$ & $0.710 * * *$ \\
\hline BANK12R & $0.358 * * *$ & $0.736^{* * *}$ & $0.965 * * *$ & $-0.766 * * *$ & $0.850 * * *$ & $-0.102 * * *$ & $0.687 * * *$ \\
\hline SMRTPHNER & $0.499 * * *$ & $0.837 * * *$ & $0.764 * * *$ & $-0.848 * * *$ & $0.904 * * *$ & $-0.575 * * *$ & $0.853 * * *$ \\
\hline WEATHER30R & $0.469 * * *$ & $0.882 * * *$ & $0.759 * * *$ & $-0.764 * * *$ & $0.889 * * *$ & $-0.510 * * *$ & $0.854 * * *$ \\
\hline MAP30R & $0.474^{* * *}$ & $0.907 * * *$ & $0.789 * * *$ & $-0.824 * * *$ & $0.934 * * *$ & $-0.560 * * *$ & $0.865 * * *$ \\
\hline LANDLNEHHR & $-0.244 * * *$ & $-0.150 * * *$ & $-0.077 * * *$ & $0.428 * * *$ & $-0.318 * * *$ & $0.610 * * *$ & $-0.173 * * *$ \\
\hline CLLONLYHHR & $0.265 * * *$ & $0.240 * * *$ & $0.155^{* * *}$ & $-0.486 * * *$ & $0.401 * * *$ & $-0.645 * * *$ & $0.242 * * *$ \\
\hline LNDONLYHHR & $-0.493 * * *$ & $-0.825 * * *$ & $-0.847 * * *$ & $0.794^{* * *}$ & $-0.892 * * *$ & $0.428 * * *$ & $-0.776 * * *$ \\
\hline CELLINHHR & $0.499 * * *$ & $0.850 * * *$ & $0.837 * * *$ & $-0.796 * * *$ & $0.912 * * *$ & $-0.470 * * *$ & $0.779 * * *$ \\
\hline AMZ12R & $0.412 * * *$ & $0.851 * * *$ & $0.923 * * *$ & $-0.829 * * *$ & $0.905 * * *$ & $-0.295 * * *$ & $0.797 * * *$ \\
\hline EBAY12R & $0.387 * * *$ & $0.698 * * *$ & $0.755^{* * *}$ & $-0.647 * * *$ & $0.736^{* * *}$ & $-0.256 * * *$ & $0.672 * * *$ \\
\hline ITUNE12R & $0.424 * * *$ & $0.907 * * *$ & $0.783 * * *$ & $-0.808 * * *$ & $0.850 * * *$ & $-0.484 * * *$ & $0.906 * * *$ \\
\hline WALMART12R & $-0.051^{* *}$ & $-0.317 * * *$ & $-0.254^{* * *}$ & $0.299 * * *$ & $-0.307 * * *$ & $0.124^{* * *}$ & $-0.136 * * *$ \\
\hline
\end{tabular}




\begin{tabular}{|c|c|c|c|c|c|c|c|}
\hline & WRLSSINTR & HSPEEDINTR & INTUSE30R & INTATHOMER & INTATWORKR & INTATSCHLR & EMAIL30R \\
\hline \multicolumn{8}{|l|}{ TOTHHOLDSR } \\
\hline \multicolumn{8}{|l|}{ BRDBNDHH } \\
\hline \multicolumn{8}{|l|}{ WIRELNEHH } \\
\hline \multicolumn{8}{|l|}{ DSLHH } \\
\hline \multicolumn{8}{|l|}{ CABLEHH } \\
\hline \multicolumn{8}{|l|}{ FIBERHH } \\
\hline \multicolumn{8}{|l|}{ WIRELESSHH } \\
\hline \multicolumn{8}{|l|}{ MOBILEWLHH } \\
\hline \multicolumn{8}{|l|}{ RESFIX200 } \\
\hline \multicolumn{8}{|l|}{ RESFX200BTP } \\
\hline \multicolumn{8}{|l|}{ NUMFIXPROV } \\
\hline \multicolumn{8}{|l|}{ NMRESPR200 } \\
\hline \multicolumn{8}{|l|}{ NMRESPRO3M } \\
\hline \multicolumn{8}{|l|}{ NUMPROVMOB } \\
\hline \multicolumn{8}{|l|}{ EREADERR } \\
\hline \multicolumn{8}{|l|}{ COMPINHHR } \\
\hline \multicolumn{8}{|l|}{ DIALUPINTR } \\
\hline \multicolumn{8}{|l|}{ CABLEINTR } \\
\hline \multicolumn{8}{|l|}{ DSLINTR } \\
\hline \multicolumn{8}{|l|}{ FIBERINTR } \\
\hline WRLSSINTR & 1 & & & & & & \\
\hline HSPEEDINTR & $0.830 * * *$ & 1 & & & & & \\
\hline INTUSE30R & $0.821^{* * *}$ & $0.975 * * *$ & 1 & & & & \\
\hline INTATHOMER & $0.837 * * *$ & $0.990 * * *$ & $0.989 * * *$ & 1 & & & \\
\hline INTATWORKR & $0.858 * * *$ & $0.975 * * *$ & $0.953 * * *$ & $0.966 * * *$ & 1 & & \\
\hline INTATSCHLR & $0.697 * * *$ & $0.708 * * *$ & $0.689 * * *$ & $0.694^{* * *}$ & $0.731^{* * *}$ & 1 & \\
\hline EMAIL30R & $0.831^{* * *}$ & $0.988 * * *$ & $0.981^{* * *}$ & $0.993 * * *$ & $0.958 * * *$ & $0.715 * * *$ & 1 \\
\hline IM30R & $0.774 * * *$ & $0.929 * * *$ & $0.924 * * *$ & $0.916^{* * *}$ & $0.936 * * *$ & $0.843^{* * *}$ & $0.914^{* * *}$ \\
\hline PURCH30R & $0.823 * * *$ & $0.973 * * *$ & $0.953 * * *$ & $0.977 * * *$ & $0.953 * * *$ & $0.661^{* * *}$ & $0.983 * * *$ \\
\hline BILLS30R & $0.791^{* * *}$ & $0.967 * * *$ & $0.934 * * *$ & $0.951 * * *$ & $0.966 * * *$ & $0.793 * * *$ & $0.961 * * *$ \\
\hline EMPLOY30R & $0.523 * * *$ & $0.701^{* * *}$ & $0.642 * * *$ & $0.653 * * *$ & $0.706 * * *$ & $0.878 * * *$ & $0.690 * * *$ \\
\hline
\end{tabular}




\begin{tabular}{|c|c|c|c|c|c|c|c|}
\hline & WRLSSINTR & HSPEEDINTR & INTUSE30R & INTATHOMER & INTATWORKR & INTATSCHLR & EMAIL30R \\
\hline FINANCE30R & $0.787^{* * *}$ & $0.974^{* * *}$ & $0.945^{* * *}$ & $0.970 * * *$ & $0.955 * * *$ & $0.718^{* * *}$ & $0.977 * * *$ \\
\hline MEDICAL30R & $0.756^{* * *}$ & $0.948^{* * *}$ & $0.921^{* * *}$ & $0.942^{* * *}$ & $0.907 * * *$ & $0.739 * * *$ & $0.963 * * *$ \\
\hline NEWS30R & $0.774 * * *$ & $0.972 * * *$ & $0.937 * * *$ & $0.966 * * *$ & $0.949 * * *$ & $0.724 * * *$ & $0.976 * * *$ \\
\hline BLOG30R & $0.633^{* * *}$ & $0.787 * * *$ & $0.699 * * *$ & $0.747 * * *$ & $0.777 * * *$ & $0.805^{* * *}$ & $0.786 * * *$ \\
\hline VIDAUTH30R & $0.579 * * *$ & $0.667 * * *$ & $0.575 * * *$ & $0.619 * * *$ & $0.682 * * *$ & $0.816 * * *$ & $0.658 * * *$ \\
\hline MOVIE30R & $0.672 * * *$ & $0.799 * * *$ & $0.744 * * *$ & $0.767 * * *$ & $0.798 * * *$ & $0.904 * * *$ & $0.802 * * *$ \\
\hline TVOL30R & $0.739 * * *$ & $0.759 * * *$ & $0.678 * * *$ & $0.726 * * *$ & $0.756 * * *$ & $0.877 * * *$ & $0.767 * * *$ \\
\hline FACEBOOKR & $0.802^{* * *}$ & $0.941 * * *$ & $0.929 * * *$ & $0.928 * * *$ & $0.945 * * *$ & $0.843 * * *$ & $0.936 * * *$ \\
\hline LINKEDINR & $0.696 * * *$ & $0.782 * * *$ & $0.694 * * *$ & $0.740 * * *$ & $0.802^{* * *}$ & $0.698 * * *$ & $0.772 * * *$ \\
\hline TWITTERR & $0.532 * * *$ & $0.604 * * *$ & $0.523 * * *$ & $0.544 * * *$ & $0.631 * * *$ & $0.775^{* * *}$ & $0.592 * * *$ \\
\hline YOUTUBE30R & $0.745 * * *$ & $0.915 * * *$ & $0.867 * * *$ & $0.881 * * *$ & $0.909 * * *$ & $0.835 * * *$ & $0.903 * * *$ \\
\hline GOOGLE30R & $0.839 * * *$ & $0.981 * * *$ & $0.992 * * *$ & $0.989 * * *$ & $0.972 * * *$ & $0.716 * * *$ & $0.982 * * *$ \\
\hline BANK12R & $0.845^{* * *}$ & $0.978 * * *$ & $0.973 * * *$ & $0.988 * * *$ & $0.965 * * *$ & $0.665 * * *$ & $0.979 * * *$ \\
\hline SMRTPHNER & $0.605 * * *$ & $0.832 * * *$ & $0.767 * * *$ & $0.777 * * *$ & $0.853 * * *$ & $0.701 * * *$ & $0.790 * * *$ \\
\hline WEATHER30R & $0.633^{* * *}$ & $0.834 * * *$ & $0.744 * * *$ & $0.778 * * *$ & $0.848 * * *$ & $0.626 * * *$ & $0.799 * * *$ \\
\hline MAP30R & $0.602 * * *$ & $0.849 * * *$ & $0.744 * * *$ & $0.778 * * *$ & $0.848 * * *$ & $0.626 * * *$ & $0.799 * * *$ \\
\hline LANDLNEHHR & $-0.082 * * *$ & $-0.145 * * *$ & $-0.151 * * *$ & $-0.116 * * *$ & $-0.178 * * *$ & $-0.526 * * *$ & $-0.140 * * *$ \\
\hline CLLONLYHHR & $0.118 * * *$ & $0.220 * * *$ & $0.212^{* * * *}$ & $0.189 * * *$ & $0.246^{* * *}$ & $0.587^{* * *}$ & $0.215^{* * *}$ \\
\hline LNDONLYHHR & $-0.585 * * *$ & $-0.849 * * *$ & $-0.793 * * *$ & $-0.805 * * *$ & $-0.849 * * *$ & $-0.578 * * *$ & $-0.808 * * *$ \\
\hline CELLINHHR & $0.535^{* * *}$ & $0.836^{* * *}$ & $0.774 * * *$ & $0.791^{* * *}$ & $0.827 * * *$ & $0.561^{* * *}$ & $0.797 * * *$ \\
\hline AMZ12R & $0.790^{* * *}$ & $0.962 * * *$ & $0.918 * * *$ & $0.949 * * *$ & $0.950 * * *$ & $0.750 * * *$ & $0.955^{* * *}$ \\
\hline EBAY12R & $0.779 * * *$ & $0.816 * * *$ & $0.761^{* * *}$ & $0.792 * * *$ & $0.863 * * *$ & $0.653 * * *$ & $0.770 * * *$ \\
\hline ITUNE12R & $0.711^{* * *}$ & $0.844^{* * *}$ & $0.751^{* * *}$ & $0.802^{* * *}$ & $0.864 * * *$ & $0.727 * * *$ & $0.823 * * *$ \\
\hline WALMART12R & $0.128 * * *$ & $-0.170 * * *$ & $-0.152 * * *$ & $-0.169 * * *$ & -0.034 & 0.031 & $-0.219 * * *$ \\
\hline
\end{tabular}




\begin{tabular}{|c|c|c|c|c|c|c|c|c|}
\hline & IM30R & PURCH30R & BILLS30R & EMPLOY30R & FINANCE30R & MEDICAL30R & NEWS30R & BLOG30R \\
\hline \multicolumn{9}{|l|}{ TOTHHOLDSR } \\
\hline \multicolumn{9}{|l|}{ BRDBNDHH } \\
\hline \multicolumn{9}{|l|}{ WIRELNEHH } \\
\hline \multicolumn{9}{|l|}{ DSLHH } \\
\hline \multicolumn{9}{|l|}{ CABLEHH } \\
\hline \multicolumn{9}{|l|}{ FIBERHH } \\
\hline \multicolumn{9}{|l|}{ WIRELESSHH } \\
\hline \multicolumn{9}{|l|}{ MOBILEWLHH } \\
\hline \multicolumn{9}{|l|}{ RESFIX200 } \\
\hline \multicolumn{9}{|l|}{ RESFX200BTP } \\
\hline \multicolumn{9}{|l|}{ NUMFIXPROV } \\
\hline \multicolumn{9}{|l|}{ NMRESPR200 } \\
\hline \multicolumn{9}{|l|}{ NMRESPRO3M } \\
\hline \multicolumn{9}{|l|}{ NUMPROVMOB } \\
\hline \multicolumn{9}{|l|}{ EREADERR } \\
\hline \multicolumn{9}{|l|}{ COMPINHHR } \\
\hline \multicolumn{9}{|l|}{ DIALUPINTR } \\
\hline \multicolumn{9}{|l|}{ CABLEINTR } \\
\hline \multicolumn{9}{|l|}{ DSLINTR } \\
\hline \multicolumn{9}{|l|}{ FIBERINTR } \\
\hline \multicolumn{9}{|l|}{ WRLSSINTR } \\
\hline \multicolumn{9}{|l|}{ HSPEEDINTR } \\
\hline \multicolumn{9}{|l|}{ INTUSE30R } \\
\hline \multicolumn{9}{|l|}{ INTATHOMER } \\
\hline \multicolumn{9}{|l|}{ INTATWORKR } \\
\hline \multicolumn{9}{|l|}{ INTATSCHLR } \\
\hline \multicolumn{9}{|l|}{ EMAIL30R } \\
\hline IM30R & 1 & & & & & & & \\
\hline PURCH30R & $0.873 * * *$ & 1 & & & & & & \\
\hline BILLS30R & $0.956 * * *$ & $0.949 * * *$ & 1 & & & & & \\
\hline EMPLOY30R & $0.836 * * *$ & $0.642 * * *$ & $0.820 * * *$ & 1 & & & & \\
\hline
\end{tabular}




\begin{tabular}{|c|c|c|c|c|c|c|c|c|}
\hline & IM30R & PURCH30R & BILLS30R & EMPLOY30R & FINANCE30R & MEDICAL30R & NEWS30R & BLOG30R \\
\hline FINANCE30R & $0.909 * * *$ & $0.978 * * *$ & $0.979 * * *$ & $0.733^{* * *}$ & 1 & & & \\
\hline MEDICAL30R & $0.883^{* * *}$ & $0.959 * * *$ & $0.955 * * *$ & $0.725^{* * *}$ & $0.969 * * *$ & 1 & & \\
\hline NEWS30R & $0.907 * * *$ & $0.981 * * *$ & $0.974 * * *$ & $0.740 * * *$ & $0.986 * * *$ & $0.968 * * *$ & 1 & \\
\hline BLOG30R & $0.810 * * *$ & $0.793 * * *$ & $0.885 * * *$ & $0.882 * * *$ & $0.852 * * *$ & $0.864 * * *$ & $0.864 * * *$ & 1 \\
\hline VIDAUTH30R & $0.734 * * *$ & $0.656 * * *$ & $0.796 * * *$ & $0.875 * * *$ & $0.736 * * *$ & $0.744 * * *$ & $0.730 * * *$ & $0.930 * * *$ \\
\hline MOVIE30R & $0.869 * * *$ & $0.780 * * *$ & $0.899 * * *$ & $0.925 * * *$ & $0.839 * * *$ & $0.864 * * *$ & $0.847 * * *$ & $0.946 * * *$ \\
\hline TVOL30R & $0.787 * * *$ & $0.750 * * *$ & $0.841^{* * *}$ & $0.846 * * *$ & $0.798 * * *$ & $0.826 * * *$ & $0.808 * * *$ & $0.937 * * *$ \\
\hline FACEBOOKR & $0.979 * * *$ & $0.900 * * *$ & $0.965 * * *$ & $0.842 * * *$ & $0.926 * * *$ & $0.903 * * *$ & $0.930 * * *$ & $0.839 * * *$ \\
\hline LINKEDINR & $0.751^{* * *}$ & $0.824^{* * *}$ & $0.856 * * *$ & $0.748 * * *$ & $0.831^{* * *}$ & $0.840 * * *$ & $0.852 * * *$ & $0.903^{* * *}$ \\
\hline TWITTERR & $0.707 * * *$ & $0.595 * * *$ & $0.751^{* * *}$ & $0.884 * * *$ & $0.664 * * *$ & $0.678 * * *$ & $0.670 * * *$ & $0.892 * * *$ \\
\hline YOUTUBE30R & $0.947 * * *$ & $0.884 * * *$ & $0.970 * * *$ & $0.901^{* * *}$ & $0.926 * * *$ & $0.913 * * *$ & $0.931 * * *$ & $0.921 * * *$ \\
\hline GOOGLE30R & $0.940 * * *$ & $0.965 * * *$ & $0.958 * * *$ & $0.676^{* * *}$ & $0.960 * * *$ & $0.933 * * *$ & $0.953 * * *$ & $0.743 * * *$ \\
\hline BANK12R & $0.895 * * *$ & $0.972 * * *$ & $0.941^{* * *}$ & $0.621^{* * *}$ & $0.971^{* * *}$ & $0.928 * * *$ & $0.955 * * *$ & $0.738 * * *$ \\
\hline SMRTPHNER & $0.886 * * *$ & $0.788 * * *$ & $0.907 * * *$ & $0.867 * * *$ & $0.850 * * *$ & $0.800 * * *$ & $0.842 * * *$ & $0.855^{* * *}$ \\
\hline WEATHER30R & $0.821 * * *$ & $0.814^{* * *}$ & $0.883 * * *$ & $0.815^{* * *}$ & $0.857 * * *$ & $0.791 * * *$ & $0.856 * * *$ & $0.850 * * *$ \\
\hline MAP30R & $0.835 * * *$ & $0.841^{* * *}$ & $0.910 * * *$ & $0.849 * * *$ & $0.895 * * *$ & $0.849 * * *$ & $0.895 * * *$ & $0.906 * * *$ \\
\hline LANDLNEHHR & $-0.436 * * *$ & $-0.068 * * *$ & $-0.314^{* * *}$ & $-0.638 * * *$ & $-0.202^{* * *}$ & $-0.183^{* * *}$ & $-0.186^{* * *}$ & $-0.451 * * *$ \\
\hline CLLONLYHHR & $0.497 * * *$ & $0.147 * * *$ & $0.391 * * *$ & $0.711^{* * *}$ & $0.282 * * *$ & $0.265^{* * *}$ & $0.273 * * *$ & $0.538 * * *$ \\
\hline LNDONLYHHR & $-0.850 * * *$ & $-0.798 * * *$ & $-0.882 * * *$ & $-0.736 * * *$ & $-0.855^{* * *}$ & $-0.797 * * *$ & $-0.834^{* * *}$ & $-0.777 * * *$ \\
\hline CELLINHHR & $0.833^{* * *}$ & $0.794^{* * *}$ & $0.874 * * *$ & $0.745^{* * *}$ & $0.853^{* * *}$ & $0.799 * * *$ & $0.838 * * *$ & $0.793^{* * *}$ \\
\hline AMZ12R & $0.909 * * *$ & $0.962 * * *$ & $0.967 * * *$ & $0.764 * * *$ & $0.970 * * *$ & $0.947 * * *$ & $0.979 * * *$ & $0.873^{* * *}$ \\
\hline EBAY12R & $0.822 * * *$ & $0.758 * * *$ & $0.813 * * *$ & $0.651^{* * *}$ & $0.792 * * *$ & $0.704^{* * *}$ & $0.799 * * *$ & $0.725^{* * *}$ \\
\hline ITUNE12R & $0.822 * * *$ & $0.852 * * *$ & $0.913 * * *$ & $0.807 * * *$ & $0.892 * * *$ & $0.861^{* * *}$ & $0.894 * * *$ & $0.939 * * *$ \\
\hline WALMART12R & $-0.048 * *$ & $-0.217 * * *$ & $-0.162 * * *$ & $-0.081 * * *$ & $-0.228 * * *$ & $-0.336 * * *$ & $-0.239 * * *$ & $-0.227 * * *$ \\
\hline
\end{tabular}




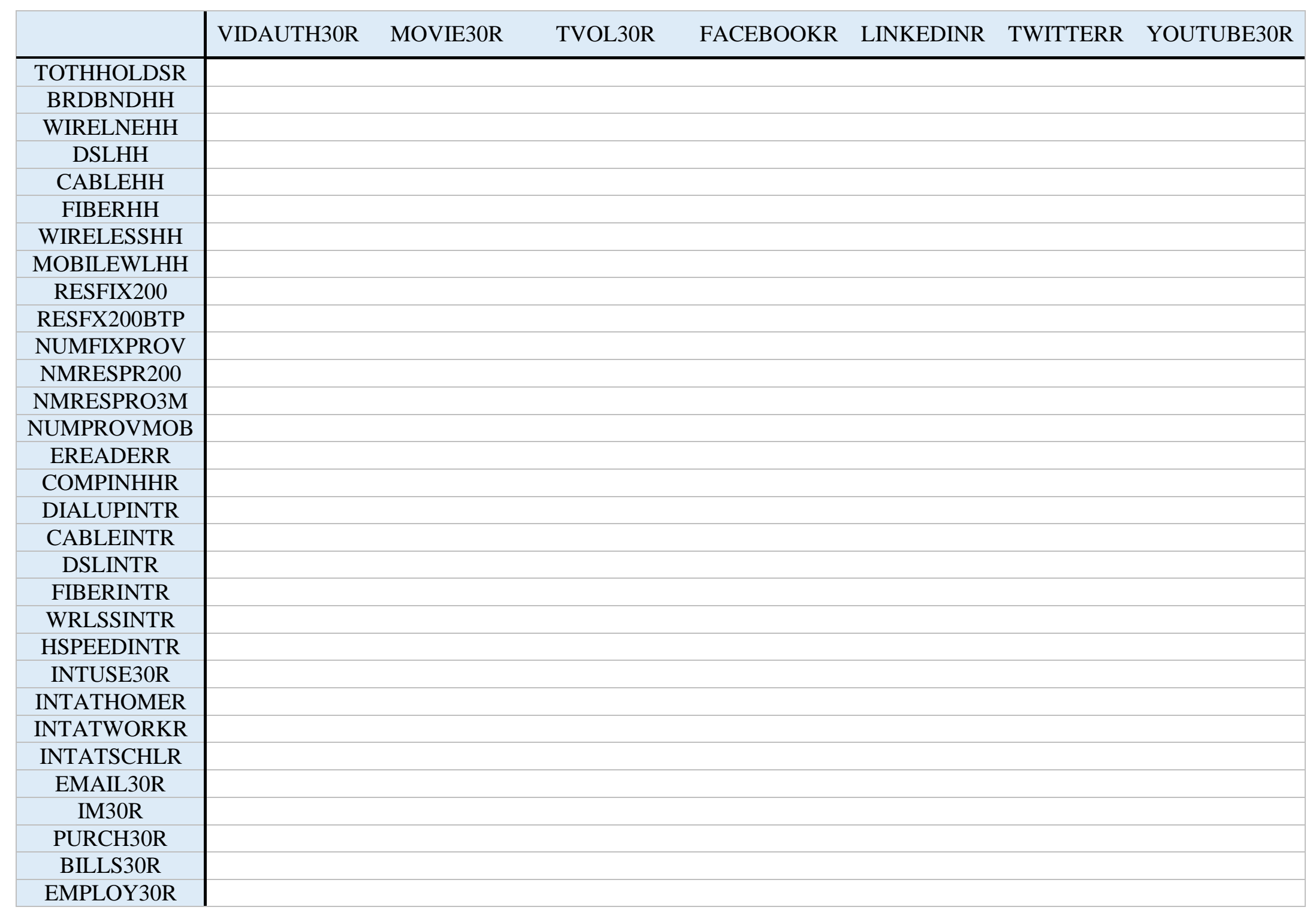




\begin{tabular}{|c|c|c|c|c|c|c|c|}
\hline & VIDAUTH30R & MOVIE30R & TVOL30R & FACEBOOKR & LINKEDINR & TWITTERR & YOUTUBE30R \\
\hline \multicolumn{8}{|l|}{ FINANCE30R } \\
\hline \multicolumn{8}{|l|}{ MEDICAL30R } \\
\hline \multicolumn{8}{|l|}{ NEWS30R } \\
\hline \multicolumn{8}{|l|}{ BLOG30R } \\
\hline VIDAUTH30R & 1 & & & & & & \\
\hline MOVIE30R & $0.913 * * *$ & 1 & & & & & \\
\hline TVOL30R & $0.903 * * *$ & $0.937 * * *$ & 1 & & & & \\
\hline FACEBOOKR & $0.751^{* * *}$ & $0.897 * * *$ & $0.830 * * *$ & 1 & & & \\
\hline LINKEDINR & $0.851^{* * *}$ & $0.872 * * *$ & $0.847 * * *$ & $0.787 * * *$ & 1 & & \\
\hline TWITTERR & $0.912 * * *$ & $0.885^{* * *}$ & $0.842 * * *$ & $0.715^{* * *}$ & $0.858 * * *$ & 1 & \\
\hline YOUTUBE30R & $0.858 * * *$ & $0.945 * * *$ & $0.871 * * *$ & $0.962 * * *$ & $0.879 * * *$ & $0.842 * * *$ & 1 \\
\hline GOOGLE30R & $0.637 * * *$ & $0.781 * * *$ & $0.715^{* * *}$ & $0.939 * * *$ & $0.754 * * *$ & $0.587 * * *$ & $0.897 * * *$ \\
\hline BANK12R & $0.600 * * *$ & $0.741^{* * *}$ & $0.716^{* * *}$ & $0.909 * * *$ & $0.754^{* * *}$ & $0.587 * * *$ & $0.861 * * *$ \\
\hline SMRTPHNER & $0.812^{* * *}$ & $0.861 * * *$ & $0.750 * * *$ & $0.882 * * *$ & $0.840 * * *$ & $0.830 * * *$ & $0.942 * * *$ \\
\hline WEATHER30R & $0.777 * * *$ & $0.812 * * *$ & $0.768 * * *$ & $0.850 * * *$ & $0.854^{* * *}$ & $0.779 * * *$ & $0.907 * * *$ \\
\hline MAP30R & $0.815^{* * *}$ & $0.859 * * *$ & $0.800 * * *$ & $0.861^{* * *}$ & $0.874 * * *$ & $0.809 * * *$ & $0.933 * * *$ \\
\hline LANDLNEHHR & $-0.510 * * *$ & $-0.535^{* * *}$ & $-0.431 * * *$ & $-0.410 * * *$ & $-0.245^{* * *}$ & $-0.554 * * *$ & $-0.442 * * *$ \\
\hline CLLONLYHHR & $0.578 * * *$ & $0.610^{* * *}$ & $0.503^{* * *}$ & $0.480^{* * *}$ & $0.321 * * *$ & $0.611^{* * *}$ & $0.516 * * *$ \\
\hline LNDONLYHHR & $-0.683^{* * *}$ & $-0.747 * * *$ & $-0.642 * * *$ & $-0.840 * * *$ & $-0.728 * * *$ & $-0.677 * * *$ & $-0.877 * * *$ \\
\hline CELLINHHR & $0.687 * * *$ & $0.750 * * *$ & $0.637^{* * * *}$ & $0.827 * * *$ & $0.734^{* * *}$ & $0.680 * * *$ & $0.874^{* * *}$ \\
\hline AMZ12R & $0.745^{* * *}$ & $0.856 * * *$ & $0.810 * * *$ & $0.925^{* * *}$ & $0.866 * * *$ & $0.708 * * *$ & $0.935^{* * *}$ \\
\hline EBAY12R & $0.621^{* * *}$ & $0.674^{* * *}$ & $0.680 * * *$ & $0.812 * * *$ & $0.705 * * *$ & $0.597 * * *$ & $0.791^{* * *}$ \\
\hline ITUNE12R & $0.871^{* * *}$ & $0.871^{* * *}$ & $0.868 * * *$ & $0.837 * * *$ & $0.932 * * *$ & $0.847 * * *$ & $0.914^{* * *}$ \\
\hline WALMART12R & $-0.106 * * *$ & $-0.204^{* * *}$ & $-0.113^{* * *}$ & $-0.088 * * *$ & $-0.177 * * *$ & $-0.098 * * *$ & $-0.175 * * *$ \\
\hline
\end{tabular}




\begin{tabular}{|c|c|c|c|c|c|c|c|}
\hline & GOOGLE30R & BANK12R & SMRTPHNER & WEATHER30R & MAP30R & LANDLNEHHR & CLLONLYHHR \\
\hline \multicolumn{8}{|l|}{ TOTHHOLDSR } \\
\hline \multicolumn{8}{|l|}{ BRDBNDHH } \\
\hline \multicolumn{8}{|l|}{ WIRELNEHH } \\
\hline \multicolumn{8}{|l|}{ DSLHH } \\
\hline \multicolumn{8}{|l|}{ CABLEHH } \\
\hline \multicolumn{8}{|l|}{ FIBERHH } \\
\hline \multicolumn{8}{|l|}{ WIRELESSHH } \\
\hline \multicolumn{8}{|l|}{ MOBILEWLHH } \\
\hline \multicolumn{8}{|l|}{ RESFIX200 } \\
\hline \multicolumn{8}{|l|}{ RESFX200BTP } \\
\hline \multicolumn{8}{|l|}{ NUMFIXPROV } \\
\hline \multicolumn{8}{|l|}{ NMRESPR200 } \\
\hline \multicolumn{8}{|l|}{ NMRESPRO3M } \\
\hline \multicolumn{8}{|l|}{ NUMPROVMOB } \\
\hline \multicolumn{8}{|l|}{ EREADERR } \\
\hline \multicolumn{8}{|l|}{ COMPINHHR } \\
\hline \multicolumn{8}{|l|}{ DIALUPINTR } \\
\hline \multicolumn{8}{|l|}{ CABLEINTR } \\
\hline \multicolumn{8}{|l|}{ DSLINTR } \\
\hline \multicolumn{8}{|l|}{ FIBERINTR } \\
\hline \multicolumn{8}{|l|}{ WRLSSINTR } \\
\hline \multicolumn{8}{|l|}{ HSPEEDINTR } \\
\hline \multicolumn{8}{|l|}{ INTUSE30R } \\
\hline \multicolumn{8}{|l|}{ INTATHOMER } \\
\hline \multicolumn{8}{|l|}{ INTATWORKR } \\
\hline \multicolumn{8}{|l|}{ INTATSCHLR } \\
\hline \multicolumn{8}{|l|}{ EMAIL30R } \\
\hline \multicolumn{8}{|l|}{ IM30R } \\
\hline \multicolumn{8}{|l|}{ PURCH30R } \\
\hline BILLS30R & & & & & & & \\
\hline EMPLOY30R & & & & & & & \\
\hline
\end{tabular}




\begin{tabular}{|c|c|c|c|c|c|c|c|}
\hline & GOOGLE30R & BANK12R & SMRTPHNER & WEATHER30R & MAP30R & LANDLNEHHR & CLLONLYHHR \\
\hline \multicolumn{8}{|l|}{ FINANCE30R } \\
\hline \multicolumn{8}{|l|}{ MEDICAL30R } \\
\hline \multicolumn{8}{|l|}{ NEWS30R } \\
\hline \multicolumn{8}{|l|}{ BLOG30R } \\
\hline \multicolumn{8}{|l|}{ VIDAUTH30R } \\
\hline \multicolumn{8}{|l|}{ MOVIE30R } \\
\hline \multicolumn{8}{|l|}{ TVOL30R } \\
\hline \multicolumn{8}{|l|}{ FACEBOOKR } \\
\hline \multicolumn{8}{|l|}{ LINKEDINR } \\
\hline \multicolumn{8}{|l|}{ TWITTERR } \\
\hline \multicolumn{8}{|l|}{ YOUTUBE30R } \\
\hline GOOGLE30R & 1 & & & & & & \\
\hline BANK12R & $0.974 * * *$ & 1 & & & & & \\
\hline SMRTPHNER & $0.807 * * *$ & $0.770 * * *$ & 1 & & & & \\
\hline WEATHER30R & $0.780 * * *$ & $0.783 * * *$ & $0.953 * * *$ & 1 & & & \\
\hline MAP30R & $0.799 * * *$ & $0.801^{* * *}$ & $0.952 * * *$ & $0.978 * * *$ & 1 & & \\
\hline LANDLNEHHR & $-0.169 * * *$ & $-0.111 * * *$ & $-0.481 * * *$ & $-0.346 * * *$ & $-0.373 * * *$ & 1 & \\
\hline CLLONLYHHR & $0.233^{* * *}$ & $0.177 * * *$ & $0.546 * * *$ & $0.419 * * *$ & $0.456 * * *$ & $-0.990 * * *$ & 1 \\
\hline LNDONLYHHR & $-0.815^{* * *}$ & $-0.809 * * *$ & $-0.931 * * *$ & $-0.880 * * *$ & $-0.889 * * *$ & $0.380 * * *$ & $-0.446 * * *$ \\
\hline CELLINHHR & $0.796 * * *$ & $0.793^{* * *}$ & $0.932 * * *$ & $0.889 * * *$ & $0.909 * * *$ & $-0.377 * * *$ & $0.452^{* * *}$ \\
\hline AMZ12R & $0.941^{* * *}$ & $0.935^{* * *}$ & $0.852 * * *$ & $0.858 * * *$ & $0.889 * * *$ & $-0.187 * * *$ & $0.277^{* * *}$ \\
\hline EBAY12R & $0.791 * * *$ & $0.814^{* * *}$ & $0.786 * * *$ & $0.798 * * *$ & $0.765 * * *$ & $-0.240 * * *$ & $0.299 * * *$ \\
\hline ITUNE12R & $0.803^{* * *}$ & $0.811^{* * *}$ & $0.897 * * *$ & $0.911^{* * *}$ & $0.932 * * *$ & $-0.290 * * *$ & $0.371 * * *$ \\
\hline WALMART12R & $-0.127 * * *$ & $-0.138 * * *$ & $-0.099 * * *$ & $-0.082 * * *$ & $-0.207 * * *$ & 0.016 & $-0.060 * * *$ \\
\hline
\end{tabular}




\begin{tabular}{|c|c|c|c|c|c|}
\hline & LNDONLYHHR CELLINHHR & AMZ12R & EBAY12R & ITUNE12R & WALMART12R \\
\hline \multicolumn{6}{|l|}{ TOTHHOLDSR } \\
\hline \multicolumn{6}{|l|}{ BRDBNDHH } \\
\hline \multicolumn{6}{|l|}{ WIRELNEHH } \\
\hline \multicolumn{6}{|l|}{ DSLHH } \\
\hline \multicolumn{6}{|l|}{ CABLEHH } \\
\hline \multicolumn{6}{|l|}{ FIBERHH } \\
\hline \multicolumn{6}{|l|}{ WIRELESSHH } \\
\hline \multicolumn{6}{|l|}{ MOBILEWLHH } \\
\hline \multicolumn{6}{|l|}{ RESFIX200 } \\
\hline \multicolumn{6}{|l|}{ RESFX200BTP } \\
\hline \multicolumn{6}{|l|}{ NUMFIXPROV } \\
\hline \multicolumn{6}{|l|}{ NMRESPR200 } \\
\hline \multicolumn{6}{|l|}{ NMRESPRO3M } \\
\hline \multicolumn{6}{|l|}{ NUMPROVMOB } \\
\hline \multicolumn{6}{|l|}{ EREADERR } \\
\hline \multicolumn{6}{|l|}{ COMPINHHR } \\
\hline \multicolumn{6}{|l|}{ DIALUPINTR } \\
\hline \multicolumn{6}{|l|}{ CABLEINTR } \\
\hline \multicolumn{6}{|l|}{ DSLINTR } \\
\hline \multicolumn{6}{|l|}{ FIBERINTR } \\
\hline \multicolumn{6}{|l|}{ WRLSSINTR } \\
\hline \multicolumn{6}{|l|}{ HSPEEDINTR } \\
\hline \multicolumn{6}{|l|}{ INTUSE30R } \\
\hline \multicolumn{6}{|l|}{ INTATHOMER } \\
\hline \multicolumn{6}{|l|}{ INTATWORKR } \\
\hline \multicolumn{6}{|l|}{ INTATSCHLR } \\
\hline \multicolumn{6}{|l|}{ EMAIL30R } \\
\hline \multicolumn{6}{|l|}{ IM30R } \\
\hline \multicolumn{6}{|l|}{ PURCH30R } \\
\hline \multicolumn{6}{|l|}{ BILLS30R } \\
\hline EMPLOY30R & & & & & \\
\hline
\end{tabular}




\begin{tabular}{|c|c|c|c|c|c|c|}
\hline & LNDONLYHHR & CELLINHHR & AMZ12R & EBAY12R & ITUNE12R & WALMART12R \\
\hline \multicolumn{7}{|l|}{ FINANCE30R } \\
\hline \multicolumn{7}{|l|}{ MEDICAL30R } \\
\hline \multicolumn{7}{|l|}{ NEWS30R } \\
\hline \multicolumn{7}{|l|}{ BLOG30R } \\
\hline \multicolumn{7}{|l|}{ VIDAUTH30R } \\
\hline \multicolumn{7}{|l|}{ MOVIE30R } \\
\hline \multicolumn{7}{|l|}{ TVOL30R } \\
\hline \multicolumn{7}{|l|}{ FACEBOOKR } \\
\hline \multicolumn{7}{|l|}{ LINKEDINR } \\
\hline \multicolumn{7}{|l|}{ TWITTERR } \\
\hline \multicolumn{7}{|l|}{ YOUTUBE30R } \\
\hline \multicolumn{7}{|l|}{ GOOGLE30R } \\
\hline \multicolumn{7}{|l|}{ BANK12R } \\
\hline \multicolumn{7}{|l|}{ SMRTPHNER } \\
\hline \multicolumn{7}{|l|}{ WEATHER30R } \\
\hline \multicolumn{7}{|l|}{ MAP30R } \\
\hline \multicolumn{7}{|l|}{ LANDLNEHHR } \\
\hline \multicolumn{7}{|l|}{ CLLONLYHHR } \\
\hline LNDONLYHHR & 1 & & & & & \\
\hline CELLINHHR & $-0.994^{* * *}$ & 1 & & & & \\
\hline AMZ12R & $-0.837 * * *$ & $0.839 * * *$ & 1 & & & \\
\hline EBAY12R & $-0.776 * * *$ & $0.758 * * *$ & $0.833^{* * *}$ & 1 & & \\
\hline ITUNE12R & $-0.841^{* * *}$ & $0.843^{* * *}$ & $0.907 * * *$ & $0.836 * * *$ & 1 & \\
\hline WALMART12R & $0.217^{* * *}$ & $-0.262 * * *$ & $-0.190 * * *$ & $0.207 * * *$ & $-0.095 * * *$ & 1 \\
\hline
\end{tabular}




\section{Appendix C. Data Visualization Maps}
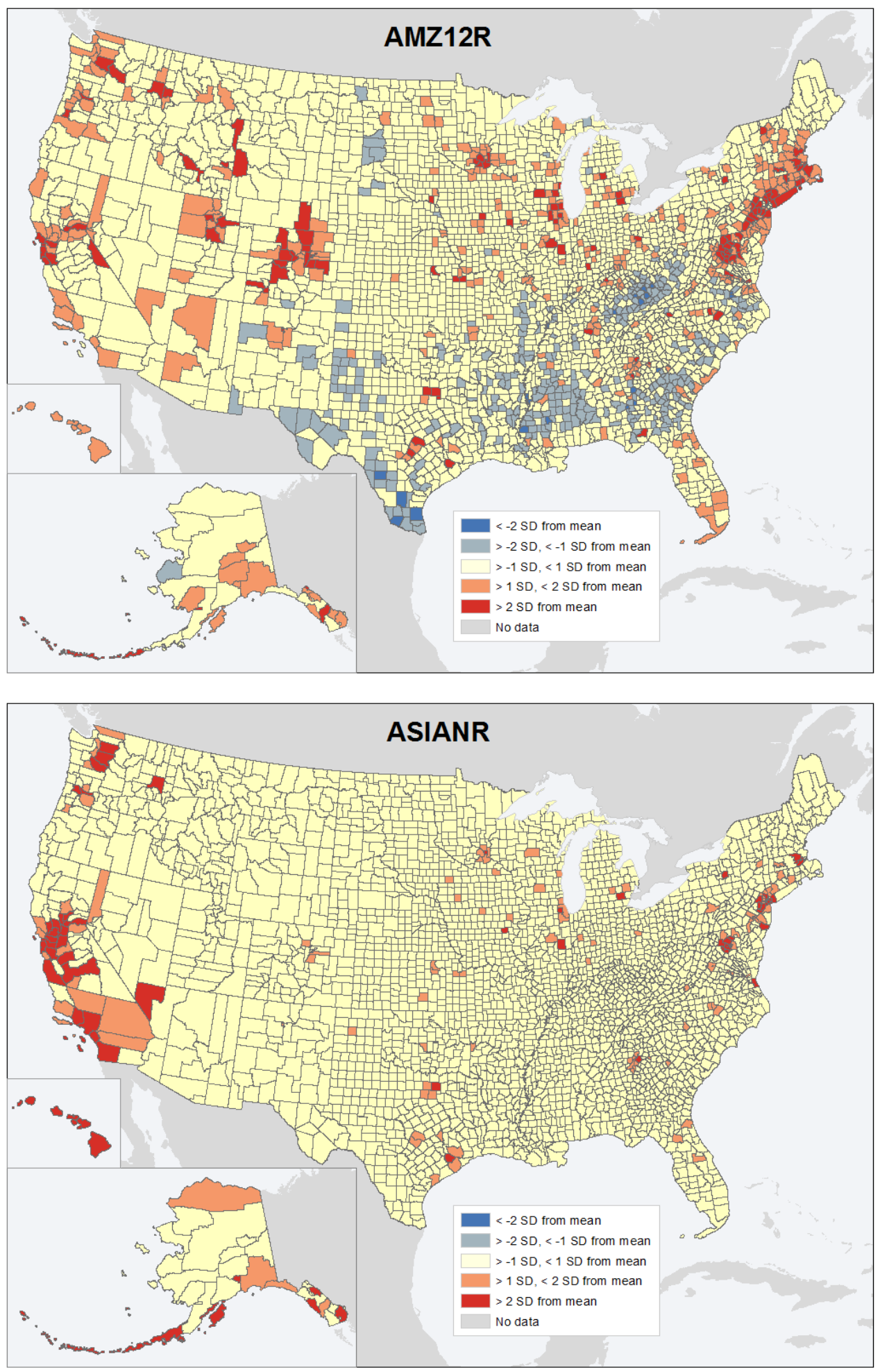

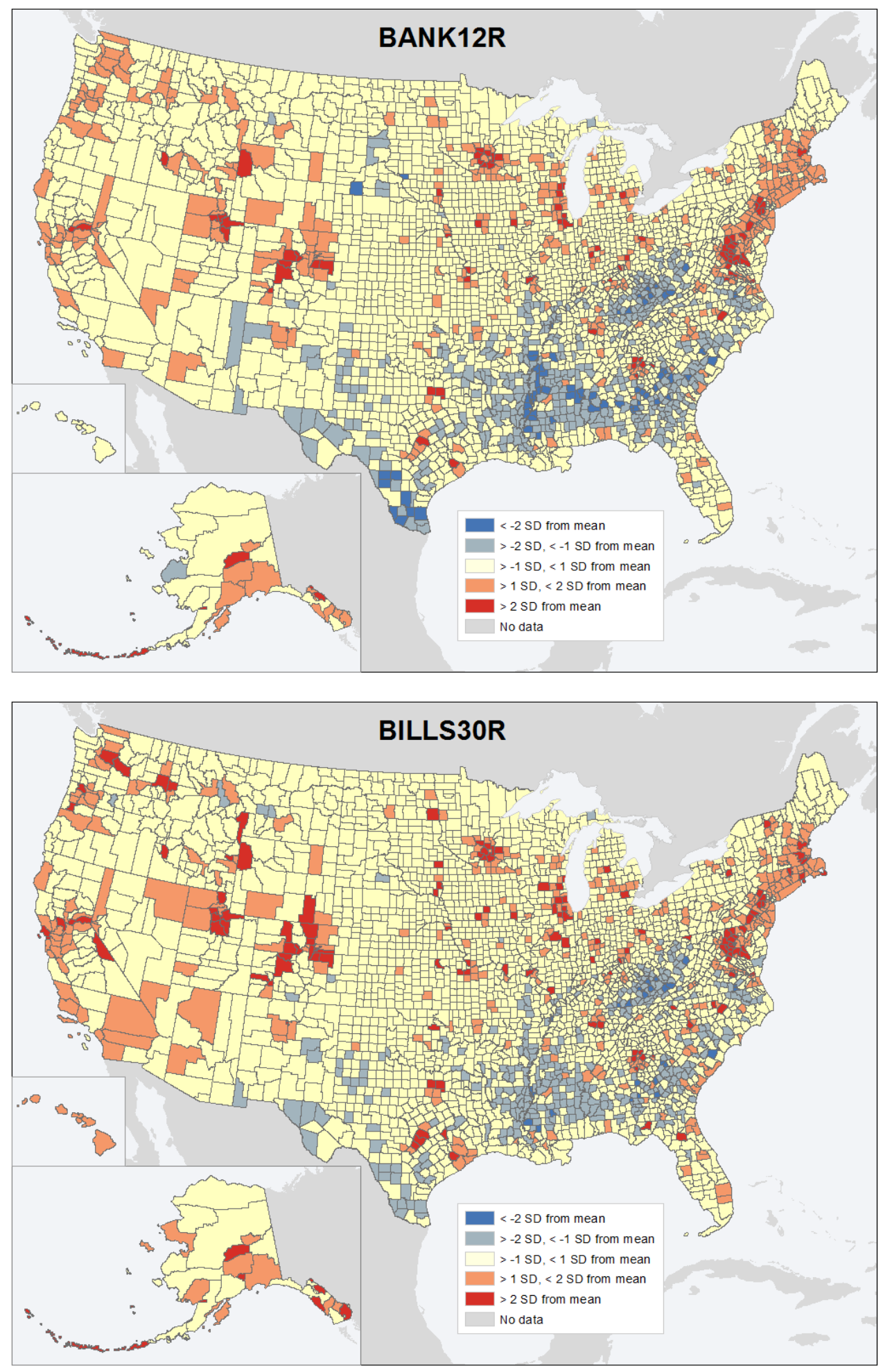

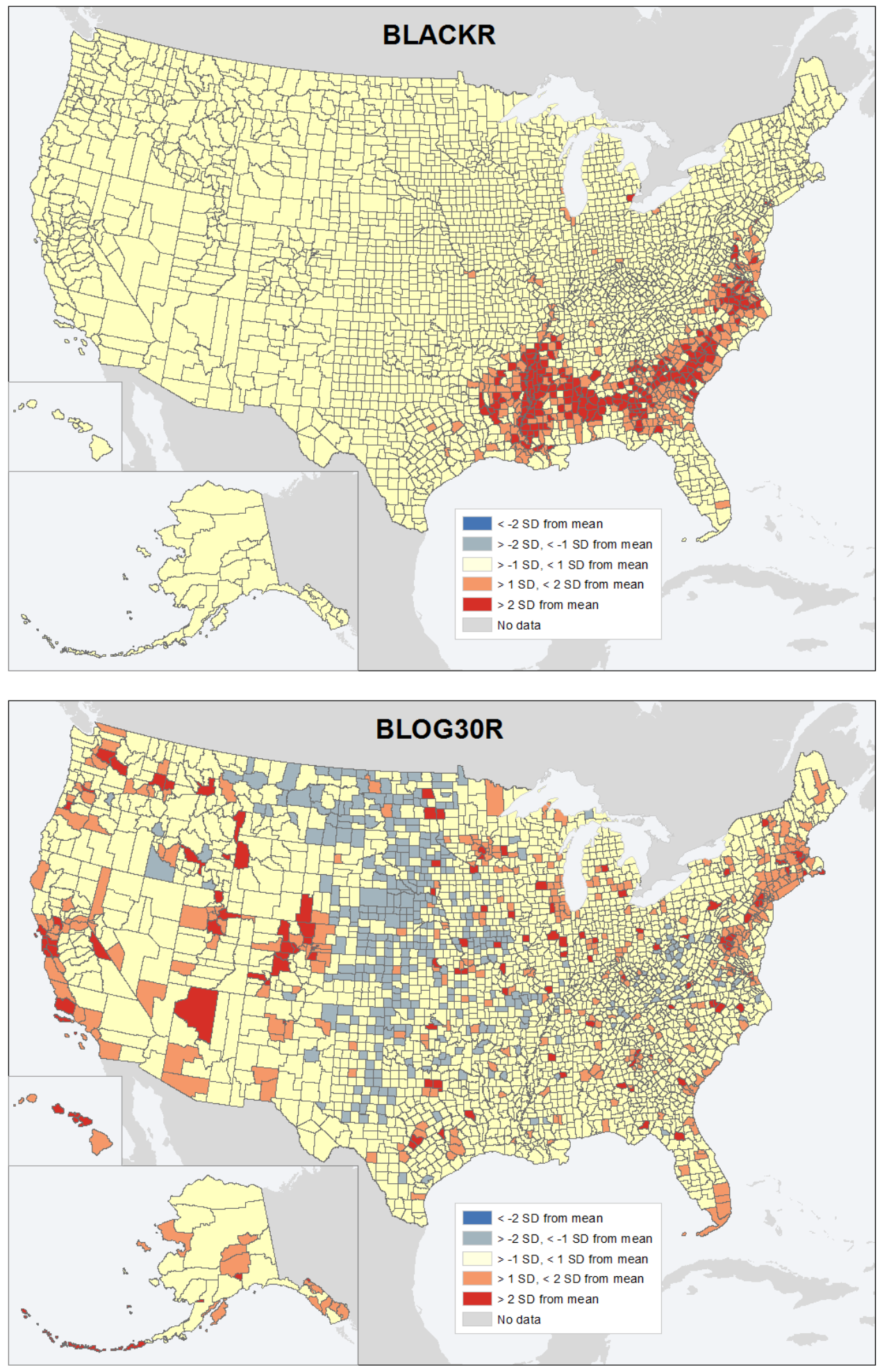

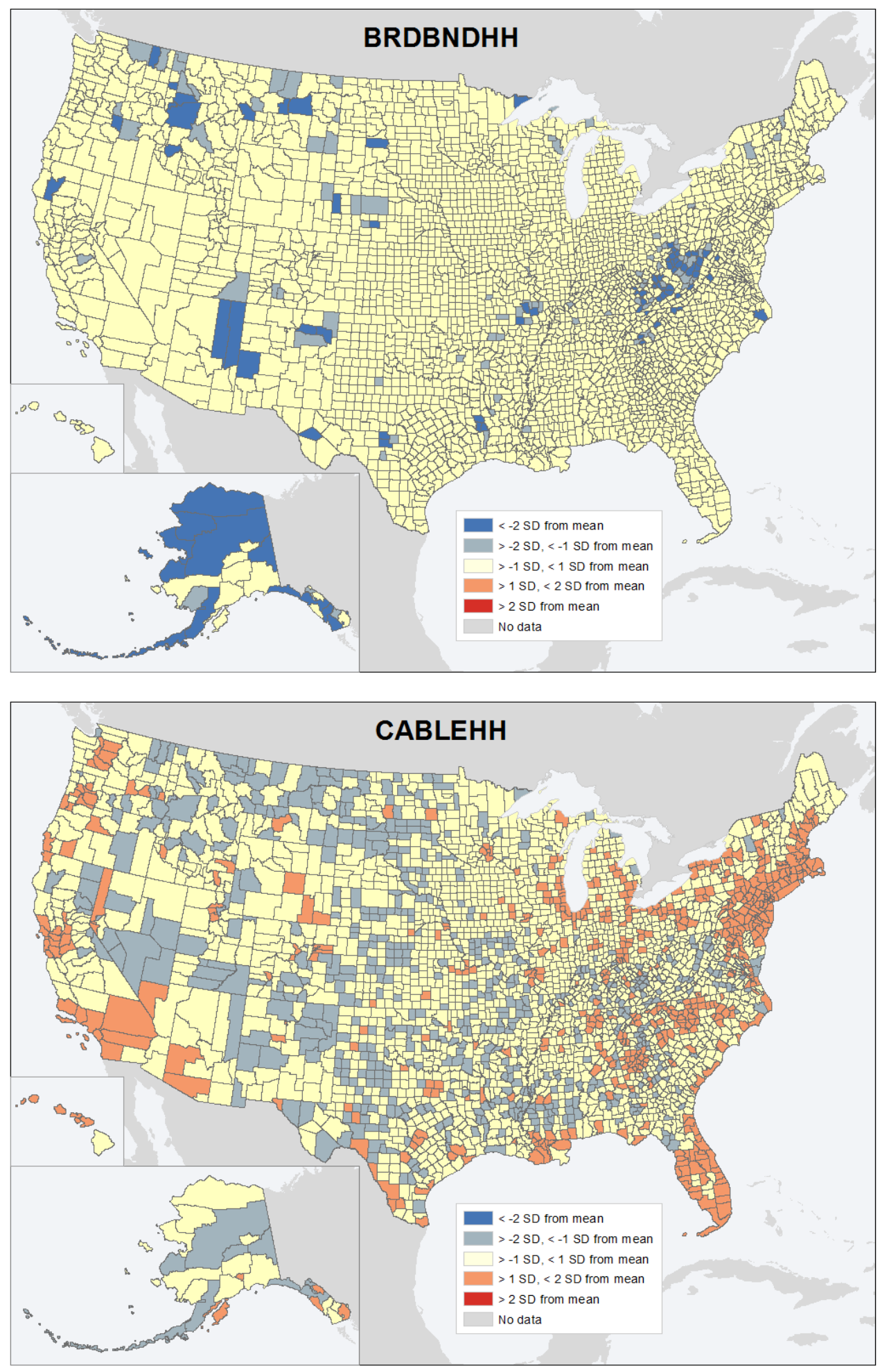

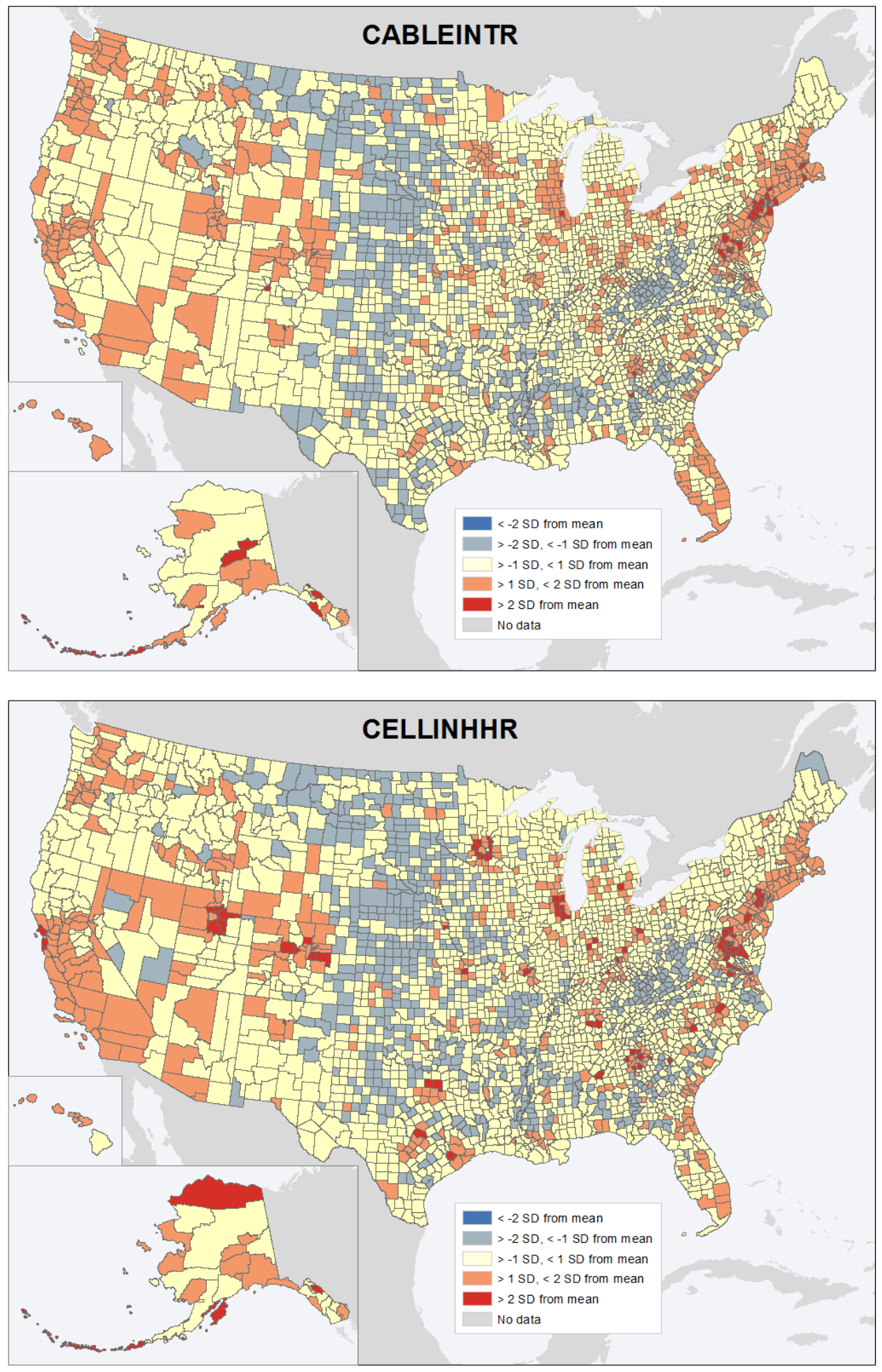

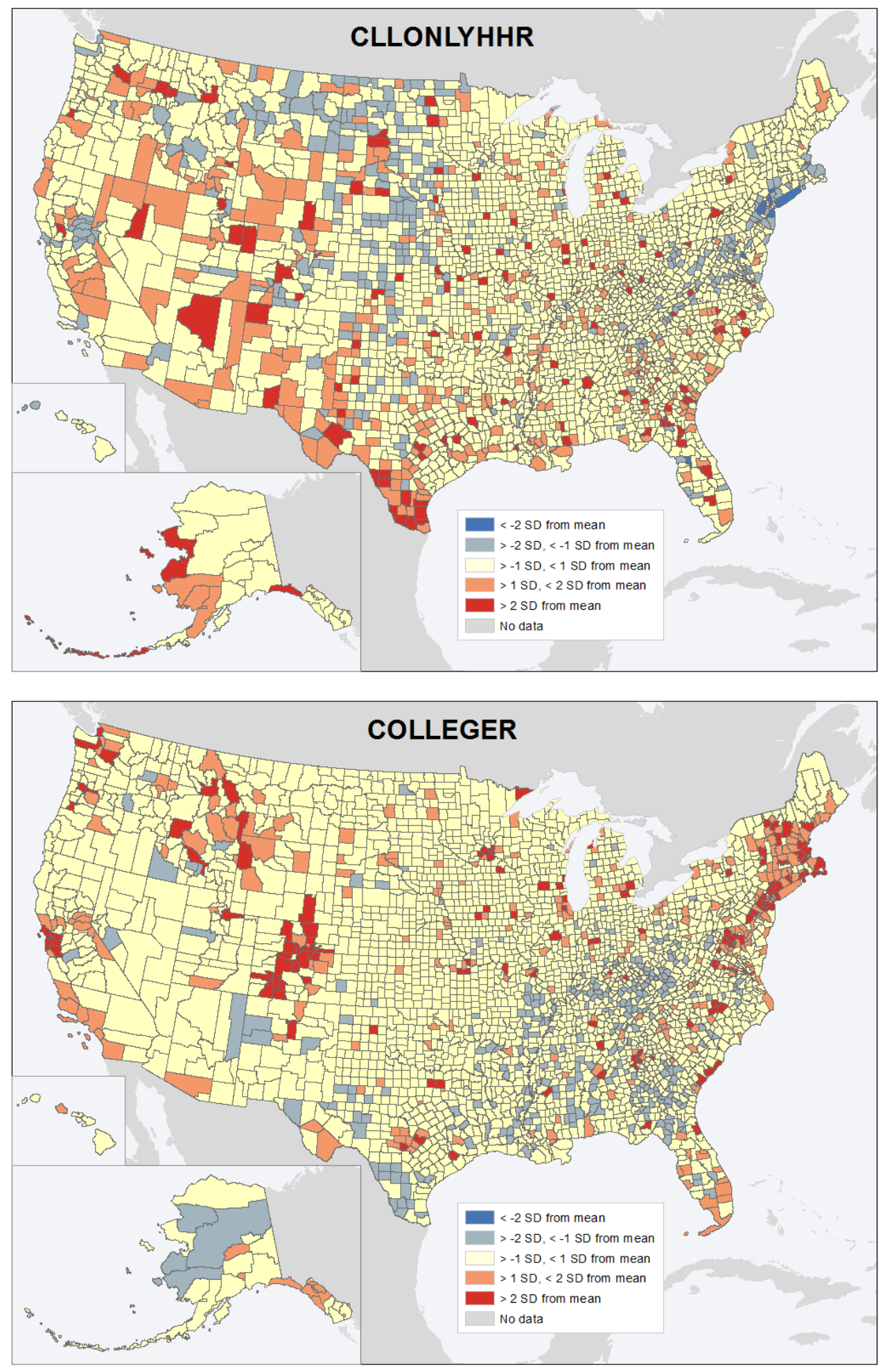

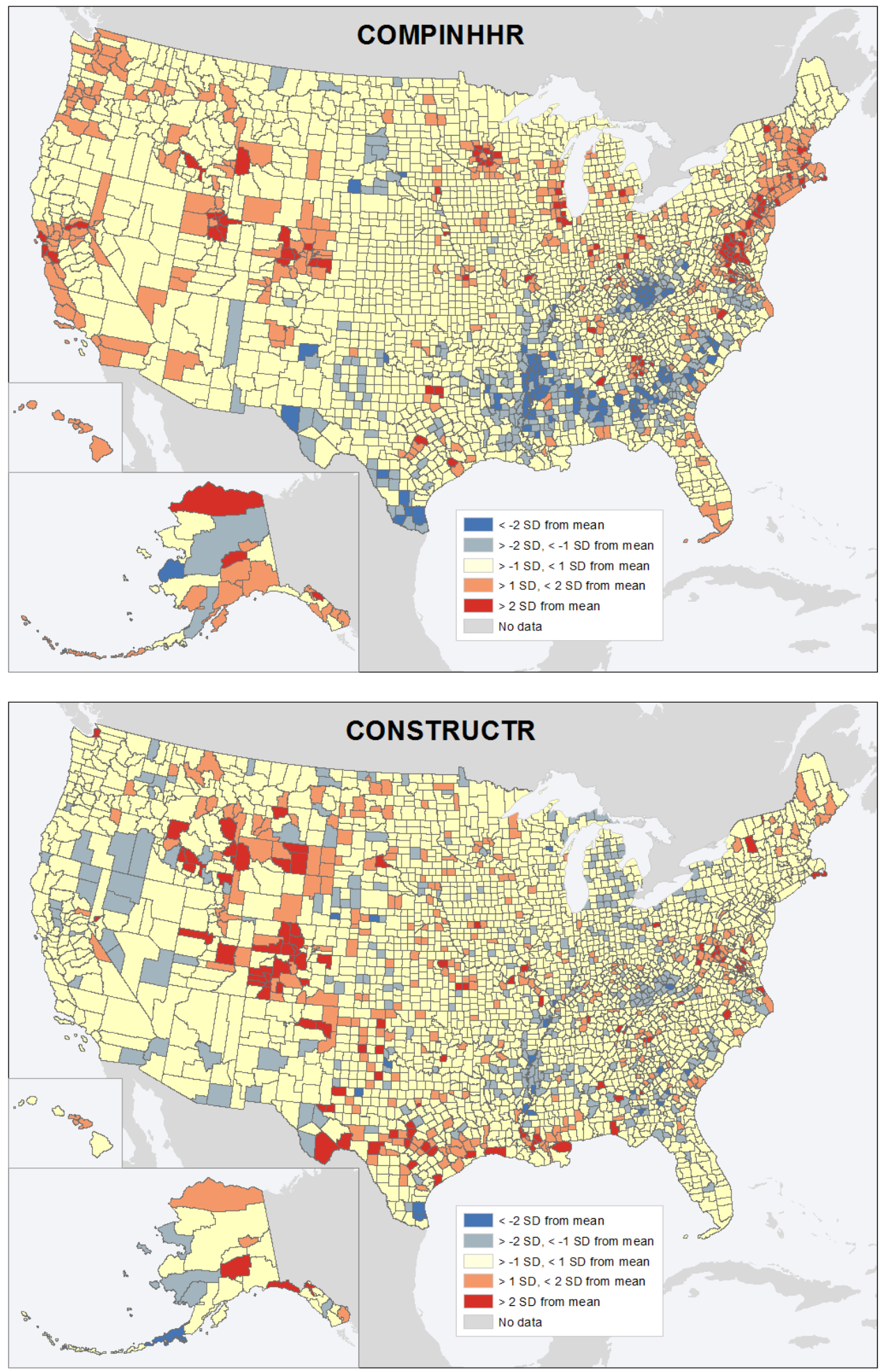

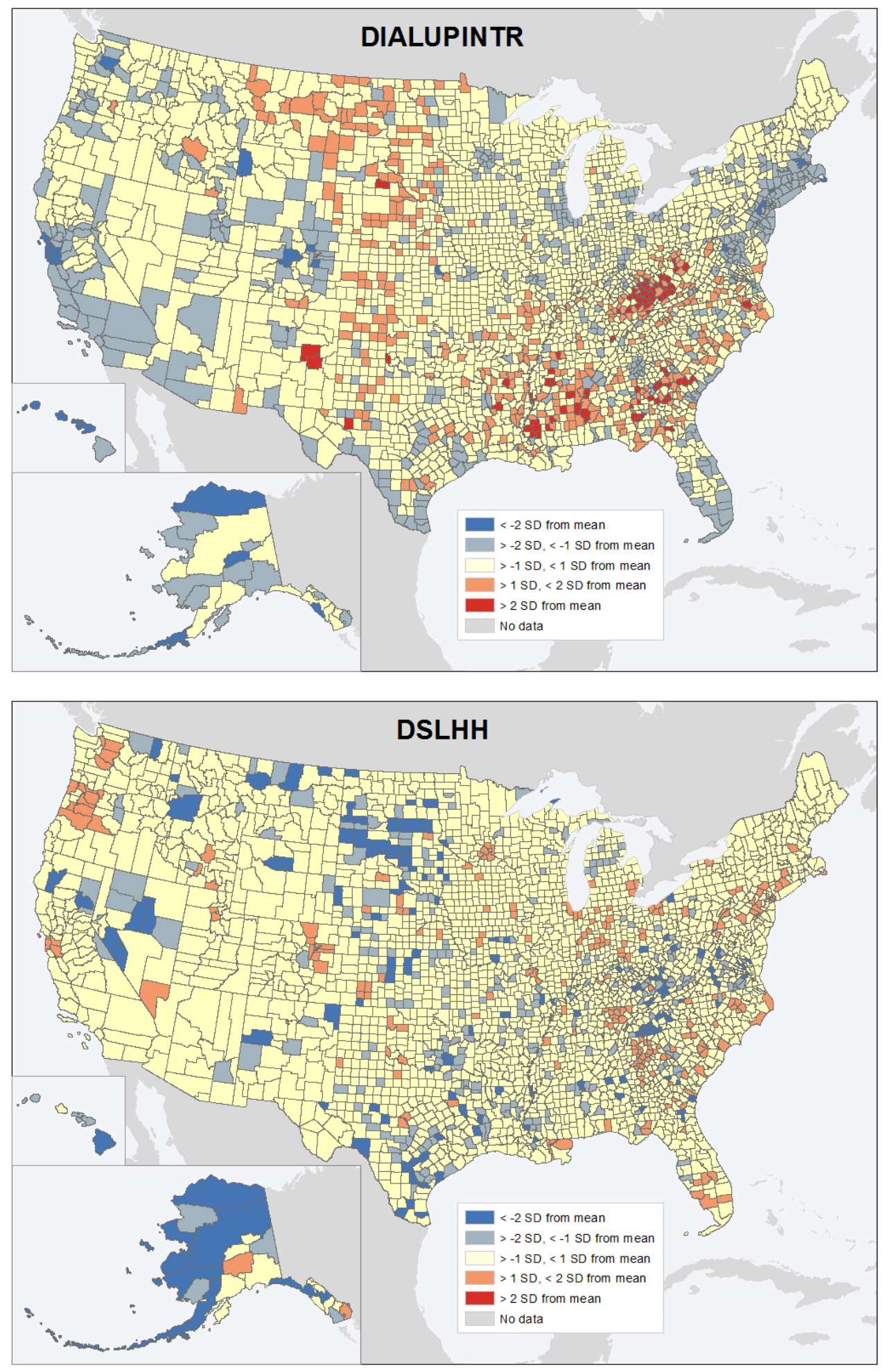

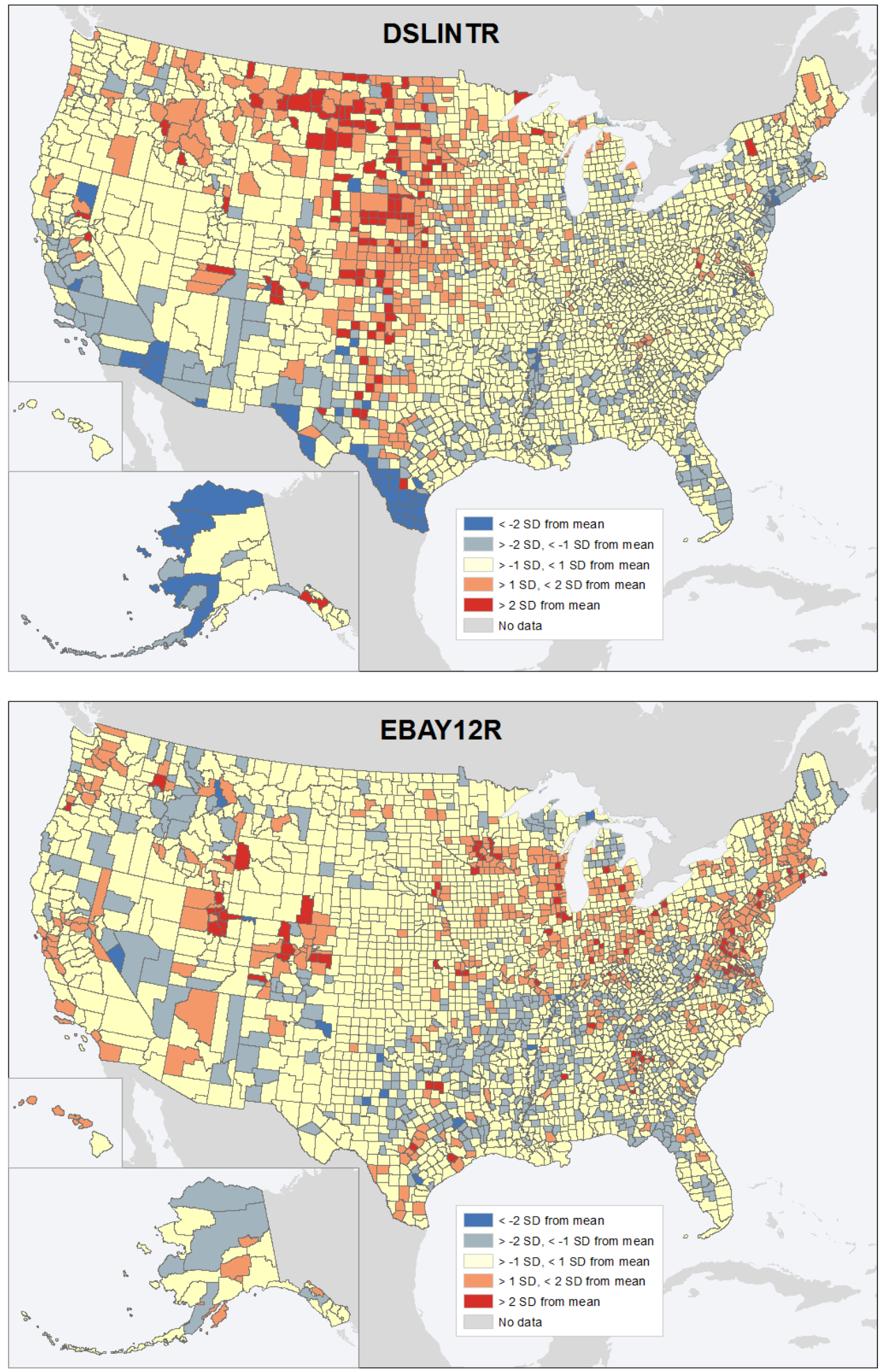

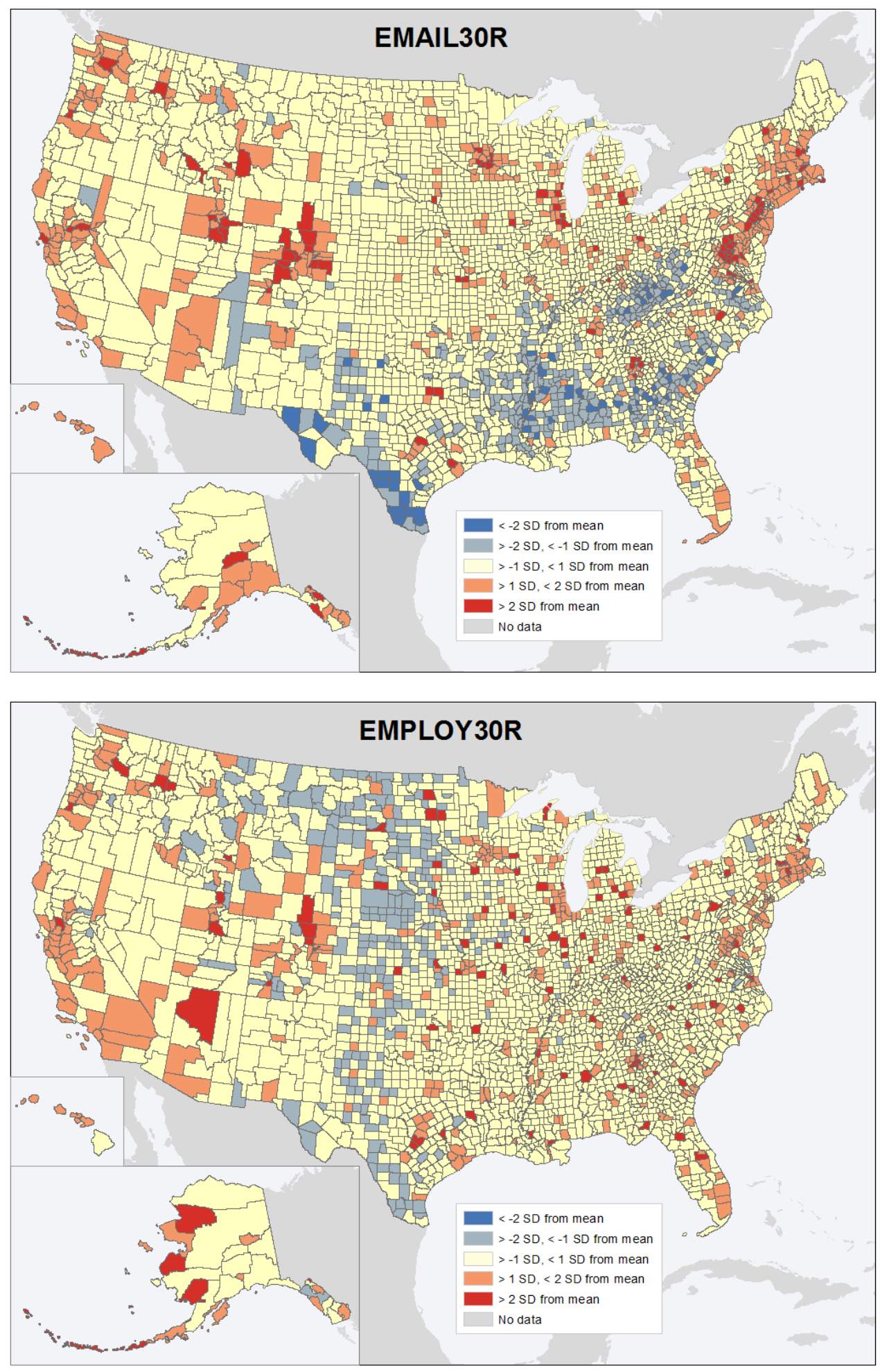

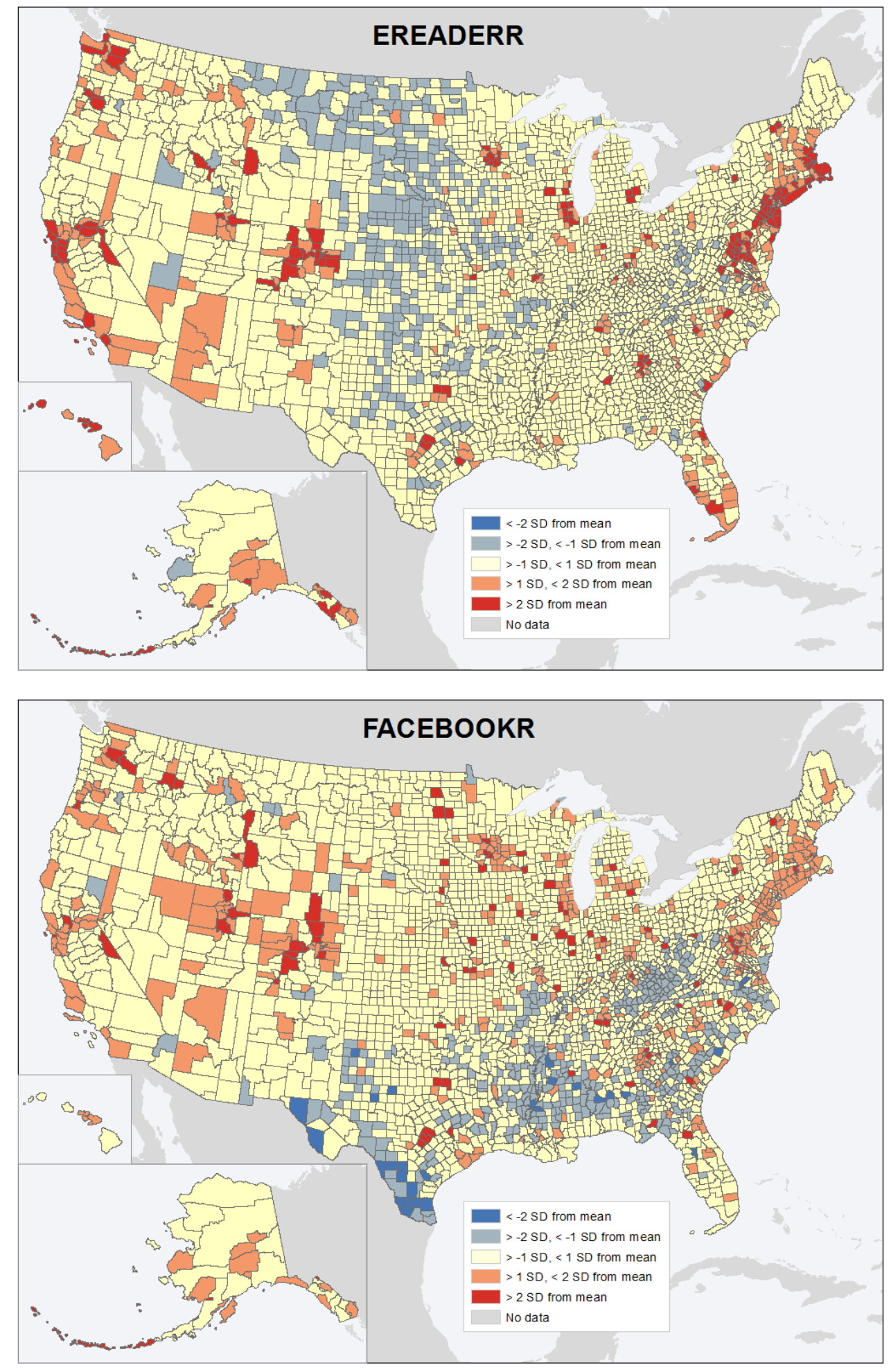

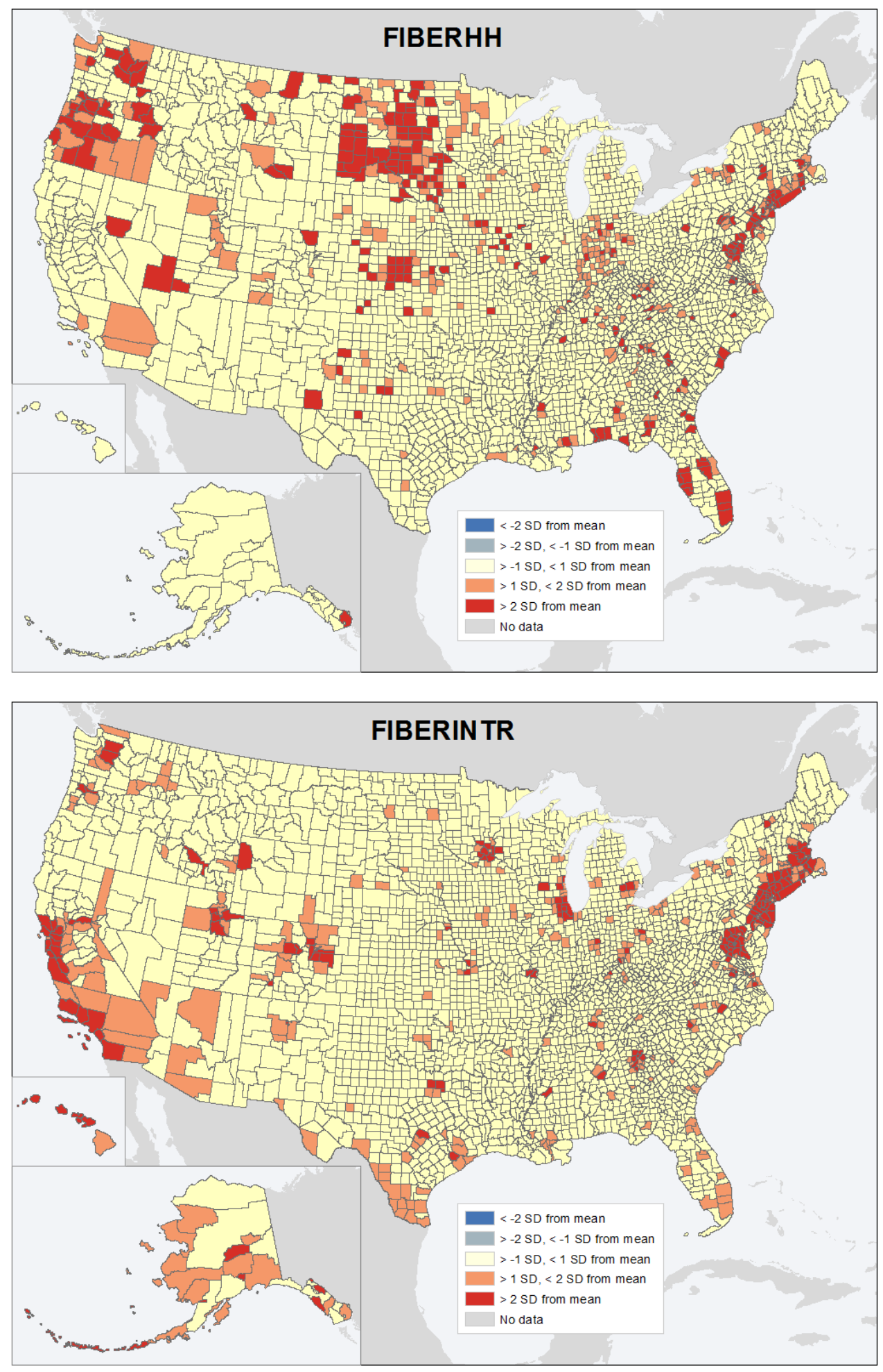

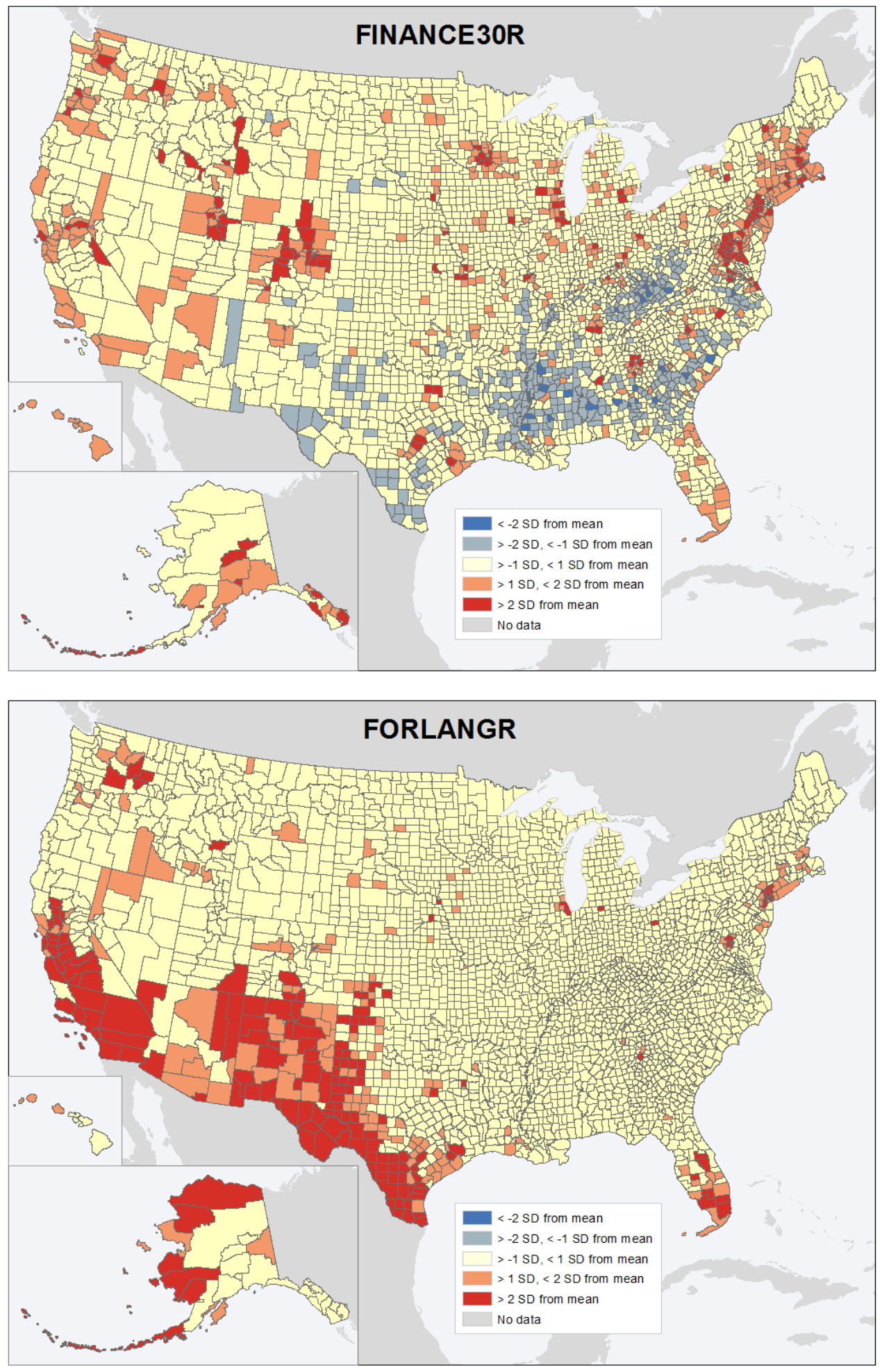

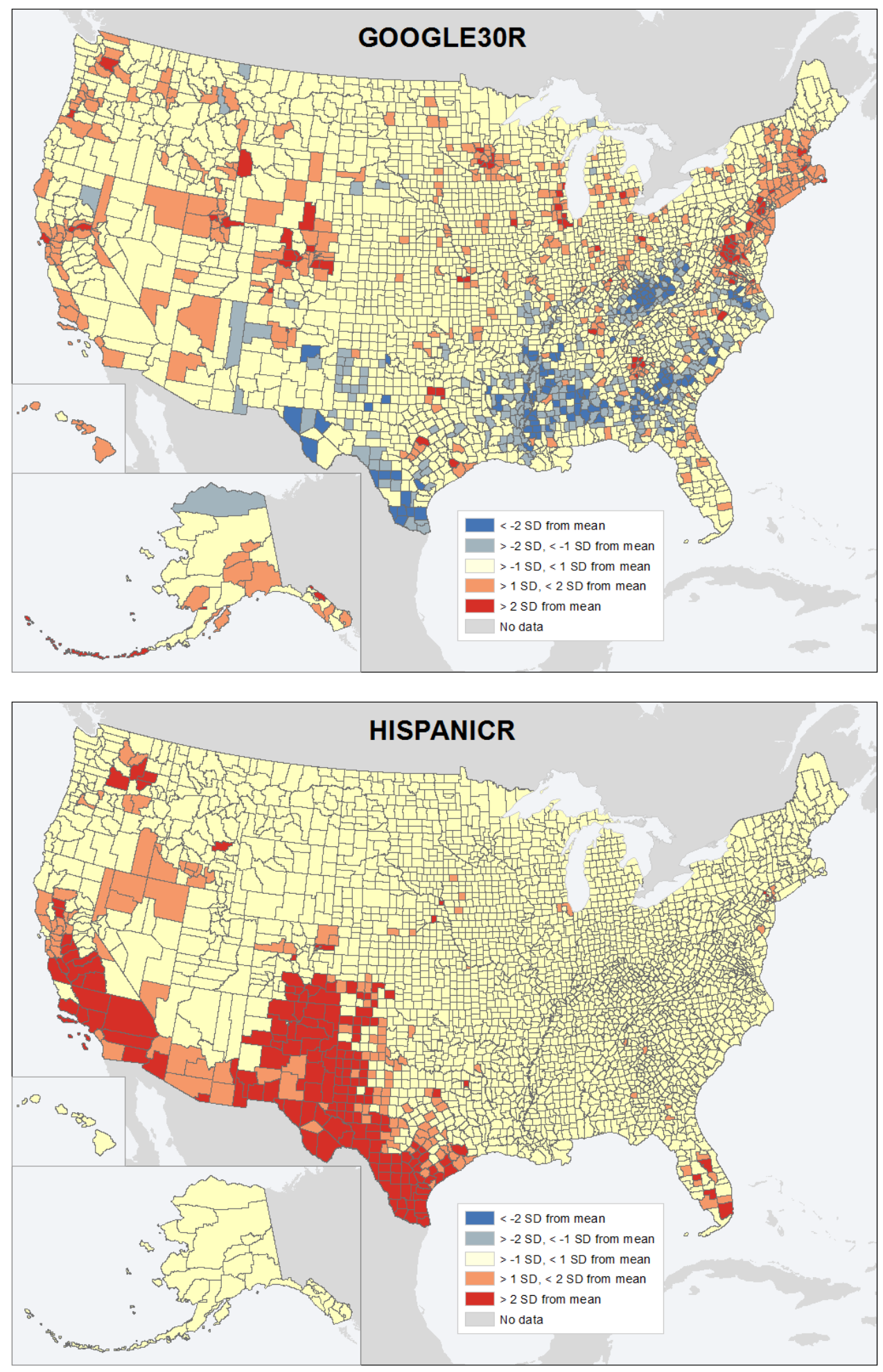

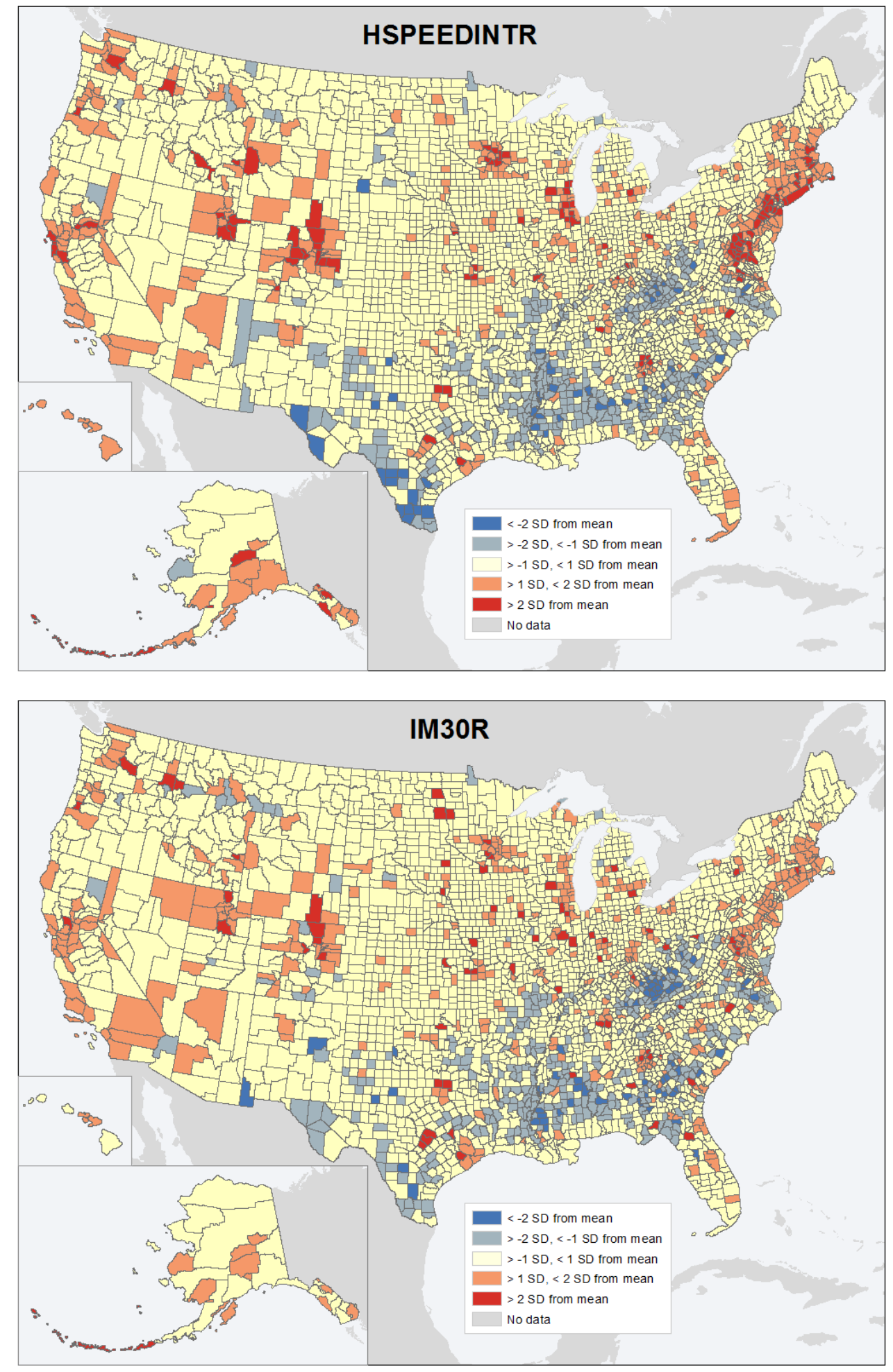

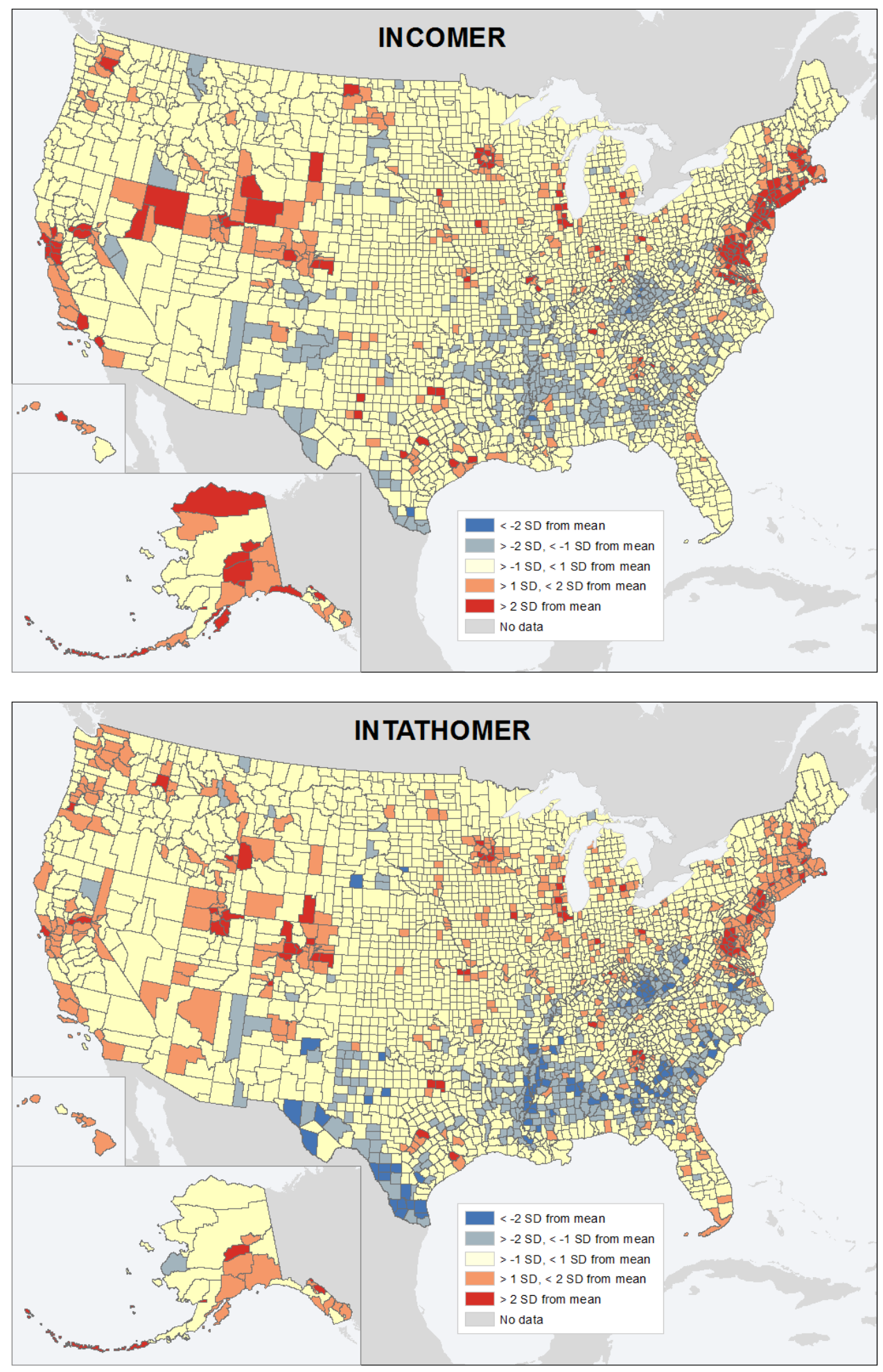

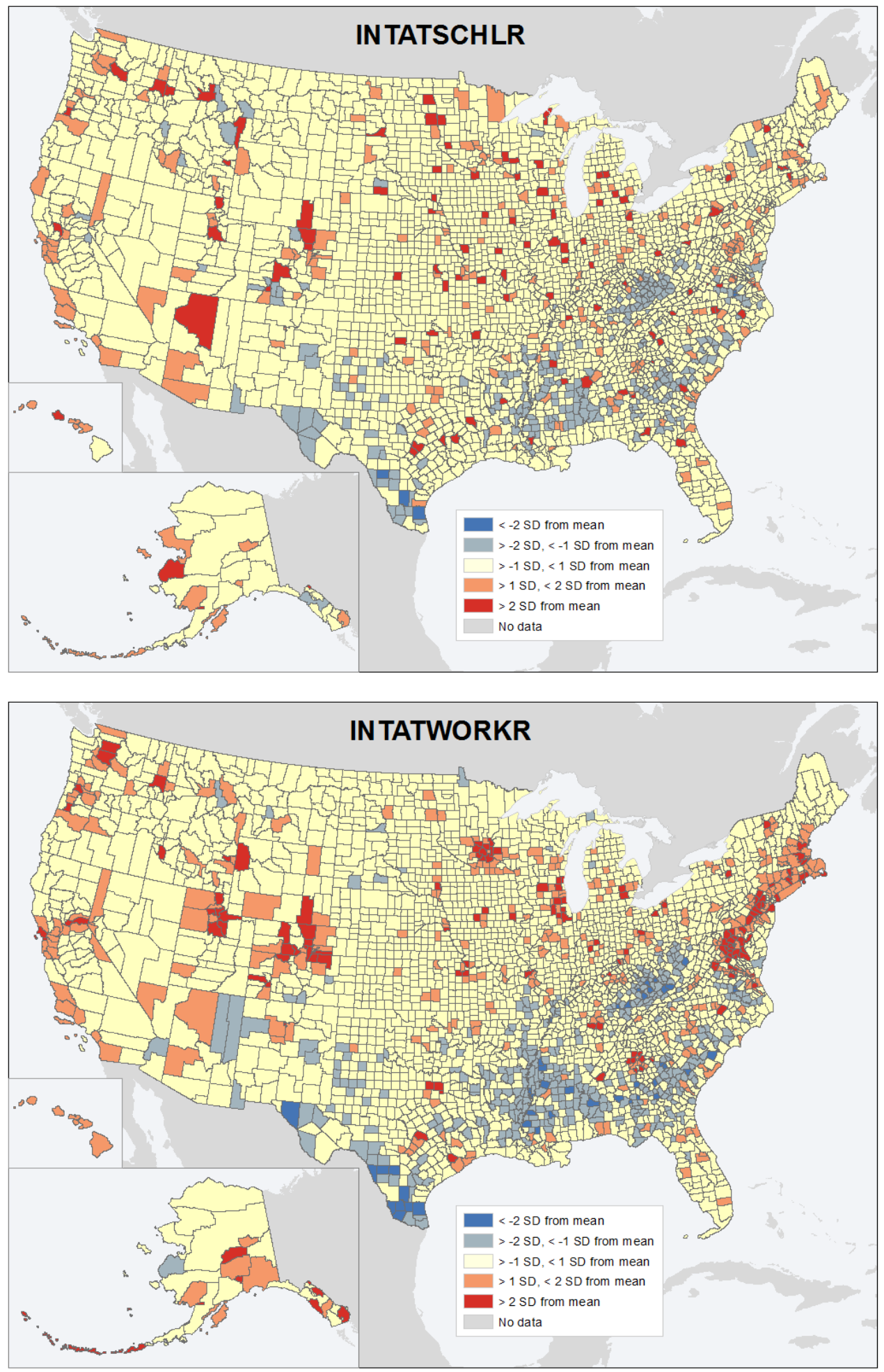

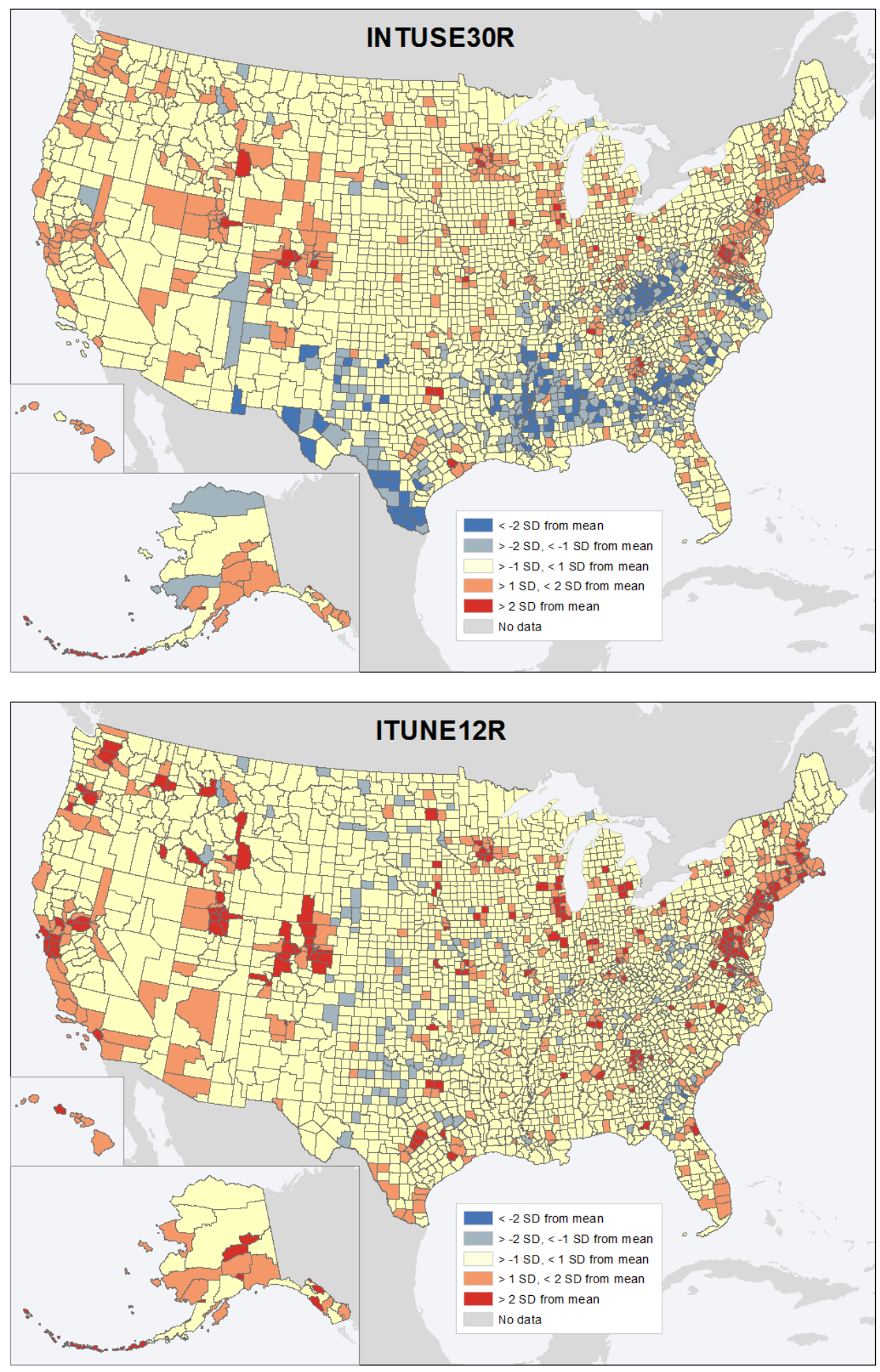

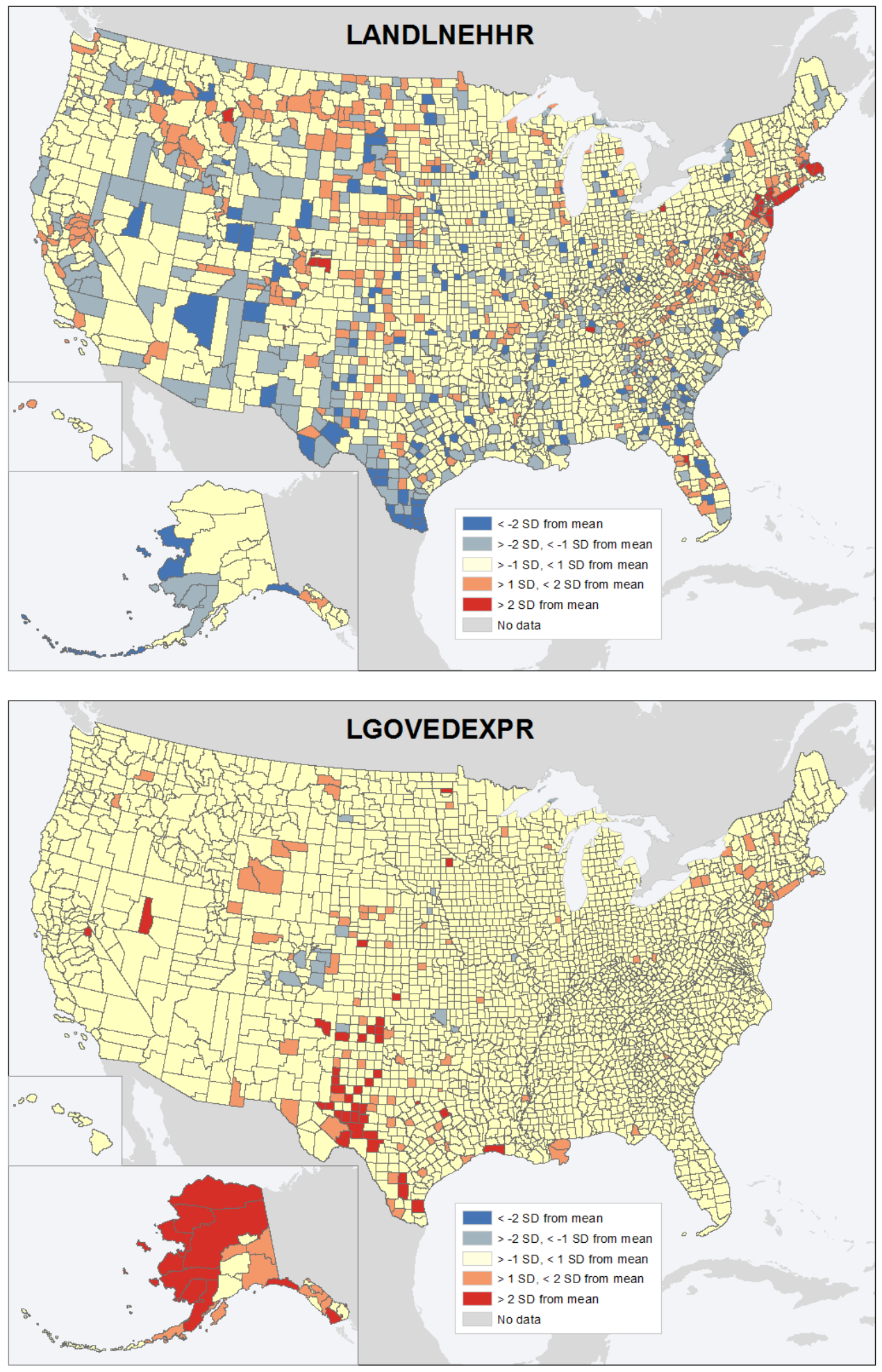

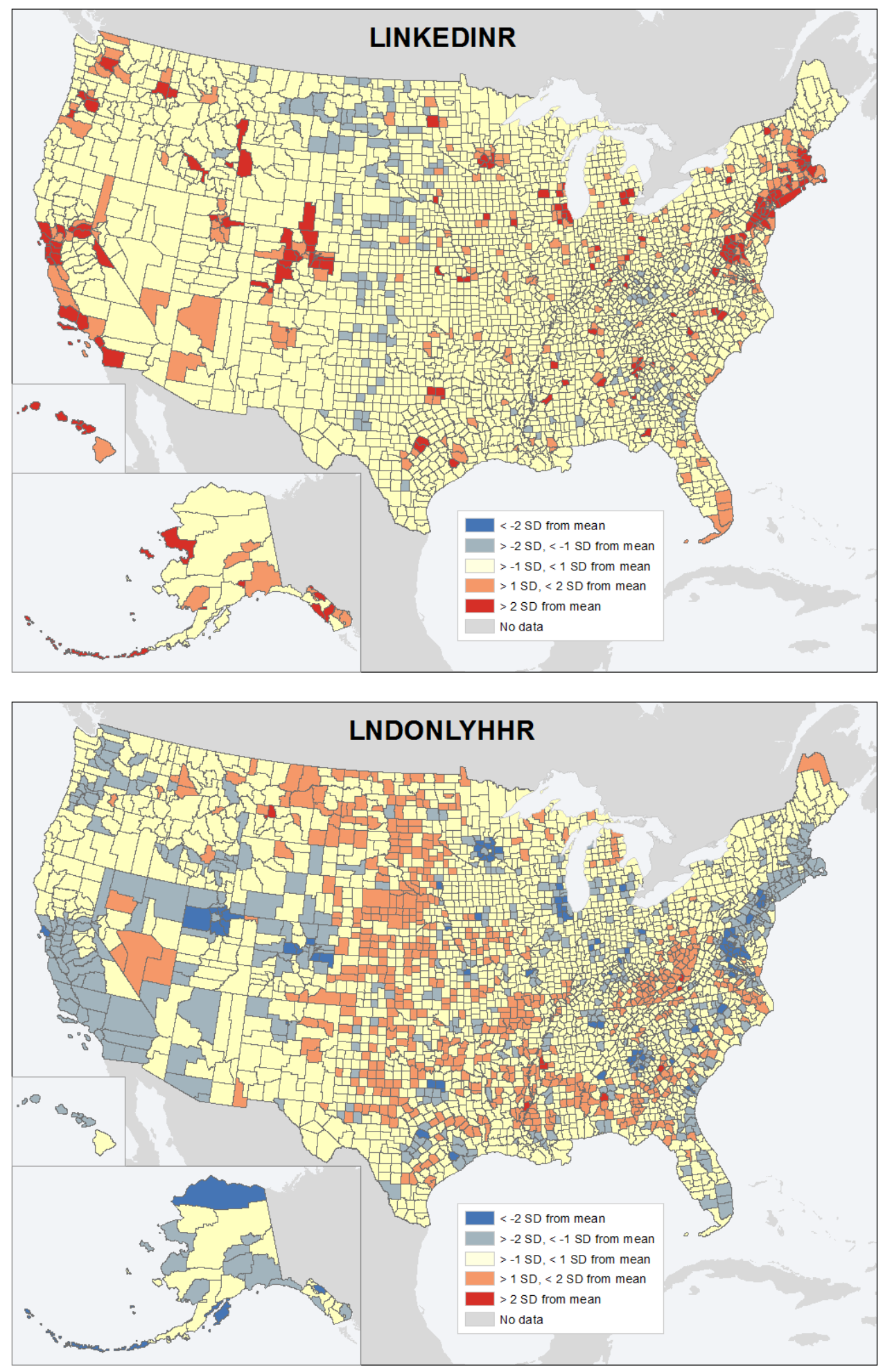

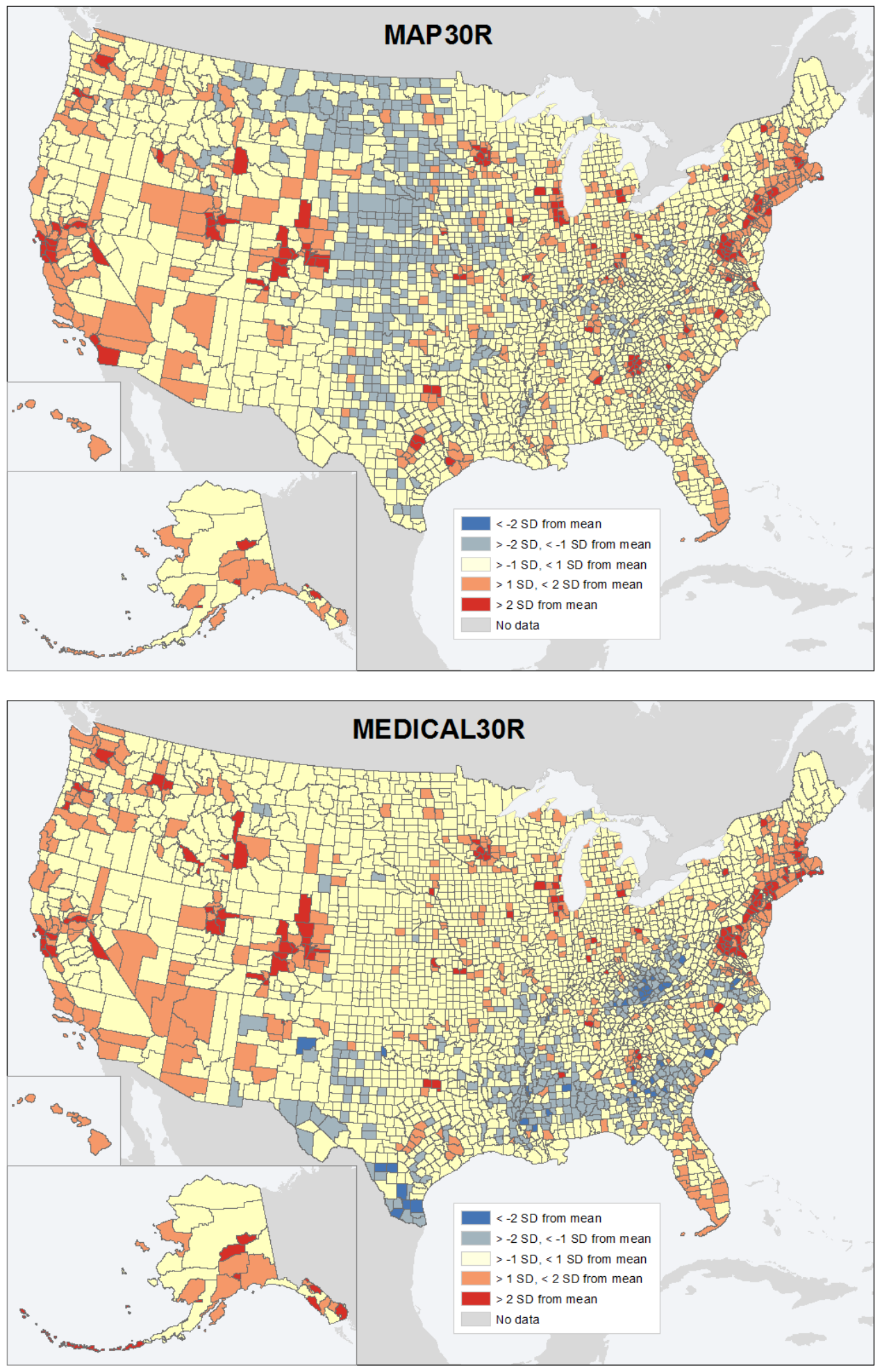

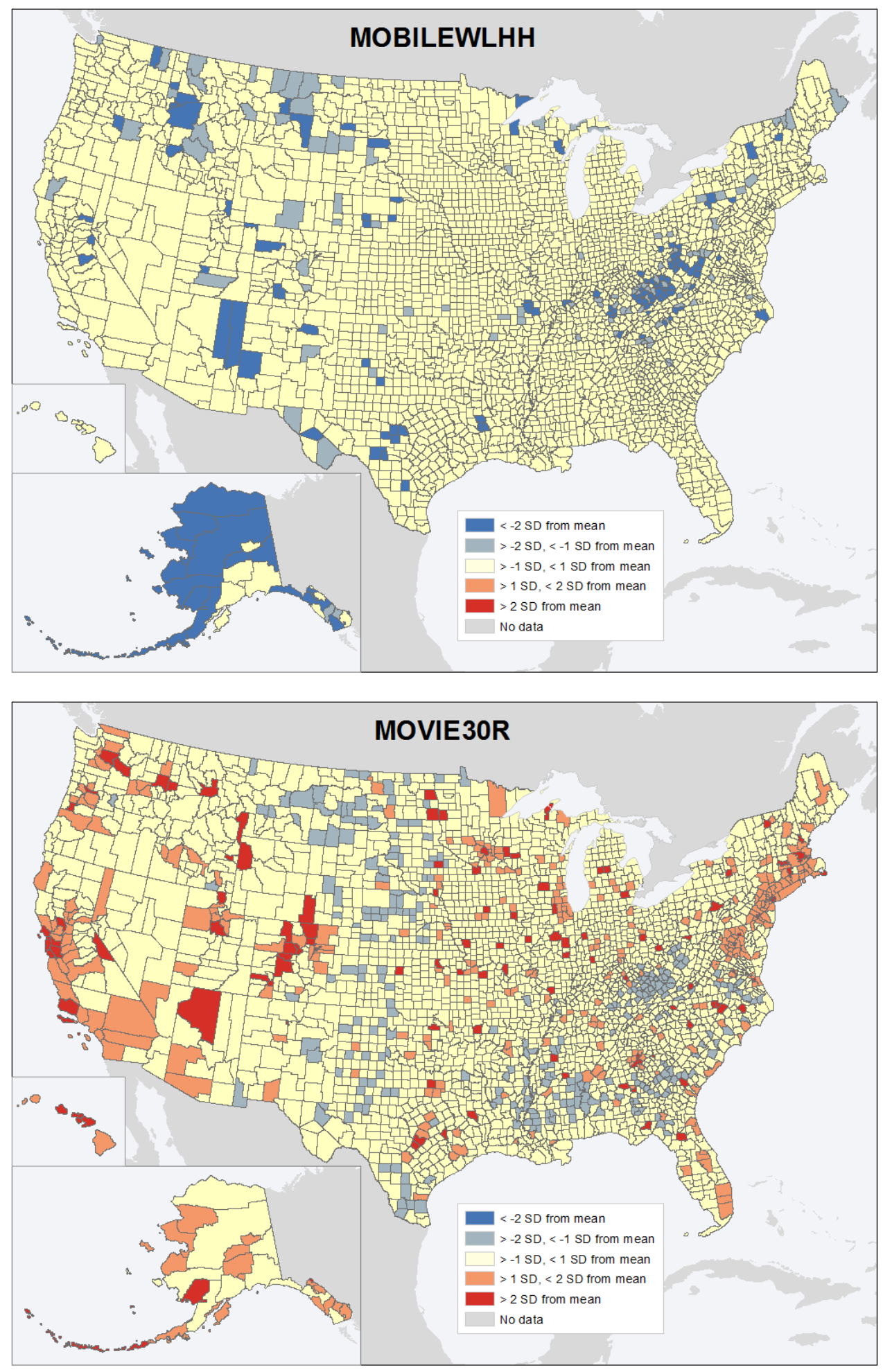

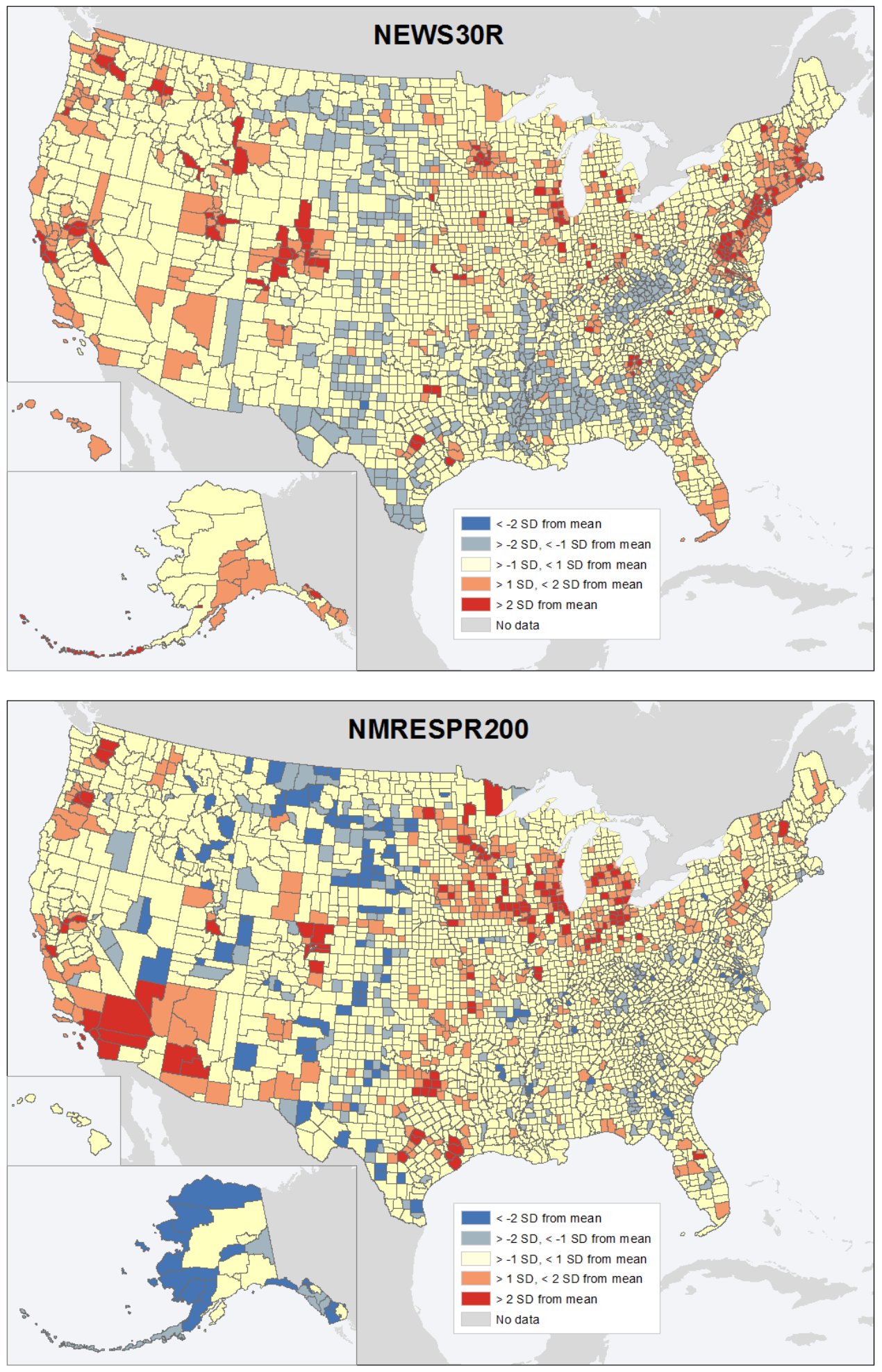

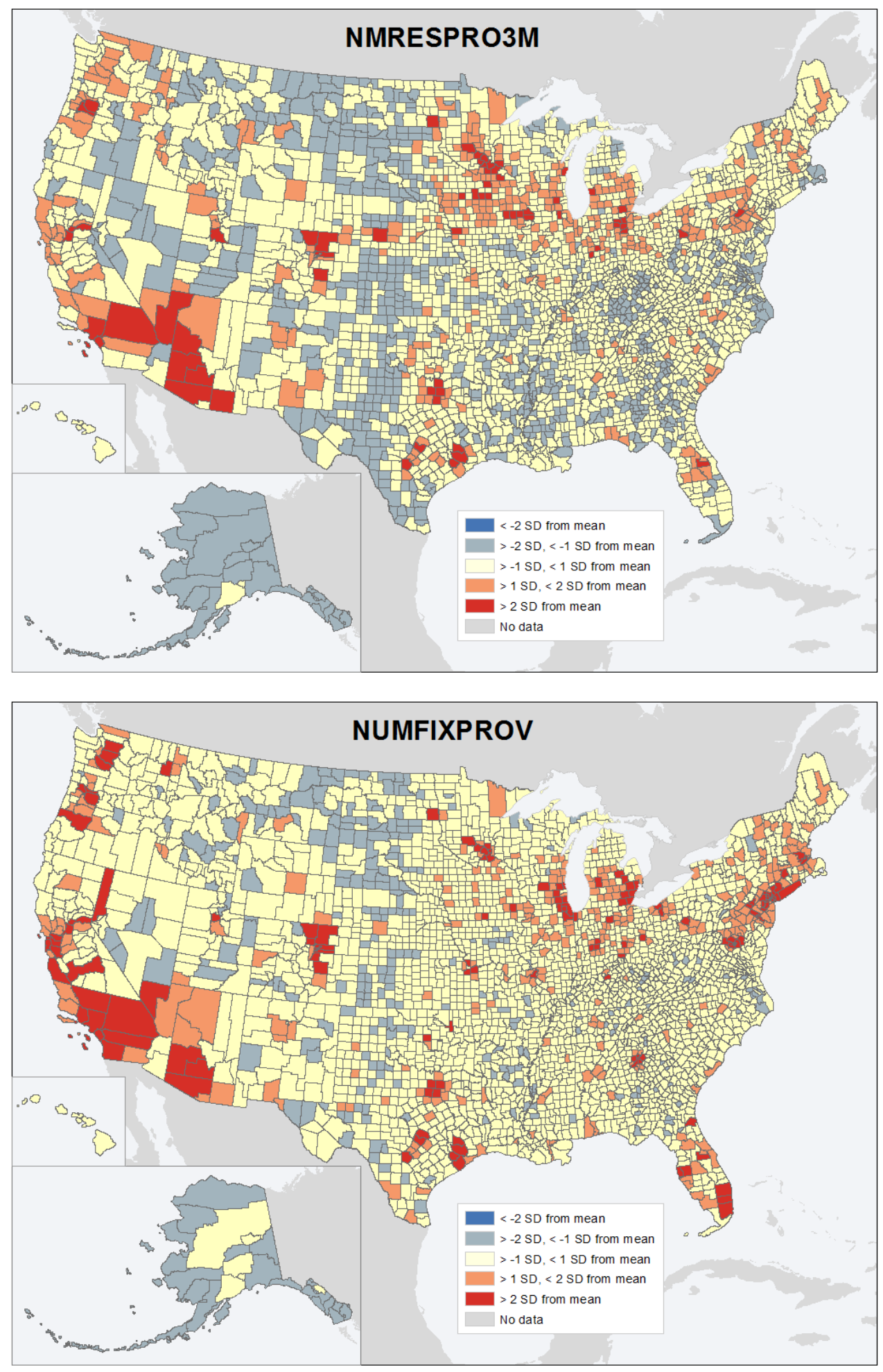

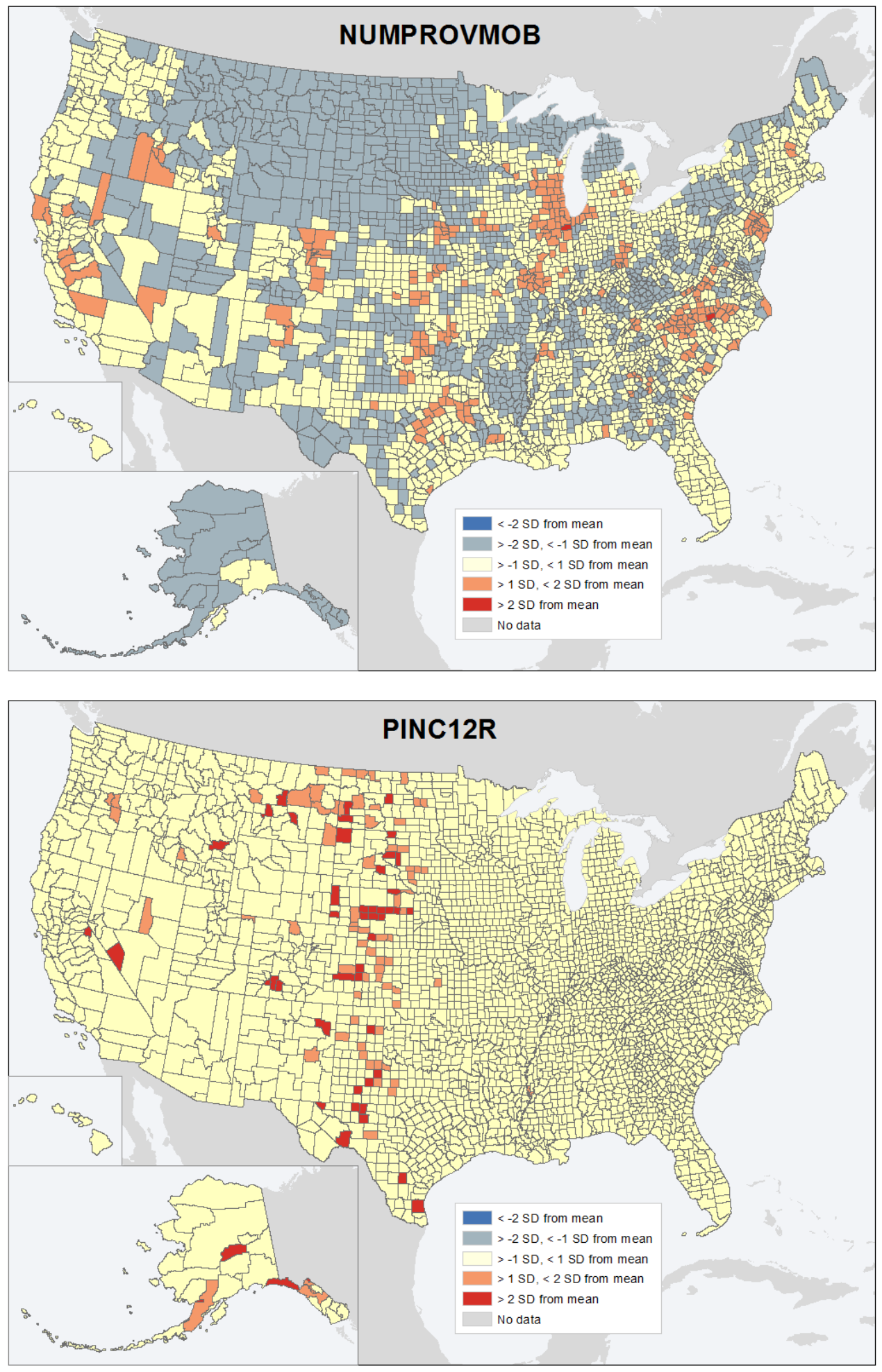

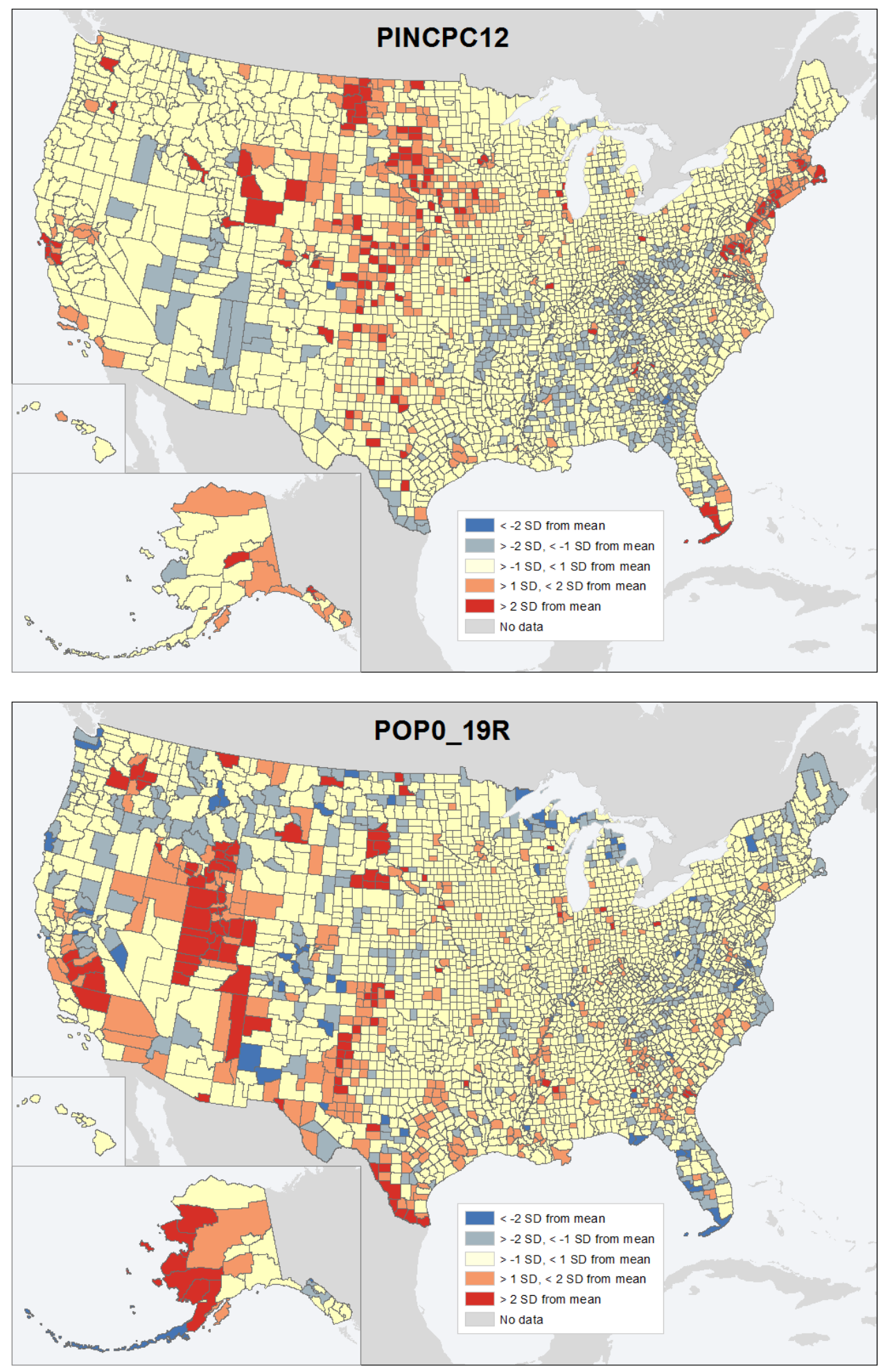

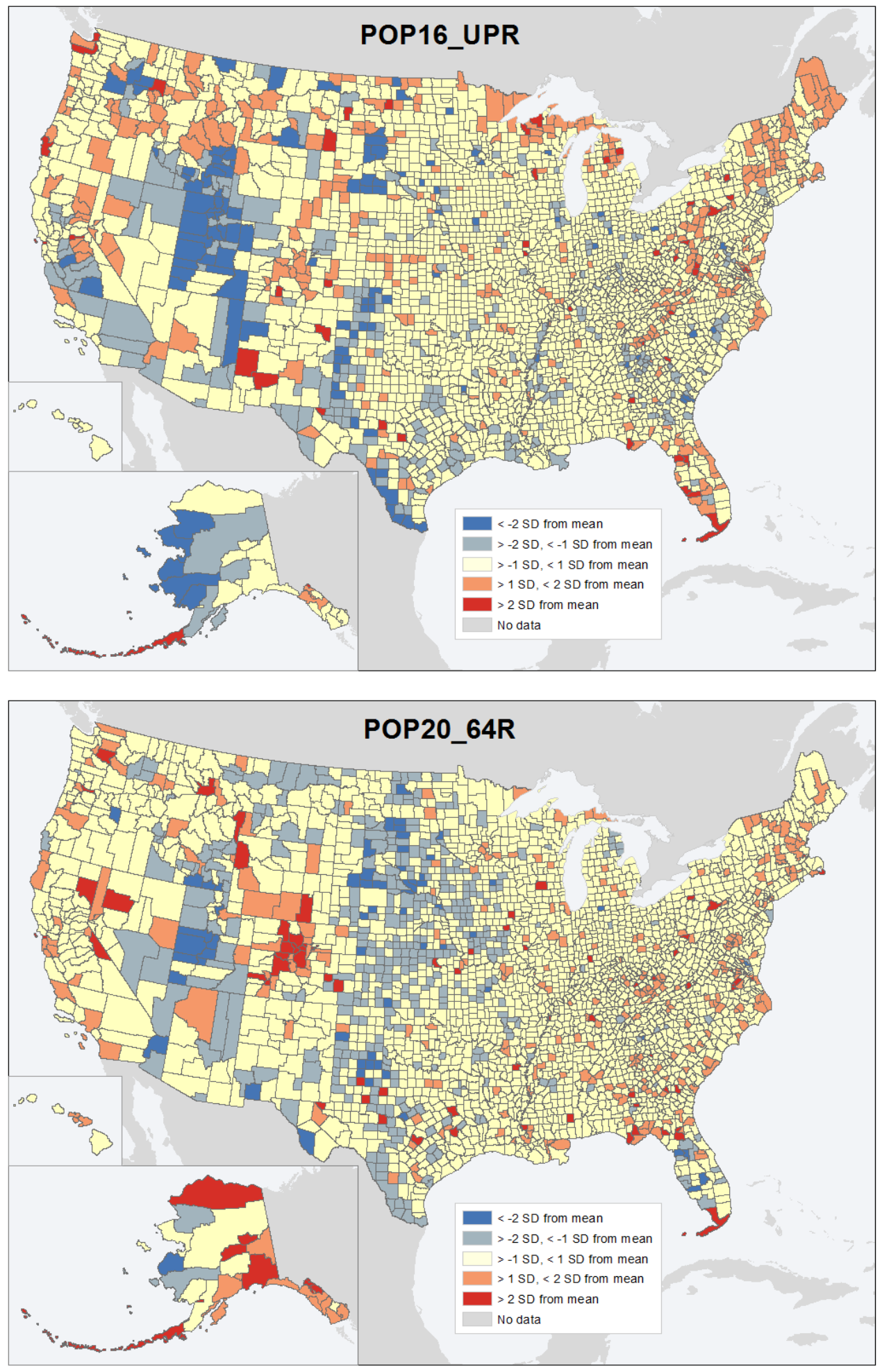

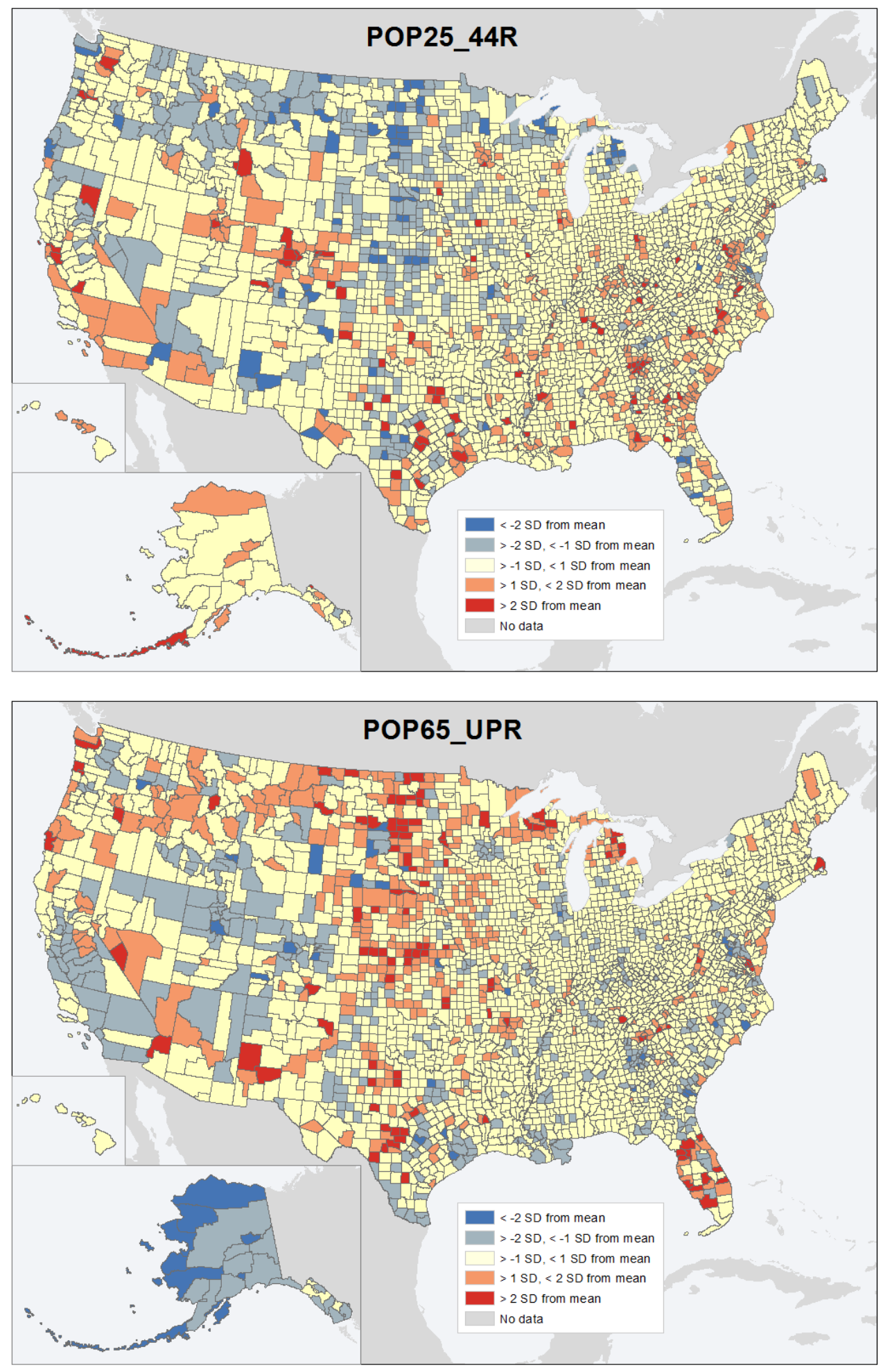

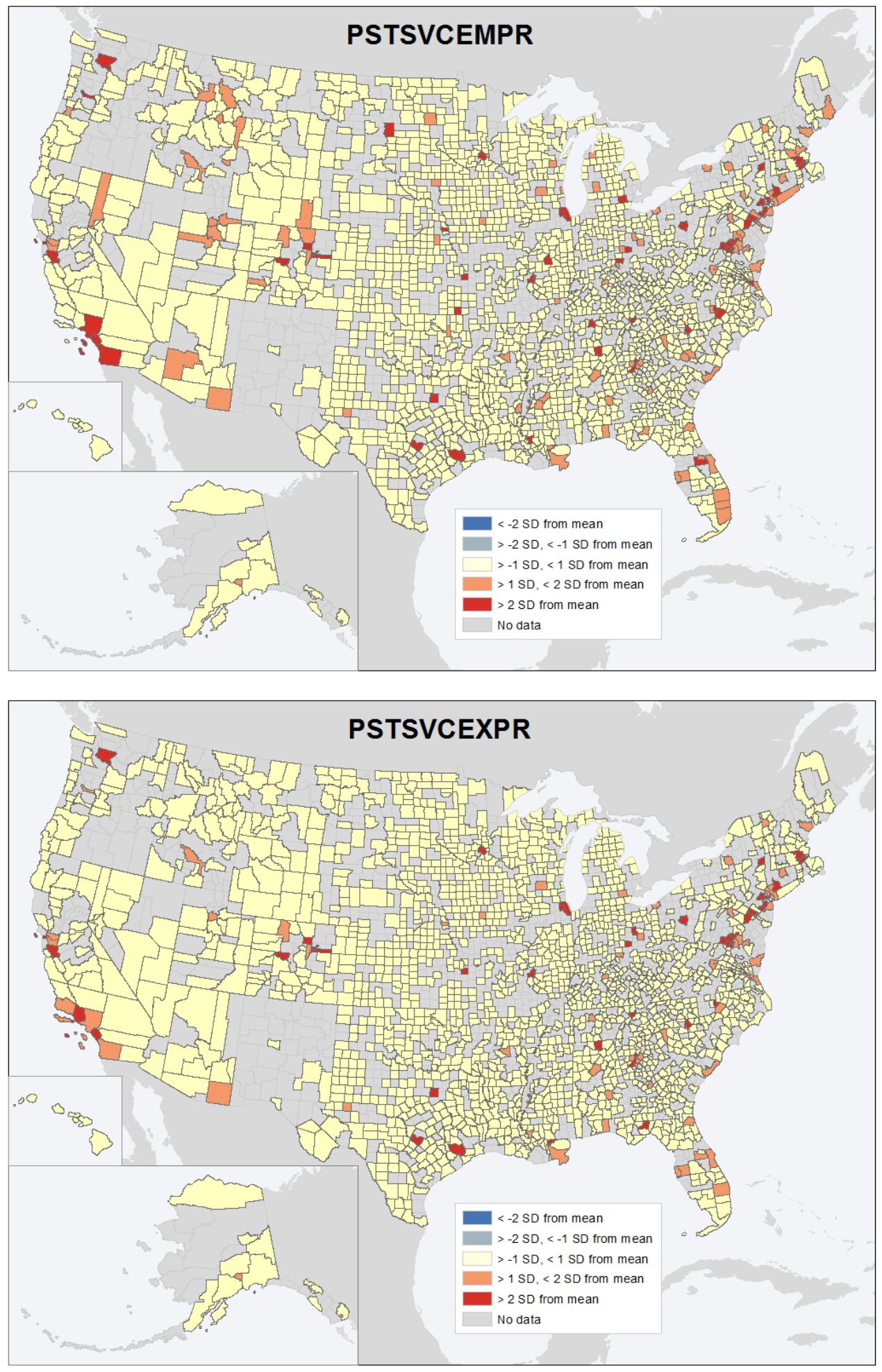

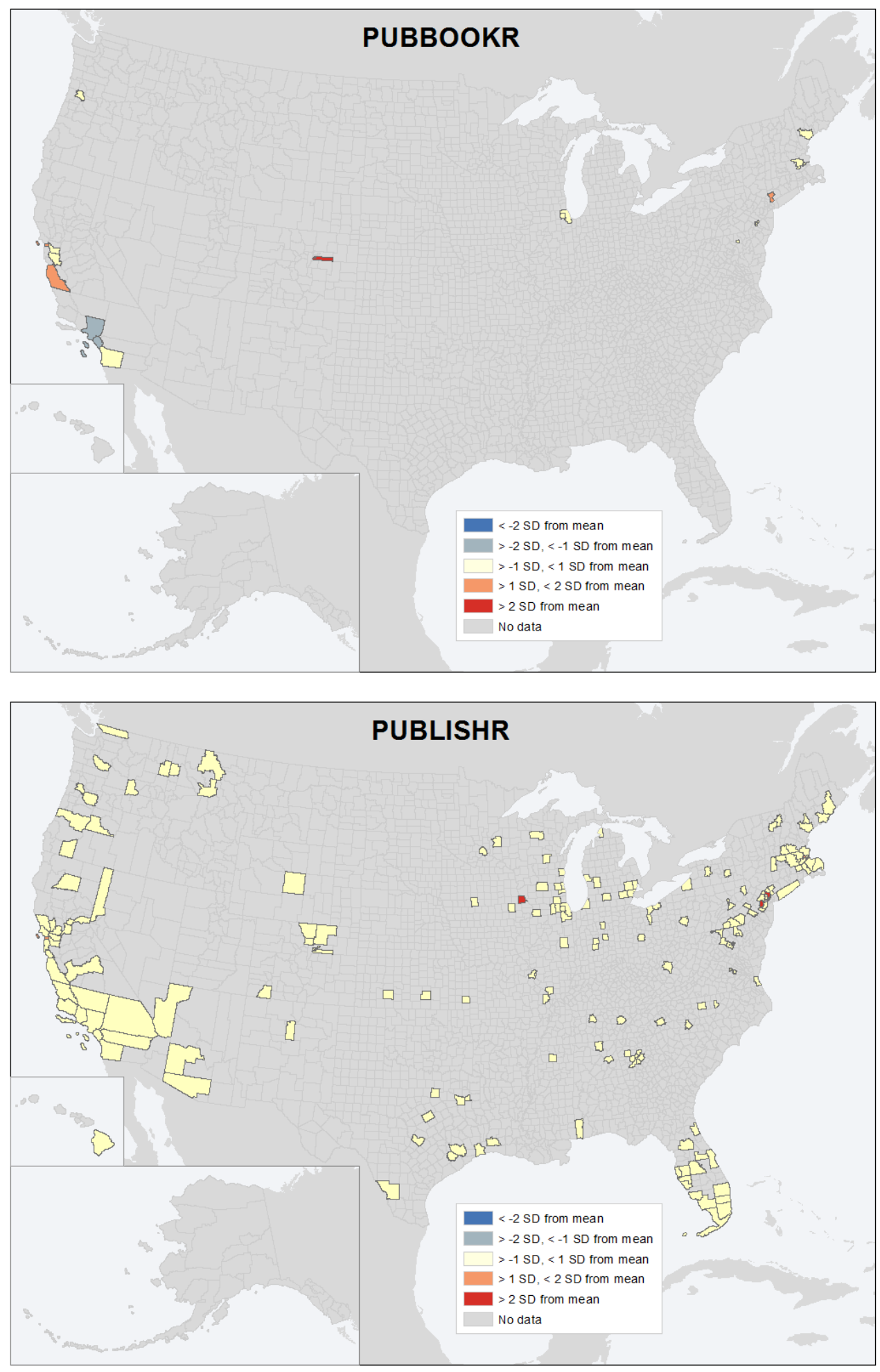

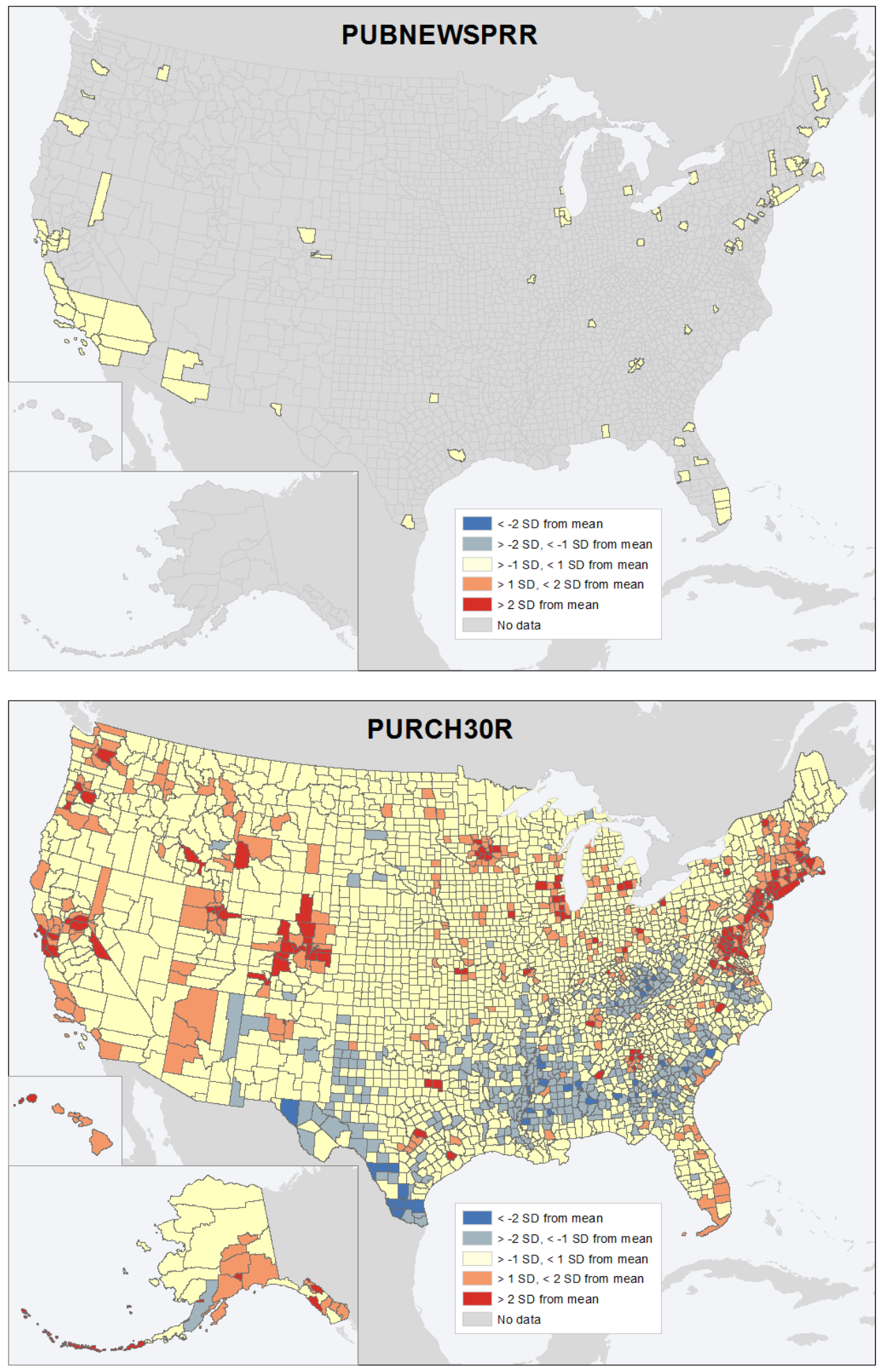

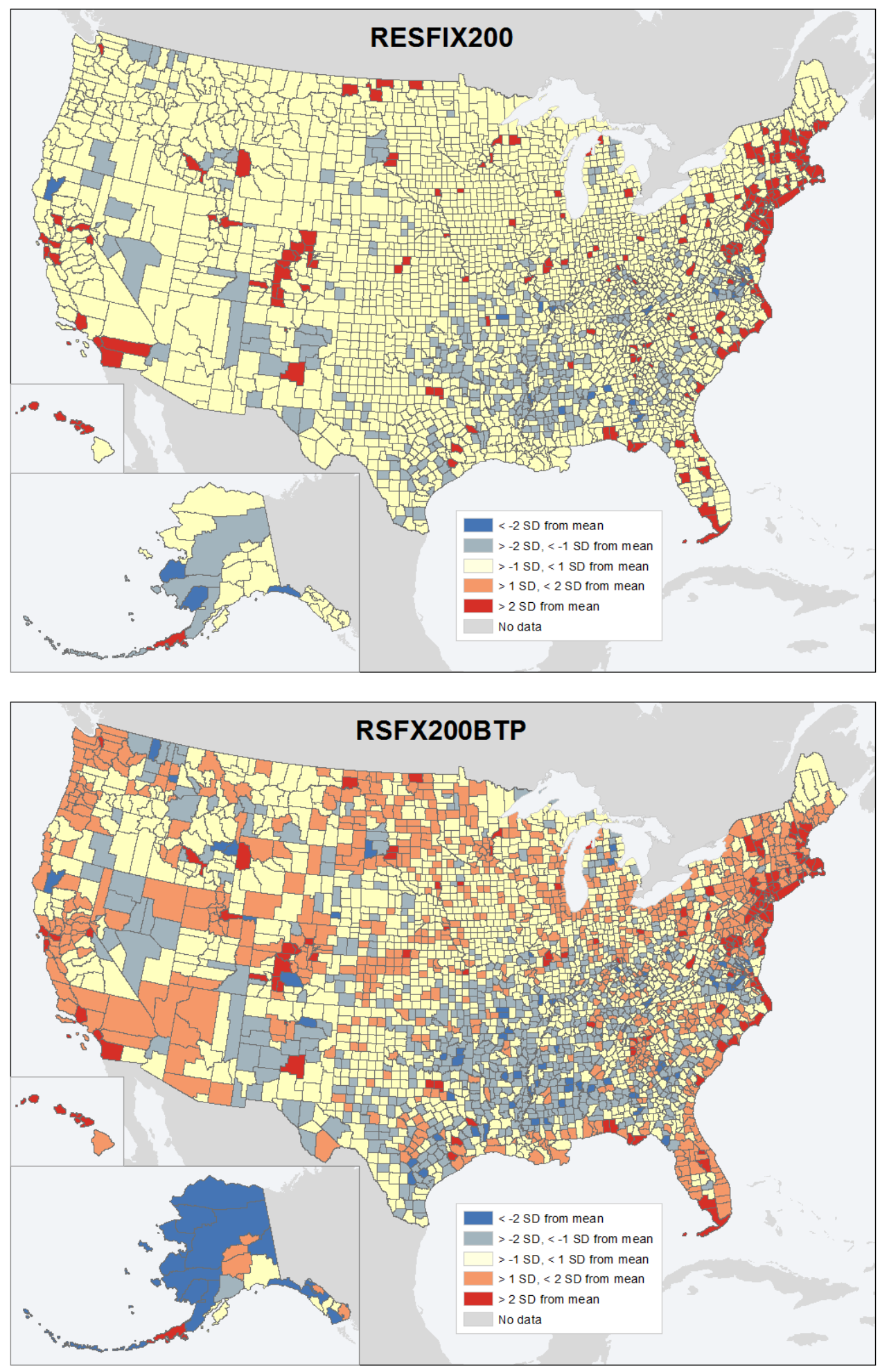

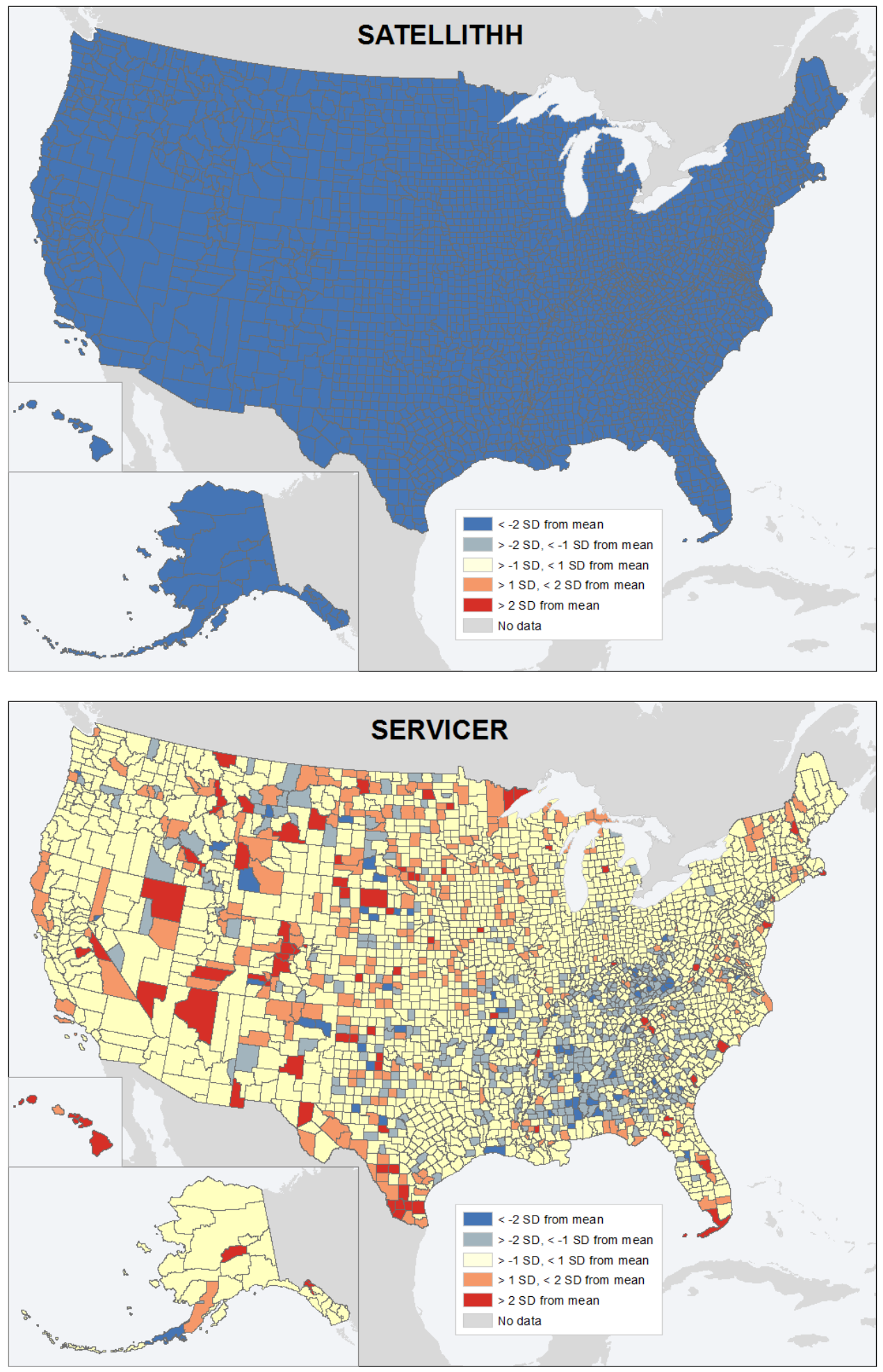

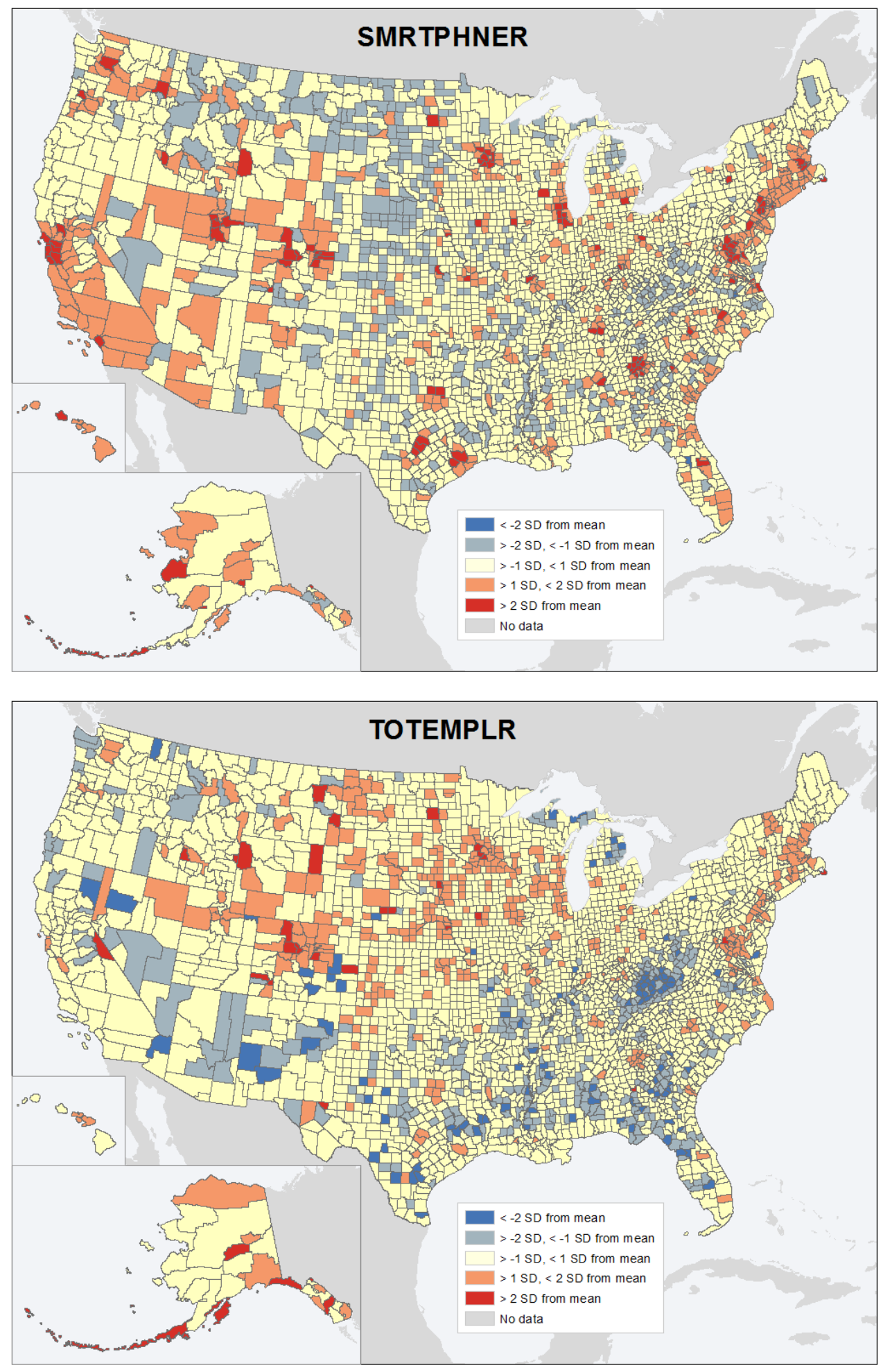

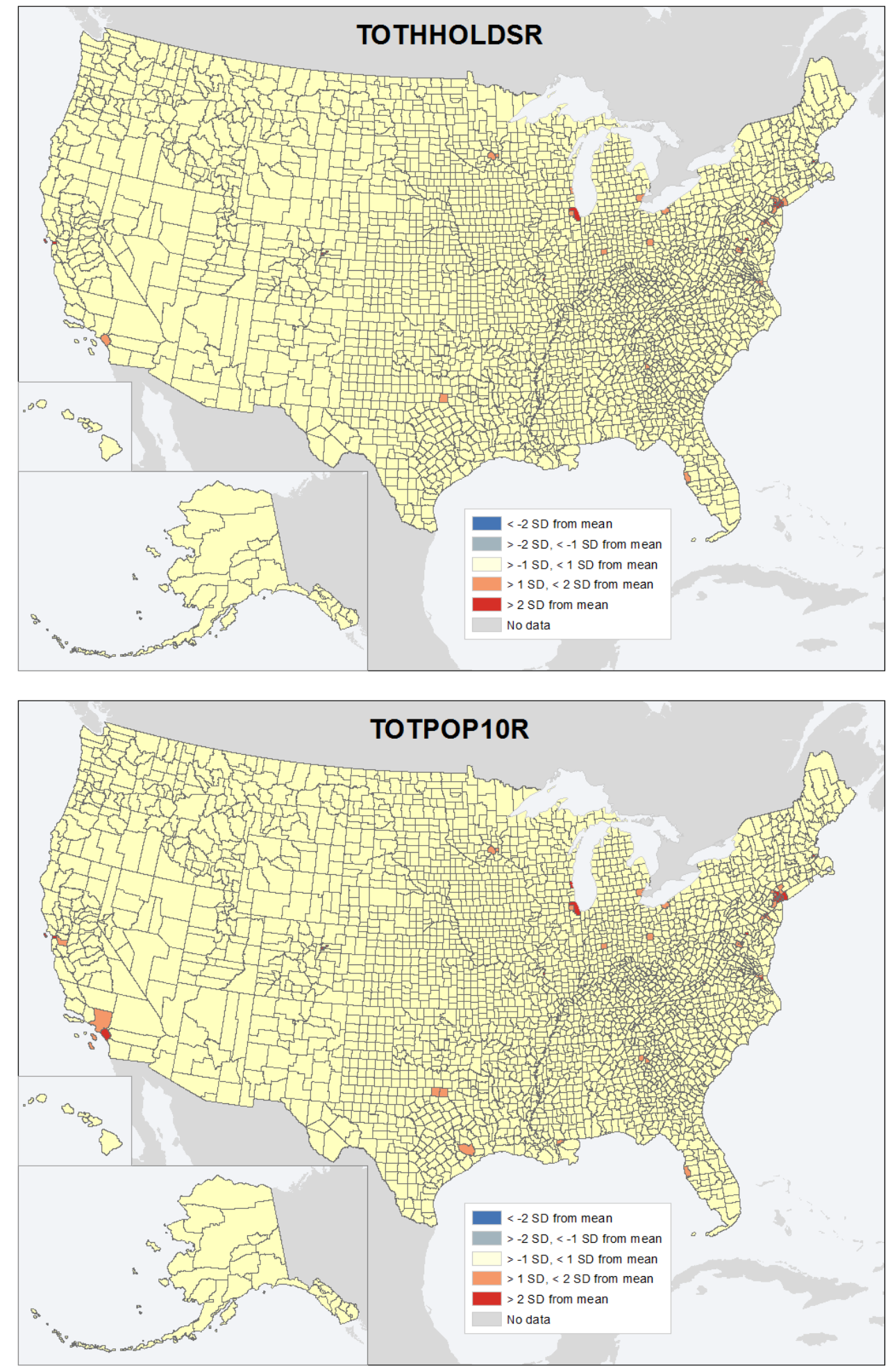

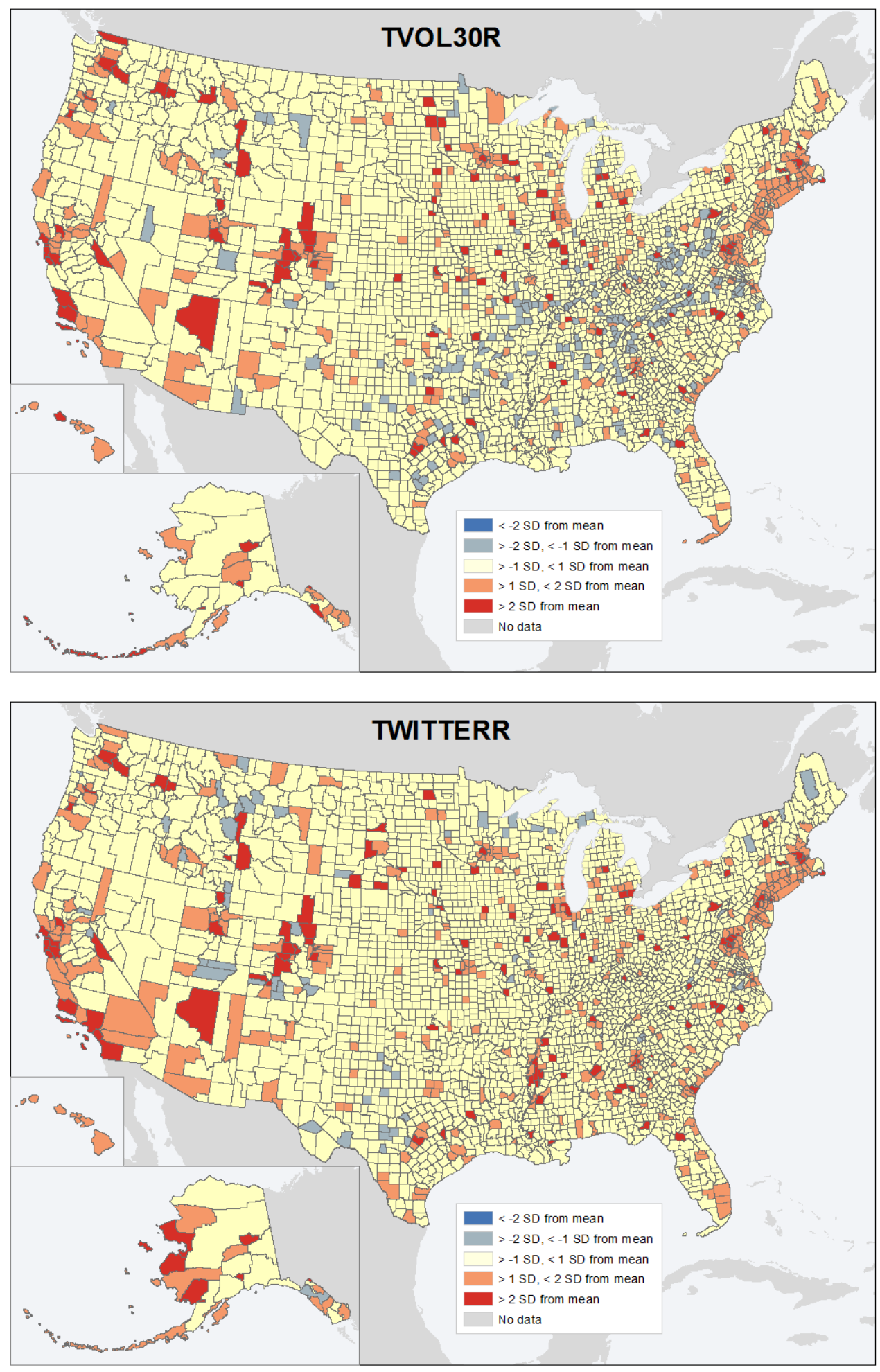

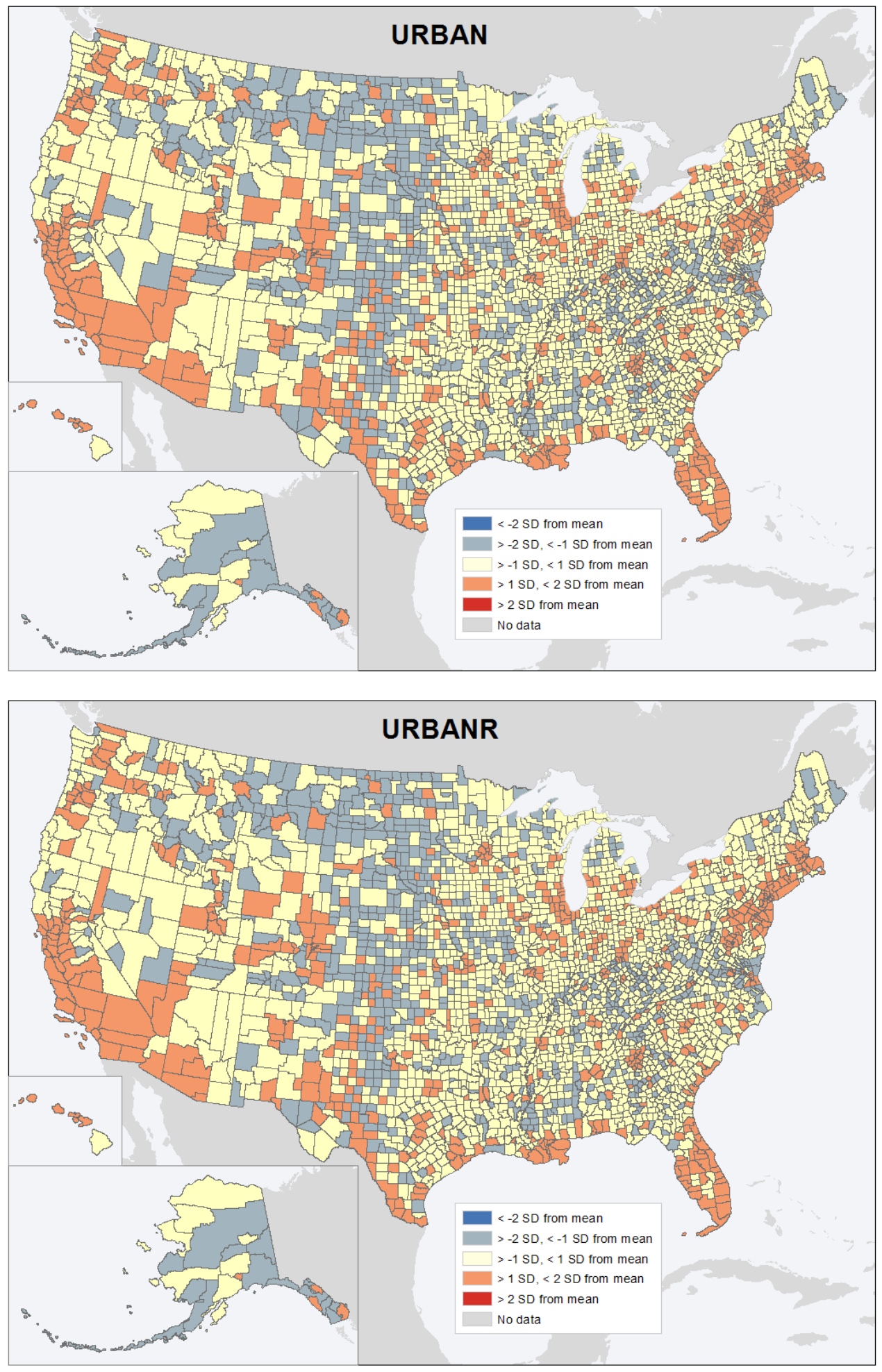

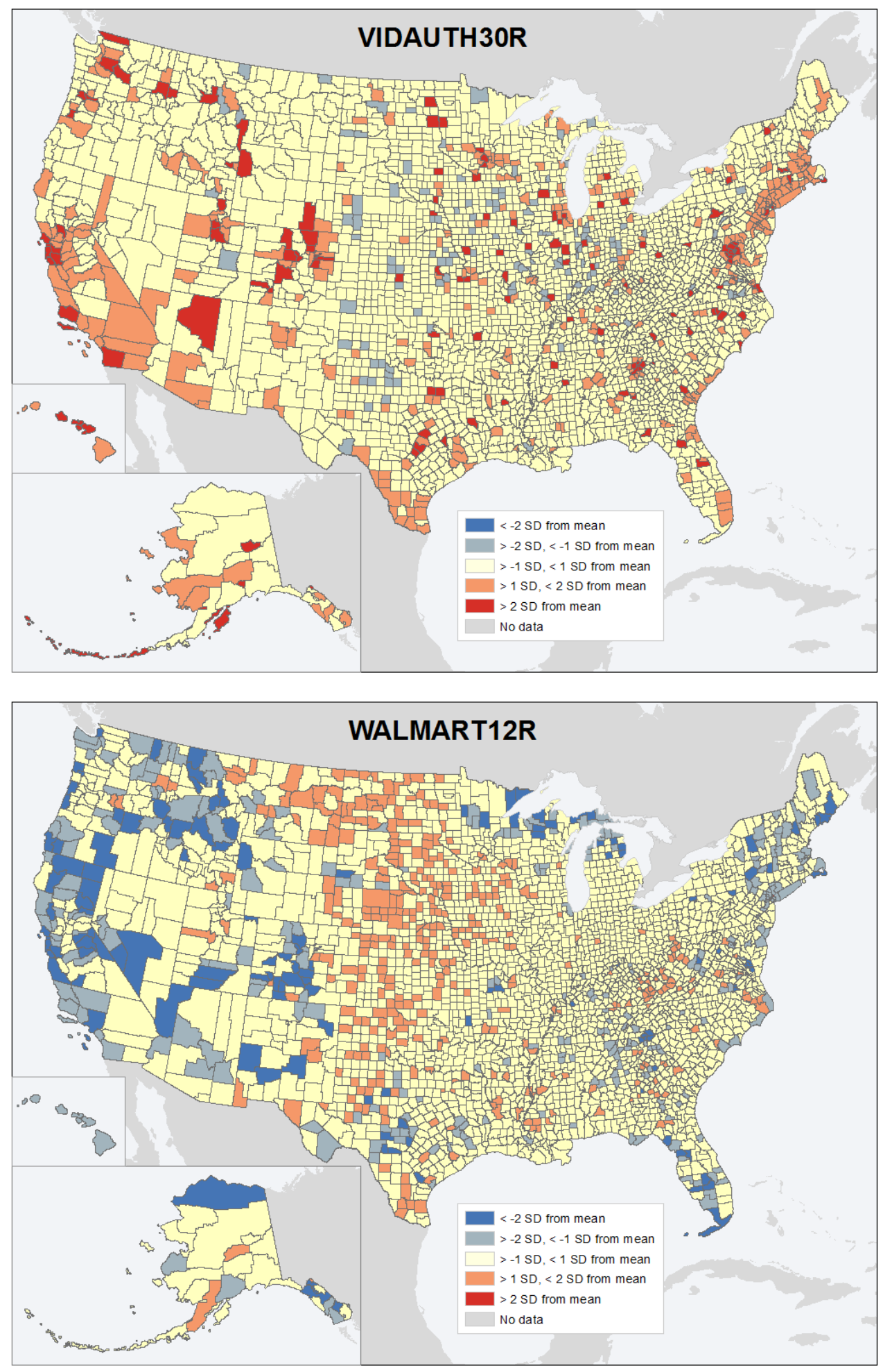

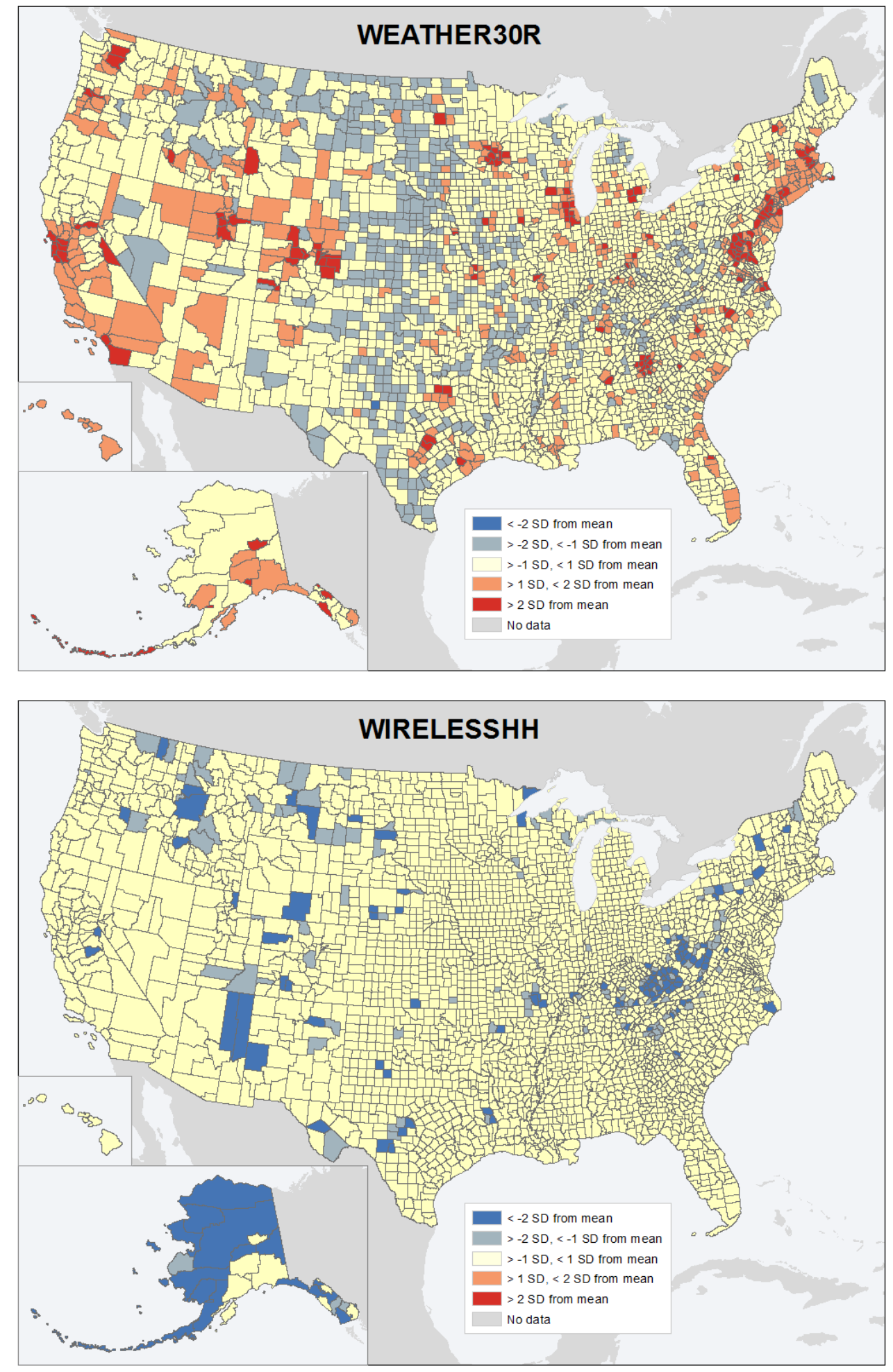

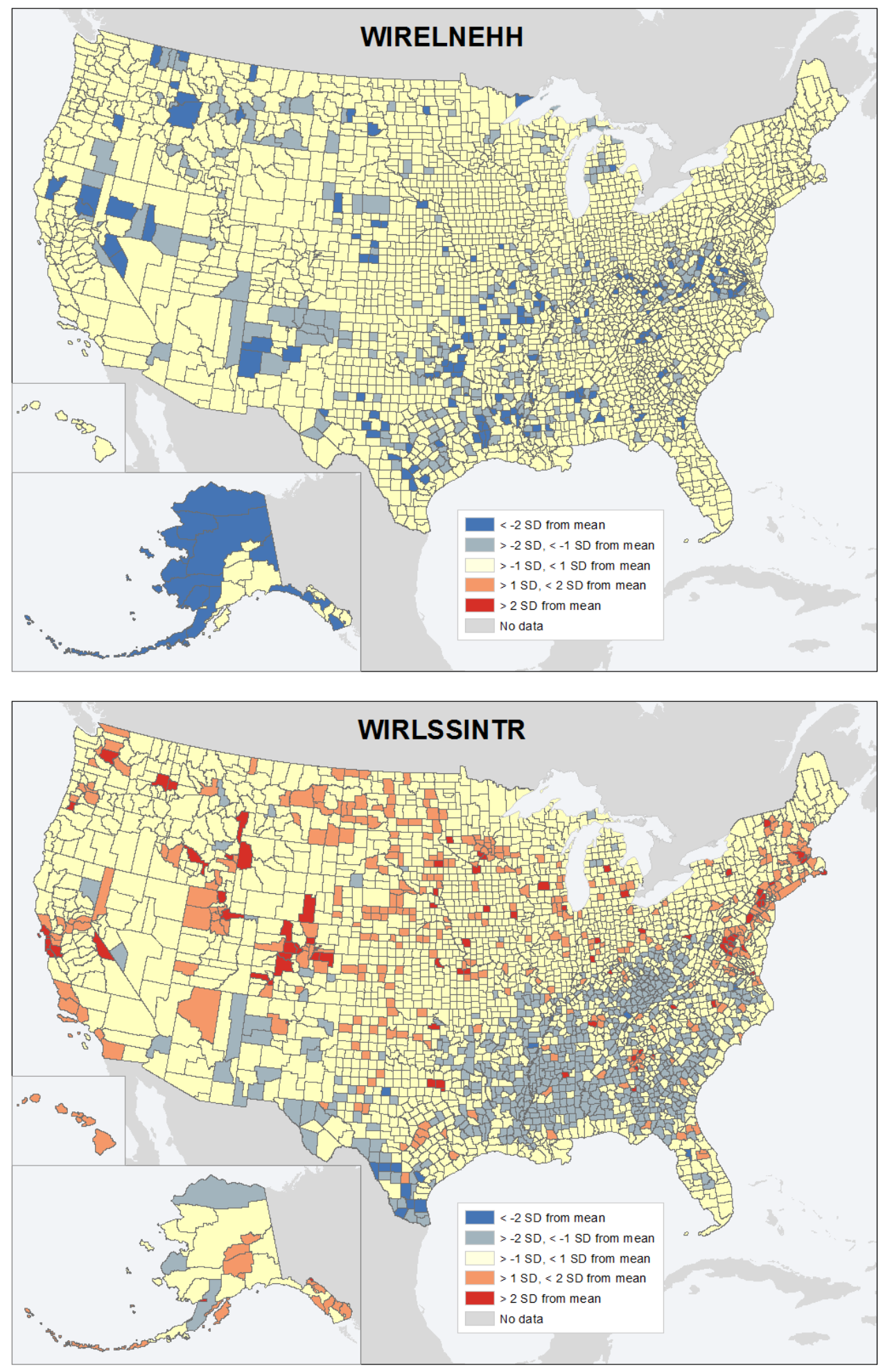

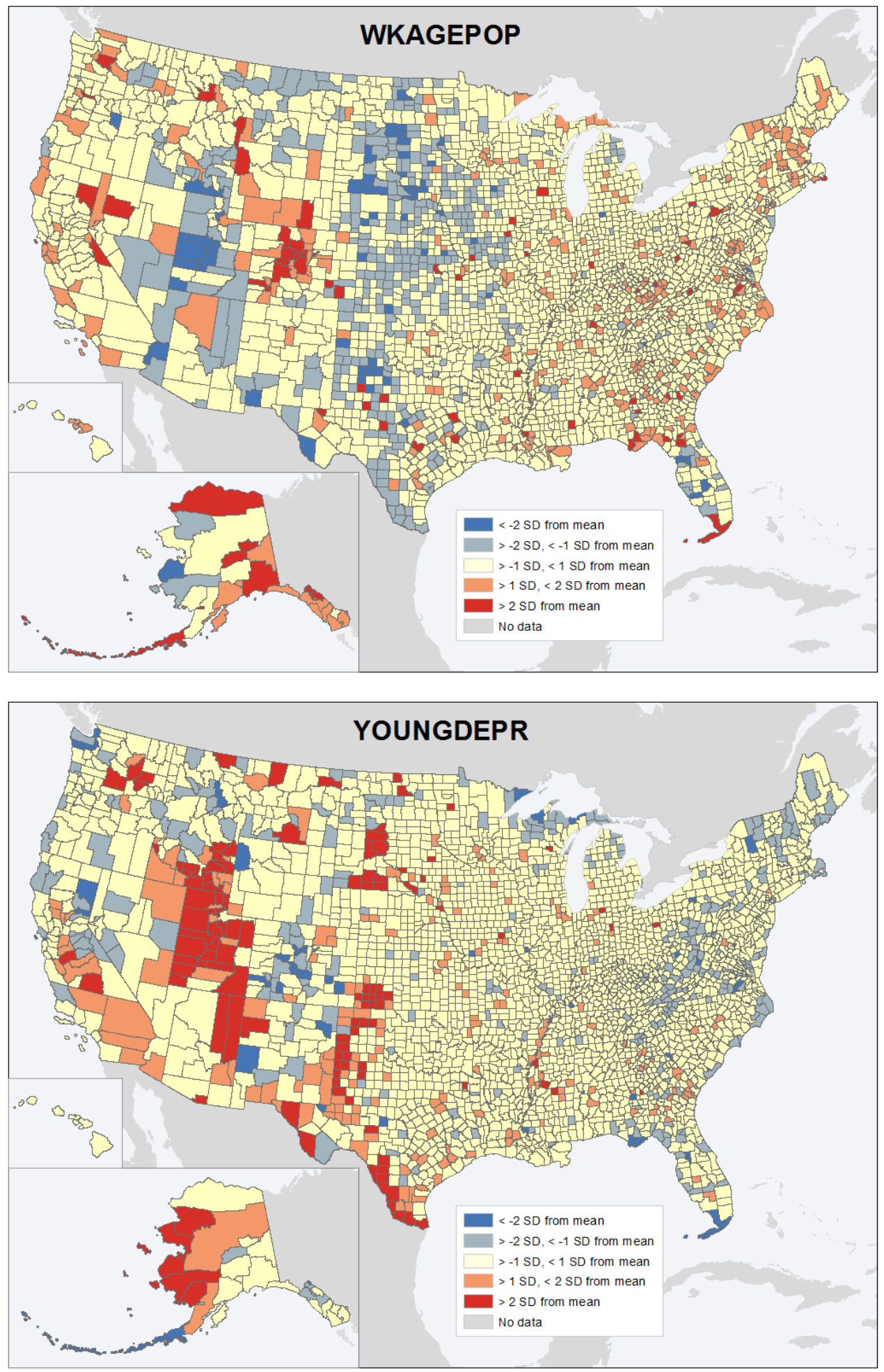


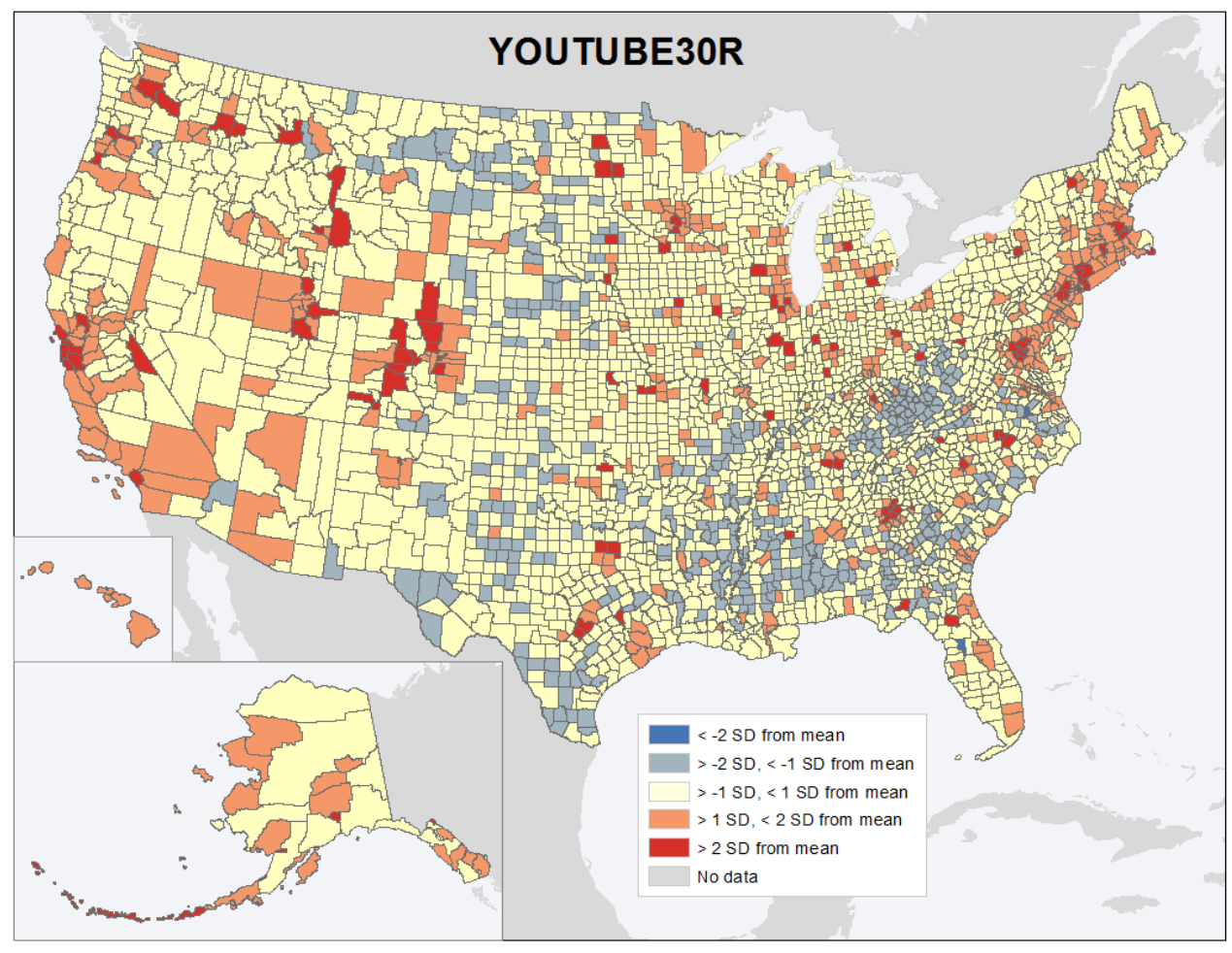




\section{Appendix D. Results of K-Means Cluster Analysis}

Table D-1: K-means cluster centers and number of cluster members.

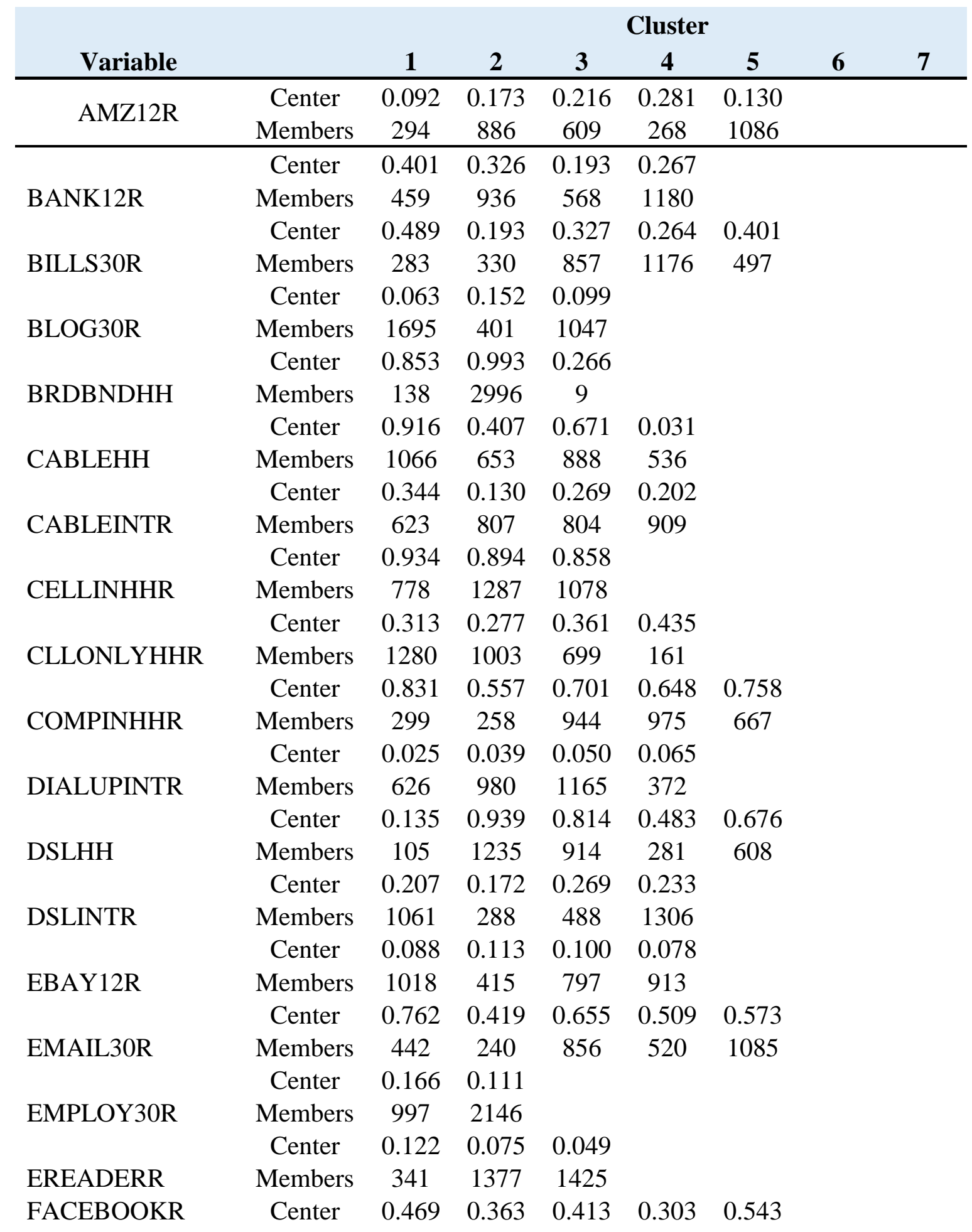




\begin{tabular}{|c|c|c|c|c|c|c|c|c|}
\hline \multirow{2}{*}{ Variable } & & \multicolumn{7}{|c|}{ Cluster } \\
\hline & & 1 & 2 & 3 & 4 & 5 & 6 & 7 \\
\hline \multirow{4}{*}{ FIBERHH } & Members & 591 & 1113 & 847 & 395 & 197 & & \\
\hline & Center & 0.020 & 0.746 & 0.333 & & & & \\
\hline & Members & 2403 & 311 & 429 & & & & \\
\hline & Center & 0.104 & 0.054 & 0.023 & & & & \\
\hline \multirow[t]{2}{*}{ FIBERINTR } & Members & 196 & 814 & 2133 & & & & \\
\hline & Center & 0.280 & 0.114 & 0.349 & 0.169 & 0.223 & & \\
\hline \multirow[t]{2}{*}{ FINANCE30R } & Members & 543 & 339 & 259 & 1062 & 940 & & \\
\hline & Center & 0.770 & 0.500 & 0.689 & 0.567 & 0.624 & 0.398 & \\
\hline \multirow[t]{2}{*}{ GOOGLE30R } & Members & 246 & 397 & 480 & 1036 & 781 & 203 & \\
\hline & Center & 0.783 & 0.666 & 0.473 & 0.576 & & & \\
\hline \multirow[t]{2}{*}{ HSPEEDINTR } & Members & 471 & 957 & 453 & 1262 & & & \\
\hline & Center & 0.413 & 0.373 & 0.455 & 0.299 & 0.337 & 0.249 & 0.511 \\
\hline \multirow[t]{2}{*}{ IM30R } & Members & 605 & 689 & 371 & 348 & 800 & 190 & 140 \\
\hline & Center & 0.723 & 0.525 & 0.809 & 0.590 & 0.655 & 0.428 & \\
\hline \multirow[t]{2}{*}{ INTATHOMER } & Members & 487 & 465 & 250 & 925 & 772 & 244 & \\
\hline & Center & 0.114 & 0.066 & 0.085 & 0.192 & & & \\
\hline \multirow[t]{2}{*}{ INTATSCHLR } & Members & 589 & 923 & 1562 & 69 & & & \\
\hline & Center & 0.422 & 0.328 & 0.260 & 0.189 & & & \\
\hline \multirow[t]{2}{*}{ INTATWORKR } & Members & 376 & 813 & 1400 & 554 & & & \\
\hline & Center & 0.837 & 0.523 & 0.758 & 0.626 & 0.694 & & \\
\hline \multirow[t]{2}{*}{ INTUSE30R } & Members & 467 & 213 & 899 & 434 & 1130 & & \\
\hline & Center & 0.127 & 0.064 & 0.083 & 0.048 & 0.104 & & \\
\hline \multirow[t]{2}{*}{ ITUNE12R } & Members & 115 & 811 & 467 & 1496 & 254 & & \\
\hline & Center & 0.597 & 0.659 & 0.703 & & & & \\
\hline \multirow[t]{2}{*}{ LANDLINEHHR } & Members & 419 & 1132 & 1592 & & & & \\
\hline & Center & 0.075 & 0.028 & & & & & \\
\hline \multirow[t]{2}{*}{ LINKEDINR } & Members & 490 & 2653 & & & & & \\
\hline & Center & 0.062 & 0.097 & 0.128 & & & & \\
\hline \multirow[t]{2}{*}{ LNDONLYHHR } & Members & 790 & 1265 & 1088 & & & & \\
\hline & Center & 0.246 & 0.199 & 0.160 & 0.124 & 0.093 & & \\
\hline \multirow[t]{2}{*}{ MAP30R } & Members & 240 & 491 & 724 & 1044 & 644 & & \\
\hline & Center & 0.097 & 0.193 & 0.235 & 0.133 & 0.160 & & \\
\hline \multirow[t]{2}{*}{ MEDICAL30R } & Members & 328 & 575 & 290 & 1069 & 881 & & \\
\hline & Center & 0.981 & 0.201 & 0.746 & & & & \\
\hline \multirow[t]{2}{*}{ MOBILEWLHH } & Members & 2876 & 42 & 225 & & & & \\
\hline & Center & 0.082 & 0.059 & 0.179 & 0.117 & & & \\
\hline \multirow[t]{2}{*}{ MOVIE30R } & Members & 1036 & 1503 & 89 & 515 & & & \\
\hline & Center & 0.257 & 0.433 & 0.311 & 0.515 & 0.371 & & \\
\hline \multirow[t]{2}{*}{ NEWS30R } & Members & 623 & 498 & 965 & 231 & 826 & & \\
\hline & Center & 6.6 & 10.0 & 14.4 & 2.7 & & & \\
\hline NMRESPRO200 & Members & 1786 & 838 & 169 & 350 & & & \\
\hline
\end{tabular}




\begin{tabular}{|c|c|c|c|c|c|c|c|c|}
\hline \multirow{2}{*}{ Variable } & & \multicolumn{7}{|c|}{ Cluster } \\
\hline & & 1 & 2 & 3 & 4 & 5 & 6 & 7 \\
\hline \multirow{3}{*}{ NMRESPRO3M } & Center & 10.6 & 14.6 & 0.98 & 4.9 & 7.6 & & \\
\hline & Members & 129 & 11 & 805 & 1636 & 562 & & \\
\hline & Center & 14.6 & 23.5 & 36.6 & 7.8 & & & \\
\hline \multirow[t]{2}{*}{ NUMFIXPROV } & Members & 1098 & 312 & 63 & 1670 & & & \\
\hline & Center & 4.478 & 6.148 & 0.993 & & & & \\
\hline \multirow[t]{2}{*}{ NUMPROVMOB } & Members & 1646 & 284 & 1213 & & & & \\
\hline & Center & 0.254 & 0.466 & 0.391 & 0.338 & 0.297 & 0.193 & \\
\hline \multirow[t]{2}{*}{ PURCH30R } & Members & 936 & 161 & 326 & 590 & 737 & 393 & \\
\hline & Center & 4 & 1 & 3 & 2 & 5 & & \\
\hline \multirow[t]{2}{*}{ RESFIX200 } & Members & 1103 & 24 & 1439 & 377 & 200 & & \\
\hline & Center & 4 & 3 & 2 & 1 & 5 & 0 & \\
\hline \multirow[t]{2}{*}{ RSFX200BTP } & Members & 833 & 1423 & 654 & 86 & 144 & 3 & \\
\hline & Center & 0.403 & 0.327 & 0.215 & 0.268 & & & \\
\hline \multirow[t]{2}{*}{ SMRTPHNER } & Members & 445 & 666 & 1072 & 960 & & & \\
\hline & Center & 0.137 & 0.075 & 0.205 & 0.100 & & & \\
\hline \multirow[t]{2}{*}{ TVOL30R } & Members & 462 & 1717 & 89 & 875 & & & \\
\hline & Center & 0.082 & 0.054 & 0.032 & & & & \\
\hline \multirow[t]{2}{*}{ TWITTERR } & Members & 249 & 816 & 2087 & & & & \\
\hline & Center & 0.056 & 0.036 & & & & & \\
\hline \multirow[t]{2}{*}{ VIDAUTH30R } & Members & 689 & 2454 & & & & & \\
\hline & Center & 0.066 & 0.055 & 0.077 & 0.082 & 0.072 & & \\
\hline \multirow[t]{2}{*}{ WALMART12R } & Members & 435 & 142 & 1046 & 568 & 952 & & \\
\hline & Center & 0.224 & 0.187 & 0.157 & 0.270 & 0.130 & & \\
\hline \multirow[t]{2}{*}{ WEATHER30R } & Members & 433 & 721 & 889 & 189 & 911 & & \\
\hline & Center & 0.985 & 0.386 & 0.802 & & & & \\
\hline \multirow[t]{2}{*}{ WIRELESSHH } & Members & 2835 & 51 & 257 & & & & \\
\hline & Center & 0.639 & 0.961 & 0.820 & 0.334 & & & \\
\hline \multirow[t]{2}{*}{ WIRELINEHH } & Members & 347 & 1844 & 846 & 88 & & & \\
\hline & Center & 0.222 & 0.273 & 0.175 & & & & \\
\hline \multirow[t]{2}{*}{ WIRLSSINTR } & Members & 1490 & 556 & 1097 & & & & \\
\hline & Center & 0.353 & 0.299 & 0.253 & 0.214 & 0.418 & & \\
\hline YOUTUBE30R & Members & 494 & 700 & 1005 & 670 & 274 & & \\
\hline
\end{tabular}


Table D-2: Cluster centers for traditional ICT research variables. Clusters are ordered from highest to lowest values.

\begin{tabular}{|c|c|c|c|c|c|}
\hline \multirow{2}{*}{} & \multicolumn{5}{|c|}{ Cluster } \\
\cline { 2 - 6 } & 1 & 2 & 3 & 4 & 5 \\
\hline CLLONLYHHR & .338 & .314 & .327 & .309 & .283 \\
\hline LNDONLYHHR & .066 & .106 & .105 & .124 & .124 \\
\hline CELLINHHR & .929 & .883 & .887 & .865 & .864 \\
\hline HSPEEDINTR & .744 & .603 & .584 & .486 & .549 \\
\hline INTUSE30R & .810 & .708 & .680 & .585 & .654 \\
\hline COMPINHHR & .784 & .687 & .670 & .599 & .656 \\
\hline MOBILEWLHH & .989 & .976 & .143 & .963 & .682 \\
\hline BRDBNDHH & .997 & .992 & .674 & .986 & .901 \\
\hline FACEBOOKR & .482 & .390 & .382 & .316 & .344 \\
\hline LINKEDINR & .061 & .027 & .036 & .023 & .023 \\
\hline TWITTERR & .059 & .035 & .046 & .036 & .030 \\
\hline
\end{tabular}

Table D-3: Cluster centers for Internet use variables. Clusters are ordered from highest to lowest values.

\begin{tabular}{|c|c|c|c|c|}
\hline \multirow{2}{*}{ Variable } & \multicolumn{4}{|c|}{ Cluster } \\
\cline { 2 - 5 } & 1 & 2 & 3 & 4 \\
\hline EMAIL30R & .755 & .643 & .554 & .440 \\
\hline IM30R & .470 & .400 & .342 & .272 \\
\hline EMPLOY30R & .176 & .139 & .108 & .107 \\
\hline MEDICAL30R & .221 & .171 & .138 & .100 \\
\hline NEWS30R & .480 & .383 & .307 & .245 \\
\hline BLOG30R & .145 & .096 & .064 & .066 \\
\hline VIDAUTH30R & .058 & .041 & .034 & .036 \\
\hline MOVIE30R & .128 & .087 & .065 & .051 \\
\hline TVOL30R & .147 & .099 & .077 & .074 \\
\hline YOUTUBE30R & .395 & .310 & .247 & .210 \\
\hline GOOGLE30R & .738 & .636 & .559 & .433 \\
\hline WEATHER30R & .243 & .186 & .142 & .146 \\
\hline MAP30R & .226 & .165 & .113 & .114 \\
\hline
\end{tabular}


Table D-4: Cluster centers for e-commerce variables. Clusters are ordered from highest to lowest values.

\begin{tabular}{|l|c|c|c|}
\hline \multirow{2}{*}{} & \multicolumn{3}{|c|}{ Cluster } \\
\cline { 2 - 4 } & 1 & 2 & 3 \\
\hline PURCH30R & .408 & .312 & .237 \\
\hline BILLS30R & .453 & .331 & .244 \\
\hline FINANCE30R & .319 & .229 & .154 \\
\hline BANK12R & .392 & .310 & .231 \\
\hline AMZ12R & .254 & .179 & .122 \\
\hline EBAY12R & .109 & .093 & .082 \\
\hline ITUNE12R & .103 & .065 & .048 \\
\hline WALMART12R & .073 & .072 & .076 \\
\hline
\end{tabular}

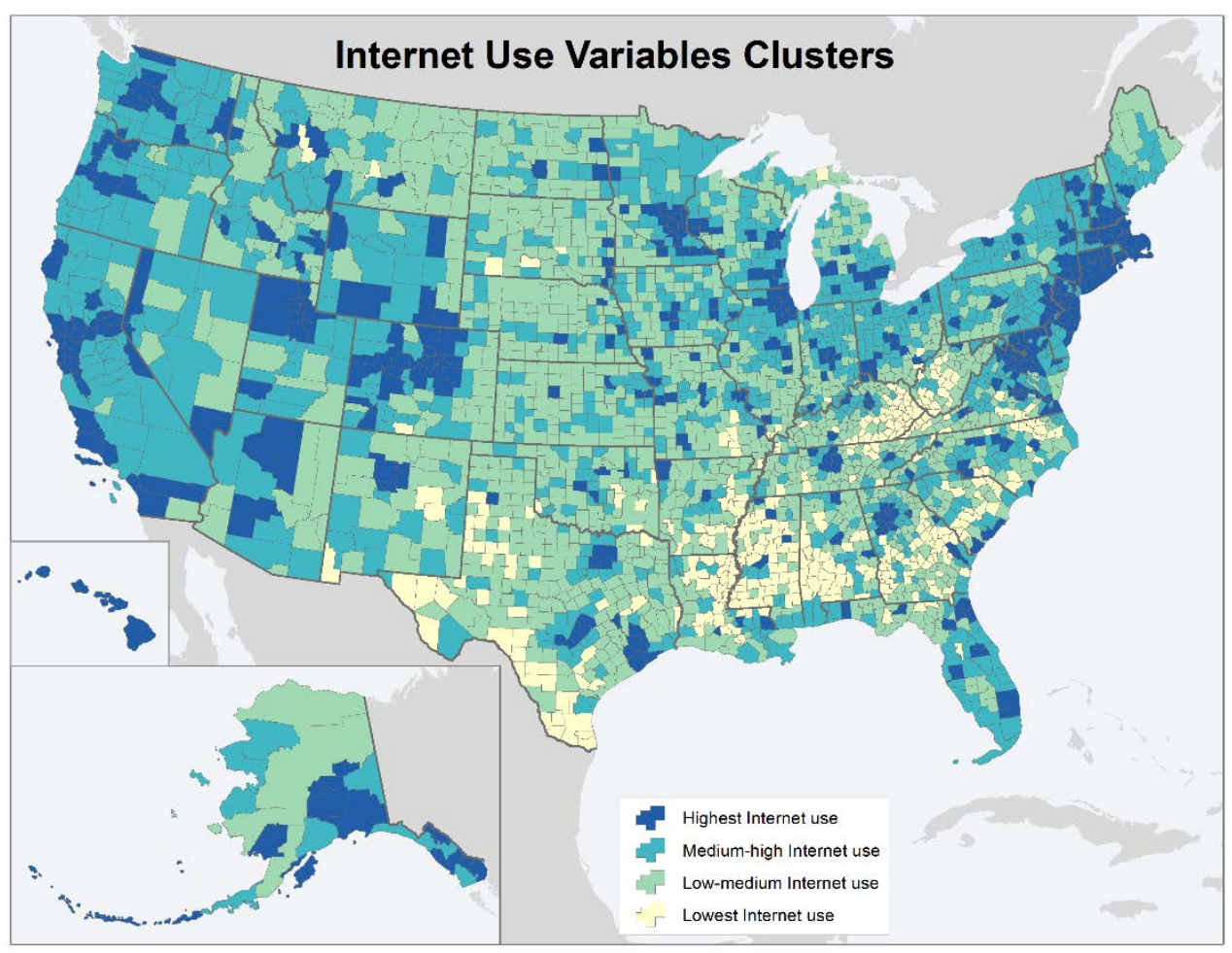



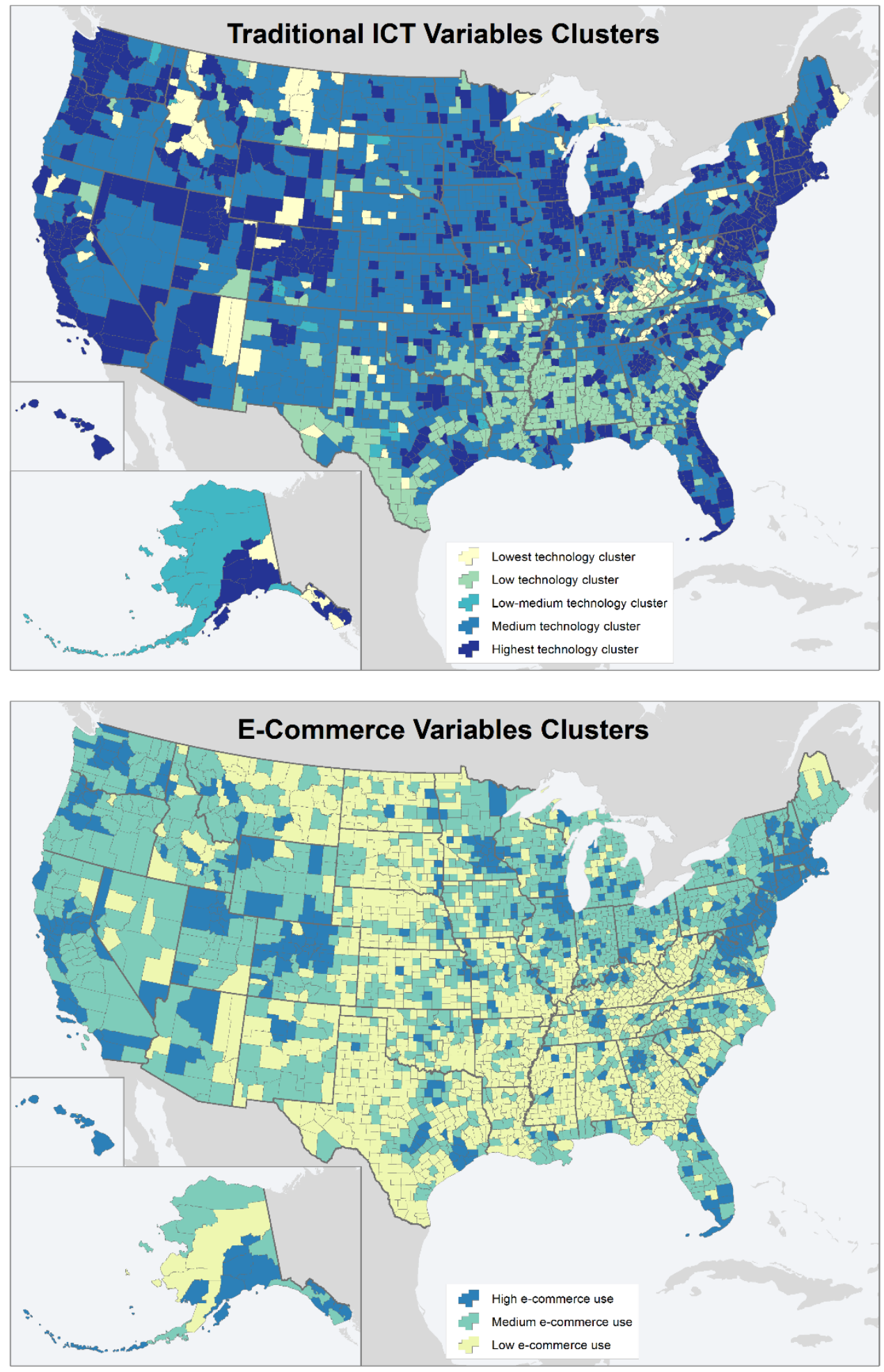

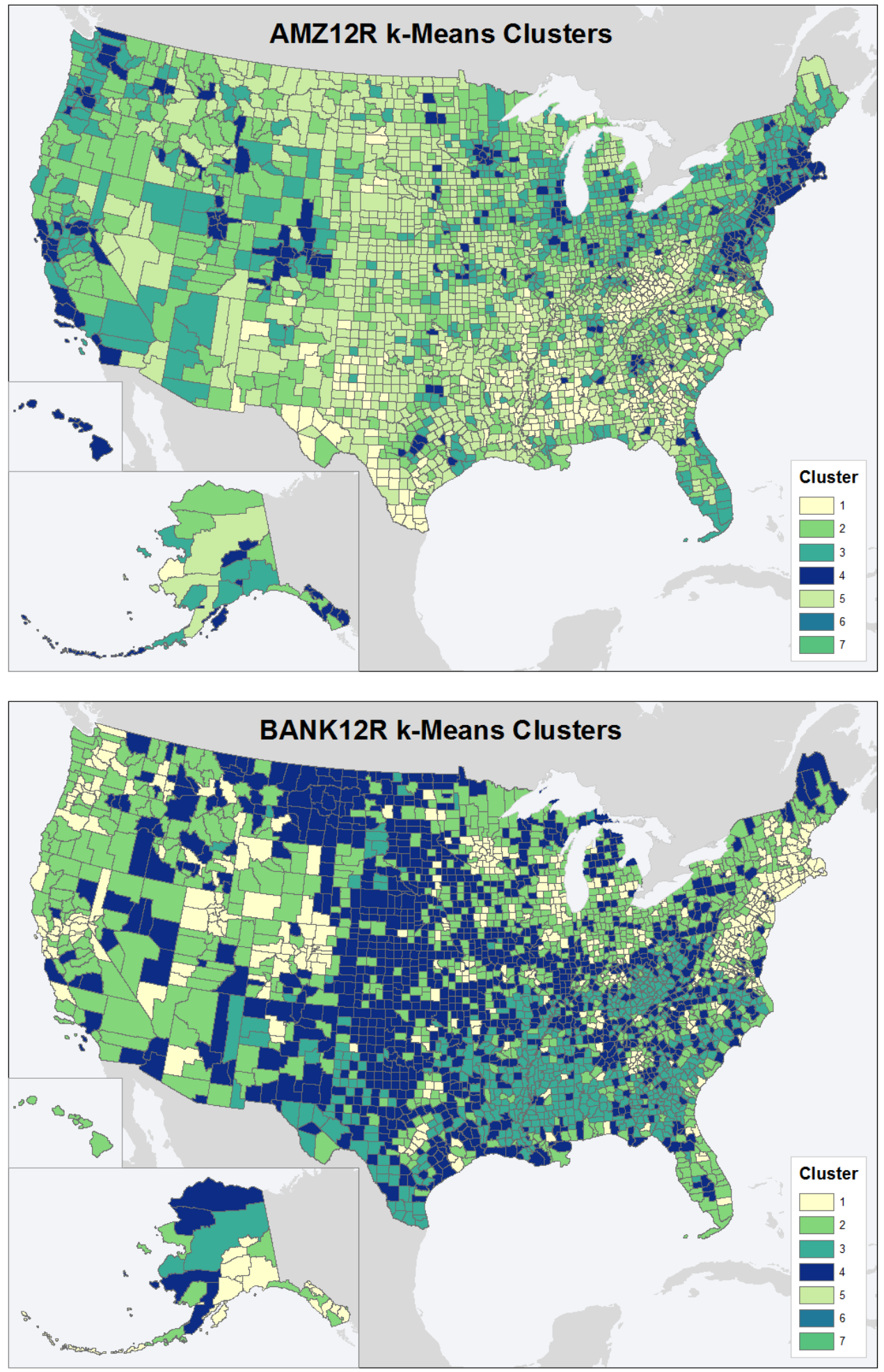

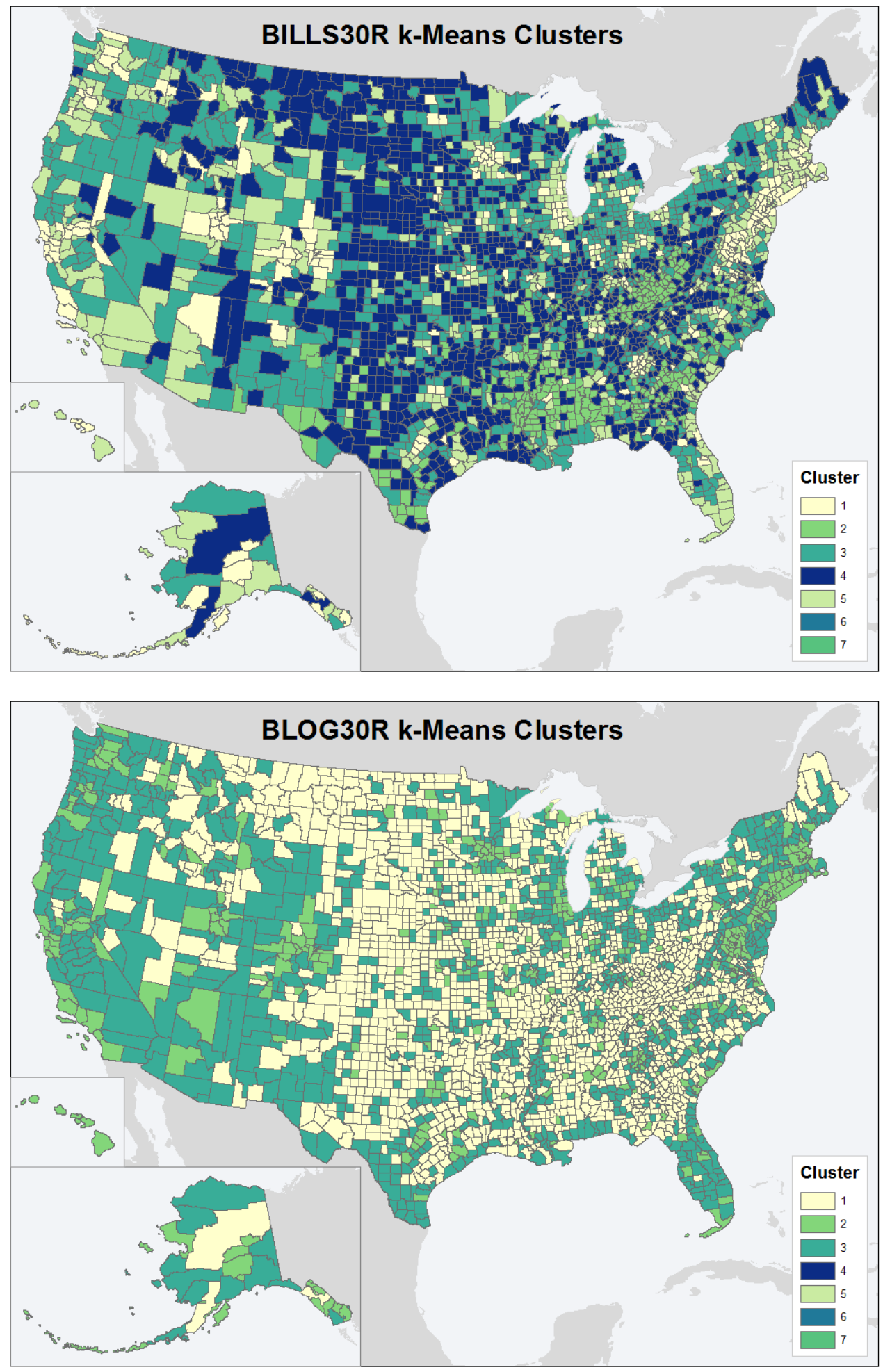

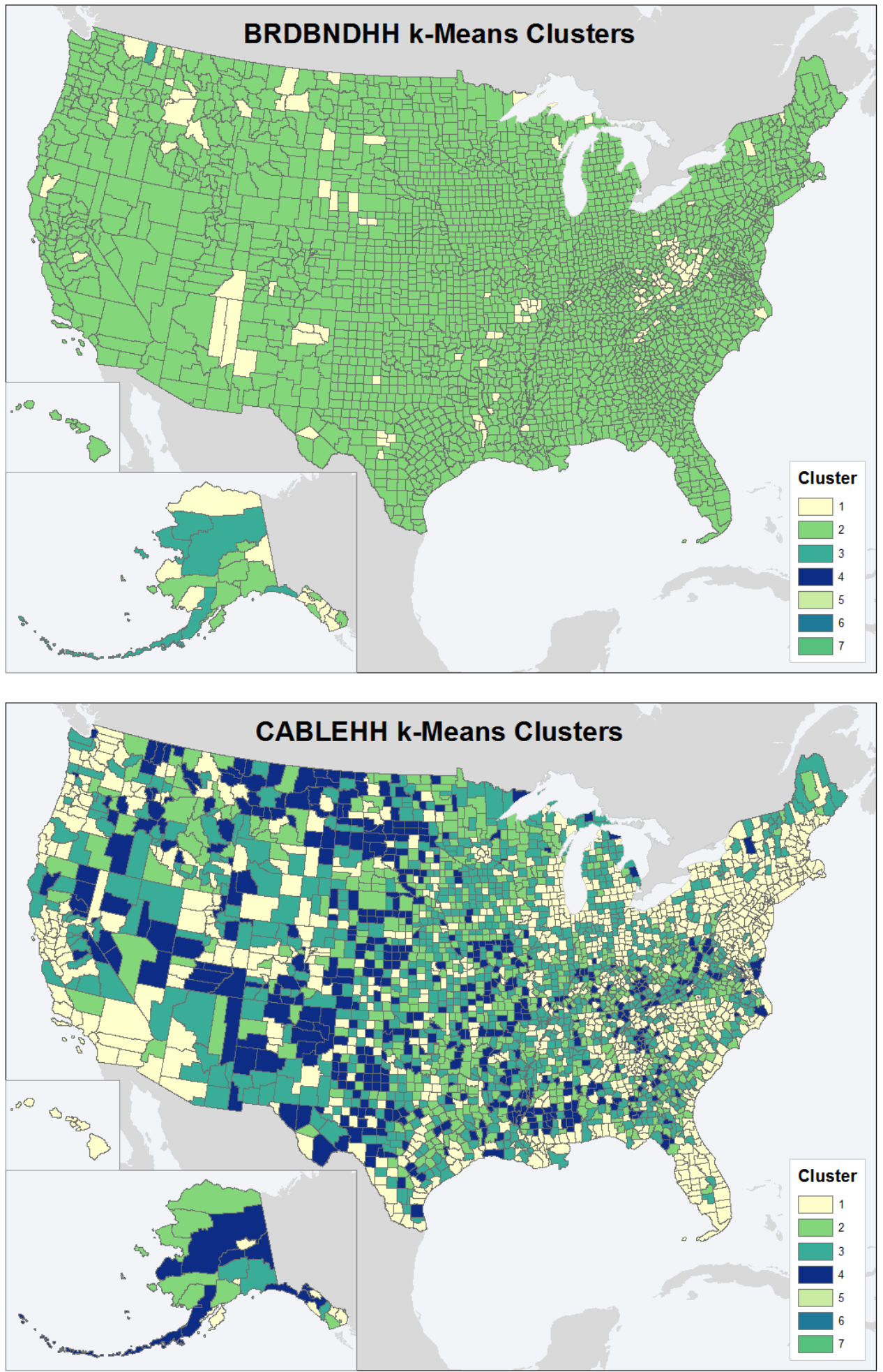

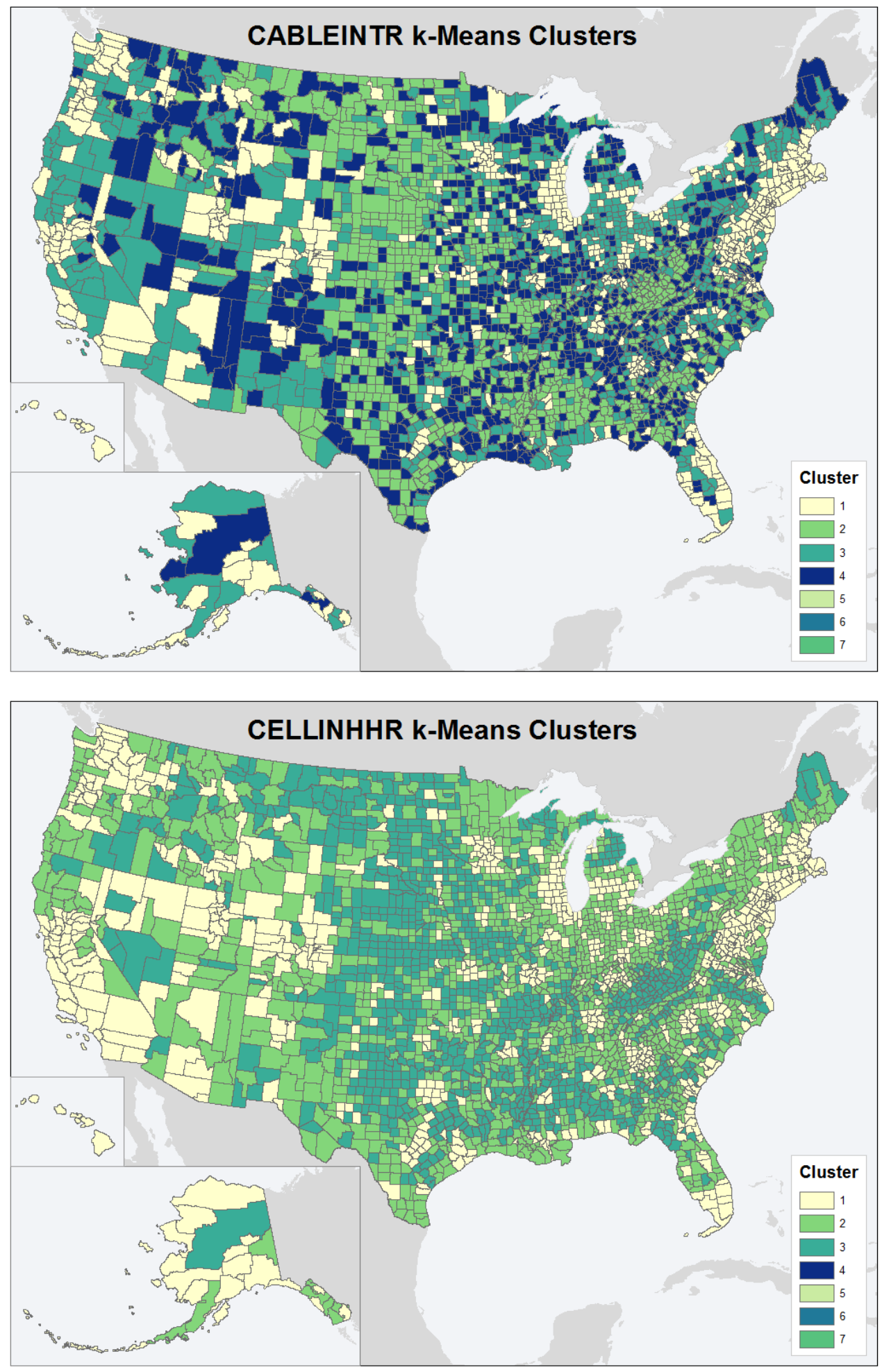

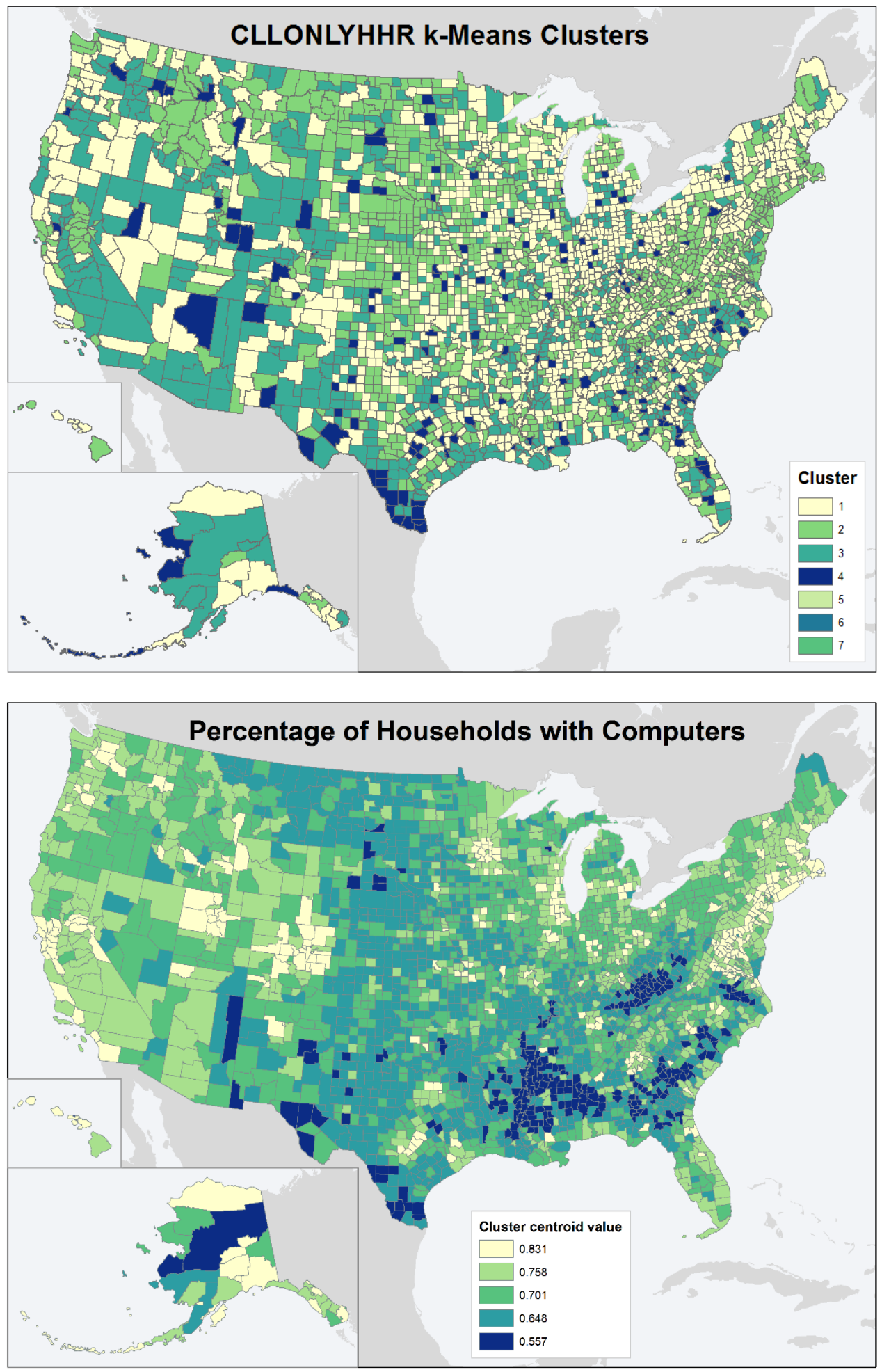

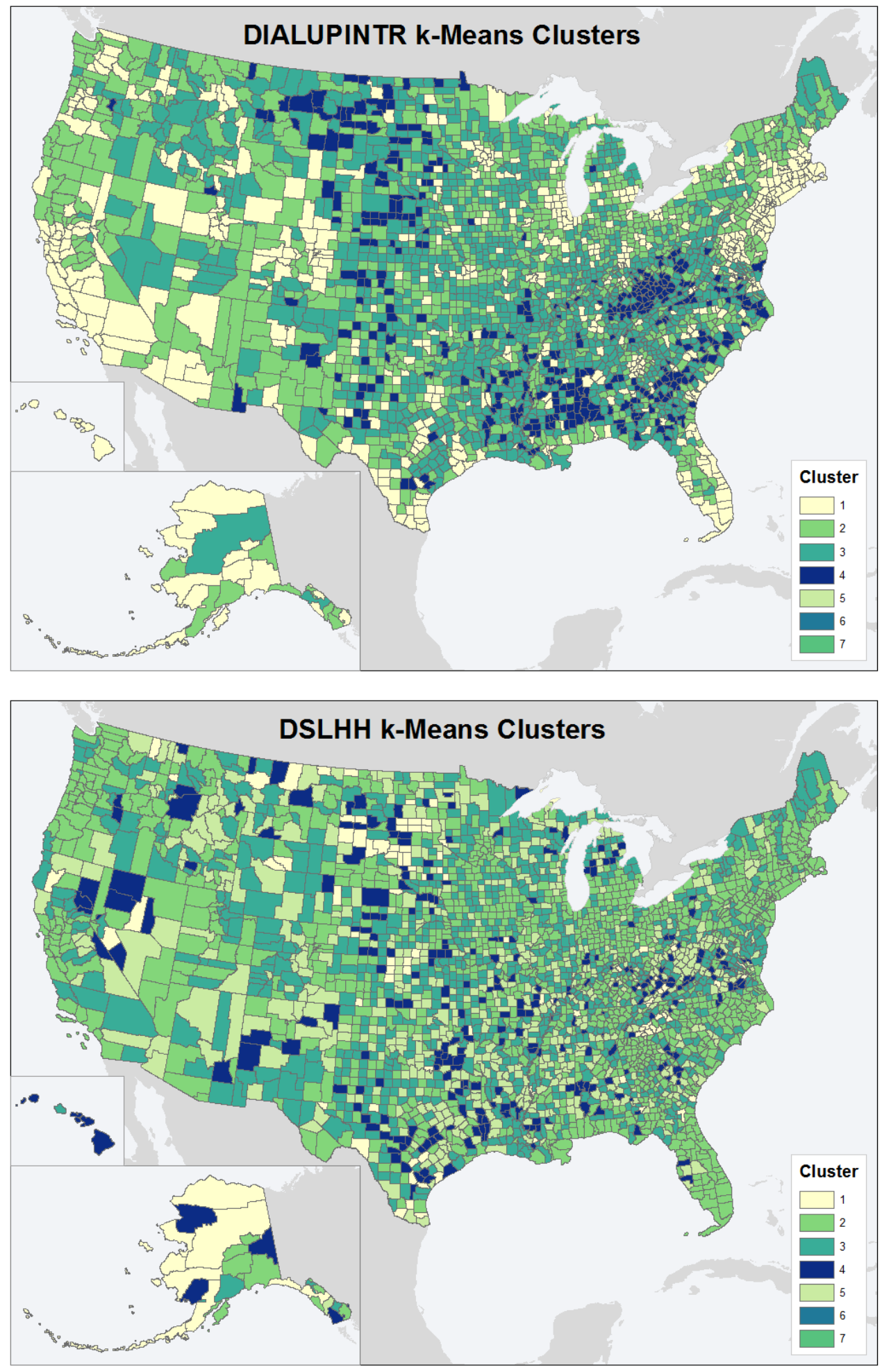

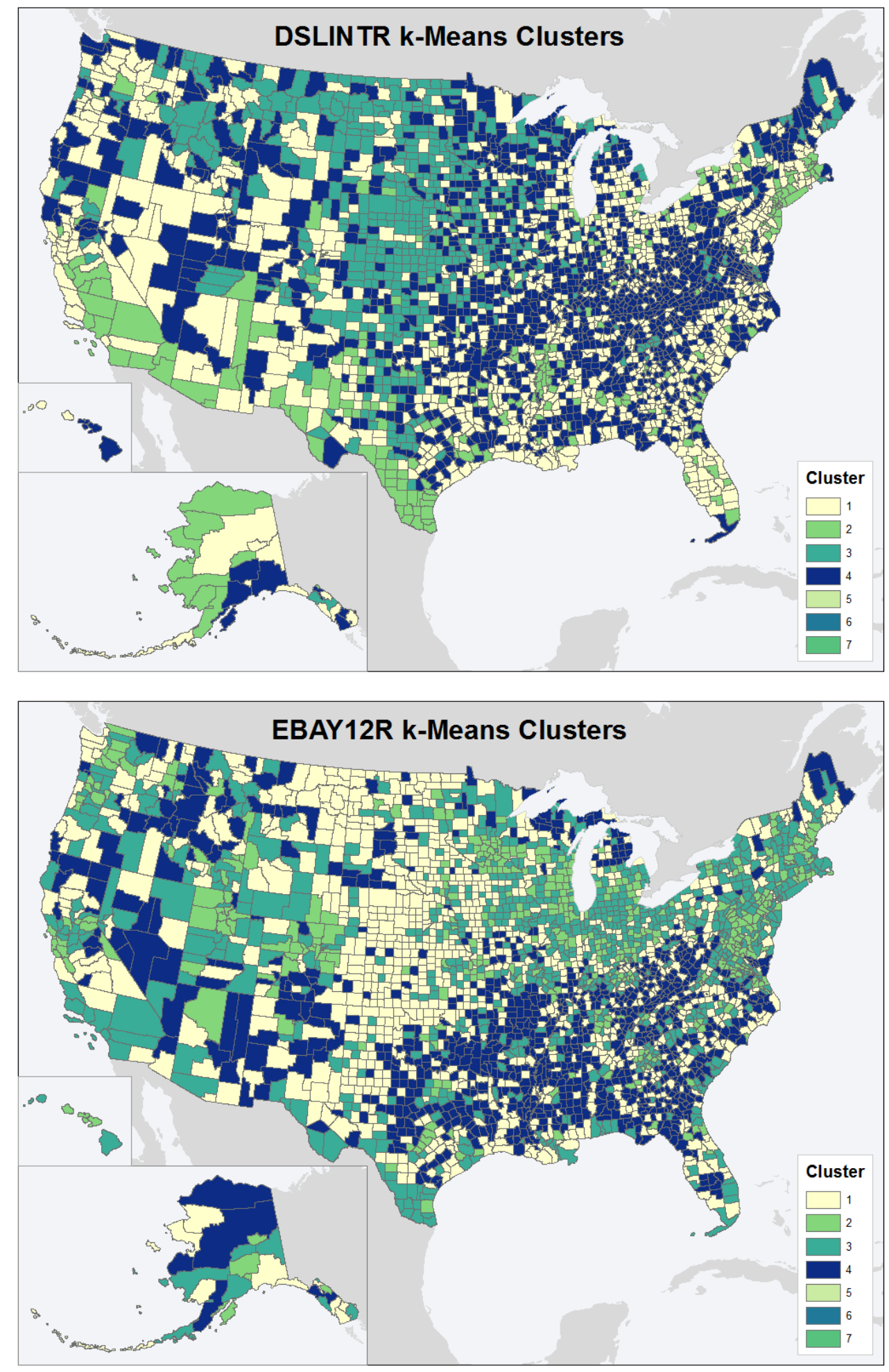

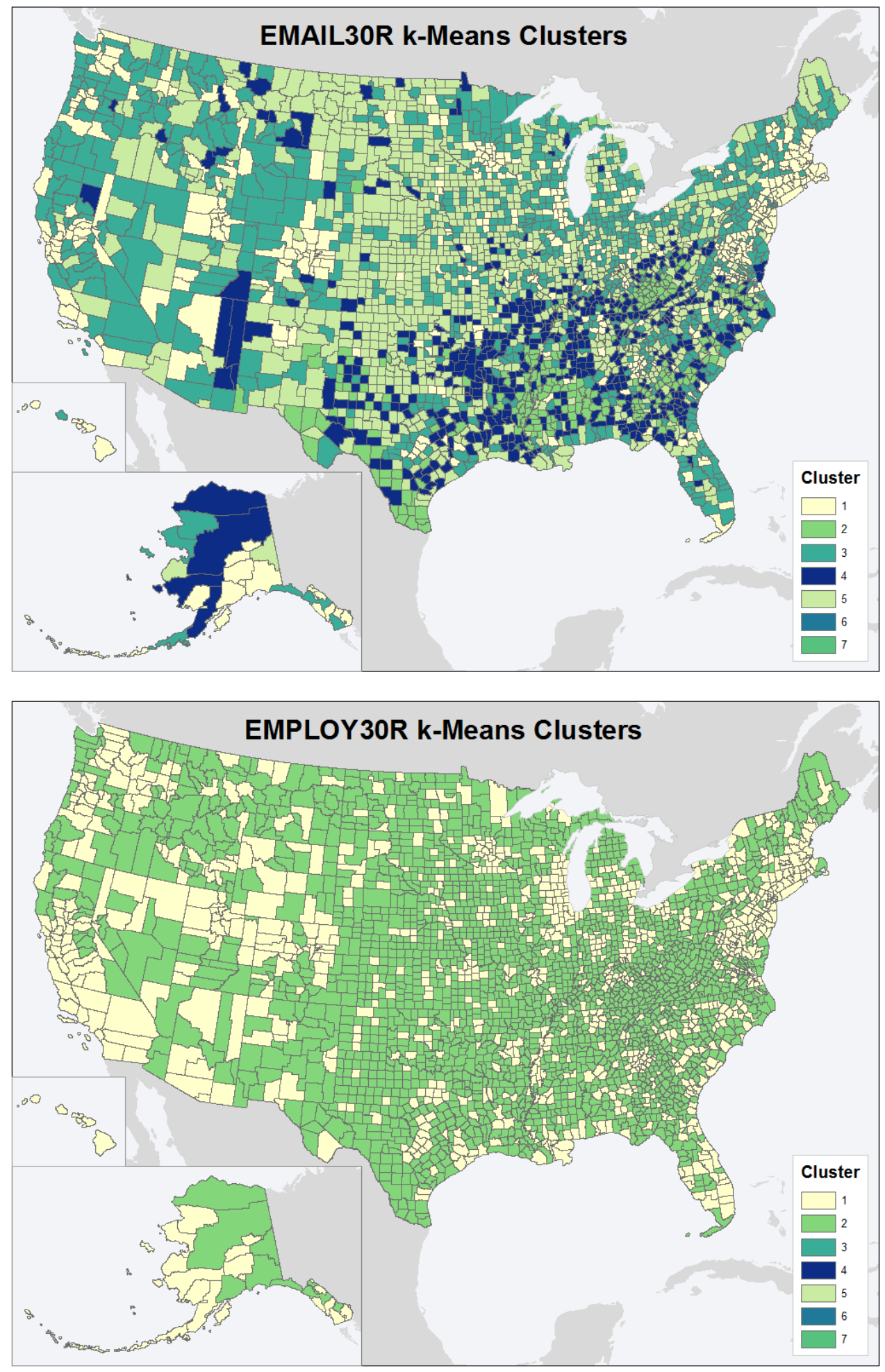

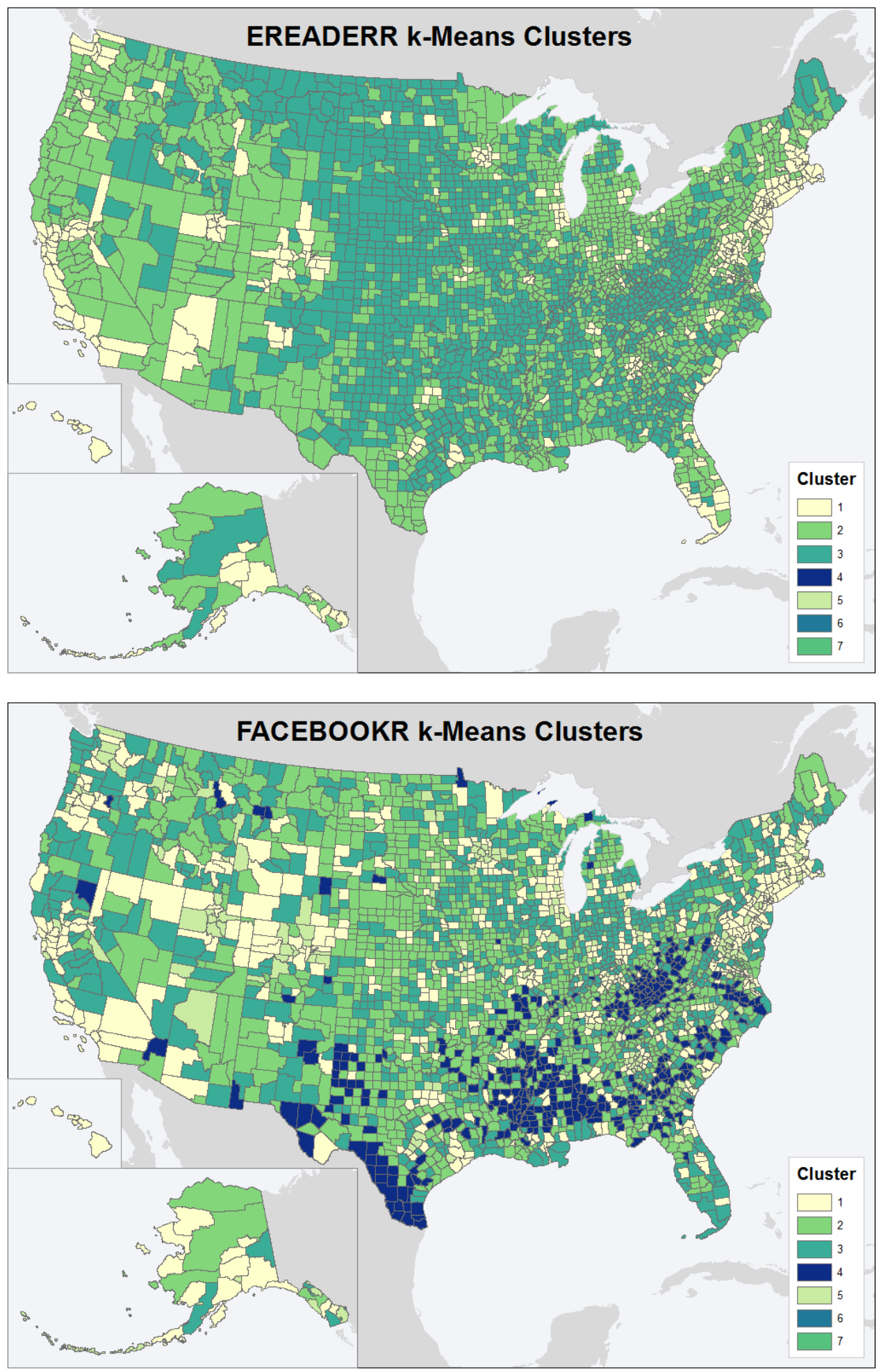

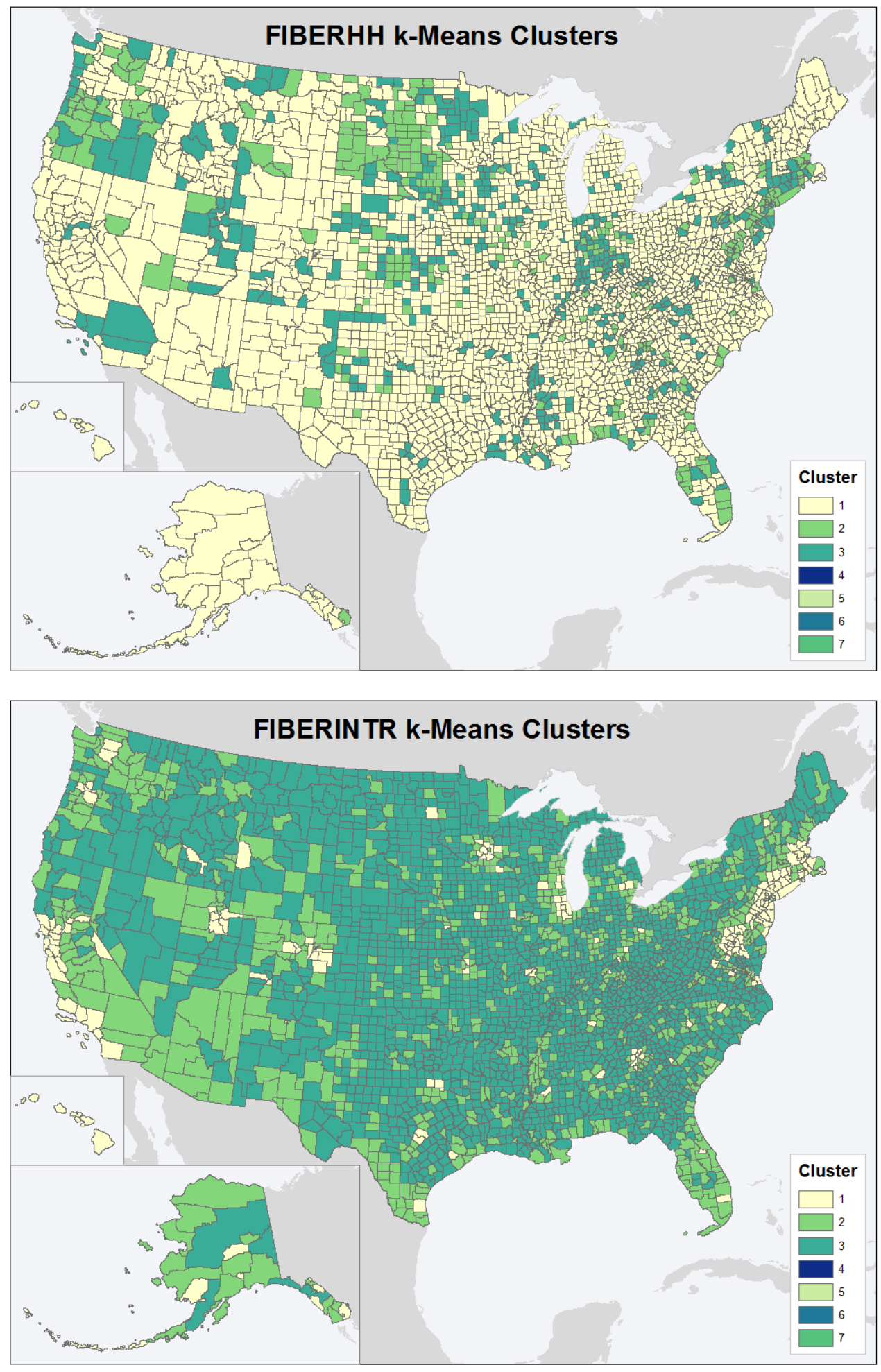

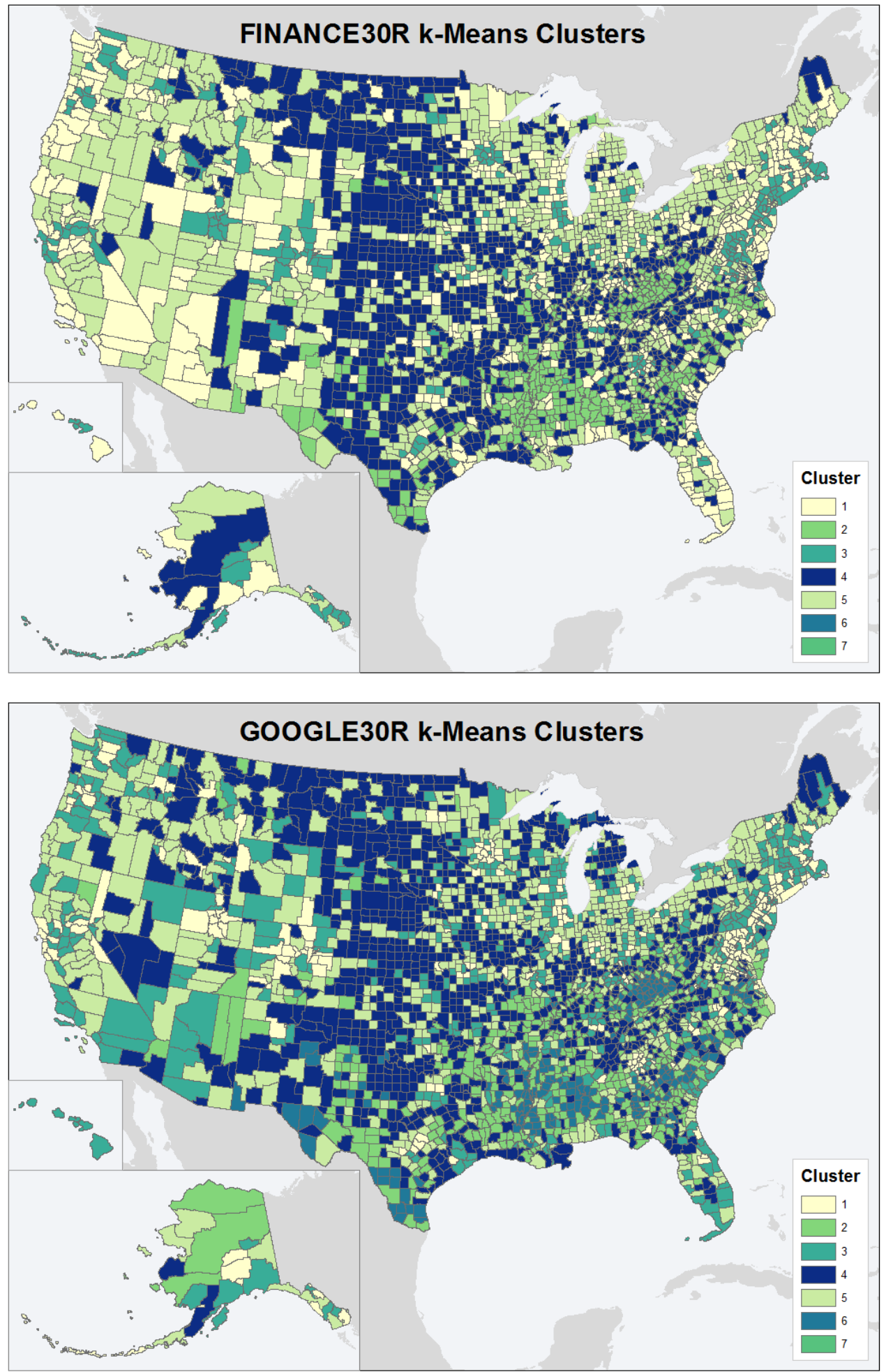

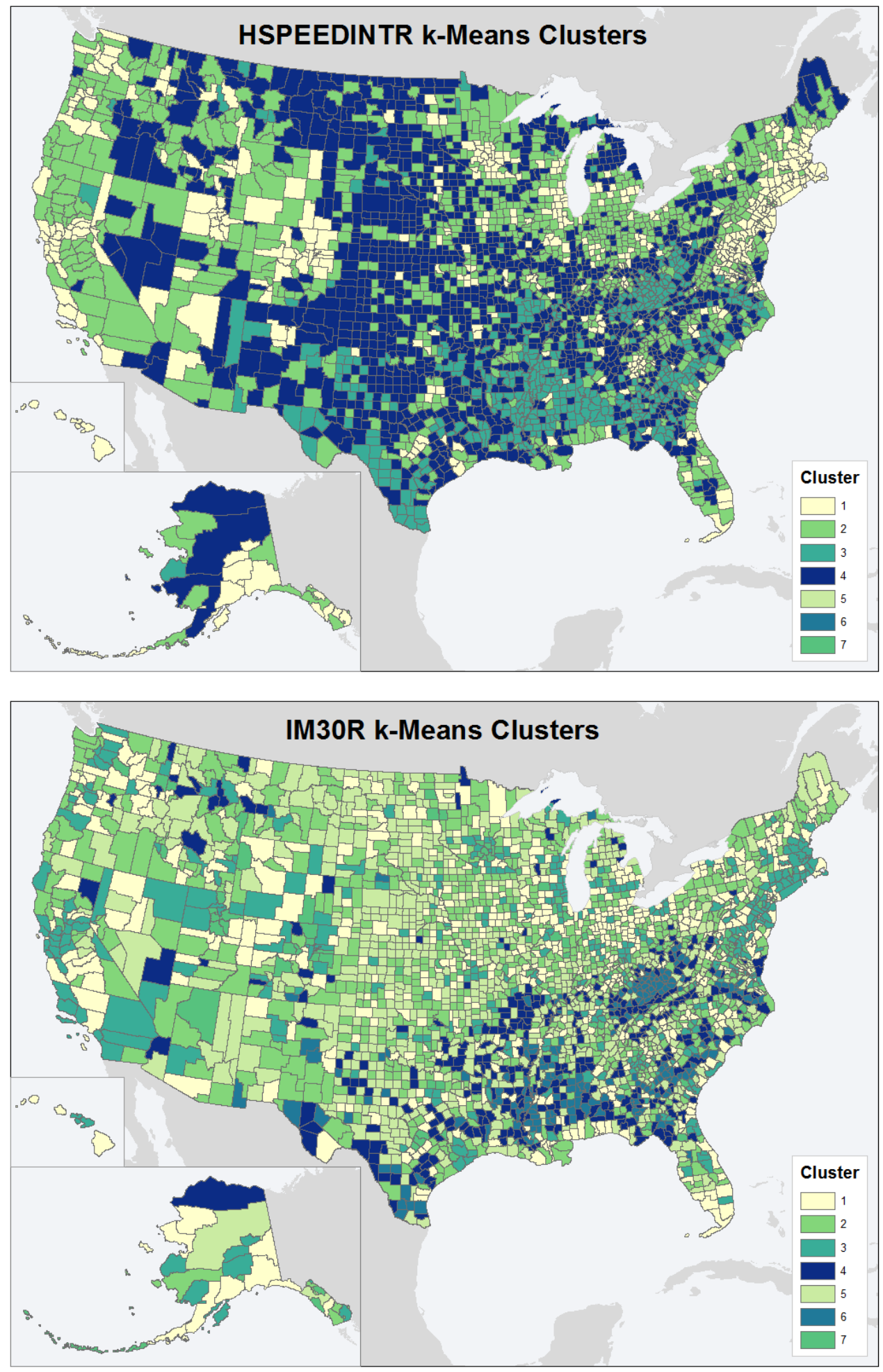

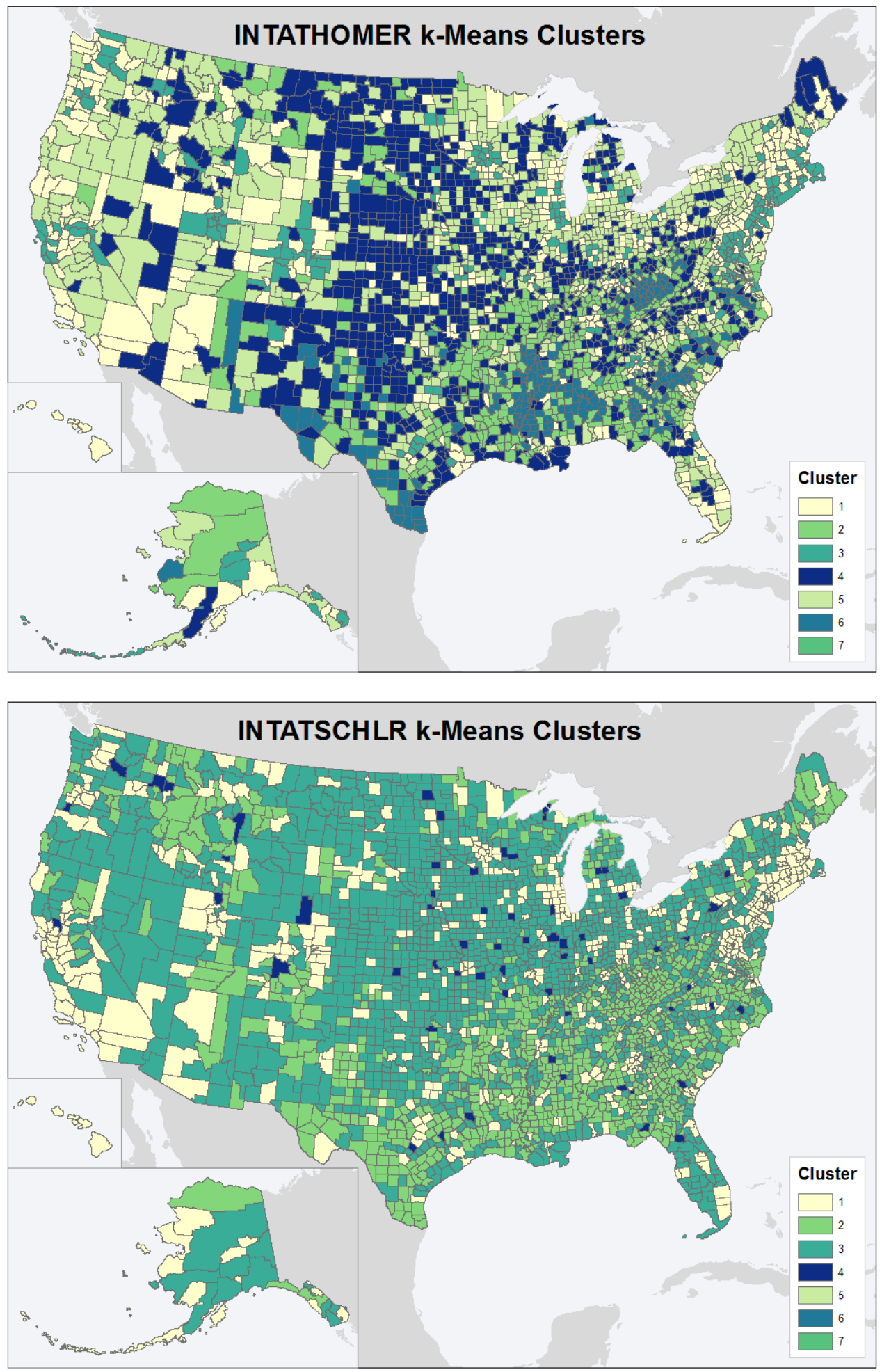

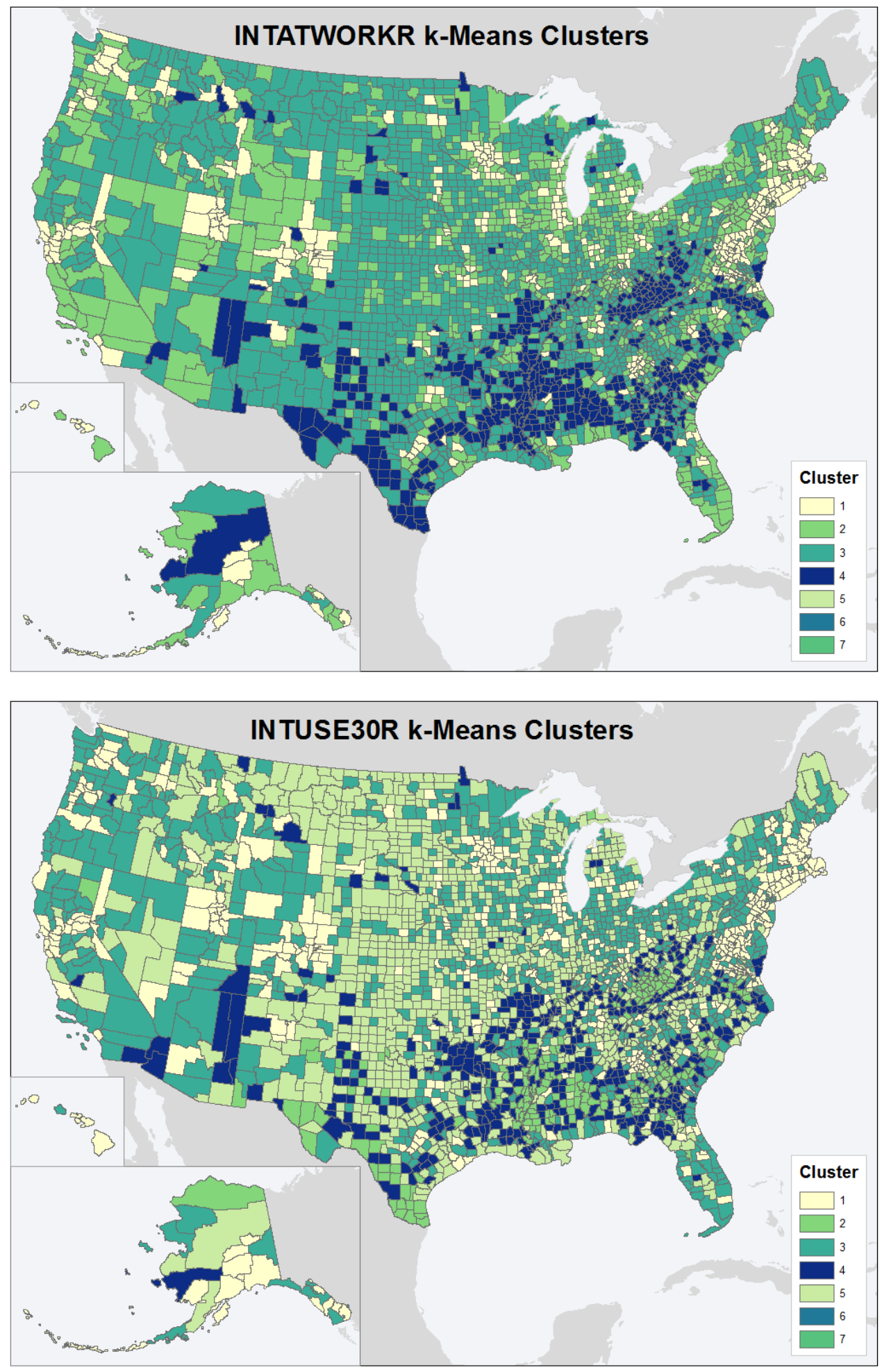

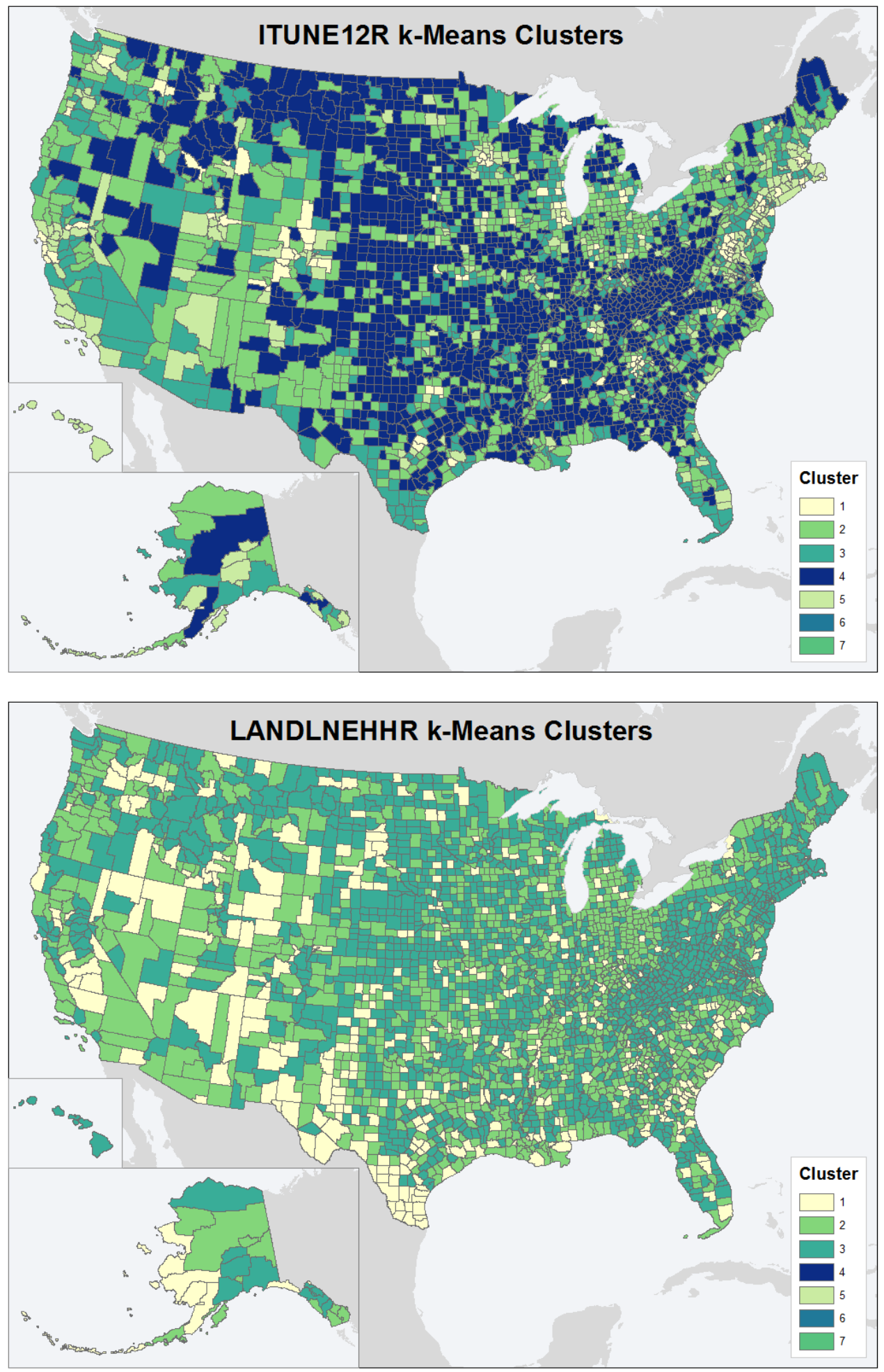

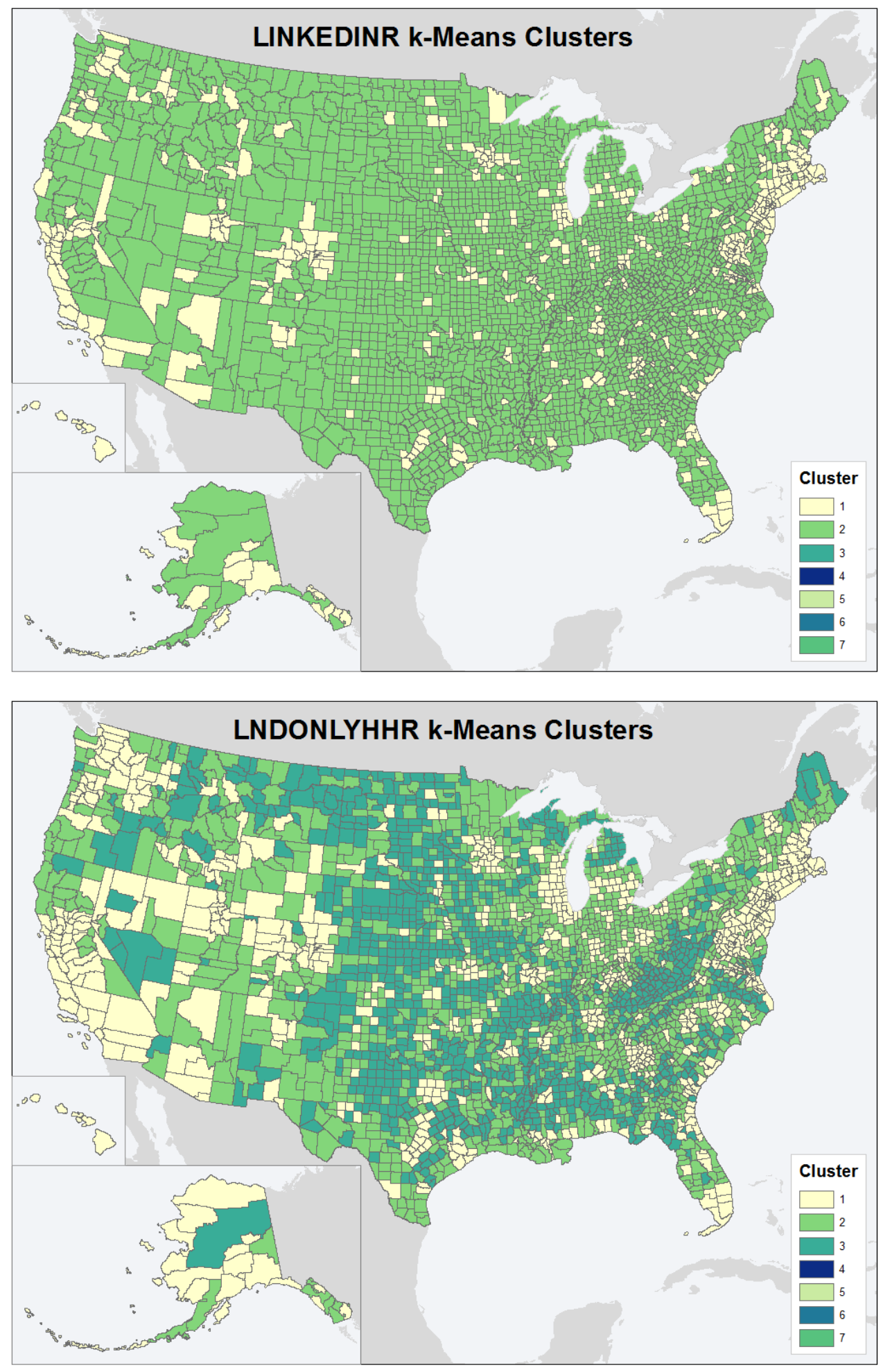

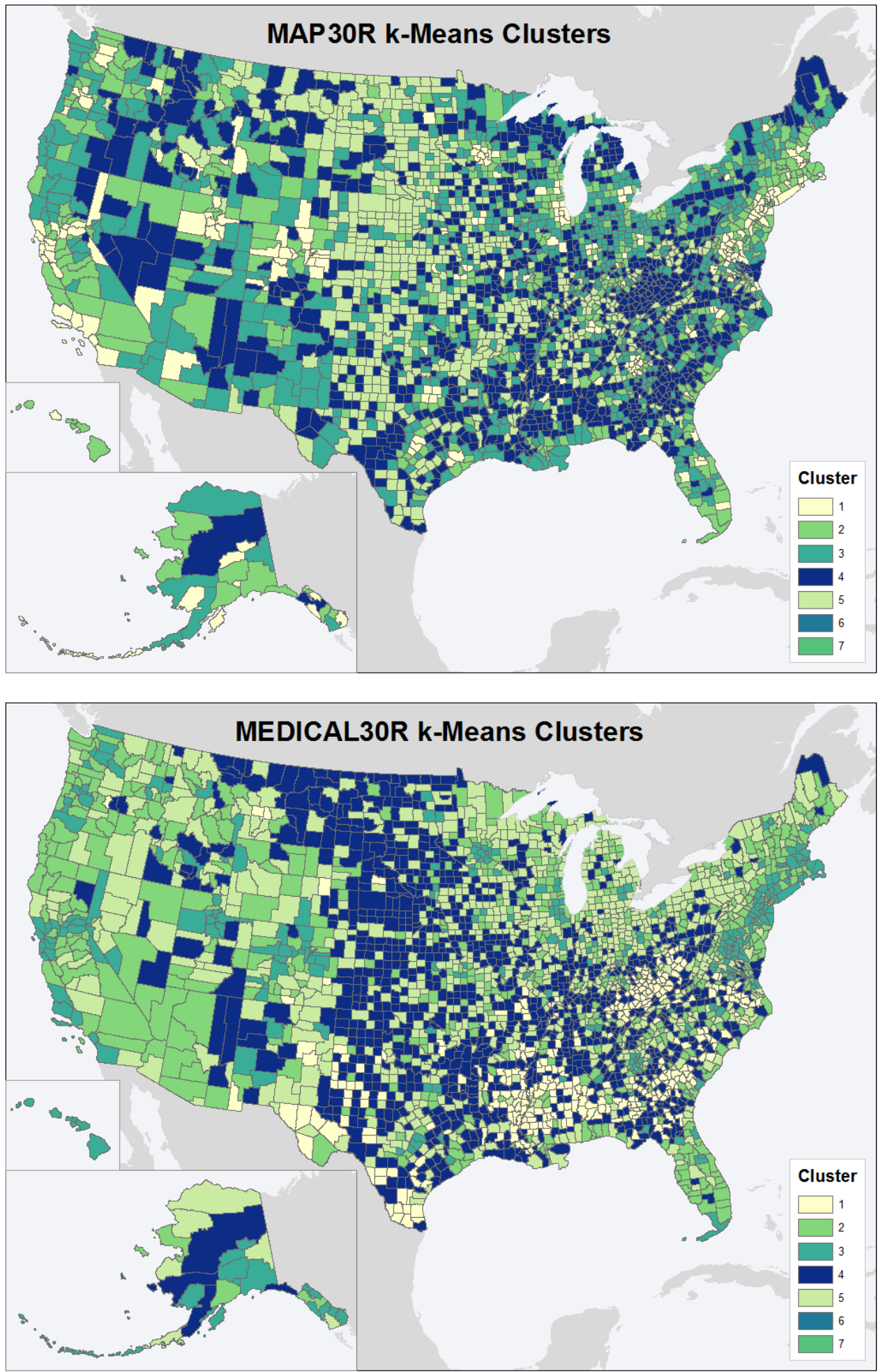

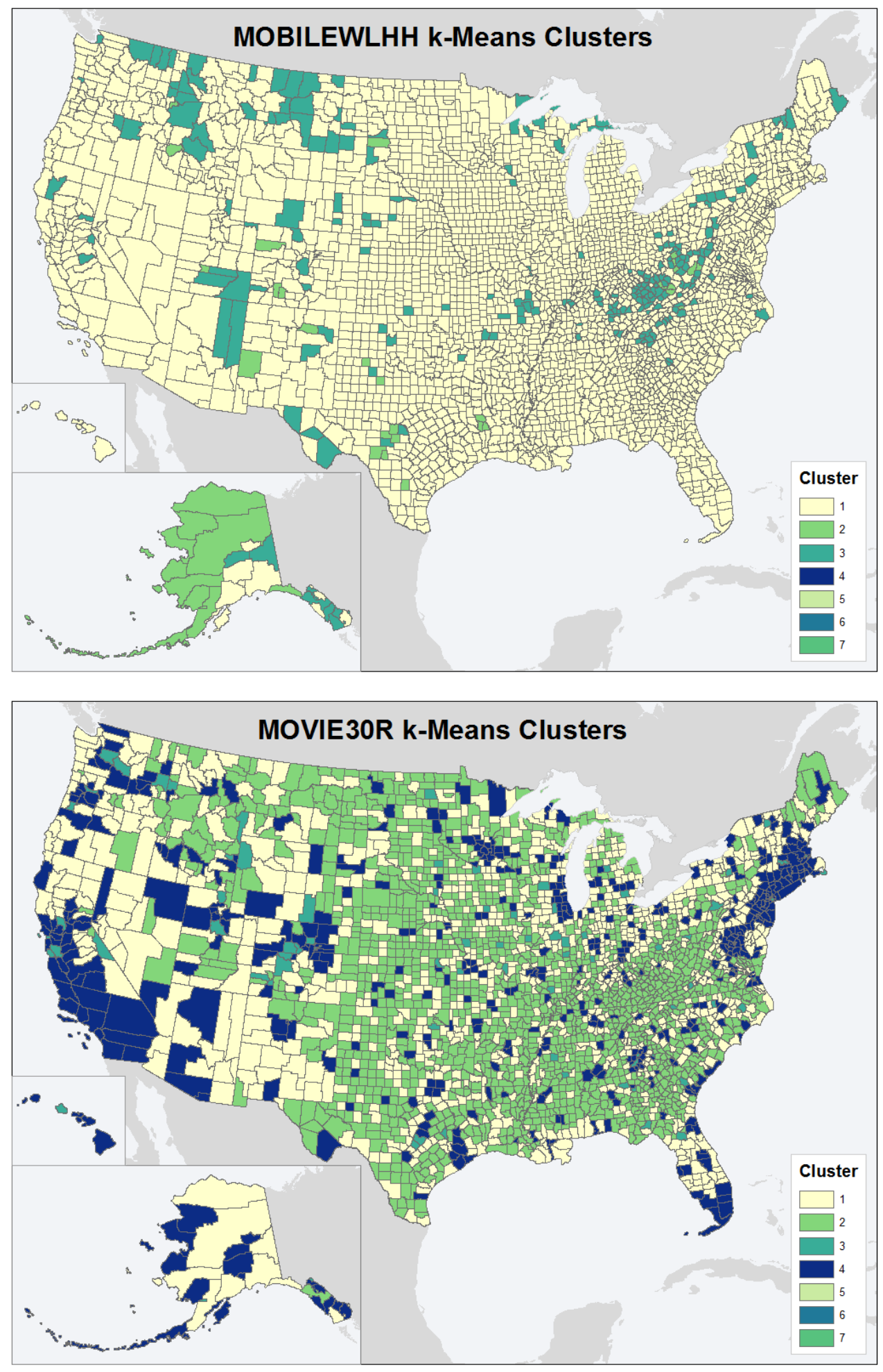

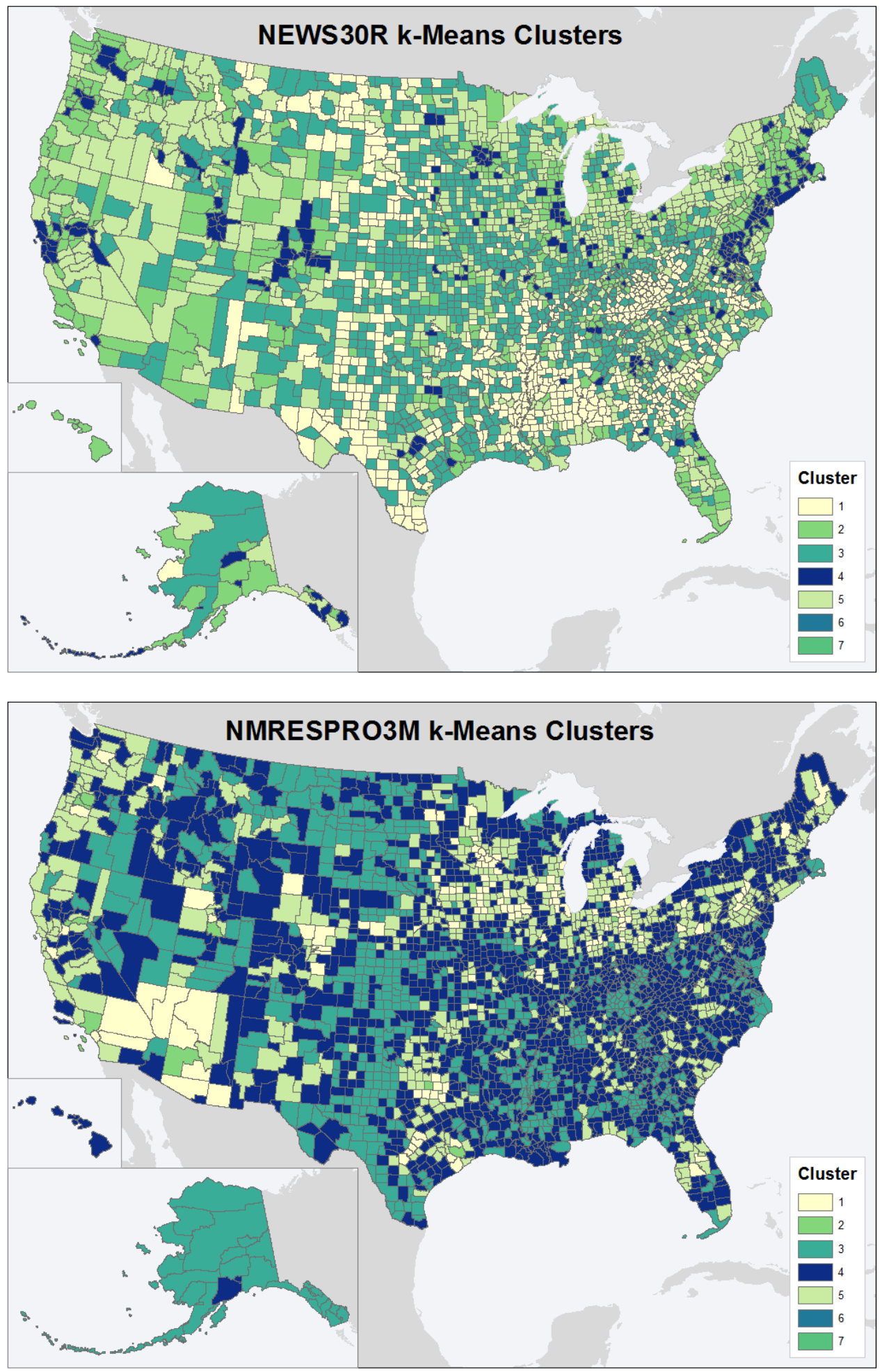

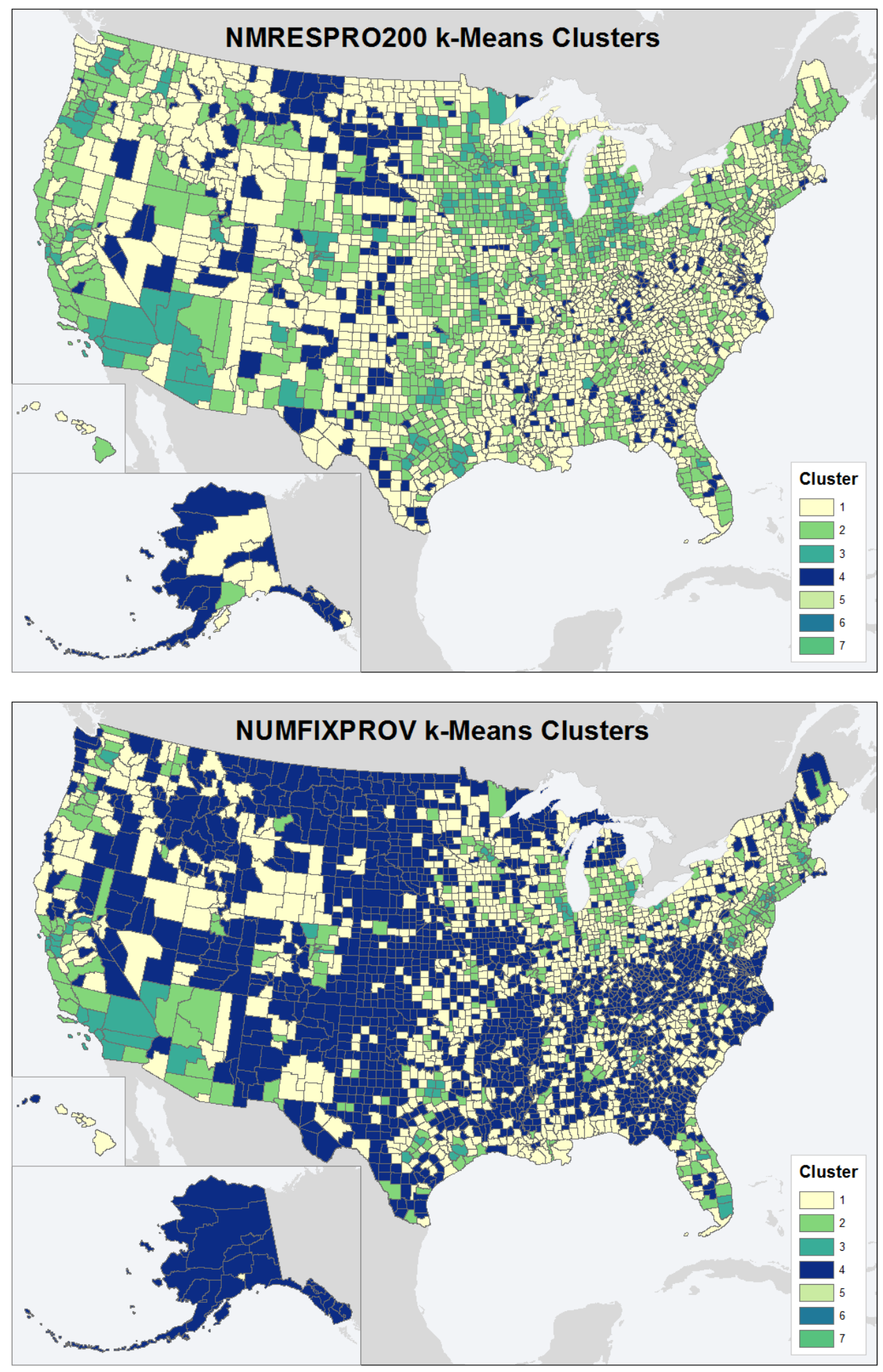

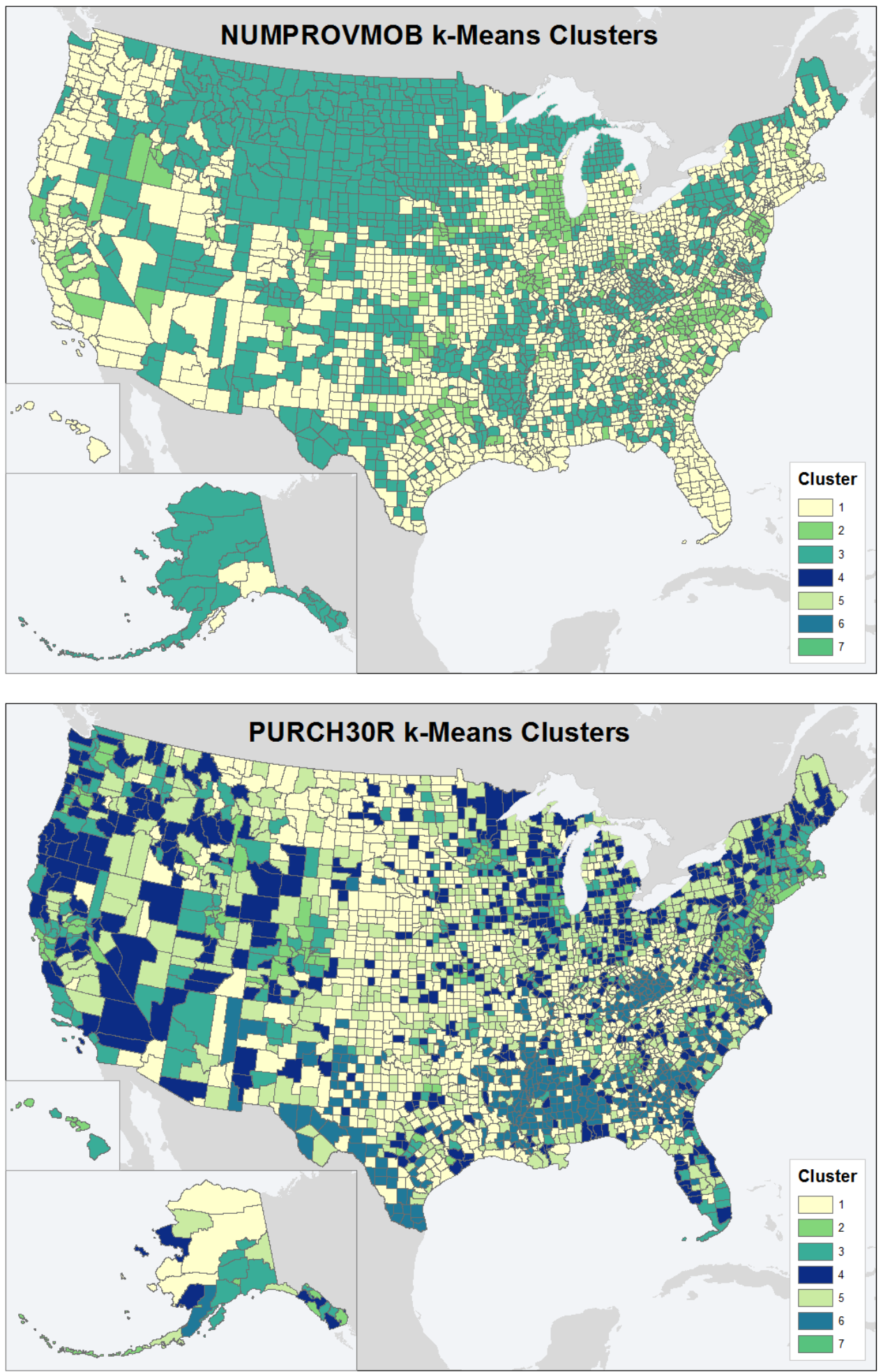

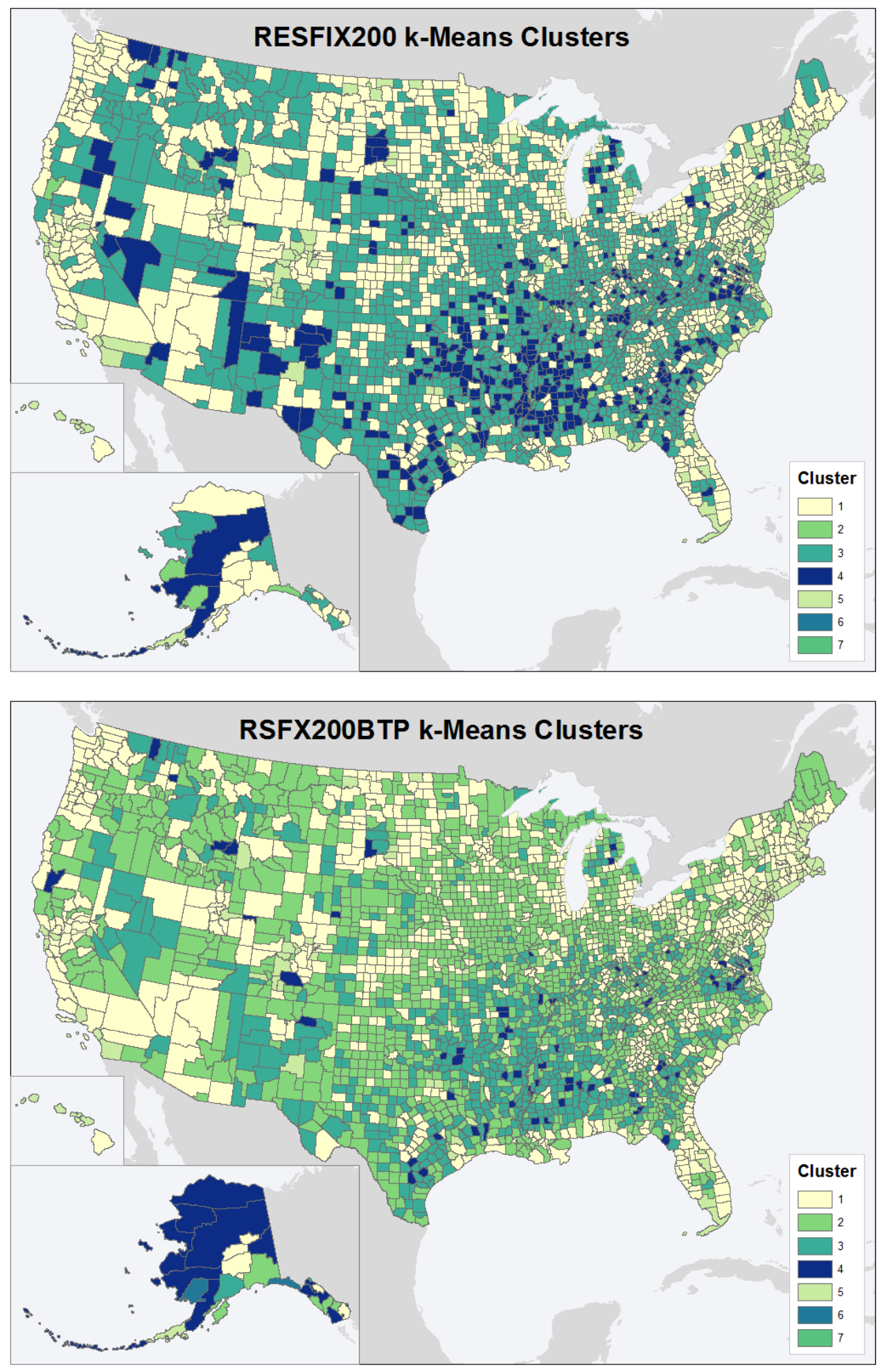

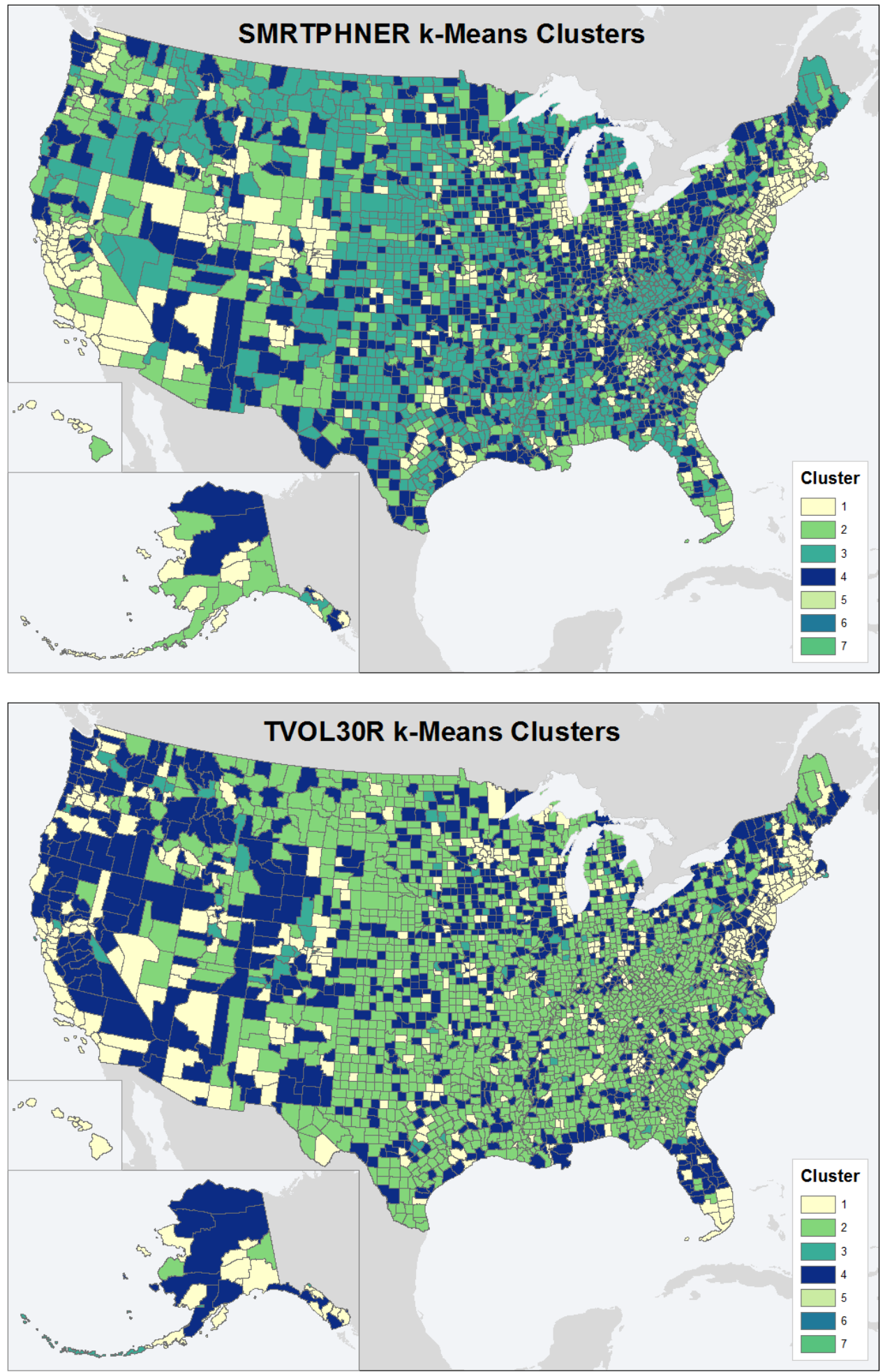

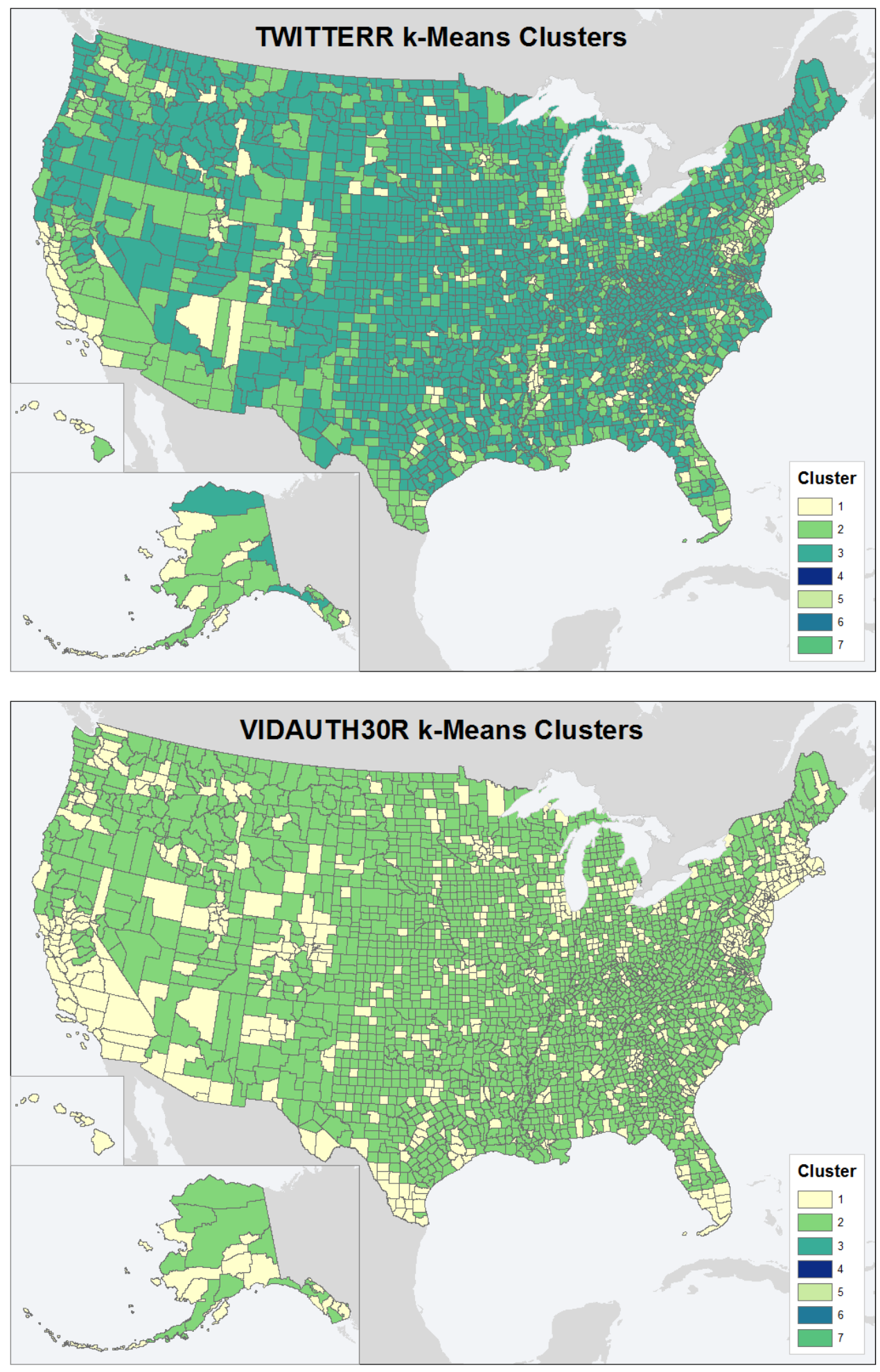

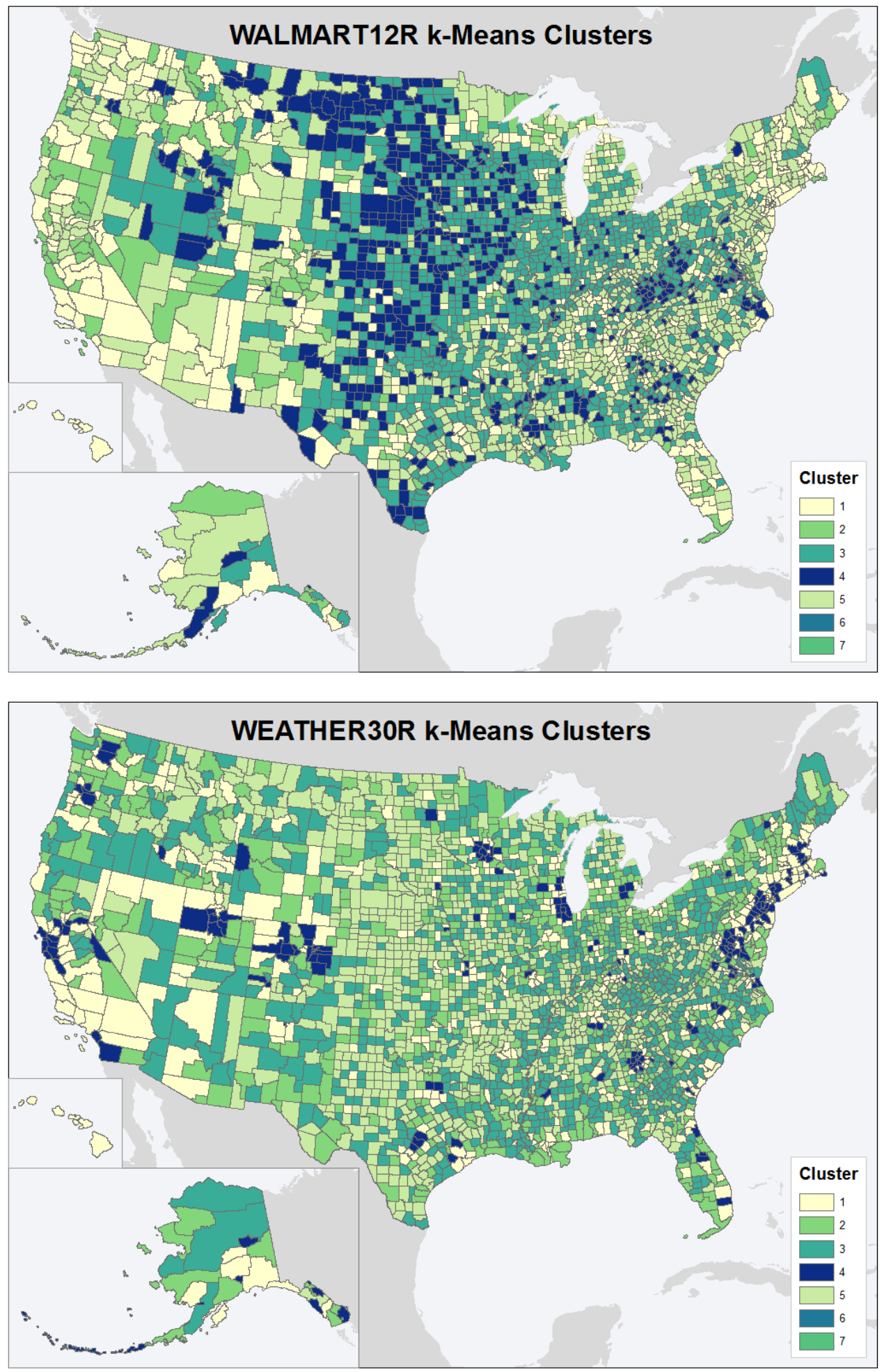

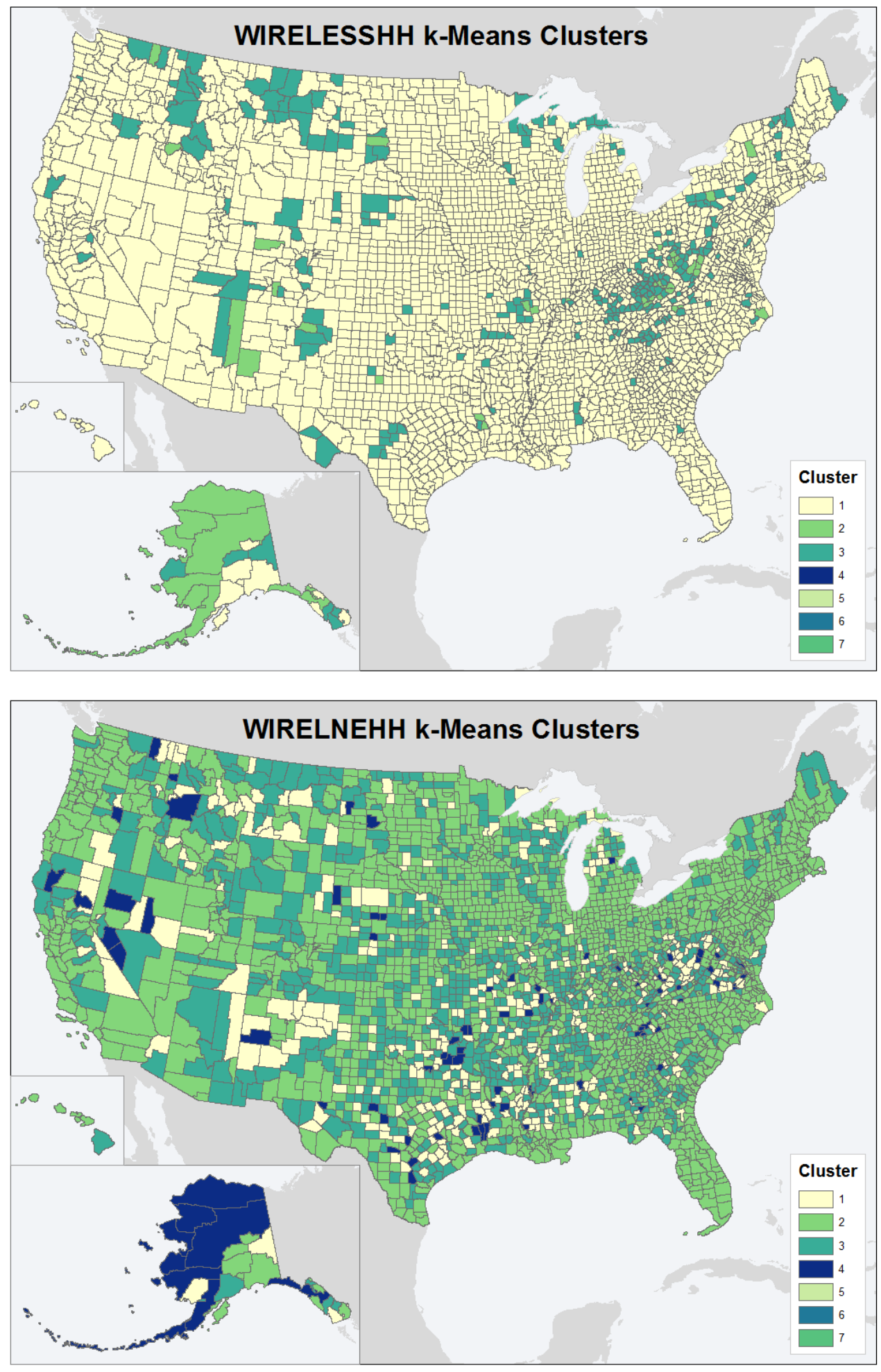

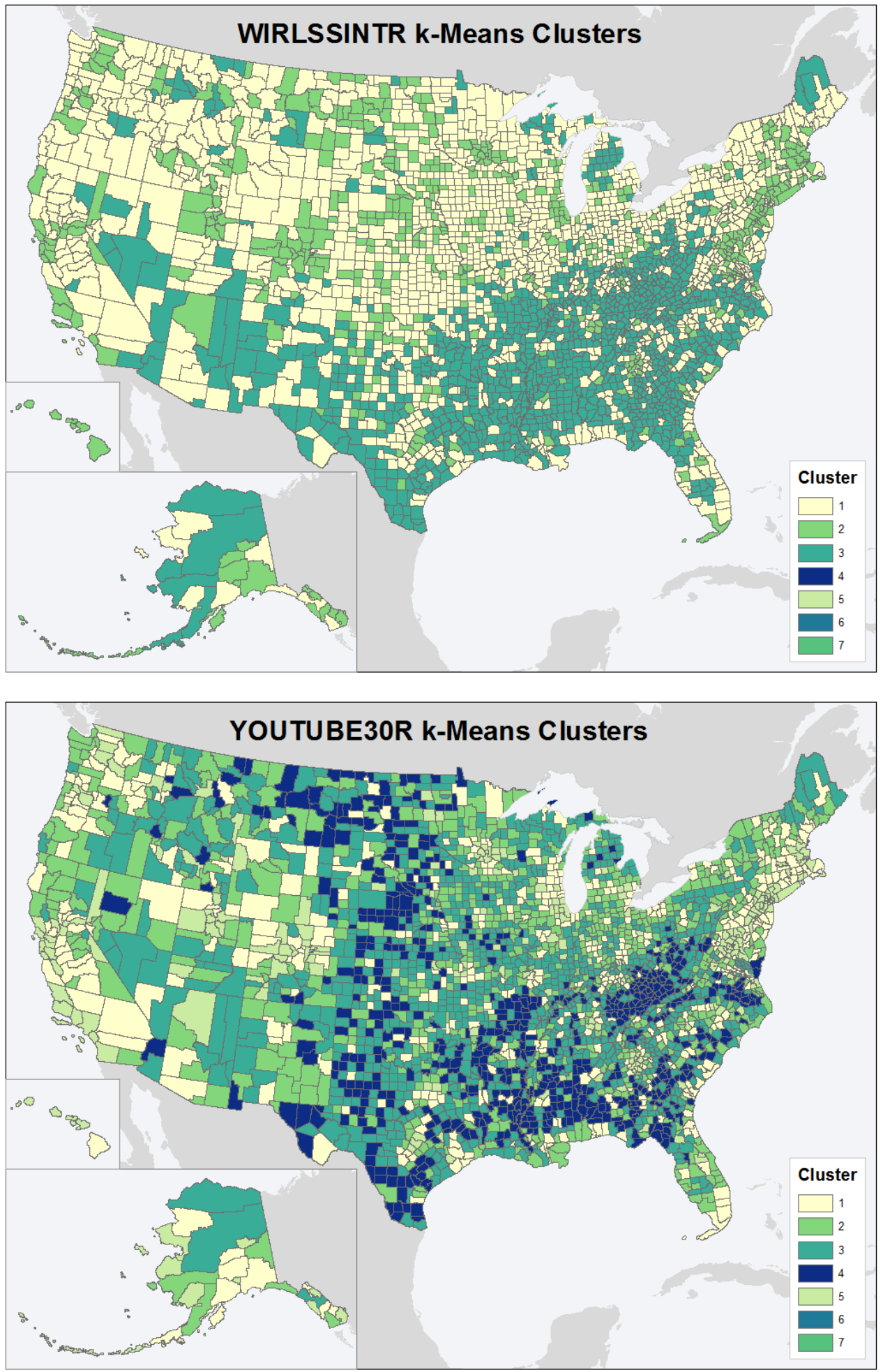



\section{Appendix E. Spatial Autocorrelation Results}

Table E-4: Results of global Moran's I spatial autocorrelation analysis using ArcGIS Desktop. Note that all values are significant at $\mathbf{p}<0.000001$ level.

\begin{tabular}{|c|c|c|c|c|c|c|}
\hline \multirow[b]{2}{*}{ Variable } & \multicolumn{6}{|c|}{ Moran's I Value } \\
\hline & Rook & Queen & $135 \mathrm{~km}$ & 195 km & 256 km & $550 \mathrm{~km}$ \\
\hline AMZ12R & 0.567 & 0.564 & 0.445 & 0.378 & 0.334 & 0.210 \\
\hline BANK12R & 0.597 & 0.595 & 0.456 & 0.387 & 0.342 & 0.219 \\
\hline BILLS30R & 0.523 & 0.521 & 0.378 & 0.308 & 0.265 & 0.160 \\
\hline BLOG30R & 0.392 & 0.388 & 0.295 & 0.247 & 0.217 & 0.140 \\
\hline BRDBNDHH & 0.380 & 0.378 & 0.253 & 0.196 & 0.152 & 0.045 \\
\hline CABLEHH & 0.361 & 0.358 & 0.274 & 0.232 & 0.211 & 0.141 \\
\hline CABLEINT & 0.554 & 0.551 & 0.430 & 0.367 & 0.326 & 0.205 \\
\hline CELLINHH & 0.559 & 0.556 & 0.399 & 0.312 & 0.260 & 0.147 \\
\hline CLLONLYHH & 0.185 & 0.183 & 0.118 & 0.095 & 0.077 & 0.045 \\
\hline COMPINHH & 0.616 & 0.614 & 0.477 & 0.400 & 0.349 & 0.216 \\
\hline DIALUPINTR & 0.465 & 0.462 & 0.339 & 0.282 & 0.245 & 0.147 \\
\hline DSLHH & 0.298 & 0.295 & 0.206 & 0.161 & 0.130 & 0.060 \\
\hline DSLINTR & 0.415 & 0.413 & 0.346 & 0.305 & 0.275 & 0.193 \\
\hline EBAY12R & 0.471 & 0.467 & 0.337 & 0.271 & 0.233 & 0.132 \\
\hline EMAIL30R & 0.587 & 0.586 & 0.458 & 0.391 & 0.346 & 0.222 \\
\hline EMPLOY30R & 0.287 & 0.282 & 0.194 & 0.156 & 0.135 & 0.080 \\
\hline EREADERR & 0.584 & 0.581 & 0.453 & 0.377 & 0.328 & 0.205 \\
\hline FACEBOOKR & 0.458 & 0.455 & 0.325 & 0.263 & 0.226 & 0.134 \\
\hline FIBERHHR & 0.415 & 0.410 & 0.286 & 0.229 & 0.195 & 0.096 \\
\hline FIBERINTR & 0.592 & 0.589 & 0.427 & 0.337 & 0.282 & 0.162 \\
\hline FINANCE30R & 0.568 & 0.566 & 0.430 & 0.363 & 0.319 & 0.201 \\
\hline GOOGLE30R & 0.590 & 0.589 & 0.445 & 0.373 & 0.326 & 0.203 \\
\hline HSPEEDINTR & 0.590 & 0.588 & 0.455 & 0.383 & 0.336 & 0.209 \\
\hline IM30R & 0.461 & 0.458 & 0.317 & 0.256 & 0.219 & 0.125 \\
\hline INTATHOMER & 0.604 & 0.602 & 0.472 & 0.403 & 0.357 & 0.228 \\
\hline INTATSCHLR & 0.204 & 0.201 & 0.142 & 0.119 & 0.105 & 0.067 \\
\hline INTATWORKR & 0.556 & 0.554 & 0.401 & 0.324 & 0.278 & 0.166 \\
\hline INTUSE30R & 0.593 & 0.592 & 0.453 & 0.382 & 0.334 & 0.207 \\
\hline ITUNE12R & 0.489 & 0.485 & 0.346 & 0.275 & 0.231 & 0.134 \\
\hline LANDLNEHH & 0.193 & 0.191 & 0.125 & 0.100 & 0.080 & 0.046 \\
\hline LINKEDINR & 0.492 & 0.489 & 0.348 & 0.280 & 0.237 & 0.142 \\
\hline LNDONLYHH & 0.547 & 0.544 & 0.376 & 0.284 & 0.231 & 0.119 \\
\hline MAP30R & 0.533 & 0.529 & 0.386 & 0.317 & 0.277 & 0.174 \\
\hline
\end{tabular}




\begin{tabular}{|c|c|c|c|c|c|c|}
\hline & \multicolumn{7}{|c|}{ Moran's I Value } \\
\hline Variable & Rook & Queen & $\mathbf{1 3 5} \mathbf{~ k m}$ & $\mathbf{1 9 5} \mathbf{~ k m}$ & $\mathbf{2 5 6} \mathbf{~ k m}$ & $\mathbf{5 5 0} \mathbf{~ k m}$ \\
\hline MEDICAL30R & 0.543 & 0.542 & 0.428 & 0.365 & 0.322 & 0.204 \\
\hline MOBILEWLHH & 0.405 & 0.400 & 0.246 & 0.180 & 0.139 & 0.043 \\
\hline MOVIE30R & 0.342 & 0.338 & 0.245 & 0.201 & 0.175 & 0.110 \\
\hline NEWS30R & 0.564 & 0.561 & 0.438 & 0.374 & 0.332 & 0.213 \\
\hline NMRESPR200R & 0.480 & 0.476 & 0.378 & 0.314 & 0.270 & 0.128 \\
\hline NMRESPRO3MR & 0.468 & 0.465 & 0.360 & 0.298 & 0.250 & 0.095 \\
\hline NUMFIXPROVR & 0.548 & 0.544 & 0.405 & 0.331 & 0.279 & 0.136 \\
\hline NUMPROVMOBR & 0.538 & 0.536 & 0.357 & 0.277 & 0.227 & 0.114 \\
\hline PURCH30R & 0.612 & 0.610 & 0.484 & 0.416 & 0.369 & 0.241 \\
\hline RESFIX200R & 0.399 & 0.395 & 0.283 & 0.246 & 0.217 & 0.145 \\
\hline RSFX200BTPR & 0.405 & 0.400 & 0.295 & 0.256 & 0.231 & 0.157 \\
\hline SMRTPHNER & 0.493 & 0.490 & 0.323 & 0.243 & 0.198 & 0.104 \\
\hline TVOL30R & 0.284 & 0.279 & 0.203 & 0.169 & 0.149 & 0.098 \\
\hline TWITTERR & 0.346 & 0.342 & 0.228 & 0.176 & 0.145 & 0.076 \\
\hline VIDAUTH30R & 0.300 & 0.295 & 0.210 & 0.170 & 0.145 & 0.092 \\
\hline WALMART12R & 0.433 & 0.432 & 0.362 & 0.327 & 0.299 & 0.208 \\
\hline WEATHER30R & 0.528 & 0.524 & 0.360 & 0.283 & 0.240 & 0.140 \\
\hline WIRELESSHH & 0.434 & 0.433 & 0.272 & 0.208 & 0.165 & 0.053 \\
\hline WIRELNEHH & 0.301 & 0.300 & 0.218 & 0.172 & 0.146 & 0.073 \\
\hline WIRLESSINTR & 0.542 & 0.540 & 0.436 & 0.387 & 0.357 & 0.265 \\
\hline YOUTUBE30R & 0.464 & 0.461 & 0.332 & 0.271 & 0.234 & 0.142 \\
\hline
\end{tabular}




\section{Appendix F. Geographically-Weighted Regression Analysis Results \\ BRDBNDHH}

BLACKR

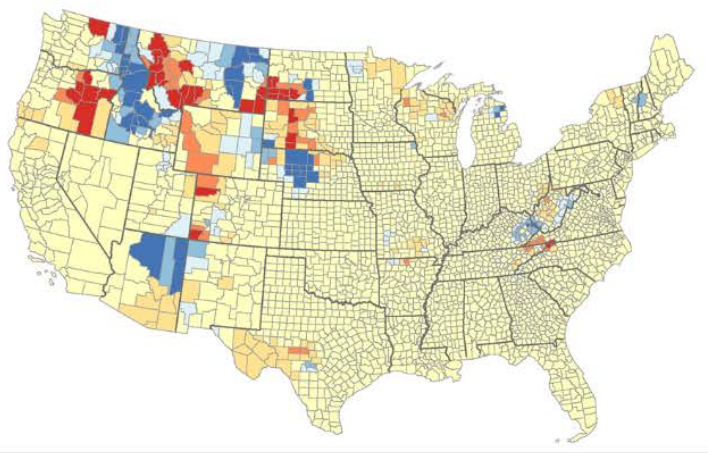

LGOVEDEXPR

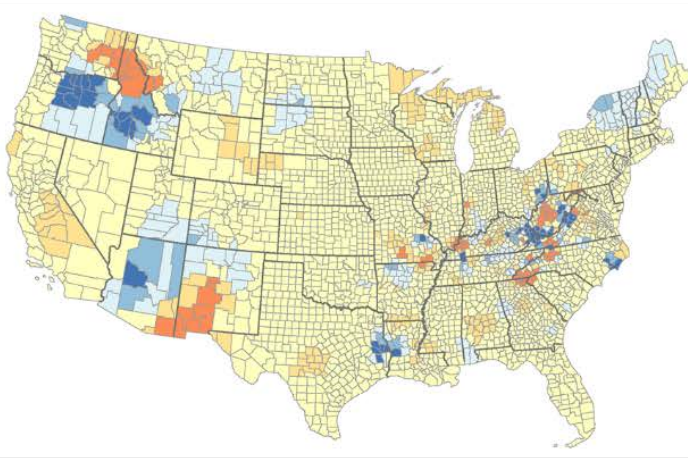

TOTEMPLR

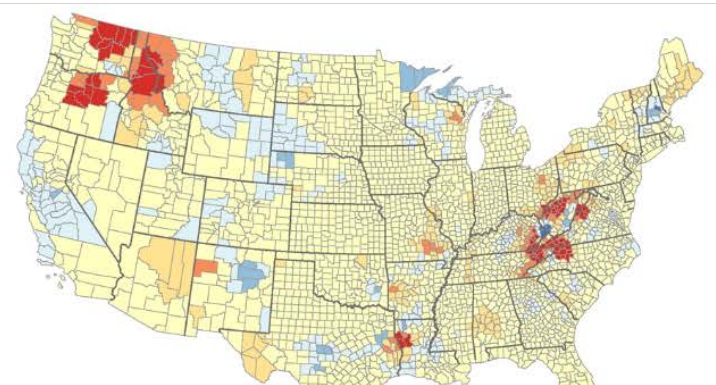

ASIANR

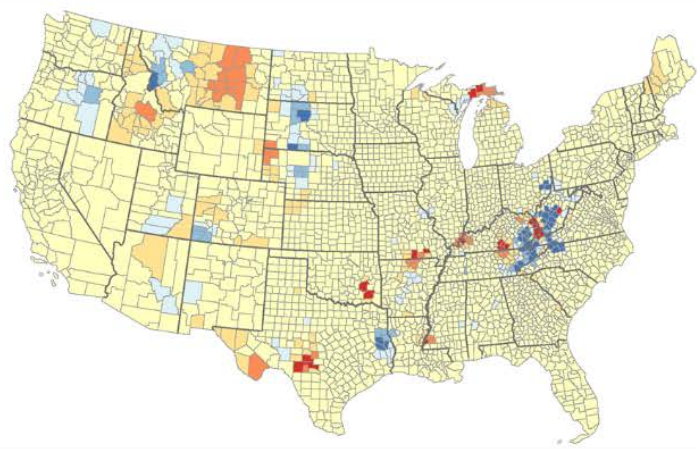

URBAN

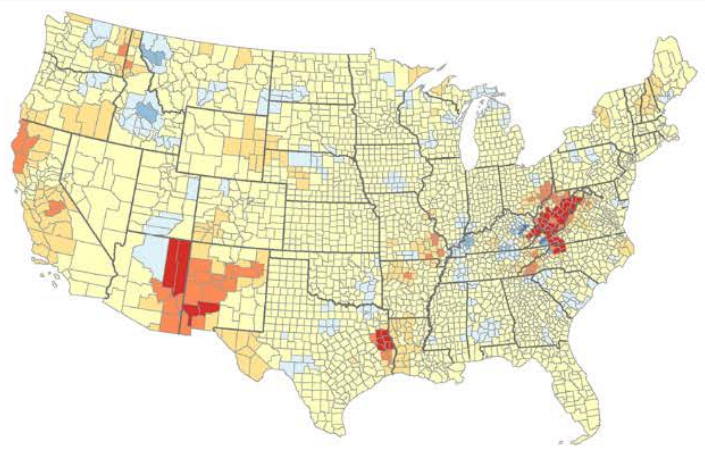

HISPANICR

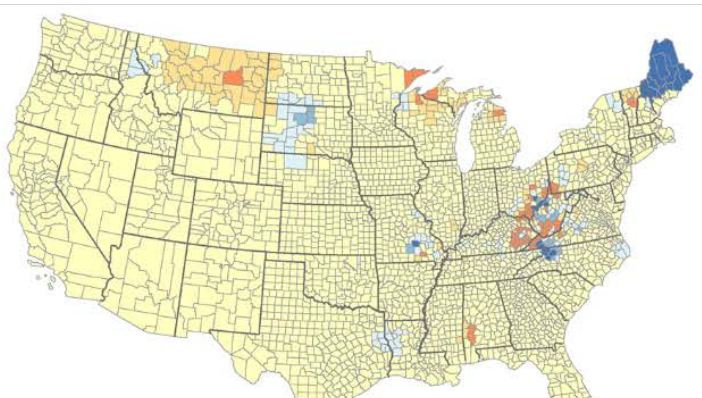

Standard deviation

\begin{tabular}{|c|}
\hline$>2.5$ \\
\hline $1.5-2.5$ \\
\hline $0.50-1.5$ \\
\hline$-0.50-0.50$ \\
\hline$-1.5--0.50$ \\
\hline$-2.5--1.5$ \\
\hline$<-2.5$ \\
\hline
\end{tabular}




\section{MOBILEWLHH}

BLACKR

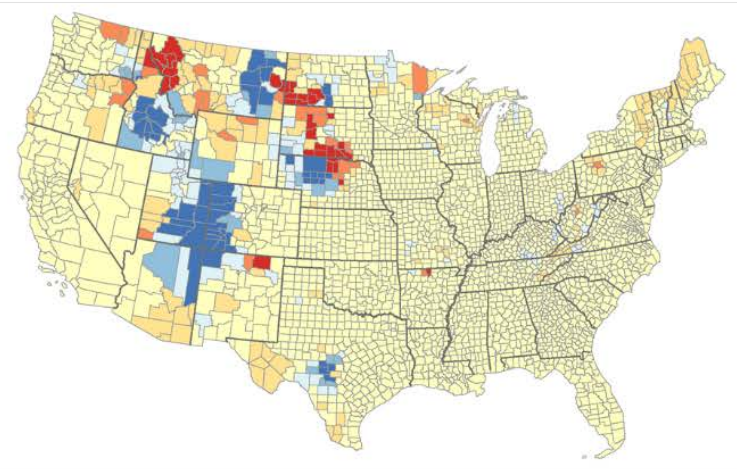

LGOVEDEXPR

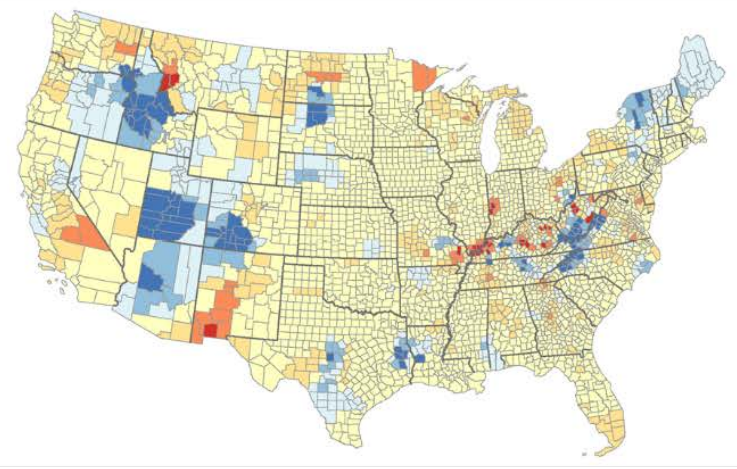

TOTEMPLR

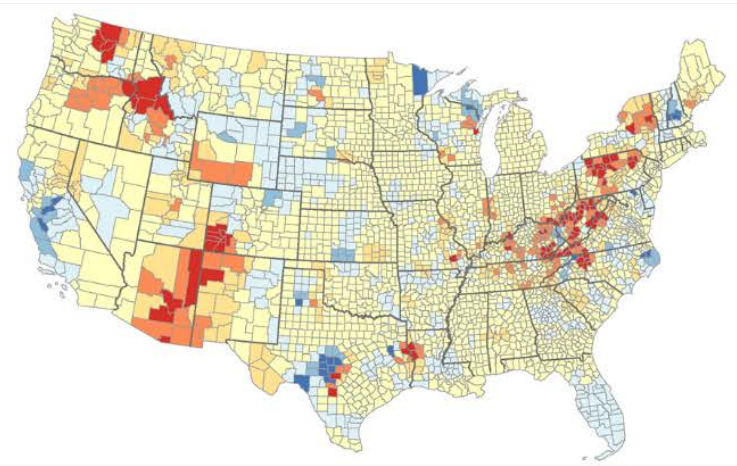

CONSTRUCTR

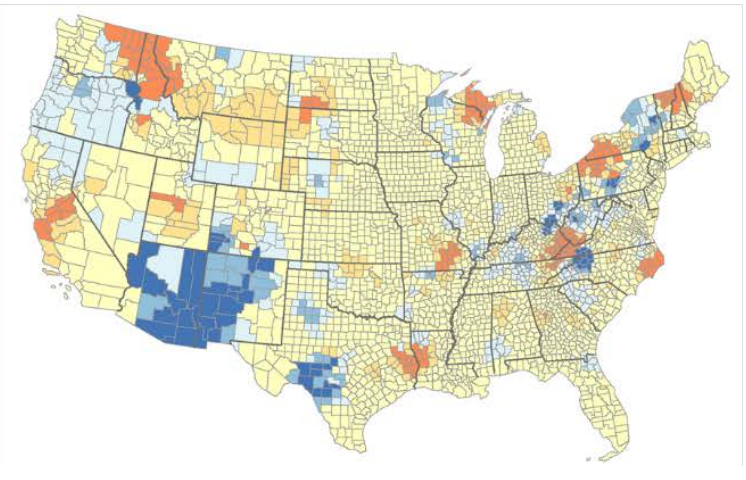

ASIANR

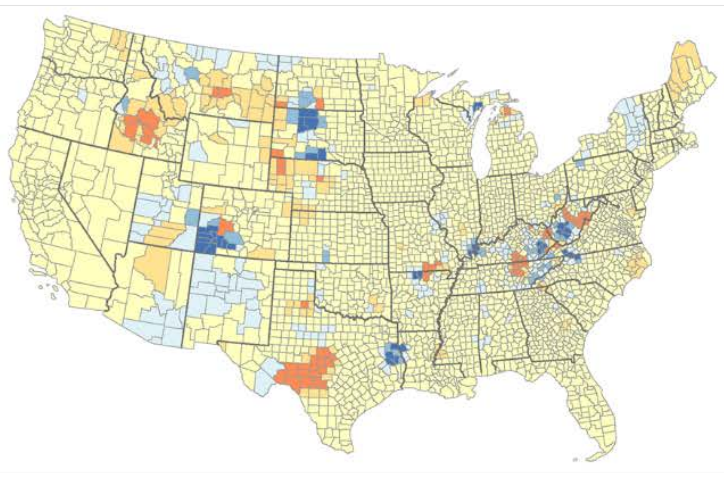

URBAN

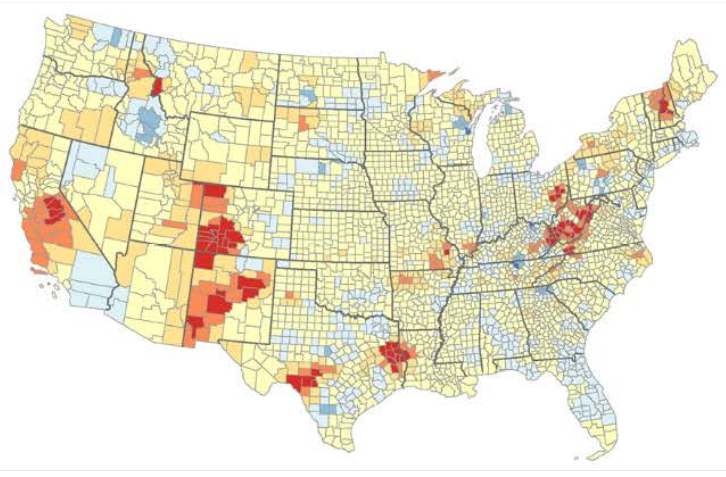

HISPANICR

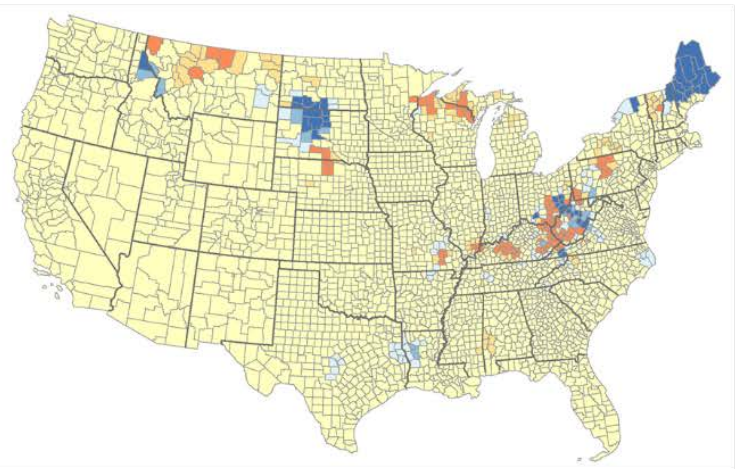

Standard deviation

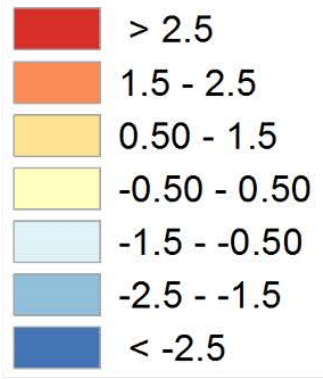




\section{CELLINHHR}
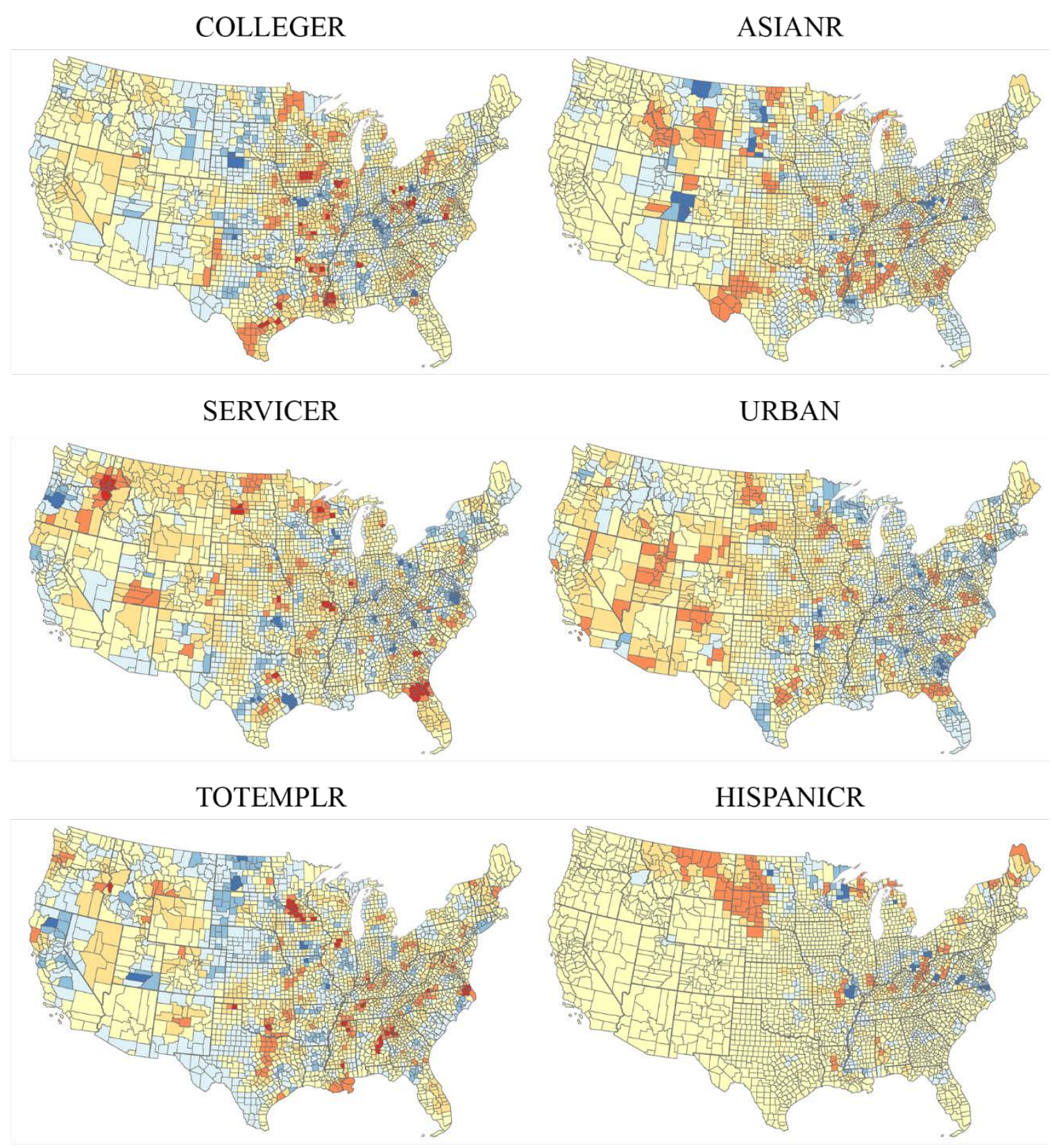

CONSTRUCTR

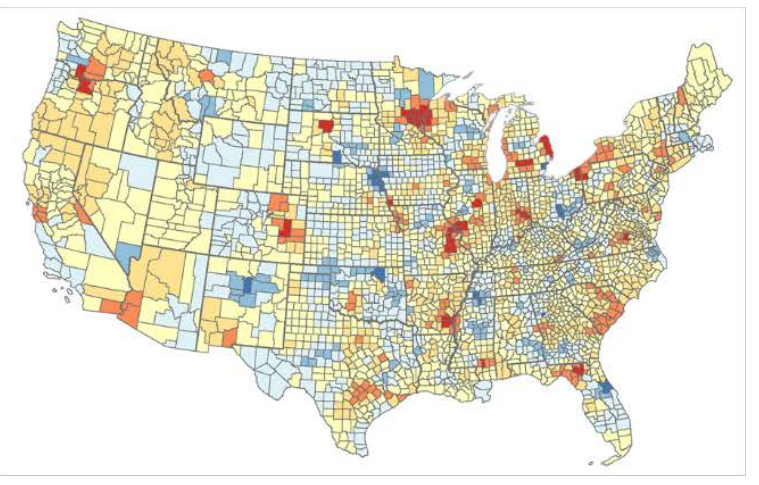

\section{Standard deviation}

\begin{tabular}{|c|}
\hline$>2.5$ \\
\hline $1.5-2.5$ \\
\hline $0.50-1.5$ \\
\hline$-0.50-0.50$ \\
\hline$-1.5--0.50$ \\
\hline$-2.5--1.5$ \\
\hline$<-2.5$ \\
\hline
\end{tabular}




\section{CLLONLYHHR}

COLLEGER

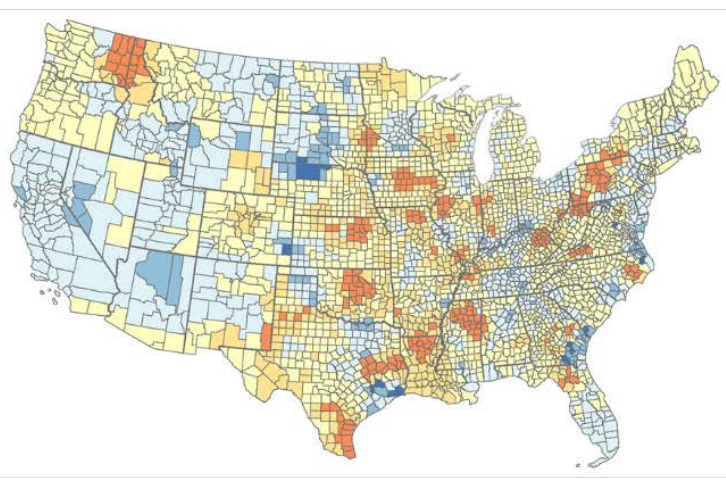

SERVICER

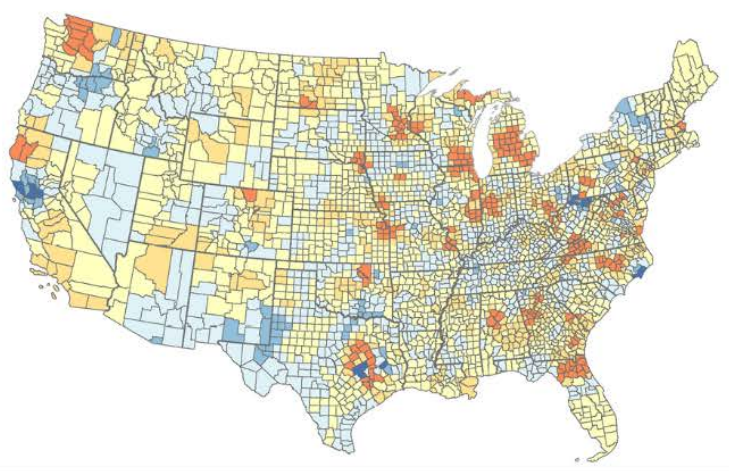

TOTEMPLR

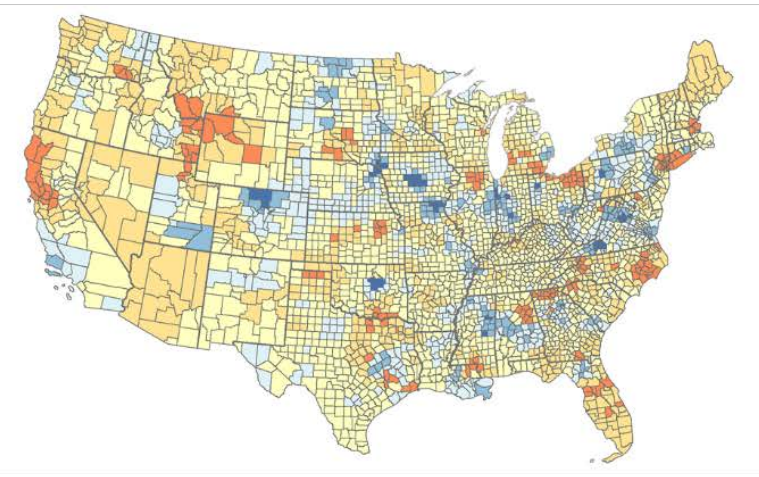

CONSTRUCTR

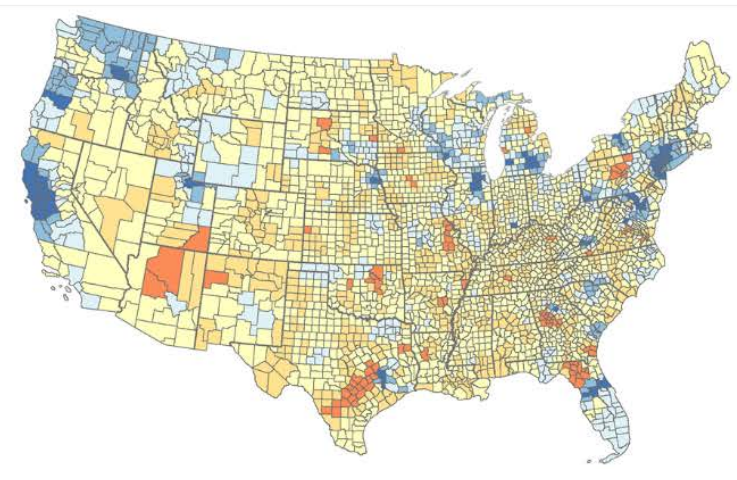

BLACKR

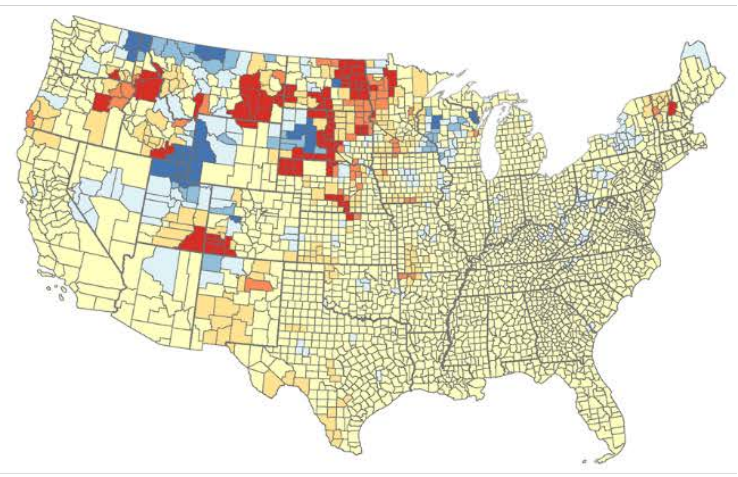

URBAN

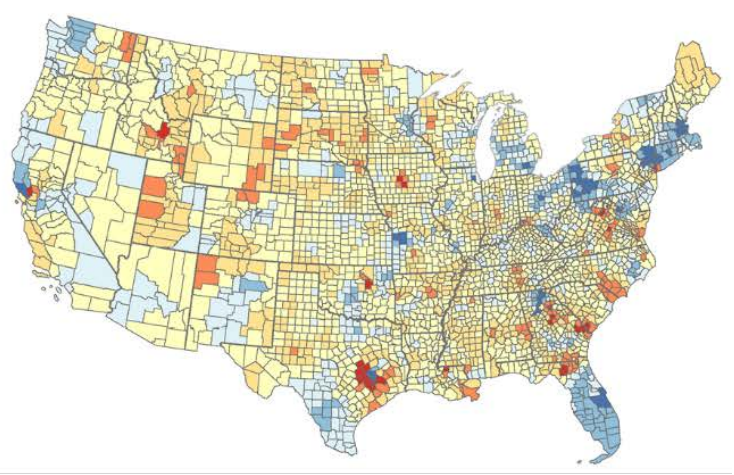

HISPANICR

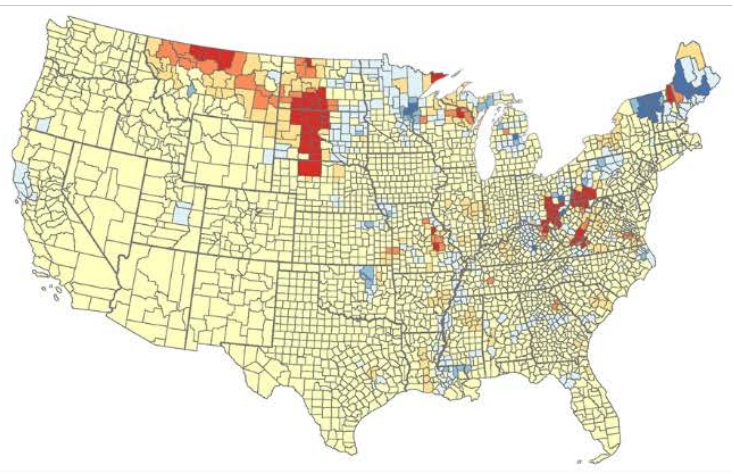

Standard deviation

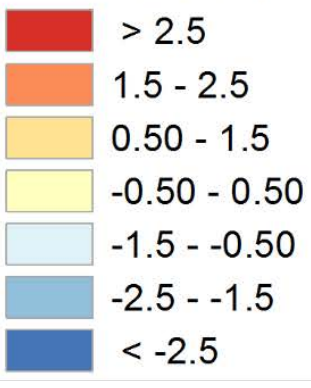




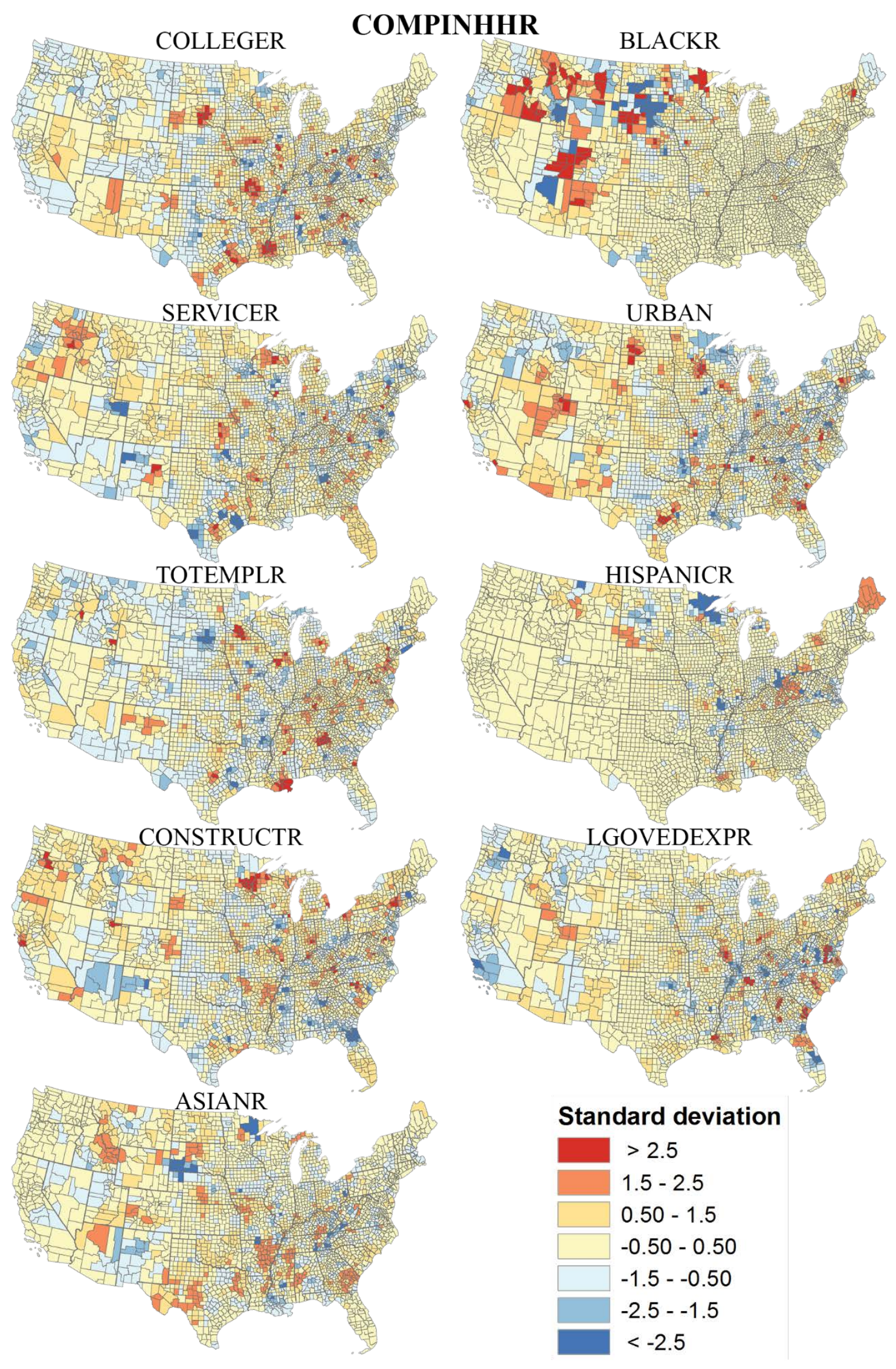




\section{HSPEEDINTR}

COLLEGER

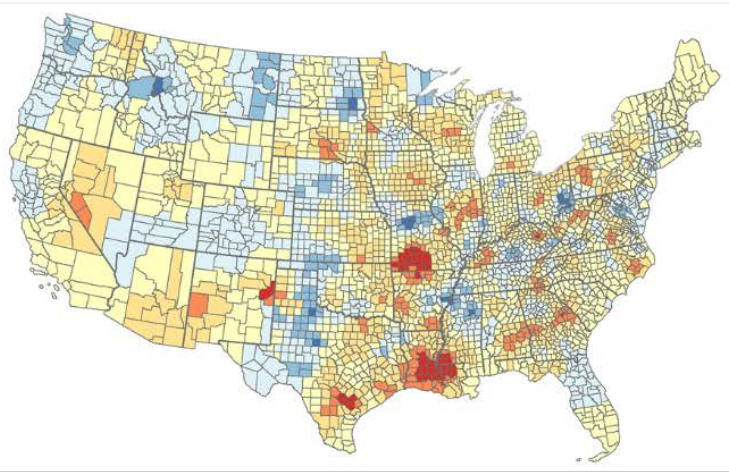

ASIANR

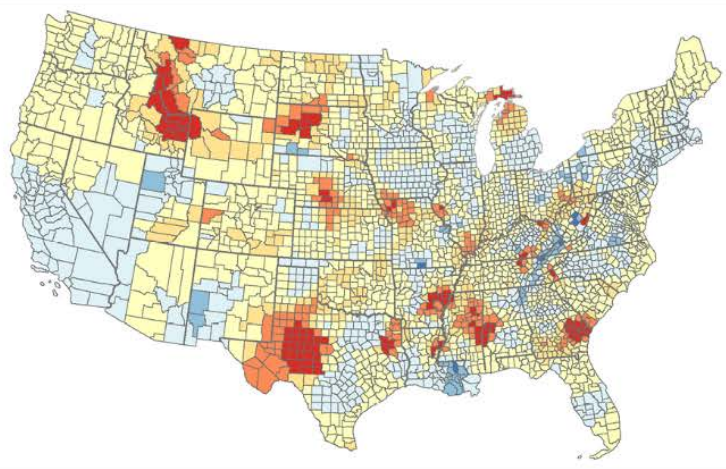

TOTEMPLR

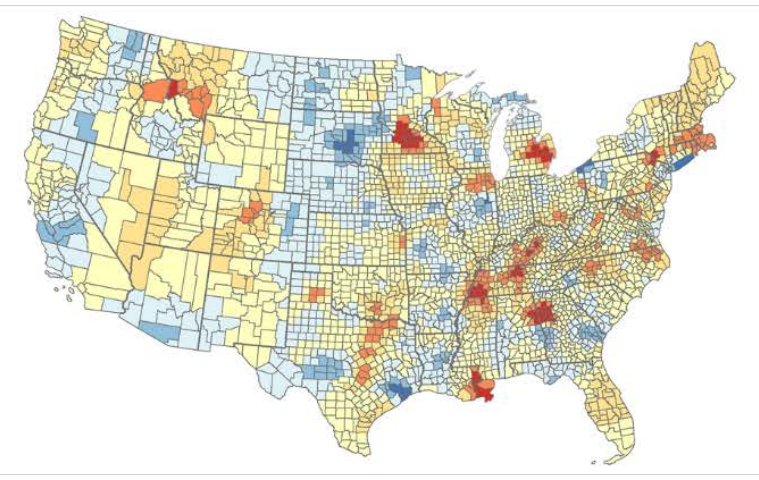

CONSTRUCTR

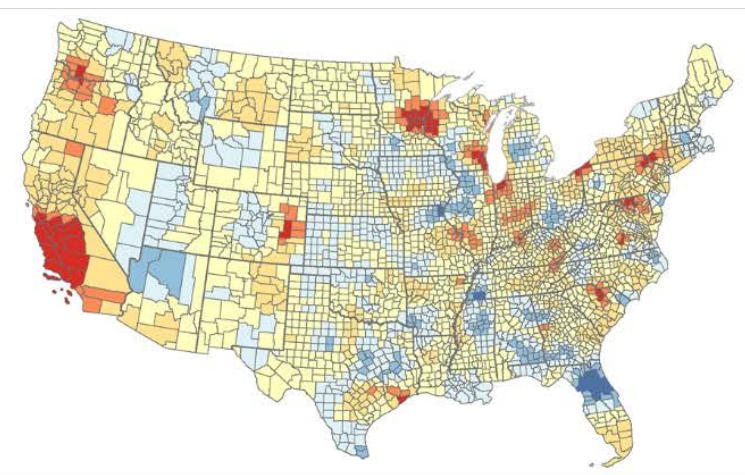

BLACKR

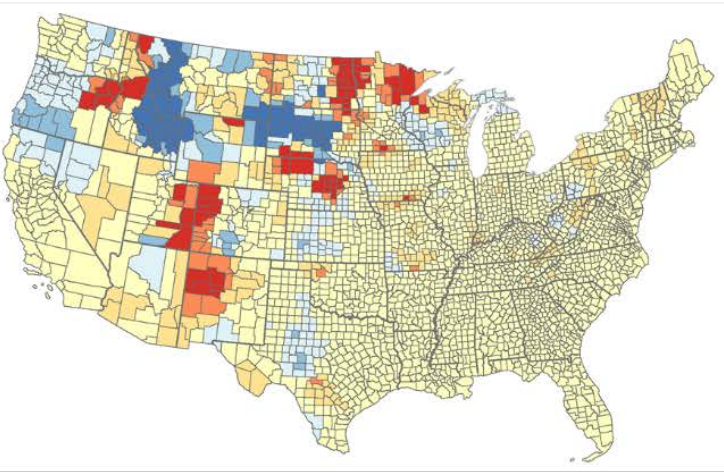

URBAN

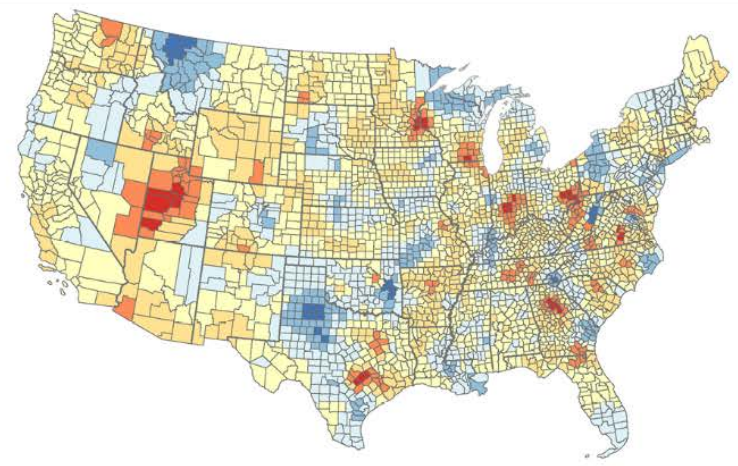

HISPANICR

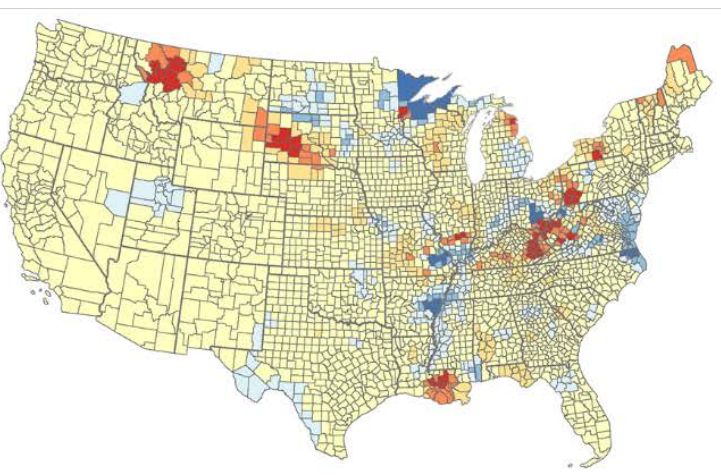

LGOVEDEXPR

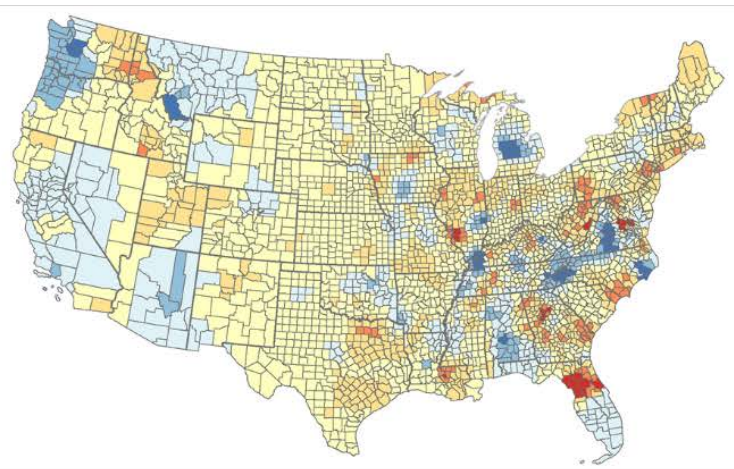




\section{INTUSE30R}
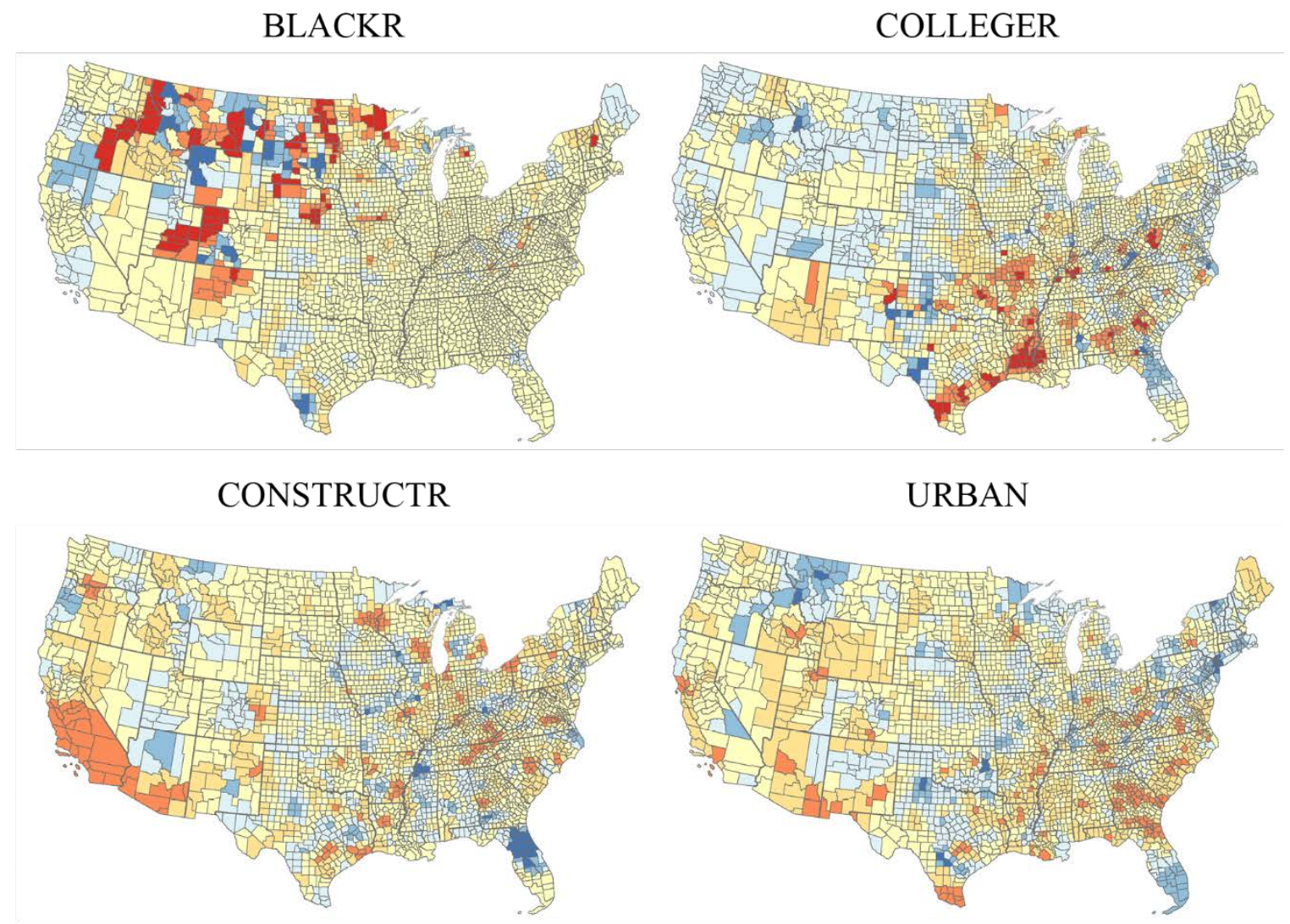

TOTEMPLR

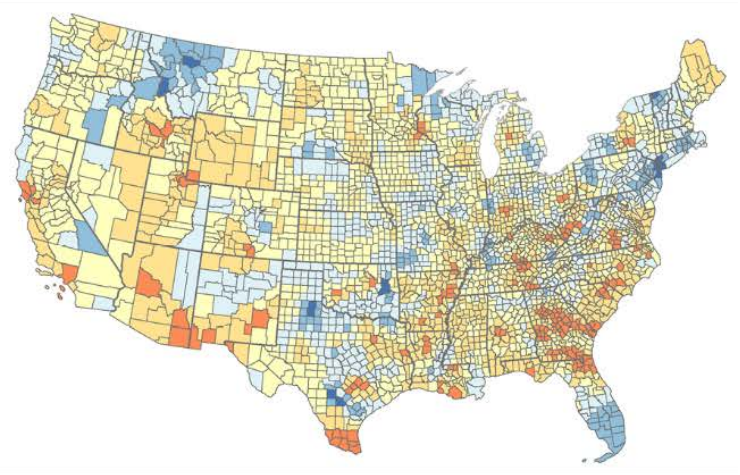

TOTEMPR

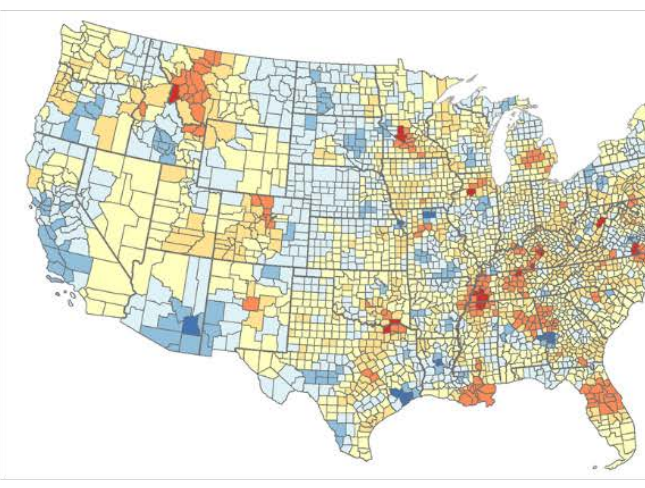

\section{Standard deviation}

HISPANICR

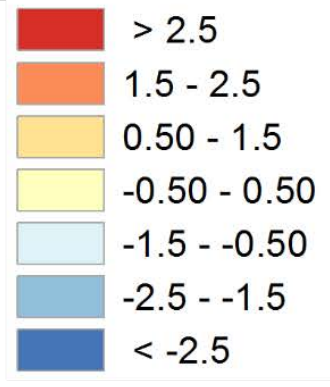




\section{LNDONLYHHR}

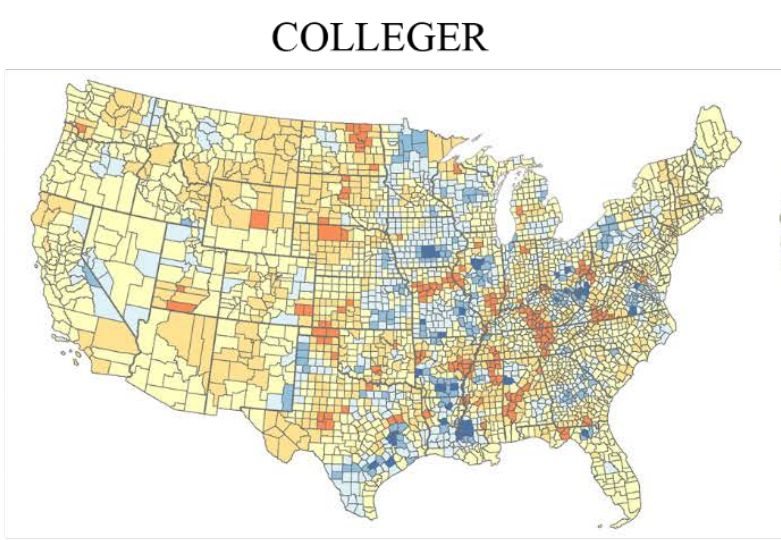

SERVICER

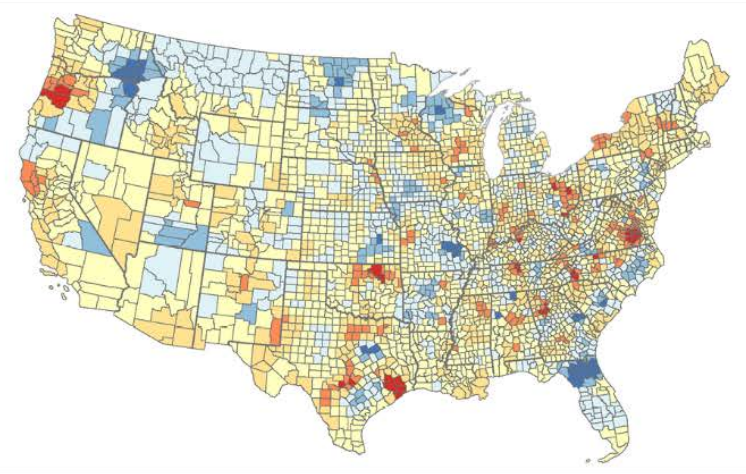

TOTEMPLR

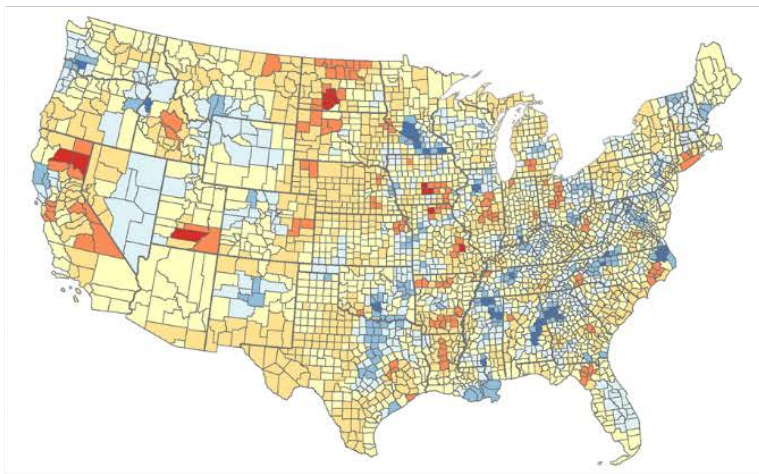

CONSTRUCTR

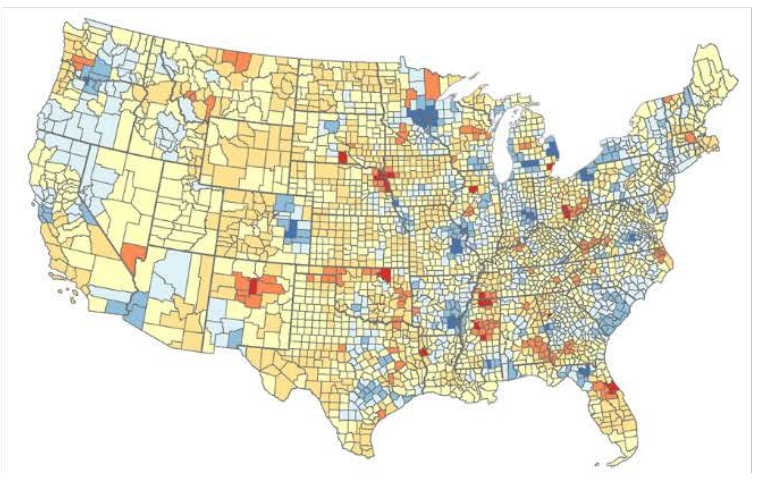

ASIANR

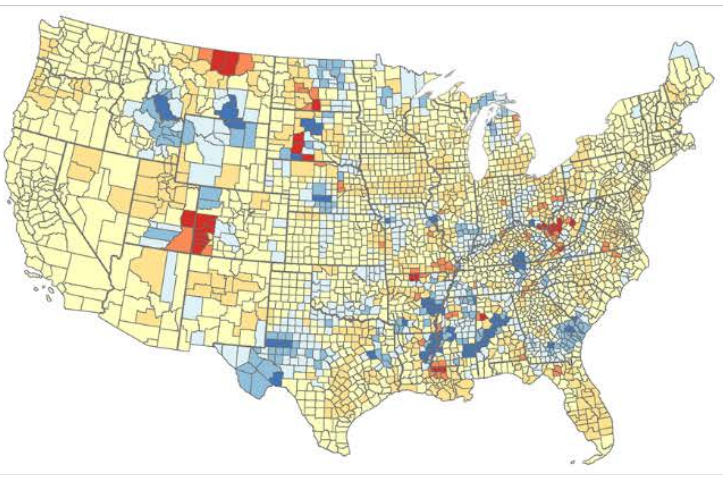

URBAN

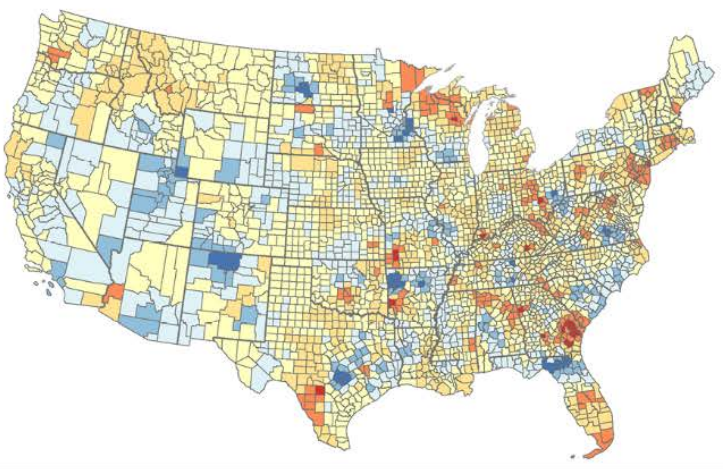

HISPANICR

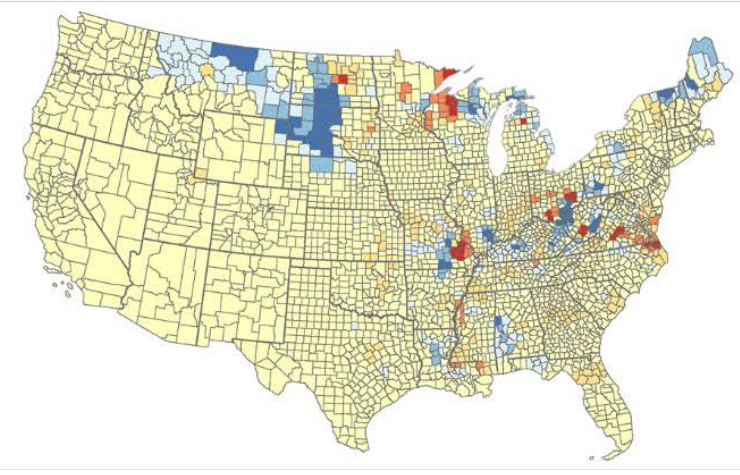

Standard deviation

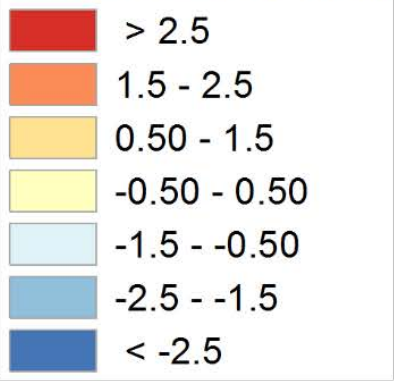




\section{TWITTERR}
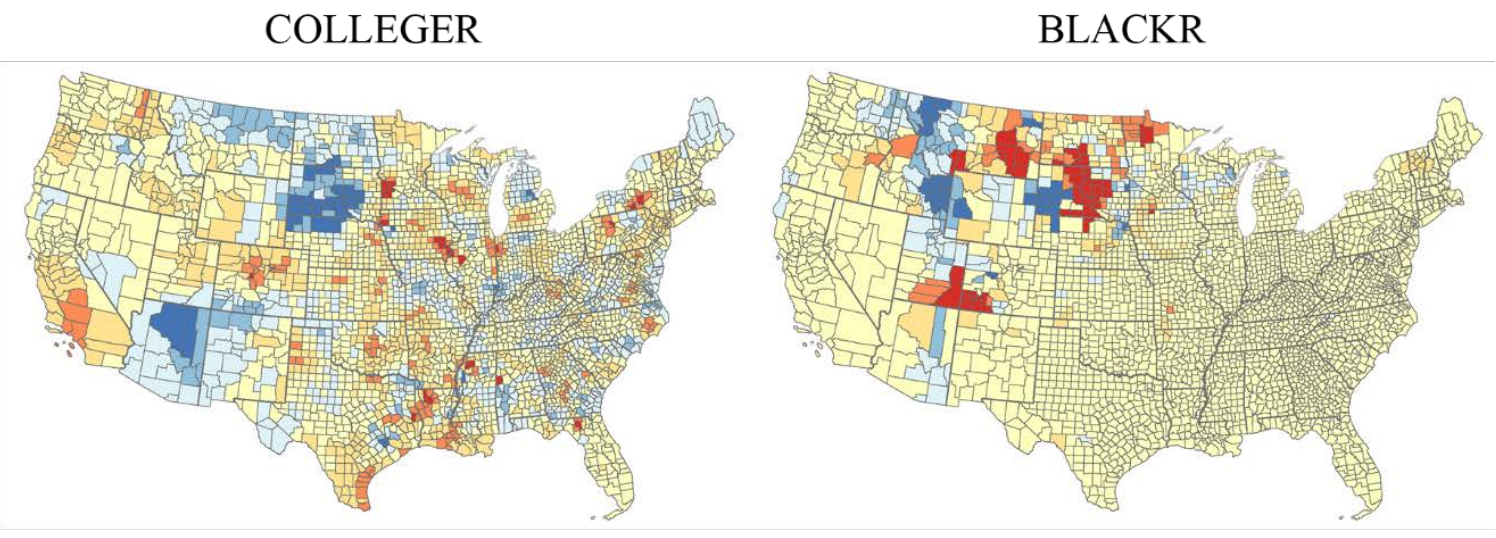

ASIANR

URBAN
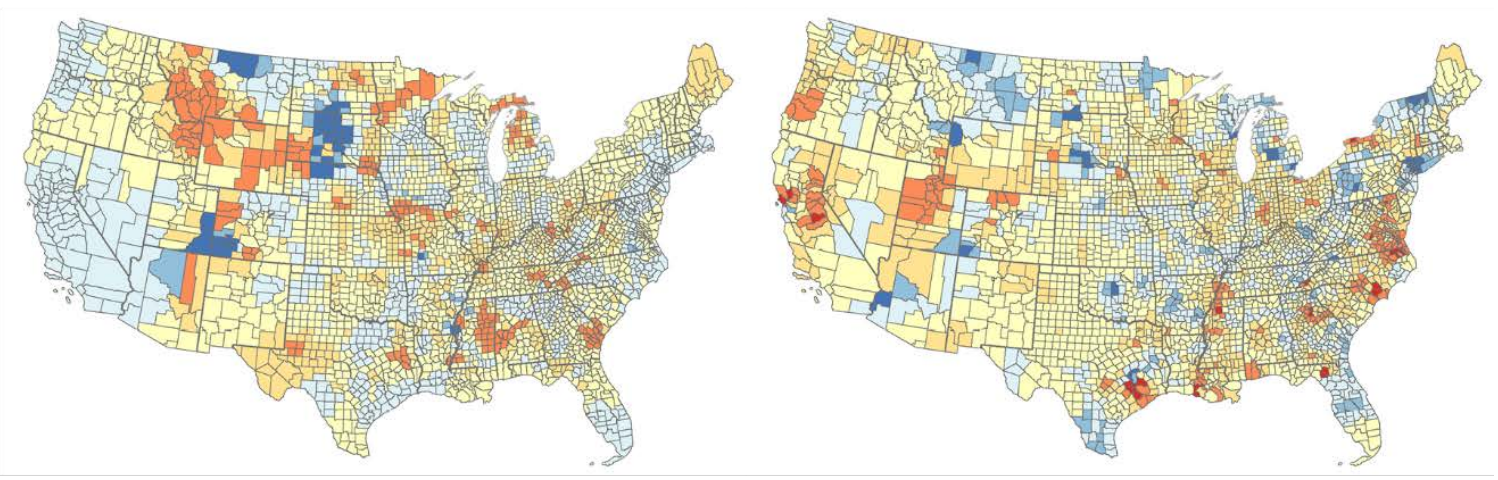

TOTEMPLR

HISPANICR
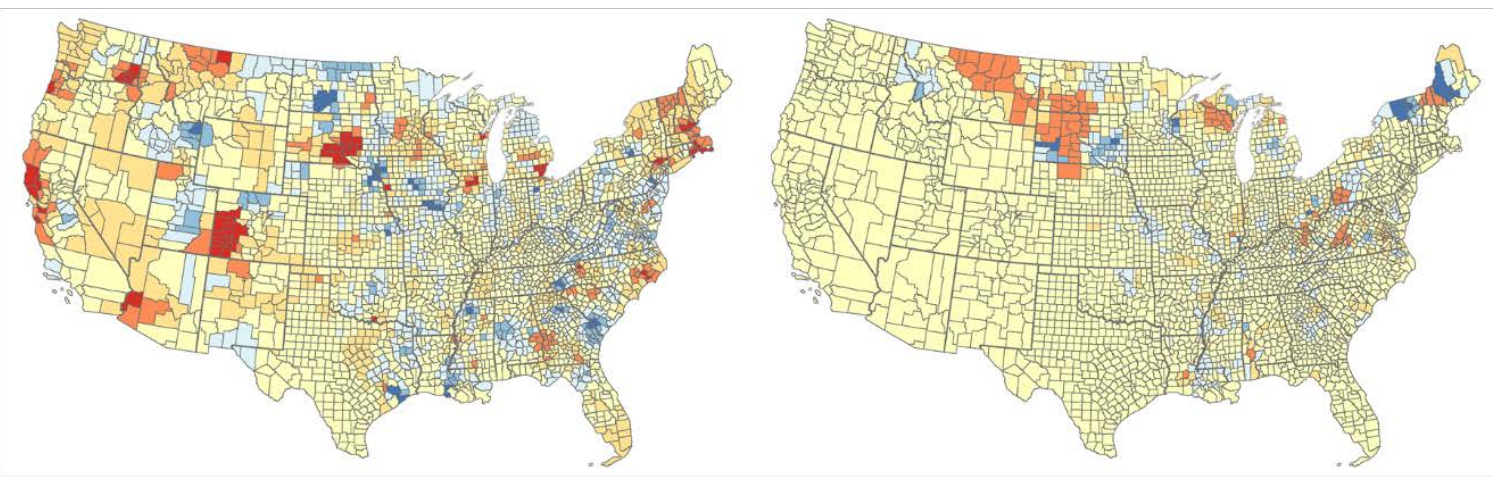

\section{CONSTRUCTR}

SERVICER
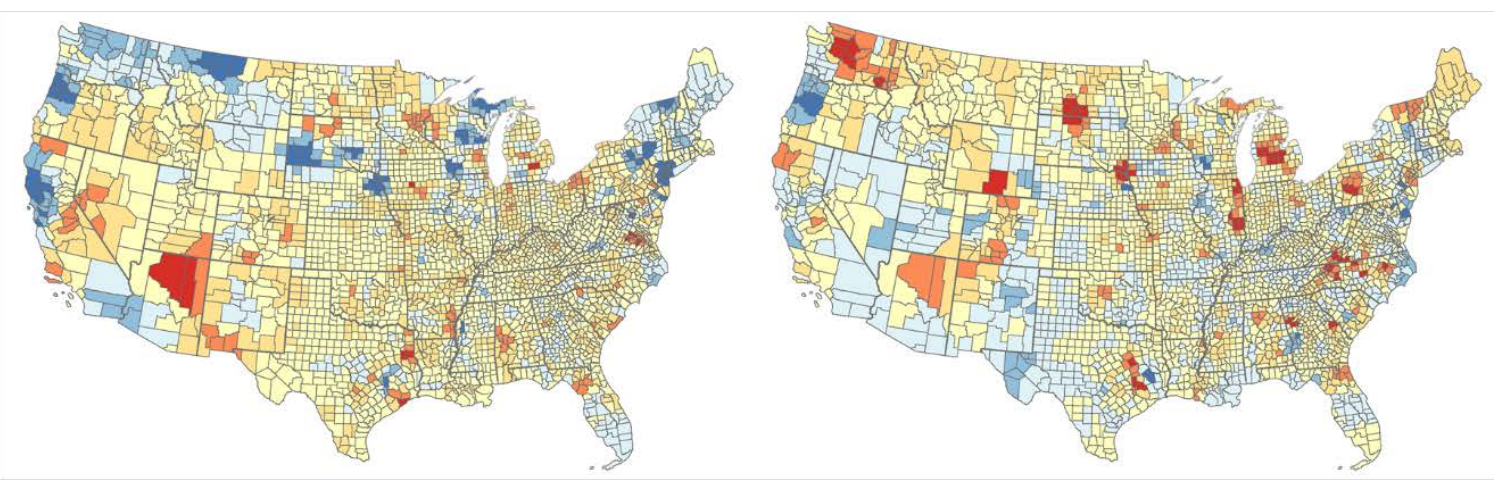